\title{
Building America Residential System Research Results: Achieving 30\% Whole House Energy Savings Level in Hot-Dry and Mixed-Dry Climates
}

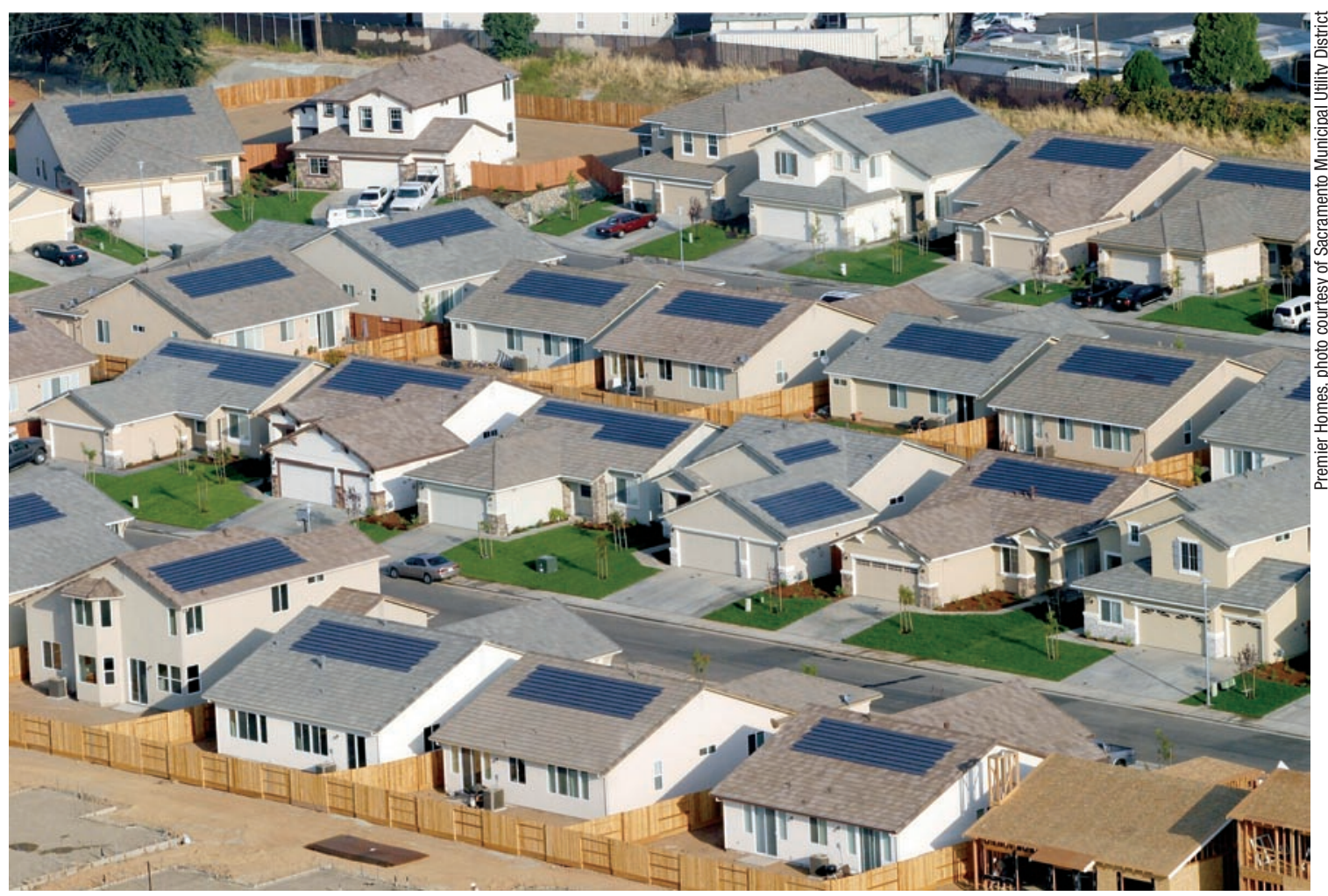




\section{Building America Residential}

System Research Results:

Achieving 30\% Whole House

Energy Savings Level in Hot-Dry

and Mixed-Dry Climates

\section{January 2005 - November 2005}

Building Industry Research Alliance (BIRA)

Stockton, California

Building Science Consortium (BSC)

Westford, Massachusetts

Consortium for Advanced Residential Buildings (CARB)

Norwalk, Connecticut

Davis Energy Group (DEG)

Davis, California

Florida Solar Energy Center (FSEC)

Cocoa, Florida

IBACOS

Pittsburgh, Pennsylvania

National Association of Home Builders Research Center (NAHBRC)

Upper Marlboro, Maryland

National Renewable Energy Laboratory (NREL)

Golden, Colorado

NREL Technical Monitor: R. Anderson, R. Hendron, M. Eastment, and A. Jalalzadeh-Azar

Prepared under Subcontract No(s). KAAX-3-32443-07, KAAX-3-33411-07, KAAX-3-33412-07, KAAX-3-33410-07

National Renewable Energy Laboratory

1617 Cole Boulevard, Golden, Colorado 80401-3393

303-275-3000 • www.nrel.gov

Operated for the U.S. Department of Energy

Office of Energy Efficiency and Renewable Energy

by Midwest Research Institute • Battelle

Contract No. DE-AC36-99-G010337

Subcontract Report NREL/SR-550-38201

January 2006

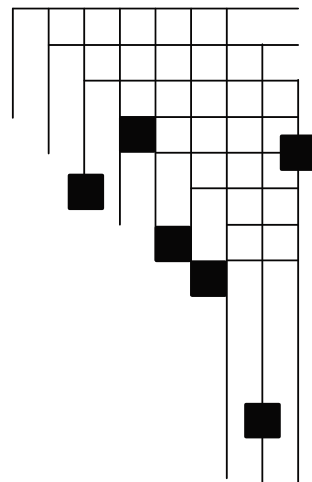




\section{NOTICE}

This report was prepared as an account of work sponsored by an agency of the United States government. Neither the United States government nor any agency thereof, nor any of their employees, makes any warranty, express or implied, or assumes any legal liability or responsibility for the accuracy, completeness, or usefulness of any information, apparatus, product, or process disclosed, or represents that its use would not infringe privately owned rights. Reference herein to any specific commercial product, process, or service by trade name, trademark, manufacturer, or otherwise does not necessarily constitute or imply its endorsement, recommendation, or favoring by the United States government or any agency thereof. The views and opinions of authors expressed herein do not necessarily state or reflect those of the United States government or any agency thereof.

Available electronically at http://www.osti.gov/bridge

Available for a processing fee to U.S. Department of Energy and its contractors, in paper, from:

U.S. Department of Energy

Office of Scientific and Technical Information

P.O. Box 62

Oak Ridge, TN 37831-0062

phone: 865.576 .8401

fax: 865.576 .5728

email: mailto:reports@adonis.osti.gov

Available for sale to the public, in paper, from:

U.S. Department of Commerce

National Technical Information Service

5285 Port Royal Road

Springfield, VA 22161

phone: 800.553 .6847

fax: 703.605.6900

email: orders@ntis.fedworld.gov

online ordering: http://www.ntis.gov/ordering.htm

This publication received minimal editorial review at NREL 


\section{Table of Contents}

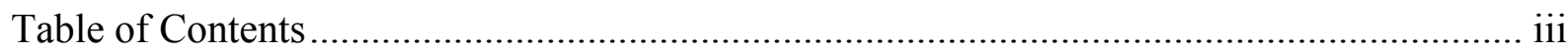

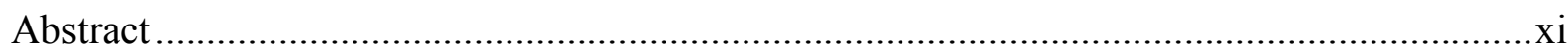

Building America Residential System Research Results: Achieving 30\% Whole House

Energy Savings Level in Hot-Dry and Mixed-Dry Climates............................................. 1

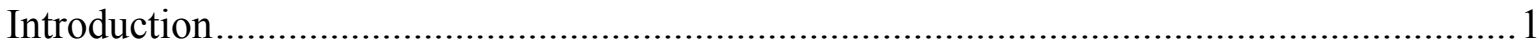

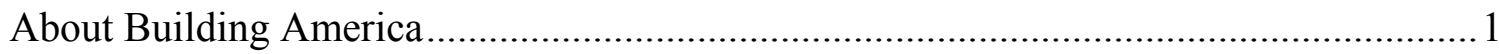

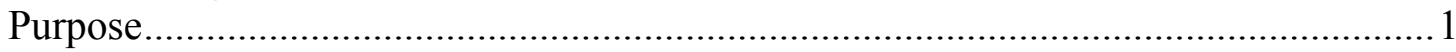

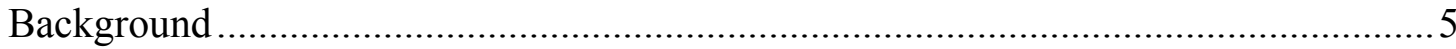

Electronic Reporting of System Research Results.......................................................9

Identification of Component Development Needs .................................................. 9

Documentation and Resource Development.............................................................9

Building America's Research Goals ............................................................................ 10

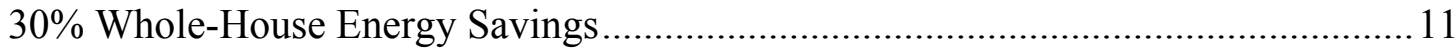

System Approach to Least-Cost Energy Savings ……….............................................. 13

Integrated Design Process ....................................................................................13

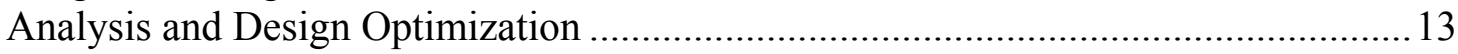

Building America Research Benchmark................................................................. 14

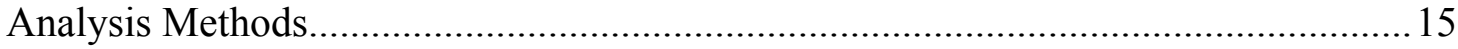

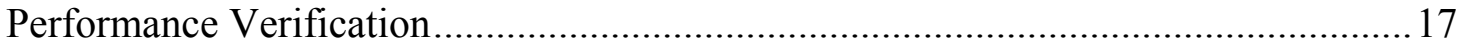

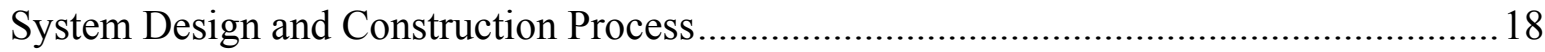

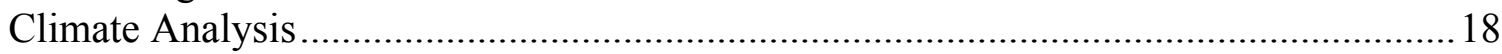

Key Climate Elements that Affect Building Design .................................................... 18

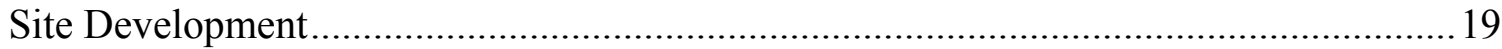

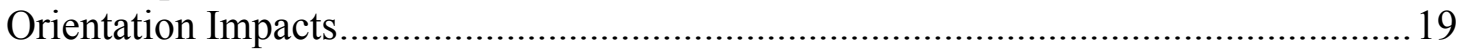

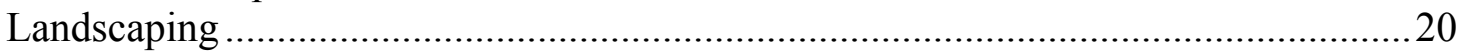

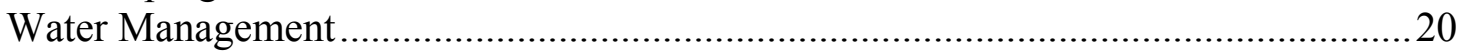

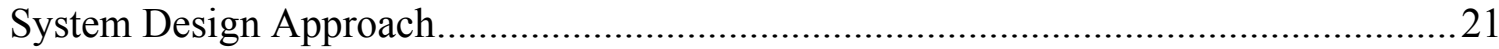

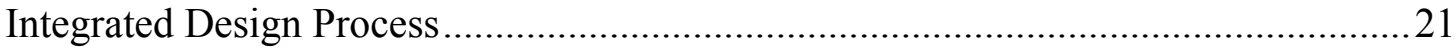

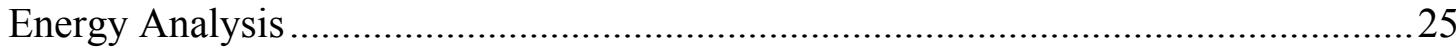

Passive Design Strategies for Minimizing Cooling and Optimizing Heating ..............27

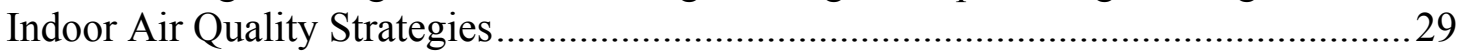

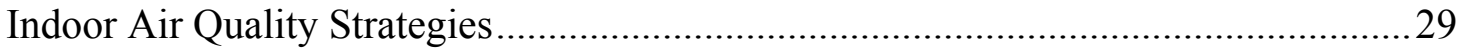

Heating and Cooling Equipment and Distribution Strategies - Creating Conditioned

Space for HVAC Systems....................................................................................... 34

First Costs, Cost Tradeoffs, and Owner Annualized PITI + Energy ...............................36

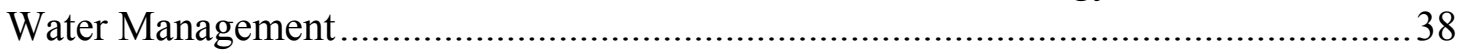

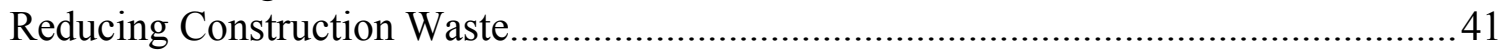

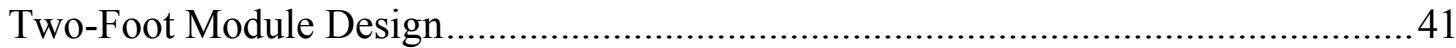

Value Engineered or "Advanced" Framing ..................................................................4 42

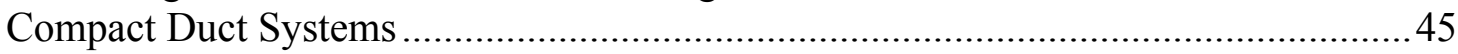

Recycling of Construction Materials ……………………….....................................4 46

Quality Project Management Approach........................................................................4 


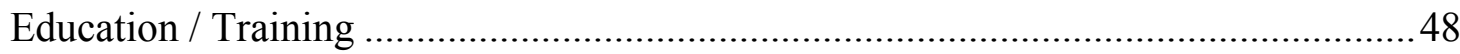

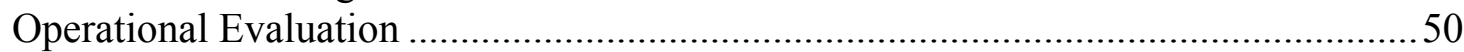

Performance Standards—Design, Specifications, Scopes............................................51

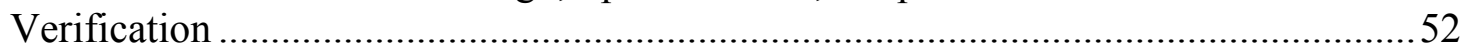

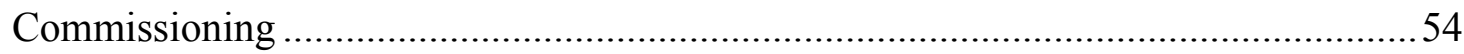

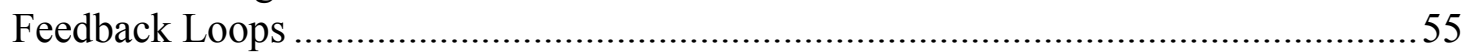

Quality Management Summary ………………………......................................55

Building Component Design Details ……………………...........................................56

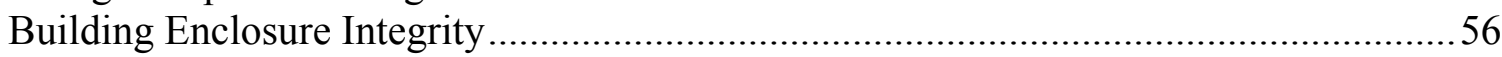

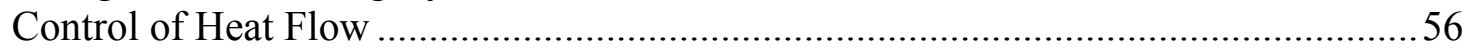

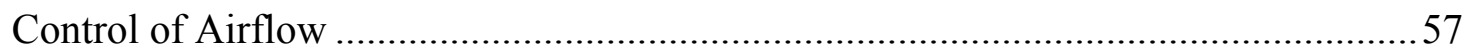

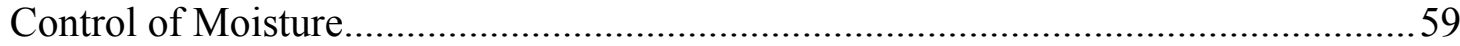

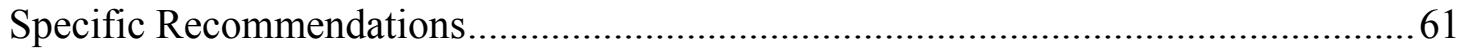

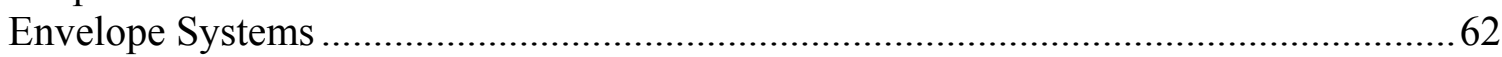

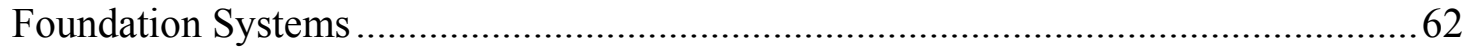

Slab on Grade

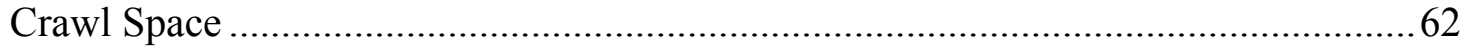

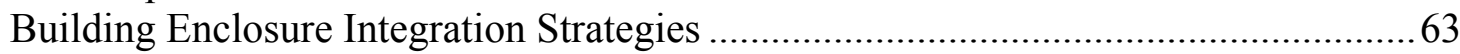

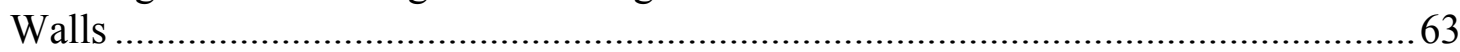

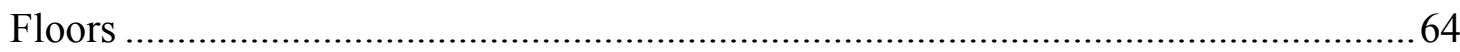

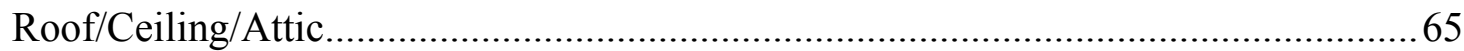

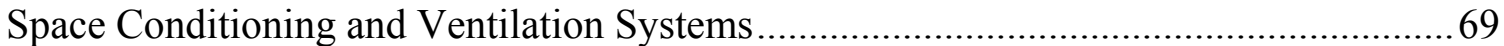

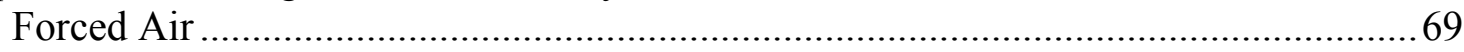

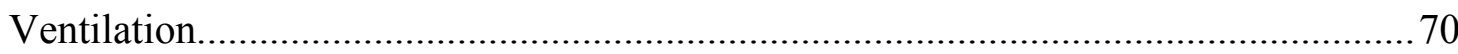

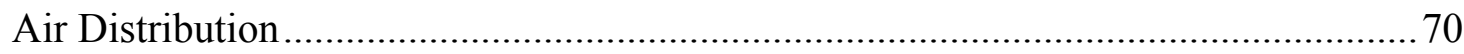

Mechanical, Electrical, and Plumbing Systems ...........................................................74

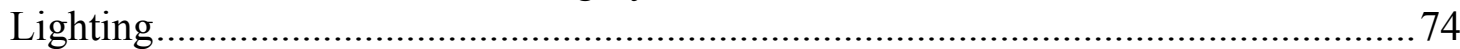

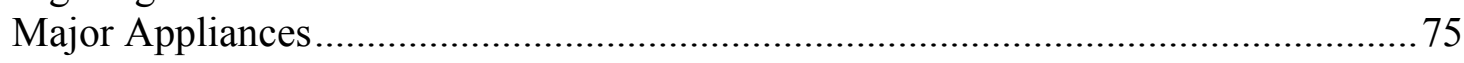

Water Heating and Distribution Systems................................................................ 76

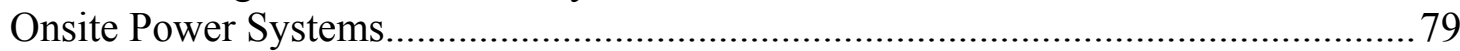

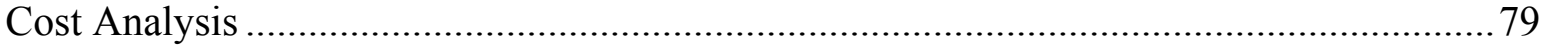

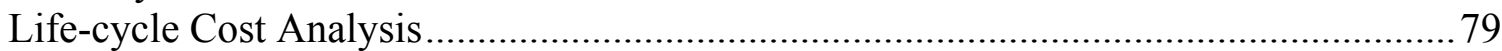

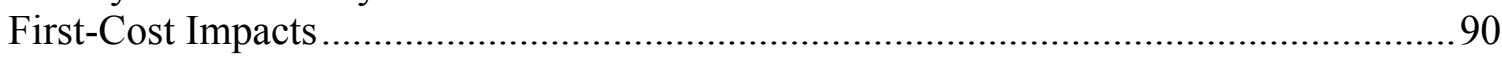

Key Cost Tradeoffs ................................................................................................ 91

Research Results and Conclusions................................................................................ 92

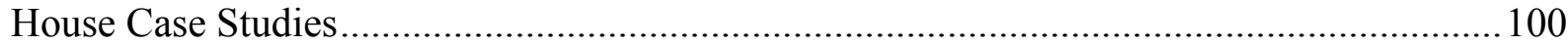

Development: Sahara Lake...................................................................................... 100

Development: Armory Park del Sol ........................................................................114

Development: Gamlen House ..............................................................................119

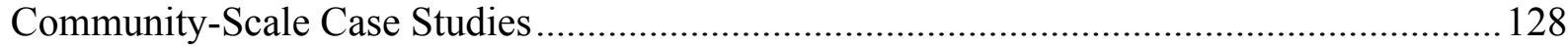

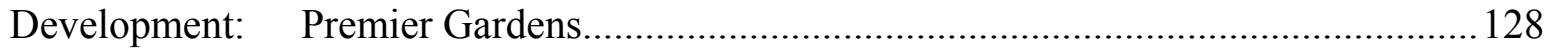

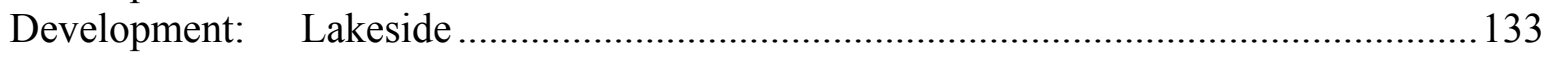

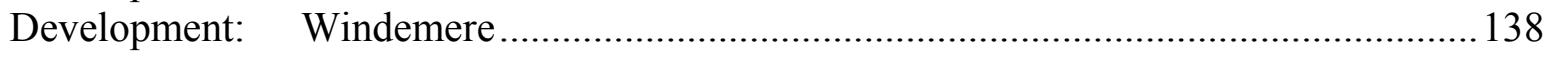

Appendix A: Passive Solar Design Considerations .............................................................. 144

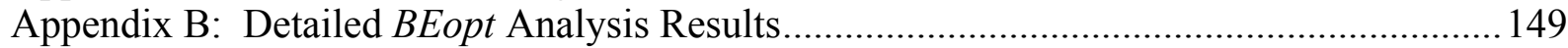

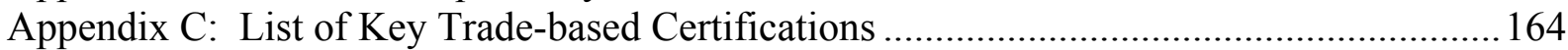




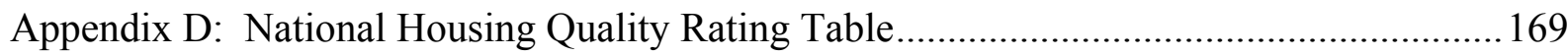

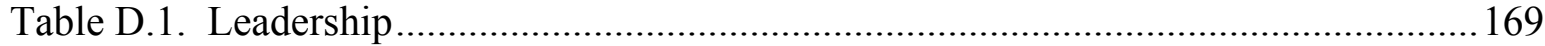

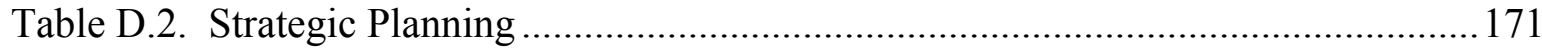

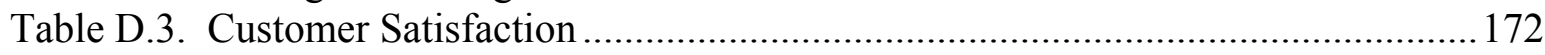

Table D.4. Performance Management ............................................................................. 175

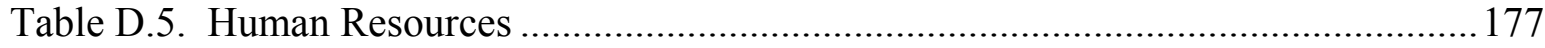

Table D.6. Quality Construction Processes ..................................................................... 179

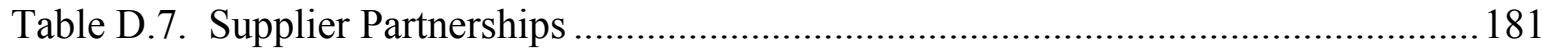

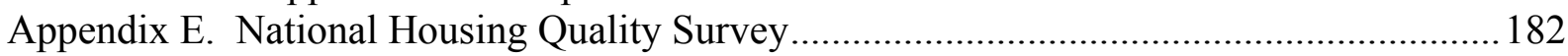

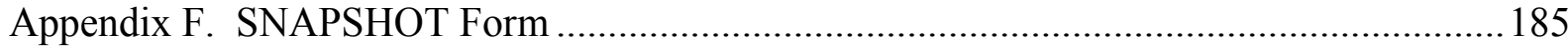




\section{Definitions}

$\mathrm{AC}$

ACCA

ACEEE

$\mathrm{ACH}$

ACT2

AFUE

$\mathrm{AH}$

$\mathrm{AHU}$

ALA

ASHRAE

BAP

BECT

BEopt

BESTEST

BII

BPI

BPM

$\mathrm{CA}_{\mathrm{Ef}}$

CAAfue

CAD

CDCU

CEC

CFL

CFM

CMU

COP

CRI

CT air conditioning

Air Conditioning Contractors of America

American Council for an Energy Efficient Economy

air changes per hour

Advanced Customer Technology Test for Maximum

Energy Efficiency

Annual Fuel Utilization Efficiency

air handler

air-handler unit

American Lung Association

American Society of Heating

Building America program

Building Energy Code Training

Software for identifying optimal building design

A benchmark for building energy simulation: Building

Energy Simulation Test and Diagnostic Method

Building Industry Institute

Building Performance Institute

brushless permanent magnet

California Energy Factor

California Annual Fuel Utilization Efficiency

computer-aided design

Community Development Corporation of Utah

California Energy Commission

compact fluorescent bulbs

cubic feet per minute

concrete masonry unit

coefficient of performance

color-rendering index

color temperature 
DHW

DOE

DOE-2

ECM

EDHA

EEBA

EEM

EER

EF

EFL

EGUSA

ELA

EPA

EPS

ERV

FF

FFA

FG

GenOpt

HVAC

HERS

HM

HPL

HRV

HSPF

HUD

IAQ

ICF

IDEC

IDP

IECC domestic hot water

U.S. Department of Energy

Building energy analysis program that can predict the energy use and cost for all types of buildings

electronically commutated motor

Eastern Dakota Housing Alliance

Energy and Environmental Building Association

Energy-efficient mortgages

Energy Efficiency Rating

energy factor

Environments for Living $®$

Energy-Gauge USA software (FSEC's residential frontend user interface for DOE-2.1E simulation tool)

effective leakage area

U.S. Environmental Protection Agency

expanded polystyrene

Energy recovery ventilation

framing factor

finished floor area

fiberglass

generic optimization program

heating, ventilation, and air conditioning

Home Energy Rating System developed by RESNET

heat mirror

high-performance lighting

heat recovery ventilators

Heating Seasonal Performance Factor

U.S. Department of Housing and Urban Development

Indoor air quality

insulated concrete forms

Indirect-Direct Evaporative Cooler

Integrated Design Process

International Energy Conservation Code 
IEQ

IOSEU

JWM

LSL

$\mathrm{MBH}$

Mcf

MEC

MEF

MERV

Micropas

NAECA

NAHB

NASEO

NATE

$\mathrm{NHQ}$

NREL

NZEH

OA

OASys

OC

OSB

$\mathrm{PA}$ or $\mathrm{Pa}$

PATH

PEX

PITI

PNNL

PSC

PV

R-Value

R.A.P.

RE
Indoor Environmental Quality

incremental overall source energy use

John Wesley Miller

linear strand lumber

$1,000 \mathrm{Btu} / \mathrm{hr}$

million cubic feet

Model Energy Code

modified energy factor

Minimum Efficiency Reporting Value

software tool for showing compliance with the California

Residential Energy Standards

National Appliance Energy Conservation Act

National Association of Home Builders

National Association of State Energy Officials

North American Technician Excellence

National Housing Quality

National Renewable Energy Laboratory

net zero energy home

outdoor air

an indirect/direct evaporative cooler

on center

oriented strand board

Pascal

Partnership for Advancing Technology in Housing

cross-linked Polyethylene tubing

principal, interest, tax, and insurance

Pacific Northwest National Laboratory

permanent split-capacitor motors

photovoltaics

A measure of thermal resistance used to describe thermal insulation materials in buildings

return-air pathway

recovery efficiency 


\begin{tabular}{|c|c|}
\hline RESNET & Residential Energy Service Network \\
\hline $\mathrm{RH}$ & relative humidity \\
\hline SA & supply air \\
\hline SEER & seasonal energy efficiency ratio \\
\hline SHGC & solar heat gain coefficient \\
\hline SHW & solar hot water \\
\hline SIP & Structural insulated panels \\
\hline SLA & specific leakage area \\
\hline SMUD & Sacramento Municipal Utility District \\
\hline TAB & testing, adjusting, and balancing \\
\hline TEP & Tucson Electric Power \\
\hline TIM & thermally interrupted metal \\
\hline TMY2 & Typical Meteorological Year weather data \\
\hline TNAH & The New American Home \\
\hline TOU & time of use \\
\hline TRNSYS & $\begin{array}{l}\text { A multidisciplinary software system for preliminary design, } \\
\text { analysis, and evaluation of space transportation systems }\end{array}$ \\
\hline TXV & thermostat expansion valves \\
\hline UL & Underwriter's Laboratory \\
\hline U-Value & $\begin{array}{l}\text { The thermal transmittance of a material, incorporating the } \\
\text { thermal conductance of the structure along with heat } \\
\text { transfer resulting from convection and radiation. }\end{array}$ \\
\hline UA & heat loss coefficient \\
\hline VOC & volatile organic compounds \\
\hline WUFI & $\begin{array}{l}\text { Modeling program for simulating heat and moisture } \\
\text { transfer }\end{array}$ \\
\hline XPS & extruded polystyrene \\
\hline ZEH & zero energy home \\
\hline ZNE & zero net energy \\
\hline
\end{tabular}




\begin{abstract}
The Building America program conducts the system research required to reduce risks associated with the design and construction of homes that use an average of $30 \%$ to $90 \%$ less total energy for all residential energy uses than the Building America Research Benchmark. This includes research on homes that will use zero net energy on annual basis.

To measure the program's progress, annual research milestones have been established for five major climate regions in the United States (Table A). The system research activities required to reach each milestone take from 3 to 5 years to complete and include research in individual test houses, studies in pre-production prototypes, and research studies with lead builders that provide early examples that the specified energy savings level can be successfully achieved on a production basis. As additional homes are completed at each performance level, future studies will be conducted to confirm the average energy savings of large numbers of homes and the impacts of improved housing quality on builder warranty and callback costs.

Two criteria are used to evaluate progress toward annual Building America research goals:

At a minimum, system energy savings must be achievable at neutral cost relative to the Building America Research Benchmark.

System solutions must be "production-ready" and meet minimum constructability, reliability, durability, and availability requirements to be implemented successfully by lead builders.

This report summarizes research results for the 30\% energy savings level and demonstrates that lead builders can successfully provide 30\% homes in the Hot-Dry / Mixed-Dry Climate Region on a cost-neutral basis. These research results represent the early starting point for the construction of increased numbers of high-performance homes. The broad diffusion of $30 \%$ homes in the Hot-Dry / Mixed-Dry Climate Region will depend upon a number of other factors in addition to the research results presented in this report. Those factors include the level of technical support provided by federal, state, and local deployment programs, the consumer cost of energy, and the development of policy incentives that support implementation of whole-house residential energy-efficiency strategies.
\end{abstract}

Table A. Target Energy Savings for Five Major Climate Regions in the United States

\begin{tabular}{cccccc}
\hline \hline $\begin{array}{c}\text { Target } \\
\text { Energy } \\
\text { Savings }\end{array}$ & Marine & Hot Humid & $\begin{array}{c}\text { Hot-Dry I } \\
\text { Mixed-Dry }\end{array}$ & $\begin{array}{c}\text { Mixed } \\
\text { Humid }\end{array}$ & Cold \\
\hline \hline $30 \%$ & 2006 & 2007 & 2005 & 2006 & 2005 \\
$40 \%$ & 2008 & 2010 & 2007 & 2008 & 2009 \\
$50 \%$ & 2011 & 2015 & 2012 & 2013 & 2014 \\
\hline
\end{tabular}




\section{Building America Residential System Research Results: Achieving 30\% Whole House Energy Savings Level in Hot-Dry and Mixed-Dry Climates}

\section{Introduction}

\section{About Building America}

\section{Purpose}

The objective of the Building America Program is to develop innovative system engineering approaches to advanced housing that will enable the housing industry in the United States to deliver energy-efficient, affordable, and environmentally sensitive housing while maintaining profitability and competitiveness of homebuilders and product suppliers in domestic markets. For innovative building energy technologies to be viable candidates over conventional approaches, it must be demonstrated that they can cost-effectively increase overall product value and quality while significantly reducing energy use and use of raw materials when used in community-scale developments. To make this determination, an extensive, industry-driven, team-based, system-engineering research program is necessary to develop, test, and design advanced-building energy systems for all major climate regions of the United States in conjunction with material suppliers, equipment manufacturers, developers, builders, designers, and state and local stakeholders.

Building America research results are based on use of a team-based systems research approach, including use of systems research techniques ${ }^{1}$ and cost and performance trade-offs that improve whole-building performance and value while minimizing increases in overall building cost. Figure 1 shows the Building America system research approach in its most basic form. Building America is an analysis-focused research program that specifically targets technical barriers that limit residential system energy performance. Building America applies system-research approaches to the development of advanced energy-efficient residential buildings using systemperformance studies in test houses, pre-production houses, and community-scale developments. Research includes analysis of system performance and cost tradeoffs as they relate to wholebuilding energy performance and cost optimization, including interactions between advanced envelope designs, mechanical and electrical systems, lighting systems, space-conditioning systems, hot water systems, appliances, plug loads, energy-control systems, and onsite power generation systems. Use of a systems approach creates process innovations that improve efficiency and flexibility of housing production and increase control over component interactions that improve house efficiency and performance.

Use of a systems approach also accelerates adoption of new technologies by increasing integration between the design and construction process, increasing system performance, increasing system cost effectiveness, and increasing system reliability and durability. Community-scale evaluation of advanced system concepts in partnership with builders,

\footnotetext{
${ }^{1}$ Systems Research is research focused on understanding cost, performance, and reliability interactions between different system components.
} 


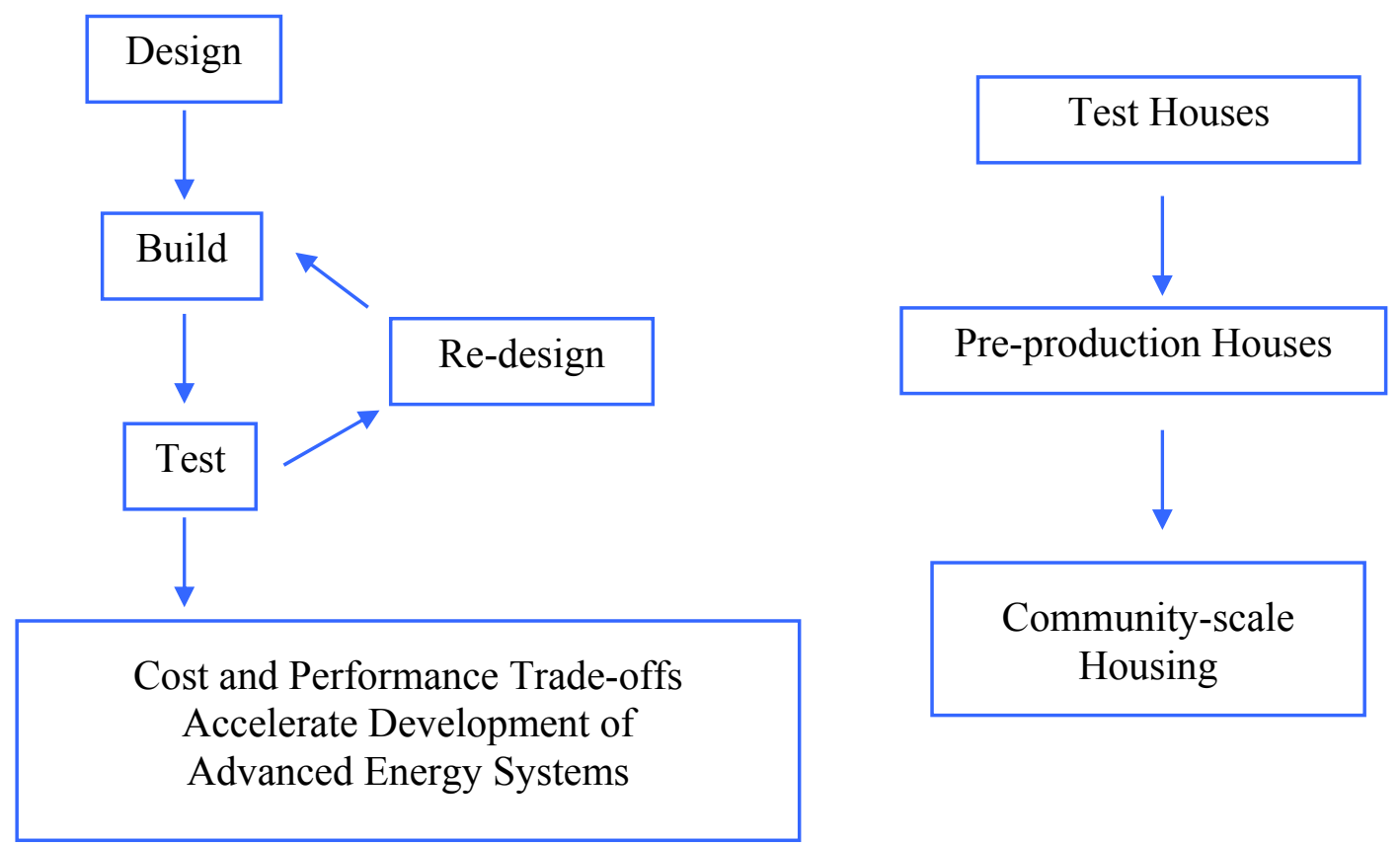

Figure 1. Overview of Building America's systems-engineering approach. The development of production-ready results covering the range from test houses to community-scale housing takes 3 to 5 years.

contractors, and state and local governments, provides opportunities for early adopters and industry leaders to directly contribute to key results from the research program. A systems approach for development of advanced residential buildings is defined to be any approach that utilizes comprehensive examination and analysis of overall design, delivery, business practices, and construction processes, including financing, and that performs cost and performance tradeoffs between individual building components and construction steps that produce a net improvement in overall building value and performance. A systems approach requires integrated participation and team building among all interested parties in the building process including developers, architects, designers, engineers, builders, equipment manufacturers, material suppliers, community planners, mortgage lenders, state and local governments, utilities, and others.

The final products of each Building America research project include performance measurements and cost/performance evaluations in test houses, pre-production homes, and community-scale developments. These measurements and evaluations lead to development of innovative system concepts that can be applied on a production basis by the industry partners and stakeholders involved in the program. The range of innovative system concepts considered in projects include onsite power systems, innovative envelope systems, advanced mechanical and lighting systems, advanced space-conditioning systems, efficient water heating systems, 
renewable energy systems, efficient appliances, energy control systems, and design and construction strategies. Performance results from the evaluation of these systems are presented to a broad residential building science audience via development of technical papers, the Building America Web site, and presentations at major building industry conferences.

Building America industry teams and team leads continuously evolve and increase the partners and stakeholders that participate in their projects so that the number of buildings and systems influenced by the program continues to grow over time.

The overall objective of the Building America research program is to develop integrated energy efficiency and onsite/renewable power solutions that can be successfully used on a production basis to reduce whole-house energy use in new homes by an average of $50 \%$ by 2015 and $90 \%$ by 2025 relative to the Building America Research Benchmark ${ }^{2}$, including homes that are capable of achieving zero net energy (ZNE) use on an annual basis.

The key system research questions addressed by Building America research teams include the following:

- Evaluation of overall system cost tradeoffs relative to current systems. What are the system's incremental costs and how will the system affect overall building costs?

- Evaluation of overall system benefits relative to current systems. What overall value is delivered by the system to builders? To contractors? To consumers? (Examples of system benefits include utility bill savings, contribution to whole-house energy-savings goals, increased durability, reduced warranty and callback costs, increased comfort, reduced construction waste, increased labor productivity, increased water efficiency, increased safety and health, reduced peak loads)

- Evaluation of the expected market impact of new residential energy systems. What fraction of the residential housing market will be directly affected by research results? What are barriers to broad market use? What research can be done to reduce barriers to broad use?

- Evaluation of the constructability of new residential energy systems. What are barriers and risks associated with the use of new systems? Can results be implemented on a production basis? What additional research is required to develop a clear description of whole-house system-performance requirements and key system design details that minimize barriers and risks and maximize benefits?

- Evaluation of the potential community-scale benefits of advanced residential energy systems. What additional benefits will result when systems are implemented on a community scale?

Taken together, these research questions frame the overall difficulty of resolving the risks associated with use of advanced energy systems, help to define the systems research required to integrate new systems seamlessly into a production construction process and emphasize the importance of documenting the performance benefits of advanced systems.

\footnotetext{
${ }^{2}$ The Research Benchmark provides a detailed description of all residential energy uses and serves as the reference point for the energy savings goals in Building America research project. More information about the Benchmark can be found on the Building America website: www.buildingamerica.gov. Hereafter in this report, it is referred to as the Benchmark. Hendron, R. 2005. Building America Research Benchmark Definition, Updated December 29, 2004. NREL/TP-550-37529. Golden, CO: National Renewable Energy Laboratory.
} 


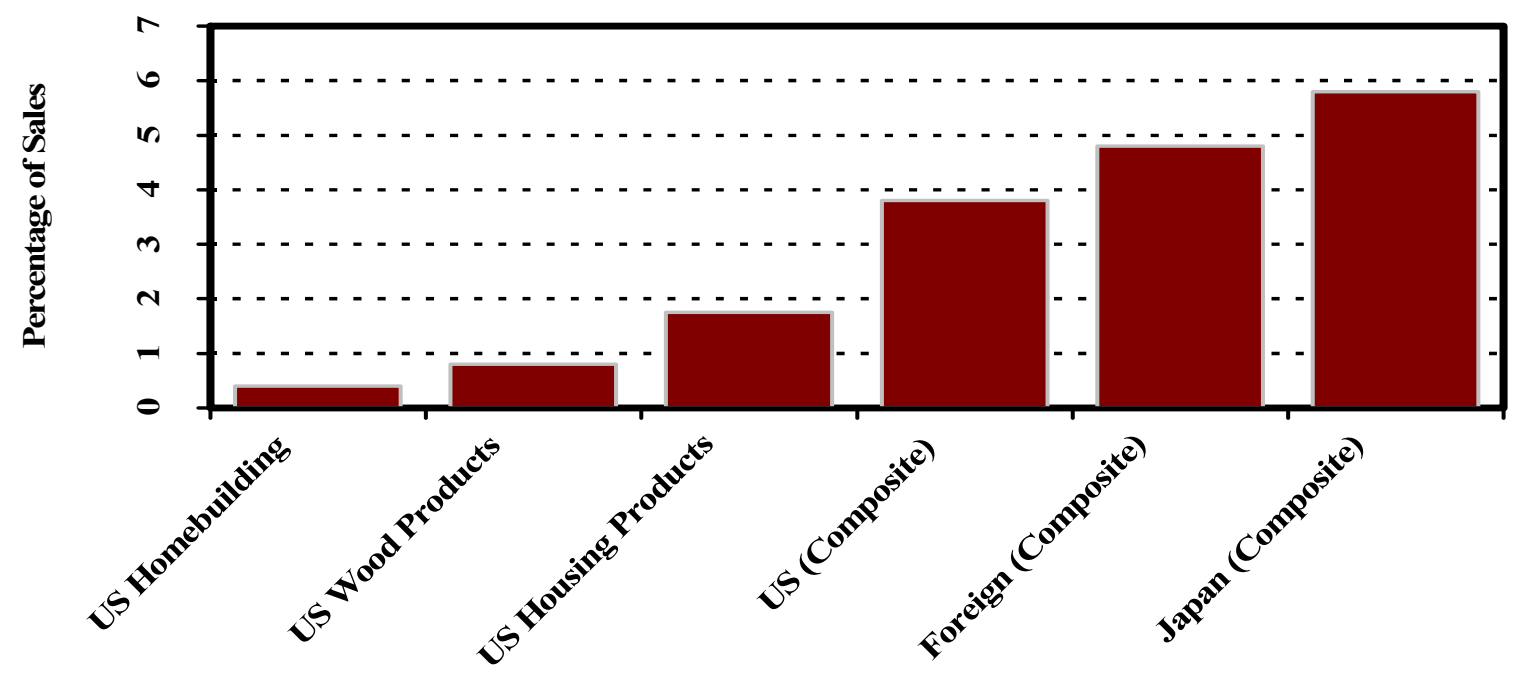

Figure 2. Research and Development expenditures ${ }^{3}$

Construction of new homes requires the combined efforts of a large number of suppliers and contractors whose efforts are coordinated by a large number of builders. Because of the high costs of failure, the residential construction industry is highly risk-intolerant and first-cost sensitive. Development of new systems and corresponding changes in design and the relatively low level of R\&D investment further complicate construction practices by the housing industry.

Figure 2 compares R\&D expenditures for various residential markets. The key market barriers to development of advanced residential energy systems are the large number of market players, the relatively low level of investment in R\&D relative to other sectors of the economy, and strict requirements for market acceptance based on achievement of low incremental costs and high reliability.

The key technical barriers to the development of advanced residential energy systems are the large number of technical performance requirements that must be met before a new system can be implemented on a production basis. These technical performance requirements are driven by regional differences in building energy loads and construction techniques. Systems that work well in Cold Climates may not be applicable in hot climates. Systems that work well in Hot-Dry Climates may not function well in Hot-Humid Climates.

A recent study by the RAND Corporation for HUD's Partnership for Advancing Technology in Housing (PATH) entitled, Building Better Homes: Government Strategies for Promoting Innovation in Housing, ${ }^{4}$ concludes that,

... the housing industry is large and complex, involving many public and private entities. The interests, roles, and capacities of each participant and the relationships they share have shaped the housing industry into what it is today...Instead of trying to identify barriers and asking the industry to change

\footnotetext{
${ }^{3}$ The United States homebuilding industry invests $0.25 \%$ of sales in research compared to $\$ 3.8 \%$ for all market sectors (Business Week R\&D Scoreboard, June 28, 1993).

${ }^{4}$ RAND, Building Better Homes: Government Strategies for Promoting Innovation in Housing, 2003
} 
itself (or asking the government to change it), this study seeks to identify options to accelerate innovation within the housing industry as it exists today. It begins by critically examining the concept of innovation and how it might be better understood within the context of the housing industry. What results is a departure from the linear model of innovation that assumes logical and unidirectional movement from research to development, demonstration, and deployment to one that recognizes much greater interactive dynamics in the innovation process. Research in this model is a base for knowledge, which contributes to invention, development, demonstration, and deployment. Moreover, all these activities or stages in the innovation process are affected by market forces."

Because of the strong interaction between technical and market barriers, a linear research approach that begins with basic R\&D and ends with technology deployment is not likely to be successful when applied to residential systems. A market-driven, system-based research approach can provide valuable benefits to builders, consumers, and utilities while simultaneously resolving market and technical barriers to innovation.

Pulte Homes Southwest Division has used technical assistance from the Department of Energy's Building America program to create what one residential expert calls "the best production house in the world," which won the 2001 National Association of Home Builders' Energy Value Housing Award. In Tucson, Phoenix, and Las Vegas, Pulte Homes has worked with the Department of Energy to redesign the energy features of its basic models. Using advanced insulation techniques, highly efficient equipment and windows, and right-sized heating and cooling systems, the homes look the same, but perform so well they use half the energy for heating and cooling at virtually no increase in construction costs. The whole-building/systems engineering approach used in the Building America program allows builders to add more insulation and more efficient windows while reducing the size of the heating and cooling equipment. The trade-off means no added cost to the builder, better value for the buyer, reduced electric load for the utility and improved affordability.

\section{Background}

Building America was started in 1995 (Table 1) to conduct the systems research required to develop residential energy efficiency solutions that achieve 30\%-100\% savings when used on a production basis by builders of new homes. The long-term 2025 research goal for the program is to develop cost-effective system designs that can result in Net Zero Energy Homes (NZEH). ${ }^{5}$ In the past 10 years, Building America has made significant progress on the path to NZEH, including the completion of more than 30,000 homes.

Building America research participants have developed an in-depth systems research process by combining operations research ${ }^{6}$ and systems engineering. ${ }^{7}$ The first step of the systems-research

\footnotetext{
${ }^{5}$ A net zero energy house is a house that produces as much energy as it uses on an annual basis through integration of energy efficiency solutions and onsite power systems.

6 Operations Research is research aimed at understanding the best way to operate a system to maximize performance, based on system constraints.

7 Systems Engineering is engineering based on knowledge from systems research aimed at maximizing the performance and durability of a system, subject to operating constraints.
} 
Table 1. Building America Background

\begin{tabular}{ll}
\hline \hline Start date & 1995 \\
Target market(s) & New, single-family residential buildings \\
Accomplishments to date & $\begin{array}{l}\text { 1. Developing the Benchmark Definition } \\
\text { 2. Developing protocols for validating whole- } \\
\text { house energy performance }\end{array}$ \\
& $\begin{array}{l}\text { 3. Documenting research and publishing } \\
\text { Houses That Work, Builder Guides, and Best } \\
\text { Practices }\end{array}$ \\
& 4. Increasing the number of ENERGY STAR $~$ \\
& homes \\
Developing integrated cost-effective, whole- \\
building strategies to enable new, single-family \\
residential buildings to use 30\% less total \\
energy than the Benchmark in the Cold and Hot- \\
Dry/Mixed-Dry Climate regions. \\
Continuing to develop the strategies for new, \\
single-family residential buildings to use 40\%- \\
100\% less energy than the Benchmark in the \\
Marine, Hot-Humid, Hot-Dry/Mixed-Dry, Mixed- \\
Humid, and Cold Climate regions \\
2025
\end{tabular}

process is to use operations research techniques to identify the technology pathways that will achieve the target energy savings in each region for the lowest potential installed cost. From these results, the optimal efficiency targets can be identified and technologies can be developed that will meet the energy-savings needs cost effectively in all climate regions. The second step in the systems research is to implement the optimal technology pathways through systems engineering in homes. The systems-engineering step will identify challenges and barriers unanticipated by the optimization. The combination of operations research and systems engineering ensures that the solutions created meet the energy savings and cost goals and can be used on a production basis. Figure 3 shows a more detailed look at the Building America systems research approach. 


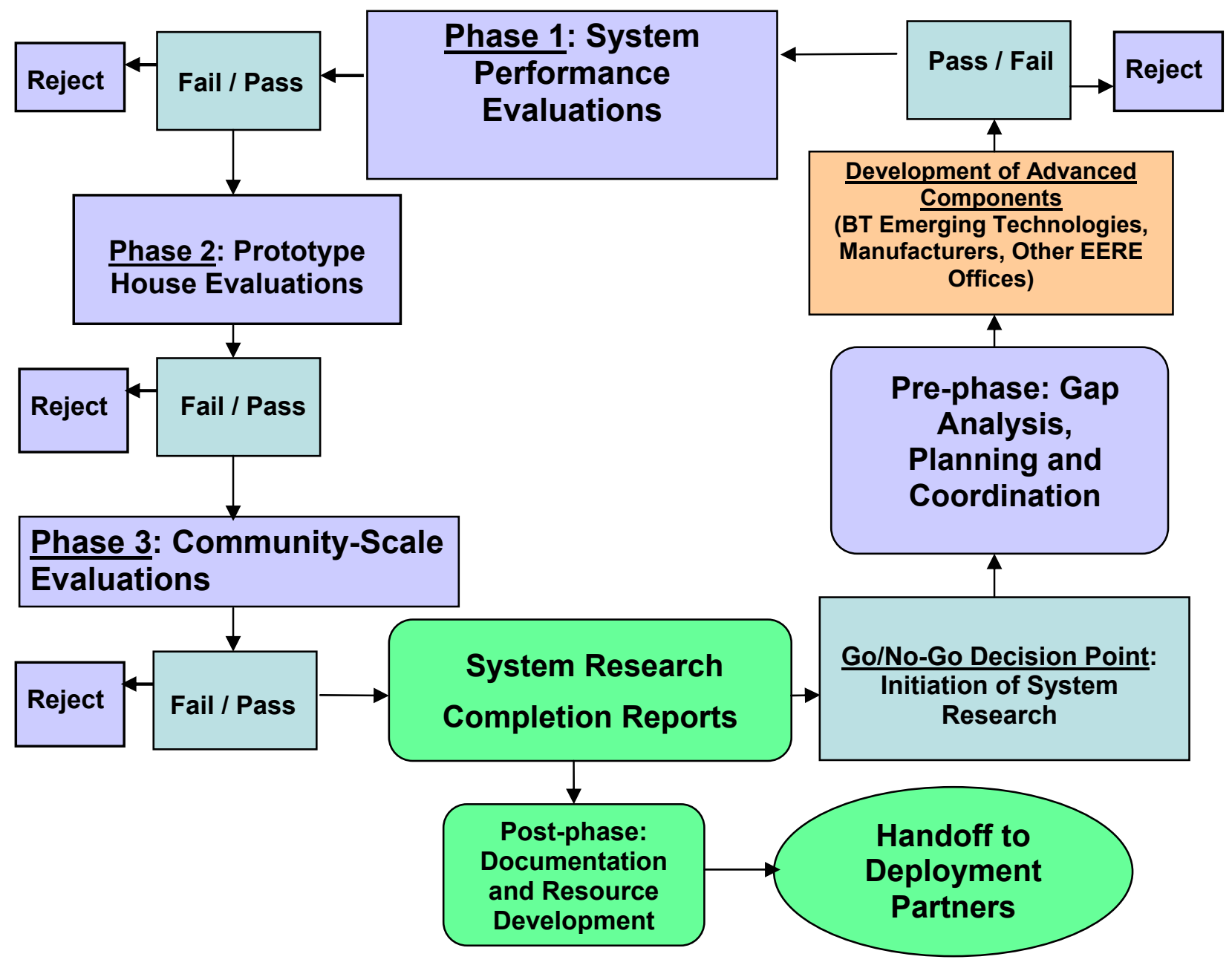

Figure 3. A more detailed look at the Building America system research strategy 
The systems research described above is applied in three phases for each climate zone. During the three phases, which are conducted in parallel to allow feedback between phases, Building America acts as a national residential energy systems test-bed where homes with different system options are designed, built, and tested at three levels of system integration, including research houses, production prototype houses, and evaluations in community-scale housing to validate the reliability, cost effectiveness, and marketability of the energy systems when integrated in production housing. After completion of the community evaluations, a low level of technical support may be provided as needed to ensure successful implementation of system research results at each performance level targeted by the program. A detailed summary of the three phases of the system research process is captured in Table 2.

The three system-engineering stages overlap one another to allow issues to be quickly resolved as they are identified. The three system-research stages currently take about 3 to 4 years, but for more advanced energy efficiency levels at and above $40 \%$ whole-house savings, the systemsresearch process is expected to take additional iterations of whole-house testing before implementation in production ready homes. At the $50 \%$ whole-house level and above, the system research stages are expected to take 4 to 5 years to complete.

Table 2. Residential Integration Systems Research Approach

\section{Phase 1 - System Evaluations}

In Phase 1, the Building America Consortia design, construct, and test subsystems for whole-house designs in research houses to evaluate how components perform. The focus of Phase 1 is to evaluate and field-test prototype subsystems to determine the most reliable and cost-effective solution for a given performance level and climate.

\section{Phase 2 - Prototype Houses}

In Phase 2, the successful Phase 1 subsystems are designed and constructed by production builders working with the Building America Consortia to evaluate the ability to implement the systems on a production basis. The focus of Phase 2 research is to move the research prototype house and building practices to the point that they are production-ready and capable of being integrated with production construction techniques practiced by today's builders.

\section{Phase 3 - Community Evaluations}

In Phase 3, the Building America Consortia provide technical support to builder partners to advance from the production prototypes to evaluation of production houses in a subdivision. The results are documented in a case-study report. Several of these reports are distilled into a final research report that describes the system design and construction practices needed to achieve a particular level of energy savings within each climate zone targeted by the program. 


\section{Electronic Reporting of System Research Results}

Final research results from the program are reported electronically via the Building America Website (www.buildingamerica.gov). Research results include project data, research reports, case studies, research highlights, and background information on the research program and its participants. The website also includes a document database and reference materials on the performance analysis and measurement procedures.

\section{Identification of Component Development Needs}

The three-phase systems-engineering approach (Table 2) requires identification of future system needs to allow the lead time required to develop and evaluate options to meet those needs. Before initiation of Phase 1 studies in research houses, components must be developed and evaluated to determine their potential to fill gaps between the performance of current systems and future whole-house performance goals. The component research requires significant lead time in some cases and focuses on communication of system-integration needs and requirements to component developers. Building America's role is to provide inputs to component developers that help to identify residential system integration needs, requirements, and gaps based on annual residential cost/performance studies using the BEopt analysis method. ${ }^{8}$ Components must be developed for Phase 1 and have to meet minimum requirements for energy performance, reliability, and cost effectiveness before they are included as part of the residential integration activities in Phases 2 and 3.

\section{Documentation and Resource Development}

At the completion of Phase 3, the research results are documented in technical research reports that serve as references for students, educators, building scientists, architects, designers, and engineers. For the research results to be successfully transferred to additional important participants in the housing industry, they must be translated into a format appropriate for dissemination to developers, builders, contractors, homeowners, realtors, insurance companies, and mortgage providers.

This post-Phase-3 DOE activity fosters movement of the research and building techniques of the Building America Program to the market and establishes voluntary collaborations with housing and financial industries to make the nation's houses more energy-efficient and affordable. This final stage of the process focuses on documentation of best practices and development and evaluation of resources to hand-off DOE building-research findings to private- and public-sector implementation programs. This work supports activities that improve the energy efficiency of public and privately owned single-family housing. The program coordinates presentations at technical conferences on peer-reviewed, validated, research results and facilitates validation, field-testing, and evaluation of the post-phase- 3 documentation.

The Building America resource development effort creates "Best Practices" manuals from the Phase- 3 research reports that are designed for builders, manufacturers, homeowners, realtors, educators, insurance companies, and mortgage providers. The Best Practices manuals summarize best-practice recommendations in illustrated text that is targeted to a specific

\footnotetext{
${ }^{8}$ Analysis of System Strategies Targeting Near-Term Building America Energy-Performance Goals for New SingleFamily Homes, Anderson, Ren et al. November 2004, NREL/TP-550-36920.
} 
audience to make it easily assimilated and that synthesize research findings into energy-efficient processes for the building industry. To facilitate construction of affordable homes designed for non-profit organizations and small builders, Building America plans to make floor plans and section details available through the web and other means.

\section{Building America's Research Goals}

Building America's energy-saving goals form the core of the research effort and have been staged to complete an additional $10 \%$ of incremental savings every 3-5 years (Table 3 ).

To ensure meeting the interim targets along the path to Zero Energy Homes, Building America has also specified the interim performance targets for each climate region (Table 4).

In addition to energy savings, Building America has additional system performance goals that are critical to the success of the systems research process. These include the following:

- Accelerating the development and implementation of advanced-energy systems in new and existing residential construction through application of systems-engineering research projects by cross-cutting industry teams

Table 3. Building America Research Goals ${ }^{9}$

\begin{tabular}{lcccccc}
\hline \multirow{2}{*}{ Characteristics } & Units & \multicolumn{5}{c}{ Year } \\
\cline { 3 - 7 } & & 2007 & 2010 & 2015 & 2020 & 2025 \\
\hline \hline $\begin{array}{l}\text { Average Source Energy } \\
\text { Savings }\end{array}$ & $\%$ & 30 & 40 & 50 & 70 & 90 \\
Cost & $\$$ & & Zero or Less Net Cash Flow ${ }^{10}$ \\
\hline
\end{tabular}

Table 4. Building America Performance Targets by Climate Region

\begin{tabular}{cccccc}
\hline $\begin{array}{c}\text { Target } \\
\text { (Energy Savings) }\end{array}$ & Marine & Hot Humid & $\begin{array}{c}\text { Hot-Dry / } \\
\text { Mixed Dry }\end{array}$ & $\begin{array}{c}\text { Mixed } \\
\text { Humid }\end{array}$ & Cold \\
\hline $30 \%$ & 2006 & 2007 & 2005 & 2006 & 2005 \\
$40 \%$ & 2008 & 2010 & 2007 & 2008 & 2009 \\
$50 \%$ & 2011 & 2015 & 2012 & 2013 & 2014 \\
\hline
\end{tabular}

\footnotetext{
${ }^{9}$ Year of completion of annual performance targets in six climate regions. Energy savings are measured relative to Building America Research Benchmark. The targets in Table 4 are updated on an annual basis dependent on technical progress and funding.

${ }^{10}$ Life cycle cost, see the benchmark report: Hendron, R. (2005). Building America Research Benchmark Definition, Updated December 29, 2004.43 pp., NREL Report No. TP-550-37529.
} 
- Reducing residential building construction site waste, increasing the use of recycled materials, reducing construction cycle time, increasing system durability and reliability, and reducing warranty and call-back costs

- Developing innovative technologies and strategies that enable the housing industry in the United States to deliver environmentally sensitive, quality housing on a community scale while maintaining profitability and competitiveness of homebuilders and product suppliers

- Increasing housing value and affordability for homeowners in the United States.

\section{0\% Whole-House Energy Savings}

Building America's current research activities target 30\% total energy savings in new singlefamily homes in six climate regions. Residential buildings include a limited number of different end uses with many similarities in a particular climate region. Therefore, a climate region approach is appropriate because residential system solutions can be easily replicated on a regional basis. The climate regions defined by Building America can be seen in Figure 4 .

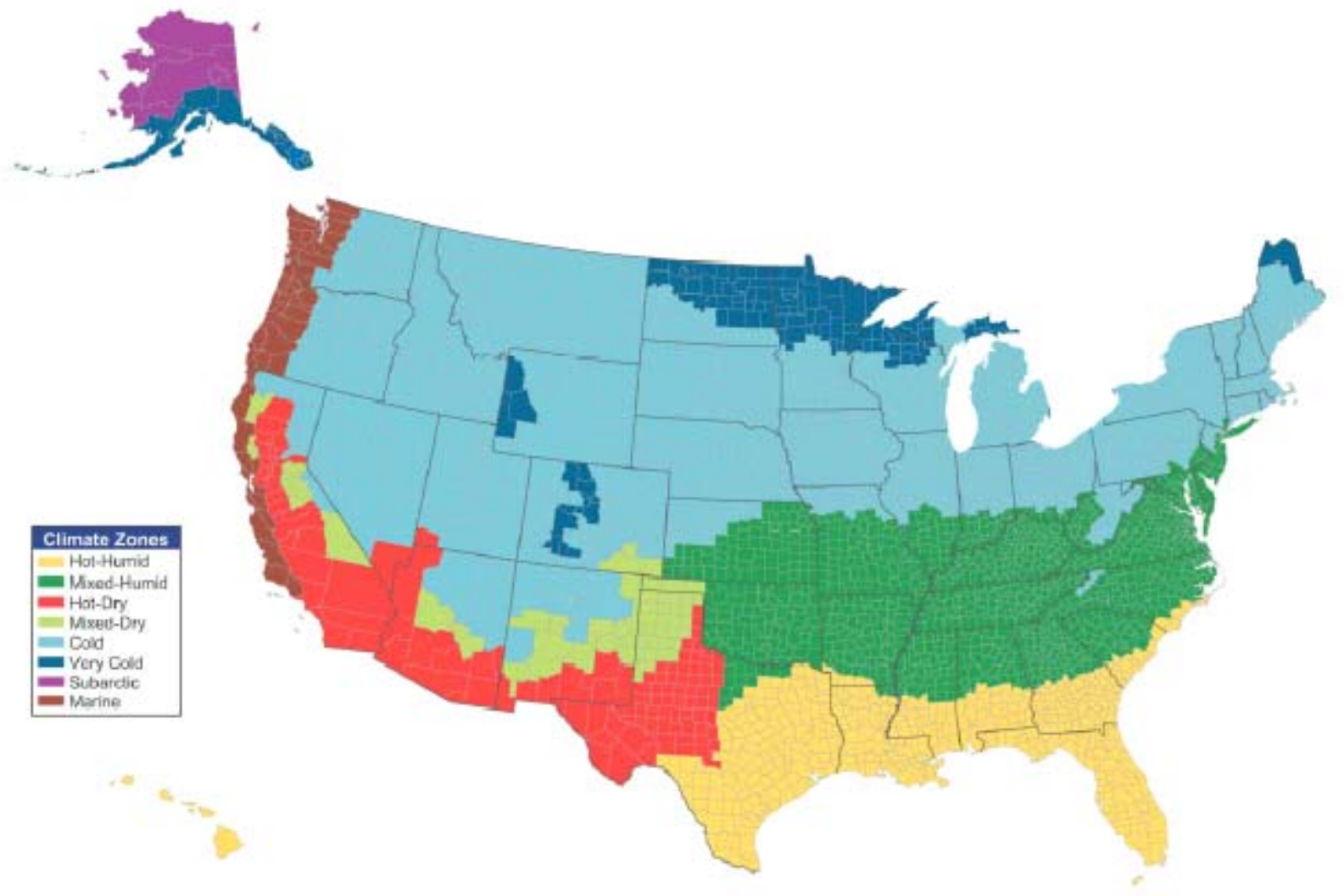

Figure 4. Building America climate regions 
Because of limited resources, Building America is targeting six of the eight climate regions, including Marine, Hot-Humid, Hot-Dry/Mixed-Dry, Mixed-Humid, and Cold. The Hot-Dry and Mixed-Dry Climates have been combined into a single climate target for Building America planning purposes because of the similarities of the solutions for the two climates. The severe Cold and Subarctic Climate regions have been omitted because of limited resources and the lack of residential growth in those regions.

From 2003 to 2005, Building America has developed the following solutions to use $30 \%$ less total energy than the Benchmark for the Hot-Dry/Mixed-Dry and the Cold Climate regions. These climate regions present opportunities for research because of the number of new homes being built and the relationships established with builder partners. The number of new homes and builder partners for each climate region can be seen in Figure 5. Building America will focus on developing the 30\% solutions for the Mixed-Humid and Marine regions in 2006.

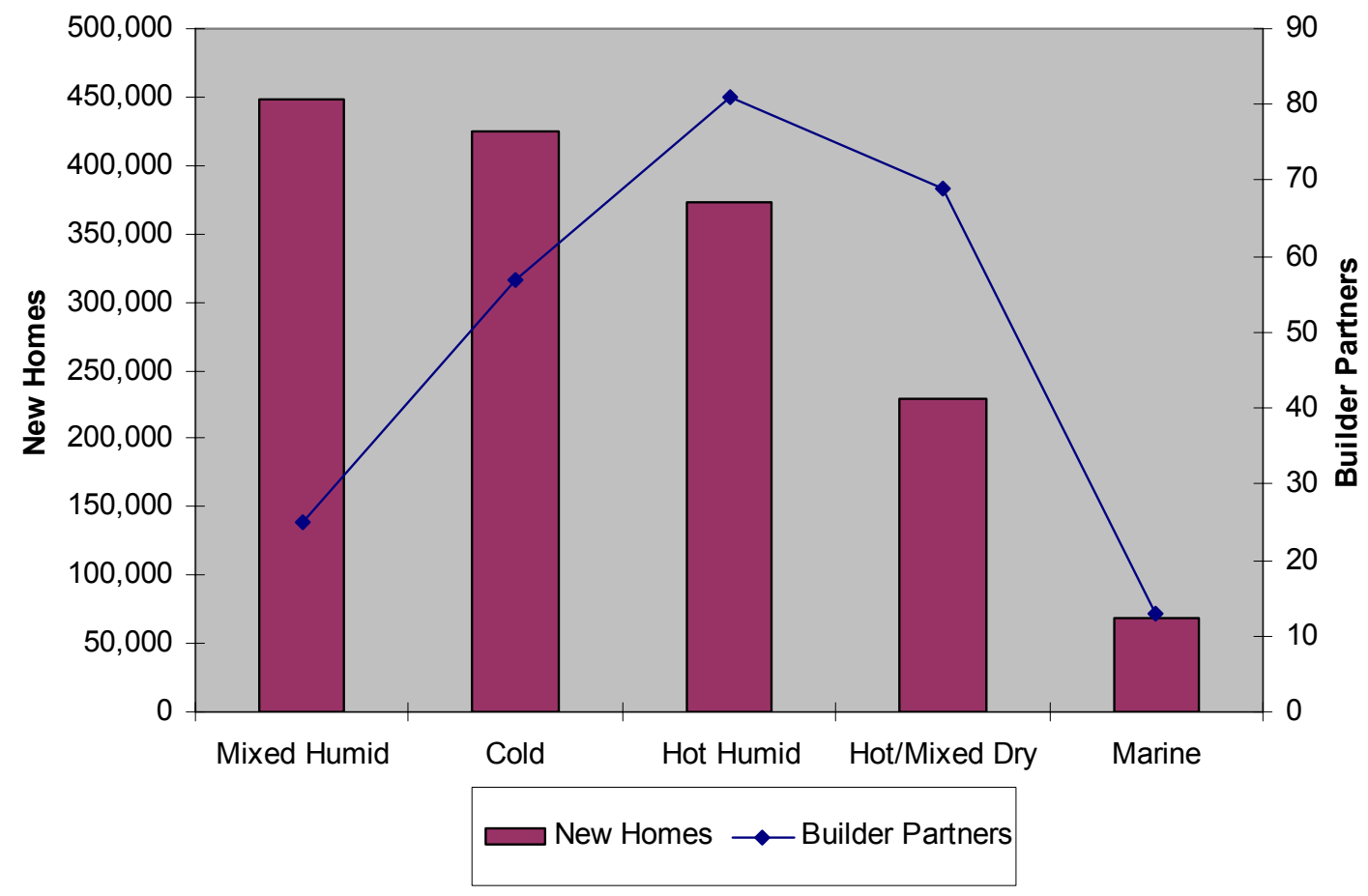

Figure 5. New homes ${ }^{11}$ and builder partners ${ }^{12}$ by climate region

\footnotetext{
11 July 1, 2002, to July 1, 2003. U.S. Census Bureau Housing Unit Estimates (HU-EST2003-04), "Annual Estimates of Housing Units for Counties: April 1, 2000, to July 1, 2003," Last revised September 2, 2004.

12 "House Counts by Climate Zone (detailed)," U.S. Department of Energy, Building America House Performance Database, January 5, 2005.
} 
Through 2025, Building America will continue to develop the strategies for new, single-family residential buildings to use $30 \%-100 \%$ less total energy in the Marine, Hot-Humid, Hotdry/Mixed-Dry, Mixed-Humid, and Cold Climate regions over the full range of house sizes, styles, and price points.

The purpose of this report is to provide an overview of 3 years of Building America system research that led to the development of homes that save $30 \%$ relative to the Benchmark. ${ }^{13}$ Based on the research results and case studies included in this report, the Building America Research teams have demonstrated that $30 \%$ homes can be reliably designed and constructed by production builders in Cold Climates. The actual rate of adoption of the research results contained in this report will depend upon a number of factors, including residential energy costs and national, state, and local incentives for the use of energy-efficient construction techniques.

\section{System Approach to Least-Cost Energy Savings}

\section{Integrated Design Process}

Building America's team-based systems-research approach, including use of systems-engineering and operations research techniques, provides opportunities for cost and performance trade-offs that improve whole-building performance and value, while minimizing increases in overall building cost. Systems engineering is conducted at multiple scales, including individual test houses, pre-production houses, and community-scale developments. Systems research includes analysis of system performance and cost tradeoffs as they relate to whole-building energy performance and cost optimization, including interactions between advanced envelope designs, mechanical and electrical systems, lighting systems, space-conditioning systems, hot water systems, major appliances, miscellaneous electric loads, energy control systems, renewable energy systems, and onsite power generation systems. Accordingly, the best practice recommendations in this report have been demonstrated to cost effectively increase overall product value and quality compared to conventional approaches, while significantly reducing energy use and use of raw materials when used on a production basis.

The final products of each research project include performance measurements and cost/performance evaluations in prototype houses, pre-production homes, and community-scale developments, and climate-based system research design/technology packages, including system performance specifications. These measurements, evaluations, and system-performance packages are the basis of the recommendations provided in this report.

\section{Analysis and Design Optimization}

The research path to future residential energy savings extends from a base case (e.g., a currentpractice building, a code-compliant building, or some other reference building) to a ZNE building with $100 \%$ energy savings. To ensure a well-defined reference for evaluation of energy

\footnotetext{
${ }^{13}$ The Research Benchmark provides a detailed description of all residential energy uses and serves as the reference point for the energy savings goals in Building America research project. More information about the Benchmark can be found on the Building America website: www.eere.energy.gov/buildings/building_america/PA_Resources.html.
} 
savings and progress toward multi-year goals, a detailed Benchmark ${ }^{14}$ building definition has been developed for use by all participants in Building America research projects. A standard reporting format for research results has also been developed to facilitate comparisons of performance between different research projects.

The Benchmark is generally consistent with the 1999 Home Energy Rating System (HERS) Reference Home, as defined by the National Association of State Energy Officials/Residential Energy Services Network (NASEO/RESNET), with additions that allow the evaluation of all home energy uses. The Benchmark represents typical standard practice in the mid-1990s, when DOE initiated the Building America program. Additional documentation to support the use of the Benchmark, including spreadsheets with detailed hourly energy usage and load profiles, can be found on the Building America Web site. ${ }^{15}$ As Building America teams develop innovative new technologies and systems approaches that move the program toward its research goals, the Benchmark will be re-evaluated and refined periodically to ensure that energy savings from these features are accurately credited. Many other valid techniques and definitions have been developed by other organizations, and they can be very useful to builders for specialized applications. For example, the HERS rating procedure (RESNET 2002) must be followed to obtain an ENERGY STAR ${ }^{\circledR}$ rating for building energy efficiency. Also, it might be necessary to determine whether or not a prototype meets the International Energy Conservation Code (IECC) ${ }^{16}$ or Model Energy Code (MEC), ${ }^{17}$ which could apply if adopted by the state or local government.

\section{Building America Research Benchmark}

The Benchmark was developed to track and manage progress toward the Building America multi-year whole-building energy savings goals for new construction, using a fixed reference point. To provide a context for the potential impacts of research projects on local and regional markets at a given point in time, energy usage is also compared with current Regional Standard Practice and Builder Standard Practice. Standard occupant profiles for use in conjunction with these reference houses have also been developed based on review of the available literature; the intent is to represent typical occupant behavior. Additional analysis and end-use monitoring ${ }^{18}$ are required to evaluate energy savings for specific occupants whose individual behavior could vary from the average profiles defined in the Benchmark. In general, relative savings for an individual user are expected to be approximately the same as those for an average user.

Energy savings can be defined in terms of site energy (used at the building site) or source energy (sometimes called primary energy). For electricity purchased from a utility, site energy can be converted to source energy to account for power plant generation efficiency and electrical transmission and distribution losses. The source-to-site energy ratio for electricity typically has a value of about 3 , depending on the mix of electrical generation types (coal-fired, natural gas

\footnotetext{
${ }^{14}$ Hendron, R. 2005. Building America Research Benchmark Definition, Updated December 29, 2004. NREL/TP550-37529. Golden, CO: National Renewable Energy Laboratory.

15 www.eere.energy.gov/buildings/building_america/pa_resources.html.

${ }^{16}$ International Energy Conservation Code®: 2003 Edition with 2004 Supplement. Country Club Hills, IL: International Code Council, Inc. 2003, 2004.

${ }^{17}$ MEC 1995, Council of American Building Officials (CABO) 5203 Leesburg Pike, Falls Church, VA 22041

${ }^{18}$ Norton, P.; Hancock, E.; Barker, G.; Reeves, P., et.al. 2003. The Hathaway "Solar Patriot" House: A Case Study in Efficiency and Renewable Energy. NREL/TP-550-37731. Golden, CO: National Renewable Energy Laboratory
} 
combined cycle, nuclear, hydropower, etc.) For the purpose of Building America analysis, national average site-to-source multipliers of 3.16 for electricity, 1.02 for natural gas, and 1.00 for all other fuels are used. From the view of all stakeholders in the building process, site and source energy are both important. Source energy has been chosen as the basis for tracking progress toward the Building America energy-saving targets and is also used as the basis of the cost/performance tradeoffs analyzed in this report. Site energy savings are also calculated as part of ongoing research projects and included in project evaluations because of their importance in determining specific utility bill savings.

\section{Analysis Methods}

A key issue in any building energy analysis is which tool or program to choose to estimate energy consumption. An hourly simulation is often necessary to fully evaluate the timedependent energy impacts of advanced systems used in Building America houses. Thermal mass, solar heat gain, and wind-induced air infiltration are examples of time-dependent effects that can be accurately modeled only by using a model that calculates heat transfer and temperature in short time intervals. In addition, an hourly simulation program is also necessary to accurately estimate peak energy loads. Because of the large number of users, public availability, and level of technical support, DOE-2 is the most commonly used hourly simulation engine for systems analysis studies performed under the DOE Building America program.

EnergyGauge $^{19}$ is a frequently used interface for DOE-2; it has been tailored specifically to residential buildings. EnergyGauge can also automatically calculate HERS scores and evaluate compliance with the IECC performance path. Teams are also encouraged to use other simulation tools when appropriate for specialized building simulation analysis, provided the tool has met the requirements of BESTEST ${ }^{20}$ in accordance with the software certification sections of the RESNET/HERS Guidelines. ${ }^{21}$

Building energy simulations are often used for trial-and-error evaluation of "what-if" options in building design (i.e., a limited search for an optimal solution). In some cases, a more extensive set of options is evaluated and a more methodical approach is used. For example, in the Pacific Gas and Electric ACT2 project, ${ }^{22}$ energy-efficiency measures were evaluated using DOE-2 simulations in a sequential-analysis method that explicitly accounted for interactions. With today's computer power, the bottleneck is no longer simulation run time, but rather the human time to handle input/output. Computerized option analysis has the potential to automate the input/output, evaluate many options, and perform enough simulations to explicitly account for the effects of interactions among combinations of options. However, the number of simulations still needs to be kept reasonable, by using an efficient search technique rather than attempting exhaustive enumeration of all combinations of options. Even with simulations that run in a few seconds, run time for an exhaustive study of all possible combinations is prohibitive for the millions of combinations that can result from options in the ten or more categories needed to accurately describe a residential building. Several computer programs to automate building

\footnotetext{
${ }^{19}$ This is available for purchase from the Florida Solar Energy Center (http://energygauge.com/).

${ }^{20}$ www.eere.energy.gov/buildings/tools directory/software.cfm/ID=85/pagename=alpha list

${ }^{21}$ Residential Energy Services Network (RESNET). 2002. "Mortgage Industry National Home Energy Rating Systems Accreditation Standards.” Chapter 3, pp. 29-54. San Diego, CA: RESNET.

${ }^{22}$ Davis Energy Group. ACT2 Stanford Ranch Site, Final Design Report. Davis, CA: Davis Energy Group.
} 
energy optimization have been recently developed. For example, EnergyGauge-Pro ${ }^{23}$ uses successive, incremental optimization (similar to the ACT2 approach) with calculations based on the "energy code multiplier method" for Florida. GenOpt ${ }^{24}$ is a generic optimization program for use with various building energy simulation programs and user-selectable optimization methods.

To evaluate the cost required to reach a specific energy target, energy and cost results can be plotted in terms of annual costs (the sum of utility bills and mortgage payments for energy options) versus percent energy savings (Figure 6). The optimal least-cost path can then be determined by connecting the points for building designs that achieve various levels of energy savings at minimal cost (i.e., that establish the lower bound of results from all possible building designs). Alternatively, net present value or other economic figures of merit could be chosen. Inclusion of even a modest number of possible options for major system choices can lead to a very large number of possible building designs. One of the key challenges in developing a practical analysis method is to develop an approach that quickly focuses on the combinations that are nearest to the least-cost limit. To address these challenges, NREL is currently developing the BEopt Analysis Method.

Points of particular interest on the least-cost path are shown in Figure 6 and can be described as follows: from the Benchmark at point 1, energy use is reduced by employing building efficiency options (e.g., improvements in space-conditioning systems, hot water systems, lighting systems, thermal distribution systems, etc.) A minimum annual cost optimum occurs at point 2. Additional building efficiency options are employed until the marginal cost of saving energy for

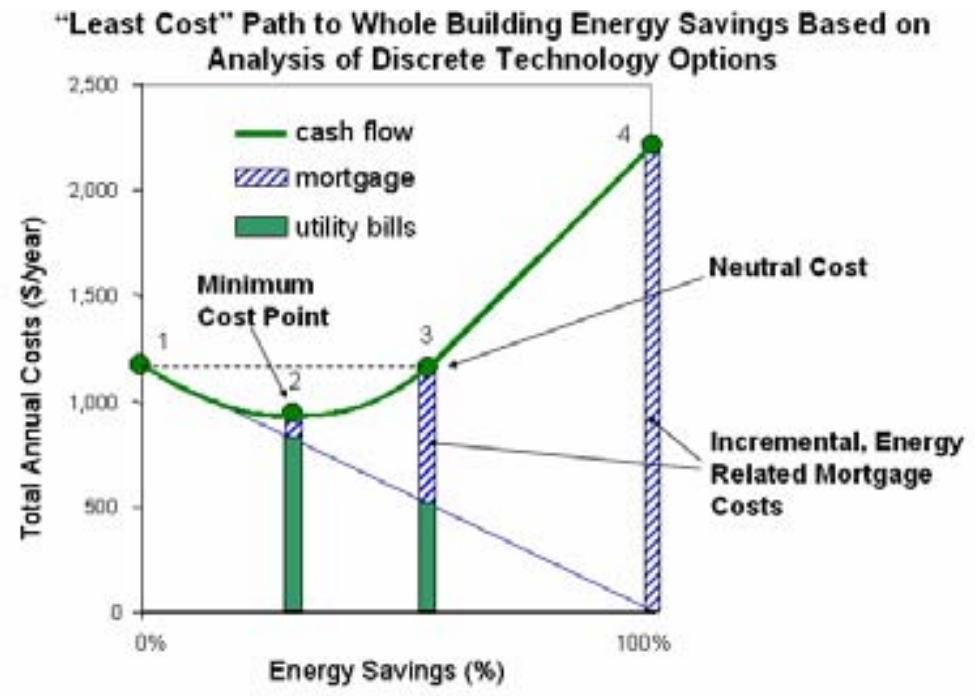

Figure 6. Least-cost curve calculated using the BE-opt analysis method

\footnotetext{
${ }^{23}$ Florida Solar Energy Center. EnergyGauge Pro. Cocoa, FL: Florida Solar Energy Center (http://energygauge.com/FlaRes/features/pro.htm).

${ }^{24}$ Wetter, M. "GenOpt ${ }^{\circledR}$, "Generic Optimization Program," Seventh International IBPSA

Conference, Rio de Janeiro, Brazil. (www.ibpsa.org/bs_01.htm).
} 
these options equals the cost of producing power onsite at point 3. In this study, residential PV systems are used as the system option for onsite power. As research on distributed energy systems continues, it is anticipated that other onsite power technologies will also become available for residential-scale projects. From point 3 on, the building design does not change and energy savings are solely a result of adding additional onsite power capacity, until ZNE is achieved at point 4 .

The horizontal dashed line in Figure 6 defines solutions that provide energy savings at an annual cost that is less than or equal to the utility cost for the reference house when energy improvements are financed as part of a 30-year mortgage. All solutions in a vertical region below the neutral cost line are essentially equivalent from an energy-savings perspective. The specific design package chosen by a builder to achieve a specific energy-savings level will depend on a number of factors, including material and equipment cost and availability and overall homeowner preferences.

\section{Performance Verification}

Modeling provides the generalized energy calculations necessary to compare a prototype house to the Benchmark. Because weather, occupant behavior, and miscellaneous electric loads can dramatically affect actual energy use, it is essential that simulations be used to separate the objective performance of a prototype house from the effects of these uncontrolled variables. Modeling also allows the evaluation of "what-if" scenarios, where alternative design features are compared to those of the as-built prototype house.

However, short-term field evaluations of actual prototype building systems provide information that modeling alone cannot. Field testing increases confidence in building models by improving simulation accuracy in areas that are difficult to know without direct measurements, such as duct and envelope air leakage, solar collector efficiency for solar hot water (SHW), and even the whole-building heat loss coefficient (UA). Common measurement techniques include tracer-gas tests, blower-door and duct-blaster tests, infrared imaging, current-voltage traces for photovoltaic systems (PV), and co-heating tests. Other tests are often developed based on the specific design features and uncertain performance characteristics of the house.

The intent of short-term testing is to characterize the performance of unoccupied building and systems under controlled conditions, not under the idiosyncratic control of random occupants. Short-term tests may be repeated seasonally to characterize performance changes from winter to summer. These tests can also help identify equipment installation issues, operational problems, or malfunctions at an early stage before the occupants are inconvenienced.

HERS raters are a valuable resource for continuing the process of energy-efficient construction with builders. Many Building America teams have successfully partnered with local HERS raters to provide initial testing, construction monitoring, and performance-verification testing services during the construction of test homes. The relationship between the builder and rater may continue after the test home, with the rater providing services, including ongoing performance verification and, in some cases, design and engineering services, depending on the rater's skill set.

The current RESNET HERS scoring system, which has been undergoing substantial change over the past few years, is of questionable value to builders participating in the Building America program, because they are generally most interested in whether they meet the overall energy 
efficiency goals of the program and not necessarily just achieving a score. It is not clear in the long run how builders will embrace and promote numeric scores provided by a system where the basis of the scoring system is periodically adjusted to reflect changes in codes or adding other energy end uses that make up the score. In this respect, a prescriptive set of criteria may be more valuable to builders - criteria such as those being developed by the Building America Program and the 2006 version of the EPA ENERGY STAR Homes ${ }^{\circledR}$ program with certain performance criteria pertaining to building and space-conditioning distribution system tightness targets. Whole-house energy-performance analysis maybe the best approach for the industry instead of a scoring system that periodically changes, is not comprehensive of all energy uses (which can cause confusion with homeowners), and is not easily marketed by the builder.

Long-term field measurements provide valuable insights into the actual performance of the home under realistic conditions, including interactions between occupants and technology. Ultimately, it is essential for Building America to demonstrate that houses can meet the target levels of energy efficiency in reality and not just on paper. However, individual long-term tests under occupied conditions must always be put in the context of the specific occupants. Number of occupants, thermostat settings, operation of windows and interior shades, hot water and appliance-use patterns, and lifestyle are all important drivers of energy consumption. The recommended approach is, therefore, to compare measurements with simulated energy use based on actual occupant behavior and weather conditions and to make adjustments to the simulation based on the results of this comparison if justified. An adjusted energy savings analysis can then be performed based on actual instead of theoretical operating conditions.

Long-term monitoring activities are still ongoing for the houses designed to meet the $30 \%$ savings target discussed in this report. The results will be reported in future technical publications, and the lessons learned will be used to inform future projects at the same or higher energy-savings target. Building America is committed to long-term energy savings, health and comfort, durability, and reliability of its system design recommendations at each performance level, and we will continue to track the performance of our prototype houses for several years to come.

\section{System Design and Construction Process}

\section{Climate Analysis}

\section{Key Climate Elements that Affect Building Design}

Houses should be designed and constructed in a manner that is suited to their environment, both exterior and interior. Sun, rain, temperature, humidity, sunlight, and wind are major environmental loads that act on houses.

The recommendations in this research report are applicable to houses constructed in Hot-Dry and Mixed-Dry climate regions. The climate regions have been defined as follows ${ }^{25}$ :

Hot-Dry: A hot-dry climate is generally defined as a region that receives less than 20 in. $(50 \mathrm{~cm})$ of annual precipitation and where the monthly average outdoor temperature remains above $45^{\circ} \mathrm{F}\left(7^{\circ} \mathrm{C}\right)$ throughout the year.

\footnotetext{
${ }^{25}$ www.eere.energy.gov/buildings/building_america/climate_zones.html
} 
Mixed-Dry: A Mixed-Dry climate is generally defined as a region that receives less than 20 in. $(50 \mathrm{~cm})$ of annual precipitation, has approximately 5,400 heating degree days $\left(50^{\circ} \mathrm{F}\right.$ basis $)$ or less, and where the average monthly outdoor temperature drops below $45^{\circ} \mathrm{F}\left(7^{\circ} \mathrm{C}\right)$ during the winter months.

It should be noted that a section of the Hot-Dry region, stretching from deserts in southern California to Phoenix, Arizona, experiences a period of 5-6 weeks in late summer with moderately high humidity that is uncharacteristic of this otherwise Hot-Dry region.

Individual locations within the broad general regions and zones described above can vary significantly. For a specific location, designers and builders should consider local weather records, local experience, and the micro-climate around a building. Elevation, incident solar radiation, wind, shade of adjacent buildings, being located on the north side of a mountain, nearby water and wetlands, vegetation, and undergrowth can all affect the micro-climate.

\section{Site Development}

\section{Orientation Impacts}

To achieve the $30 \%$ level of energy savings, it is not necessary to orient homes in any particular direction. In many instances, the builder does not have any influence over lot orientation, and the house will face the street as laid out by the developer. The predominant window placement will typically be to the street and the back of the house. If it is possible to consider orientation at the site development level of the homebuilding process, one virtually no-cost option for improving energy performance is to subdivide for solar orientation. Alternately, on larger lots that do not have to "respect the street," site planning can be undertaken to optimize the orientation of the house for passive solar benefit. An example of land planning and lot layout to allow for passive solar orientation is shown in Figure 7.

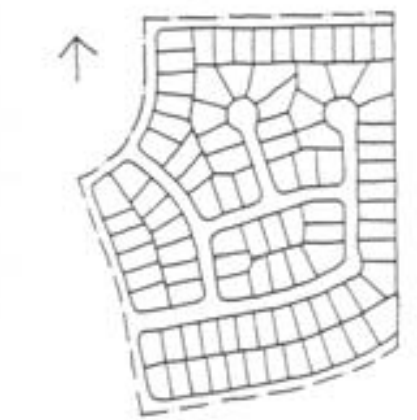

Solar Access Not Considered 60\% Solar

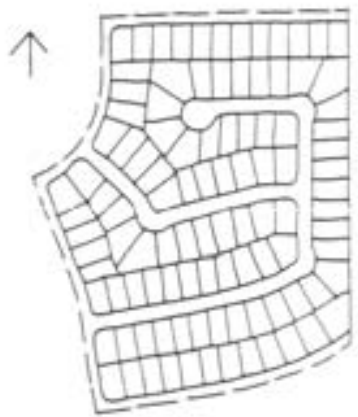

Solar Access Considered $78 \%$ Solar

Figure 7. Subdivision site plan for solar orientation ${ }^{26}$

\footnotetext{
${ }^{26}$ Shelley Dean and Fuller, Energy Principles in Architectural Design Architects California Energy Commission
} 1981. 


\section{Landscaping}

While not a required strategy for achieving 30\% whole-house savings, evaluating the vegetation on a lot and retaining trees that provide beneficial shading can be a low- or no-cost way to improve energy performance, predominantly by providing shade in the cooling season and helping to buffer or direct beneficial prevailing winds. Shade trees block summer sunlight before it strikes windows, walls, and roofs, dissipating absorbed heat to the air where it can be carried away by the breeze. It is most effective when located next to windows, walls, and air conditioners, and when located on the side of the home receiving the most solar exposure in summer. Shade to the southwest and west is especially important for blocking peak solar gain in the summer in late afternoon. Trees more than 35 feet from the structure are probably too far away for shade. Trees to the north of a house in a cold climate can help block cold north winds, reducing one driving force for air infiltration. Trees, shrubs, and vines not only block sunlight, but also can cool the nearby air beneath the canopy or behind the plant by as much as $15^{\circ} \mathrm{F}$ because of natural evaporation from the plant's leaves.

\section{Water Management}

In natural settings, most precipitation infiltrates into the ground, while a small portion runs off on the surface and into receiving waters. This surface runoff water is classified as storm-water run off. As area are constructed and urbanized, surface permeability is reduced, resulting in increased storm water run-off volumes that are transported via urban infrastructure (e.g., gutters, pipes and sewers) to receiving waters. These storm water volumes contain sediment and other contaminants that have negative impact on water quality, navigation and recreation. Furthermore, conveyance and treatment of storm water volumes require significant municipal infrastructure and maintenance.

Reduction and treatment of run-off volumes decrease or eliminate contaminants that pollute receiving water bodies. Minimizing the need for storm water infrastructure also reduces construction impacts and the overall ecological footprint of the building. Finally, infiltration of storm water on site can recharge local aquifers, mimicking the natural water cycle.

Strategies. Storm-water management strategies that prevent or reduce the pollution of water include the following:

- Reduce impervious surface: The most effective method to minimize storm water run-off volume is to reduce the amount of impervious area. By reducing impervious area, stormwater infrastructure can be minimized or deleted from the project. To minimize the impervious surface and to encourage the natural process of evaporation and infiltration, consider such methods as designing a smaller building footprint; clustering or concentrating developments to reduce the amount of paved surfaces such as roads, parking lots and sidewalks; and paving with pervious materials, such as poured asphalt or concrete with incorporated air spaces or concrete unit-paving systems with large voids that allow grass or other vegetation to grow between the voids.

- Storm-water harvesting: Capture storm water from impervious areas to reuse within the building. Storm-water harvesting from roofs and hardscapes can be used for non-potable uses, such as sewage conveyance, fire suppression, and industrial applications. 
- For storm-water volumes that must be conveyed from the site to a receiving water body, design treatment practices to match the needs of the location and the specific drainage area. Design storm-water facilities to remove contaminants and release the volumes to local water bodies. Utilize biologically based and innovative storm-water management features for pollutant load reduction, such as constructed wetlands, storm-water filtering systems, bioswales, bioretention basins, and vegetated filter strips.

- Use vegetated buffers around parking lots to remove runoff pollutants, such as oil and grit.

- Specify and install water-quality structures for pretreatment of runoff from surface parking areas. Do not disturb existing wetlands or riparian buffers when constructing ponds at the lowest elevations of a site.

- Design storm-water runoff to flow into vegetated swales rather than into structured pipes for conveyance to water-quality ponds. Swales provide filtration for storm water volumes and require less maintenance than constructed storm-water features.

\section{System Design Approach}

\section{Integrated Design Process}

Typically a house goes through the following design process:

- Conceptual Design Development. Planning Stage where the price range, square footage, number of stories, lot sizes, general features, and styles are determined.

- Preliminary Design Development. Develop floor plan sketches, number of bedrooms, major options, basic circulation, and function locations, as well as some elevation concepts.

- Design Development. Preliminary structural, mechanical, electrical, plumbing, and Compliance.

- Construction Documents Development. Final working drawings ready for bidding, submittal. Back-checking and coordination by consultants.

\section{- Construction and Commissioning.}

An Integrated Design Process (IDP) ensures that all the key players and design consultants, including the architect, planner, mechanical engineer, landscape architect, energy consultant and the site engineer, work together starting with the conceptual design stage, even though the role of each may be limited for a particular design stage. The IDP is a key aspect in achieving the systems-design approach.

An IDP approach may seem to be an expensive approach, but in the long run the overall costs and advantages significantly outweigh the traditional approach. For example, the mechanical engineer may be involved in the project much later and be asked to design the mechanical system with the already defined constraints of attic/plenum space - resulting in an inefficient HVAC distribution system.

By developing a better IDP, builders are able to incorporate the $30 \%$ improvement level strategies more effectively with less disruption of their normal construction process and do so more cost effectively. While use of an IDP at the $30 \%$ improvement level for builders is quite 
desirable, it will be even more important at higher energy performance levels, $40 \%, 50 \%$, and $70 \%$ reduction.

Approaches to an IDP will vary with different builders, as their relationships with design professionals, suppliers, and the trades are often different. For example, a builder with an inhouse architectural staff, that prepares all new house designs, may have a different level of control and continuity of design as compared to a builder that works with an independent architectural firm. Approaches to the IDP are evolving in Building America's programs, and a single, clearly defined process has not been established.

An example of this is HVAC system because HVAC designers need to provide input as early as possible. They need to tell the architect which architectural features cause comfort issues and are difficult or impossible to overcome with typical HVAC practices. They also need to make sure the architect allows adequate space to run ducts. Many architects have had to re-design plans enough times as a result of HVAC issues that they know fairly well how to accommodate HVAC items. Still many problems commonly arise that could be avoided through earlier input and better coordination.

To continue with our example, Table 5 shows the main trades and consultants who are affected by the HVAC system. The first column lists the item or issue and each subsequent column how each trade is affected by it.

As shown from the matrix, all trades are intertwined in the design and building process. This matrix could be easily applied to the builder, electrician, plumber, etc. As homes become more efficient, it will be critical that all involved in the system will need to coordinate their efforts to ensure quality control and to employ quality assurance tools and processes through the IDP.

One model of the information flows and actions associated with an integrated design process are shown in Figure 8. Some of the key activities of the integrated design process is setting a performance standard, identifying and integrating all systems in the house from the predesign stage through construction documentation, and having feedback loops in the design process from key participants in organization and trade base.

Setting Performance Standards. To implement an IDP process, the team needs to have a set of standards to which the building will be expected to achieve. The first step in setting a performance standard is to understand the customer base and what level of performance they are receptive to. Targeted customer and market-area surveys help to give as clear a picture as possible of the factors that motivate home sales in general and home purchasing patterns for the target market. This data is used to direct the design of new products and respond to market pressures. The ability to survey, synthesize, and extract meaning from customers and the market can provide a significant advantage to builders, in that they have a better understanding of market and can apply this knowledge to fulfill unmet needs. If the market is indicating a need for greater energy efficiency, durability, improved indoor air quality, or comfort, then the adoption of Building America performance packages may be appropriate as the standard.

Similarly, the builder must determine what level of quality and performance their housing will achieve. This may have to do with moisture performance, comfort, increased durability, and reduced risk. All of these issues are typically addressed by following the recommendations included in this report. 
Table 5. Matrix of Trades

\begin{tabular}{|c|c|c|c|c|c|c|c|}
\hline Item & Architect & $\begin{array}{l}\text { Builder/Framer } \\
\text { rStructural } \\
\text { Engineer }\end{array}$ & $\begin{array}{l}\text { HVAC } \\
\text { Installer }\end{array}$ & $\begin{array}{l}\text { Energy } \\
\text { Consultant }\end{array}$ & Electrical & Plumber & $\begin{array}{l}\text { Drywall } \\
\text { or } \\
\text { insulation }\end{array}$ \\
\hline $\begin{array}{l}\text { FAU } \\
\text { location }\end{array}$ & $\begin{array}{l}\text { Roof pitch, } \\
\text { furnace } \\
\text { closets, } \\
\text { clearance in } \\
\text { parage }\end{array}$ & $\begin{array}{l}\text { Truss design, } \\
\text { platloim, } \\
\text { clearance, } \\
\text { closets, bollards. } \\
\text { attic acosss } \\
\text { froming }\end{array}$ & $\begin{array}{l}\text { Type of FAY } \\
\text { fuphliciw, } \\
\text { hocizcettal, } \\
\text { clearance, } \\
\text { timing of } \\
\text { instalfation }\end{array}$ & $\begin{array}{l}\text { Modeling } \\
\text { bortect } \\
\text { location of } \\
\text { ducts for } \\
\text { computer } \\
\text { model }\end{array}$ & $\begin{array}{l}\text { Power, } \\
\text { service light, } \\
\text { control } \\
\text { wiring. etc. }\end{array}$ & $\begin{array}{l}\text { Condensate } \\
\text { fineș, gass } \\
\text { piping }\end{array}$ & $\begin{array}{l}\text { Insulation } \\
\text { usider } \\
\text { platform } \\
\text { maxy be } \\
\text { different }\end{array}$ \\
\hline $\begin{array}{l}\text { Equipment } \\
\text { size, load } \\
\text { calculations }\end{array}$ & $\begin{array}{l}\text { Clearances, } \\
\text { \# of systems, } \\
\text { building } \\
\text { features }\end{array}$ & $\begin{array}{l}\text { Structural impacts } \\
\text { (weight) }\end{array}$ & $\begin{array}{l}\text { Materials, } \\
\text { labor, costs }\end{array}$ & $\begin{array}{l}\text { Energy } \\
\text { features } \\
\text { impact sizing }\end{array}$ & $\begin{array}{l}\text { Electricel } \\
\text { loeds }\end{array}$ & & \\
\hline $\begin{array}{l}\text { Supply } \\
\text { register } \\
\text { locations }\end{array}$ & $\begin{array}{l}\text { Aesthetics, } \\
\text { clearances }\end{array}$ & $\begin{array}{l}\text { Register bo-ot } \\
\text { support }\end{array}$ & $\begin{array}{l}\text { Materials. } \\
\text { labor }\end{array}$ & & & & $\begin{array}{l}\text { Sealing } \\
\text { around } \\
\text { registers }\end{array}$ \\
\hline $\begin{array}{l}\text { Return grille } \\
\text { locations }\end{array}$ & $\begin{array}{l}\text { Avesthetics, } \\
\text { noise issues }\end{array}$ & Framed openings & $\begin{array}{l}\text { Materials, } \\
\text { lebor }\end{array}$ & & & & $\begin{array}{l}\text { Sealing } \\
\text { around } \\
\text { grilles }\end{array}$ \\
\hline $\begin{array}{l}\text { Condenser } \\
\text { locations } \\
\text { and line set }\end{array}$ & $\begin{array}{l}\text { Aesthetics, } \\
\text { nouse issues }\end{array}$ & $\begin{array}{l}\text { Clearance, } \\
\text { accessibaity to } \\
\text { yard (set-back } \\
\text { issues), } 2 \times 6 \text { wolls, } \\
\text { chases }\end{array}$ & $\begin{array}{l}\text { Selaterials, } \\
\text { labor, } \\
\text { serviceability }\end{array}$ & & $\begin{array}{l}\text { Power, } \\
\text { service } \\
\text { disconnect }\end{array}$ & & \\
\hline Attic access & Aesthetics & $\begin{array}{l}\text { Framed opening. } \\
\text { inuss issues }\end{array}$ & $\begin{array}{l}\text { Access, } \\
\text { serviceatility }\end{array}$ & & & & \\
\hline $\begin{array}{l}\text { Routing B. } \\
\text { vent }\end{array}$ & $\begin{array}{l}\text { Chases, } \\
\text { clearances, } \\
\text { eesthetics } \\
\text { (on root) }\end{array}$ & $\begin{array}{l}\text { Framed chases, } \\
\text { roof cap }\end{array}$ & $\begin{array}{l}\text { Materials, } \\
\text { labor, } \\
\text { installation }\end{array}$ & & & $\begin{array}{l}\text { No cocntlicts } \\
\text { with vent }\end{array}$ & \\
\hline $\begin{array}{l}\text { Chases, } \\
\text { soffits, and } \\
\text { drops }\end{array}$ & $\begin{array}{l}\text { Aesthetics, } \\
\text { feasibility }\end{array}$ & $\begin{array}{l}\text { Framing, } \\
\text { clearances for } \\
\text { ducts, oonflicts }\end{array}$ & $\begin{array}{l}\text { Selaterials, } \\
\text { labor, } \\
\text { instalfation }\end{array}$ & & & $\begin{array}{l}\text { No conflicts } \\
\text { with ducts }\end{array}$ & \\
\hline $\begin{array}{l}\text { Therrmóstal } \\
\text { location }\end{array}$ & Aesthétics & & $\begin{array}{l}\text { Materials, } \\
\text { labor, } \\
\text { installation }\end{array}$ & & Winng & & $\begin{array}{l}\text { Seal hole } \\
\text { for wires }\end{array}$ \\
\hline $\begin{array}{l}\text { Equipment } \\
\text { efficiency }\end{array}$ & & & Materials & $\begin{array}{l}\text { Efficiency } \\
\text { determined } \\
\text { by energy } \\
\text { consultarst }\end{array}$ & & & \\
\hline $\begin{array}{l}\text { Gombustion } \\
\text { air }\end{array}$ & $\begin{array}{l}\text { Altic ven: } \\
\text { calcs, zouting } \\
\text { for CA ducts }\end{array}$ & $\begin{array}{l}\text { Adegtate athic } \\
\text { vents (roofer) }\end{array}$ & Ducting, if any & & & & \\
\hline
\end{tabular}




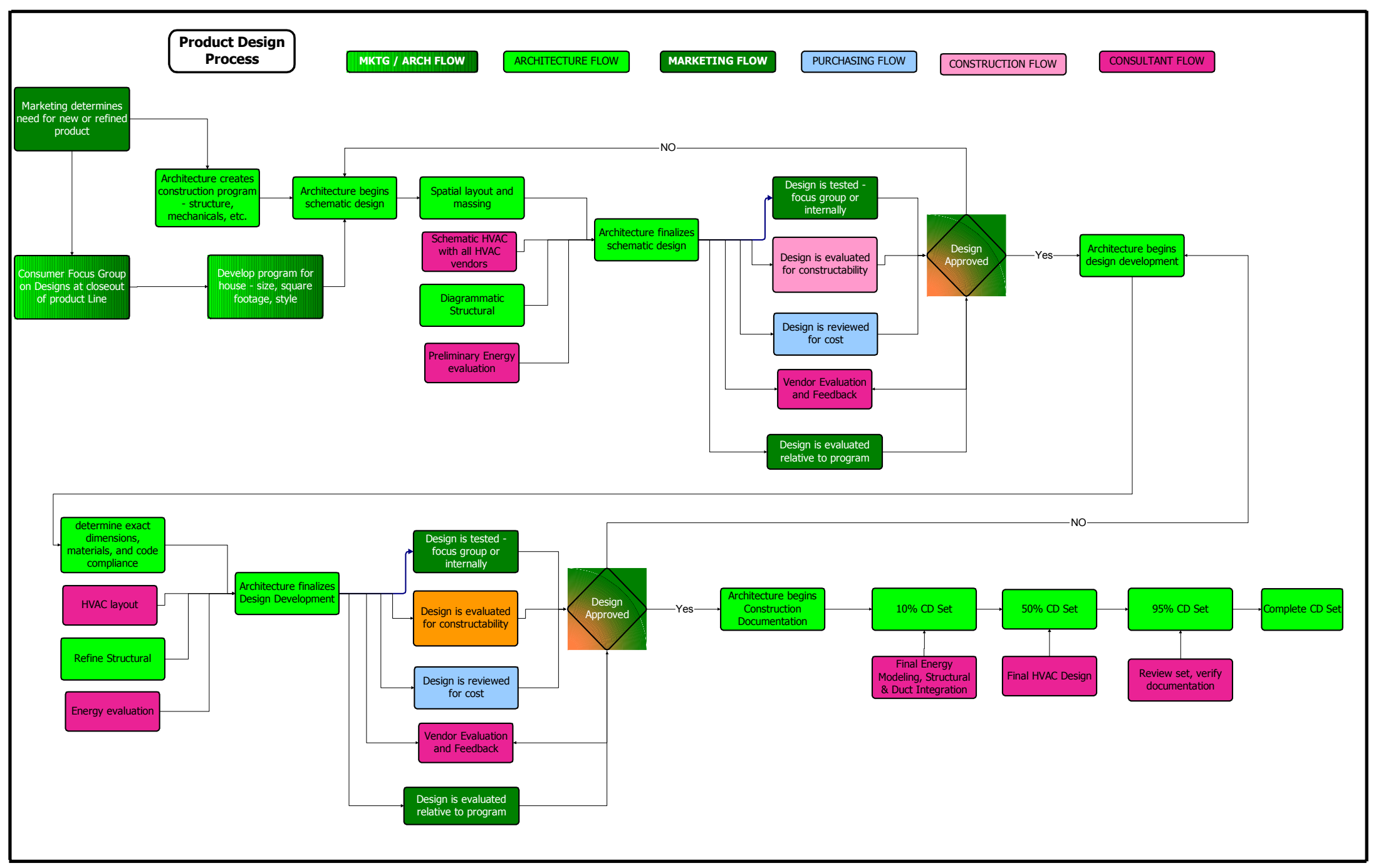

Figure $8^{27}$ Model of the information flows and actions associated with an integrated design process (IDP)

${ }^{27}$ IBACOS, Inc. KAAX-3-33410-06 B.2, Community Scale Process Research Results. Pittsburgh: IBACOS. November 2004. 
Set Goals Early in the Design Stage. By creating specific high-performance goals early in the design process, the design and construction team and their external vendors all have a clear understanding of the intent and performance metrics associated with a product line. As designs are being developed, all systems and strategies are considered, and feedback is solicited. This allows for early identification of potential conflicts or opportunities for alternate solutions before designs are finalized.

The goal setting also demonstrates to vendors that the builder has committed to a level of performance, and all parties will need to play their role in seeing that it is achieved. A recognized best practice found by many of the Building America teams is a commitment to vendors to participate in long-term relationships, as opposed to simply forming relationships based on the lowest bid. This allows for mutual trust and respect to be built and the opportunity to improve and innovate is increased.

Gain Team-Based Feedback during Design. When asked about the most important design issue in its success in achieving higher performance levels, one participating builder identified framing as the area that they spend the most time on. The location of every stud, floor truss, and roof truss must be specifically located and coordinated with all other trades in order to make installation of other systems go smoothly and efficiently. This has been true throughout the Building America program. Builders may want to consider use of advanced CAD and panelization programs for generating a specific set of architectural and framing plans for each house type. It is important to work with the framing and HVAC contractors to identify conflicts and develop solutions before houses go into production.

This process is continually being refined, and a best practice by some builders is to create a single system design that would be approved, installed, and warranted by any installing contractor. This can apply for many systems in the house, including but not limited to framing, electrical, plumbing, and HVAC. For example this level of up-front design with the HVAC system helps control consistency and allows for better performance through proper sizing and design. It is important to have proper load calculations, equipment selection, and duct layouts with documentation that is somewhat transparent, so that HVAC vendors can evaluate system design options and agree upon a final solution. At this point, design changes can also be made to floor plan and framing layouts that can facilitate duct installation. While there is never a perfect solution for all parties, this level of discussion between the vendors, design, and construction greatly enhances the opportunity to "get it right." This process can be applied for virtually any system in the house.

\section{Energy Analysis}

From a purely energy perspective, the section of this report entitled System Approach to Least-Cost Energy Savings describes the process involved with optimizing Building America Houses. It must be noted that energy cannot be evaluated in a vacuum, and other issues have to be considered in the design process. In order for higher levels of efficiency to be accepted by builders and consumers, other key attributes of the house must be addressed. The systemsdesign approach is a process by which all the various subsystems in the house are evaluated and their interrelationships are understood, planned, and optimized. All of these systems must be designed and applied to realize both energy-related and non-energy performance benefits associated with occupant health, safety, comfort and long-term building durability and 
efficiency. To only achieve energy efficiency without meeting these other criteria could cause consumer dissatisfaction and ultimately rejection of higher levels of energy efficiency, because the occupant's other expectations of a new house are not being met.

In a general sense, Building America houses include increased levels of thermal insulation, higher-performance windows, significant air sealing, a strategy that eliminates the possibility of introducing the by-products of combustion into the house, a mechanical ventilation system, a properly sized and engineered space-conditioning system, higher efficiency spaceconditioning and water-heating appliances, and may also include improvements in the efficiency of the appliances and lighting. The extent to which any of these strategies must be implemented varies by climate zone and the level of energy performance the builder seeks to achieve. A systems-design approach helps assure that the energy-related aspects of the project are being satisfied in conjunction with the non-energy benefits and is done in a way that optimizes the synergies of the various systems in the house.

An important part of getting to the $30 \%$ energy savings, or any other level of energy saving,-is to be able to evaluate alternative combinations of energy features before homes are built. Energy-simulation software, also referred to as computer or simulation models, are used to estimate energy performance of buildings quickly and inexpensively long before anything is purchased or constructed. Builders can access the costs of the various combinations of energy features to determine the most cost effective way of achieving the desired energy savings level early in the design process.

Very often, energy savings of homes only refers to savings of heating and cooling energy, or heating, cooling, and water heating. It is important to note that in the $30 \%$ savings level referenced throughout this report and throughout the Building America Program, references are made to whole-house energy savings, including all the energy used in the home for heating, cooling, water heating, and all the appliances and miscellaneous electrical uses, often referred to as plug loads.

The other challenge in energy analyses is to be able to compare energy studies done from one person to another, in fact from company to company, across the country. For this purpose, the Building America Program has developed a Benchmark, so that assumptions made in conducting energy analyses across the country can be standardized, enabling results to be fairly and reasonably compared.

The Benchmark guidelines are used to define a base-case house for determining levels of energy savings in conducting energy analyses. The Benchmark is generally consistent with mid-1990s standard practice, as reflected in the Home Energy Rating System (HERS) Technical Guidelines (RESNET 2002), with additional definitions that allow the analyst to evaluate all residential end-uses, an extension of the traditional HERS rating approach that focuses on space conditioning and water heating. A series of user profiles, intended to represent the behavior of a "standard" set of occupants, was created for use in conjunction with the Benchmark.

Energy simulations are conducted using software such as Energy Gauge, Energy 10, DOE 2.2, TRNSYS and Micropas, to predict the yearly energy consumption in homes. ${ }^{28}$ Energy

\footnotetext{
${ }^{28} \mathrm{DOE}$ 's list of energy simulation software can be found at www.eere.energy.gov/consumerinfo/reading_resources/v103.html
} 
simulations are run for both the Benchmark, as well as the designed home. The design home consists of enhanced energy-efficient features and systems. The detailed energy-simulation results are used to compute the energy savings of the designed home compared to the Benchmark base case.

\section{Passive Design Strategies for Minimizing Cooling and Optimizing Heating}

To achieve a $30 \%$ whole-house energy savings, it is not necessary to undertake any specific passive solar-design strategies. It should be recognized that proper orientation of the building and implementation of passive solar strategies can be a low or no-cost method to significantly improve the energy performance of a house.

An almost invisible way of incorporating a "passive" strategy that is beneficial in all climate zones is the use of low-SHGC glazing in all fenestration units. This product generally has little impact on the visual characteristics of the window, and incorporating it does not require aesthetic redesign of the house. The 2004 Supplement to the 2003 International Residential Code requires a SHGC of 0.4 in the Hot-Dry, Mixed-Dry, Marine, Hot-Humid, and southern parts of the Mixed-Humid climate zones. Relatively low (0.30) SHGC glazing has been used successfully in $30 \%$ improvement homes in all climate zones. While a low SHGC unit reduces beneficial heating season solar gain, Building America teams have found that where no attention is paid to passive solar design, low-SHGC windows generally provide a costeffective option for builders, when all the systems interactions benefits are considered. The following are the reasons for this:

- Traditional production-builder house models are oriented in any direction. Using lower SHGC glazing in all windows assures an overall reduction of the heat gain during the cooling season, regardless of how the house is placed with respect to the sun. This reduction in heat gain avoids some of the need for air conditioner operation, which is a net energy savings.

- Air-conditioning equipment is sized based on peak load. Using lower-SHGC glazing reduces peak load and, in turn, reduces air-conditioning unit sizes. Smaller airconditioning systems have lower airflows rates and, therefore, require smaller ducts. Lower airflow rates also require smaller fans, which use less electricity to operate. Reducing the size of the air-conditioning (AC) system also means cost savings to the builder, which can be reinvested in other energy upgrades.

- The heating season heat gain penalty from the use of lower SHGC glazing only occurs on cold, sunny days. As seen in Figure 8A, there is comparably little solar resource across much of the northern United States in the winter months; thus, there is little opportunity for beneficial solar gain. In those areas of the Cold Climate zone where there is a good winter solar resource, higher SHGC windows may be considered, but need to be carefully designed to avoid overheating south-facing rooms on sunny winter days and need to be properly shaded to reduce solar heat gain in the summer months

- Use of lower SHGC glazing, by cutting the solar gain that varies in direction throughout the day, helps maintain more uniform room temperatures throughout the house. Even with zoned systems, it is not possible to control all room temperatures individually, and solar gain is one of the largest factors causing overheating and room-to-room imbalances. 


\section{Average Daily Solar Radiation Per Month}

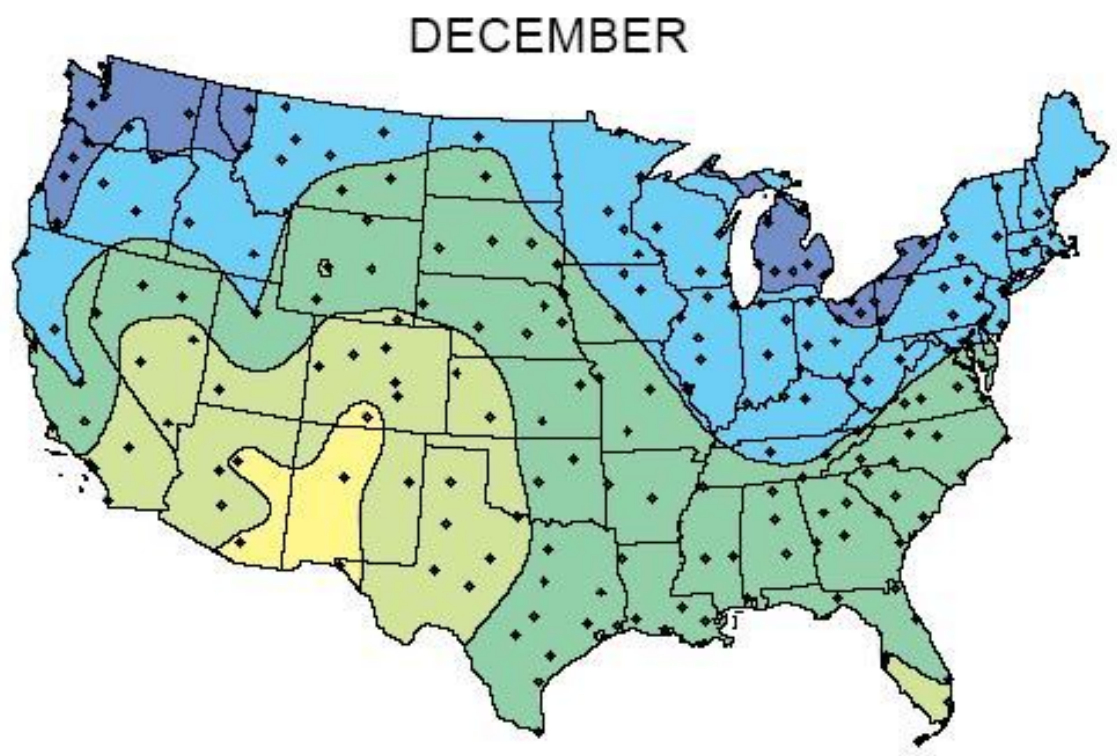

South-Facing Vertical Flat Plate

This map shows the general trends in the amount of solar radiation received in the United States and its territories. It is a spatial interpolation of solar radiation values derived from the 1961-1990 National Solar Radiation Data Base (NSRDB). The dots on the map represent the 239 sites of the NSRDB.

Maps of average values are produced by averaging all 30 years of data for each site. Maps of maximum and minimum values are composites of specific months and years for which each site achieved its maximum or minimum amounts of solar radiation.

Though useful for identifying general trends, this map should be used with caution for site-specific resource evaluations because variations in solar radiation not reflected in the maps can exist, introducing uncertainty into resource estimates

Maps are not drawn to scale.

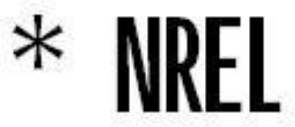

National Renewable Energy Laboratory Resource Assessment Program

$\mathrm{kWh} / \mathrm{m}^{2} /$ day

10 to 14

8 to 10

7 to 8

6 to 7

5 to 6

4 to 5

3 to 4

2 to 3

0 to 2

none

Figure 8A. Average south-facing vertical flat-plate radiation in December for the United States 


\section{Indoor Air Quality Strategies}

The Environmental Protection Agency ranks poor indoor air quality among the top five environmental risks to public health. Levels of air pollution inside the home can be 2 to 5 times higher (and occasionally 100 times higher) than outdoor levels. If too little outdoor air enters a home, pollutants can accumulate to levels that can pose health and comfort problems. Unless they are built with special mechanical means of ventilation, homes that are designed and constructed to minimize the amount of outdoor air entering the home may have a higher pollutant levels.

Providing good indoor air quality (IAQ) at the $30 \%$ improvement level is important to maintain customer health and comfort and may minimize the possibility of high humidity levels and associated mold growth. Because 30\% houses will have higher levels of insulation (which affects envelope hygrothermal characteristics) and because they will be reasonably air tight (which will affect internal moisture gain and removal), good IAQ requires a more proactive approach. Good IAQ requires control of indoor moisture, $\mathrm{CO}_{2}, \mathrm{CO}, \mathrm{NO}_{2}, \mathrm{SO}_{2}$, ozone, particulates, dust-mite dropping, odors, and other hazardous airborne contaminants. There are several approaches to good IAQ: (1) control the generating source, (2) remove the contaminant from the indoor air by ventilation or air filtration; and/or, (3) physical cleaning (vacuuming, dusting, etc.)

Source Control. Source control is the most positive approach in the $30 \%$ improved homes. A number of means of source control have been employed:

- Control of moisture to remove one of the key support elements for mold growth. This is a broad subject and includes application of all of the following principles:

○ Proper flashing details for windows, doors, wall/roof junctions, penetrations of all sorts (pipes, ducts, skylights, etc.), attachments (such as porches and decks), offsets and projections (such as bay windows) to control the entry of bulk water.

○ Control of envelope condensation potential through appropriate insulation and vapor permeability of layers. Appropriate designs must be applied for all components of the building envelope, including walls, roof, and foundations. The section of this report entitled Cost Analysis discusses climate-specific assemblies. In addition, a builder may utilize other regionally specific guidelines, such as the EEBA Builders Guides. ${ }^{29}$ At a more detailed level, static analysis techniques or dynamic models such as WUFI ${ }^{30}$ can be used. It should be noted that currently WUFI analysis will handle many wall and roof configurations, but it is not capable of foundation analysis. While ongoing research projects are adding to our knowledge of the hygrothermal performances of different forms of foundation insulation, following the practices outlined in the section of this report entitled Cost Analysis should result in good moisture performance.

- One wood-frame wall construction detail that has proven quite effective for condensation control is to use an exterior insulating sheathing in addition to the traditional cavity insulation. During the heating season, this helps to raise the

\footnotetext{
${ }^{29}$ Lstiburek, Joseph. 2004. Energy and Environmental Building Association. Builder's Guide to Hot Dry Mixed Dry Climates: A Systems Approach to Designing and Building Homes that are Healthy, Comfortable, Durable, Energy Efficient and Environmentally Responsible. Westford, MA: Building Science Press.

${ }^{30}$ WUFI 2D, Version 2.1. Simulation of heat and moisture transfer. September 2000.
} 
temperature of the interior surface of the sheathing (the first condensing surface) above the indoor air dew point. During periods of hot, humid weather, it acts as a vapor retarder and helps prevent moist outdoor air from entering the wall, which reduces the potential for condensation on the backside of the interior gypsum board in airconditioned homes. For specific design considerations of this wall assembly, see further detail in the section of this report entitled Building Enclosure Integration Strategies, Walls Section.

○ Foundation waterproofing, damp-proofing, and capillary moisture control are important moisture-management actions taken at the $30 \%$ improvement level. Failure to properly control moisture in crawlspace and full-basement constructions can result in high relative humidity in these spaces, which can lead to mold and mildew growth. Recommendations include the following:

- Exterior foundation waterproofing/damp-proofing with a drainage layer and footing drain, to intercept and drain off exterior water. The drainage layer is often an impervious plastic mat, fiberglass, or foam insulation board, or uniformly graded gravel. The insulation board offers the advantage of combining exterior foundation insulation (the most beneficial location for foundation insulation) with a good drainage material.

- After a large rainfall or after water has been applied for irrigating grass or plantings near the house, moisture can accumulate below and next to a footing. Moisture movement, by capillary action, can occur from this location through to the concrete footing and, from there, the moisture can be transferred into the slab or concrete or block foundation wall. Water stains on the perimeter of the slab or at the interior of the foundation wall can result and are not only unsightly, but they also offer an environment for mold growth to occur. This moisture pathway may be controlled by forming a continuous capillary break between the ground and the concrete foundation system. With monolithic slab-on-grade construction, polyethylene sheeting should be placed under the entire slab and footing up to grade. With footings poured independent of slabs or with foundation walls, a bituminous damp-proof coating, masonry capillary-break paint, or a layer of poly can be used to isolate the footing from the remainder of the assembly.

- Air-leakage control is another key method of reducing IAQ pollution sources. Air leaking in from the outdoors may carry outdoor air pollutants (including vehicle exhaust and plant pollens) into the house, but outdoor air is typically (though not always) considered a fresh air source. What outdoor air does bring, in hot humid weather, is moisture that can condense on internal building components that may then support mold growth. In winter, air leakage outward through the building envelope can bring relatively moist indoor air into contact with cold surfaces. Building envelope air sealing (in addition to reducing energy consumption) is valuable to reduce moist-air migration that could lead to mold growth under both summer or winter conditions and reduce occupant exposure to outdoor pollutants.

- Sealing against air leakage is primarily for thermal reasons, but when coupled with appropriate mechanical ventilation, this procedure also assists in providing good IAQ for 
the occupant. Extensive air sealing is one of the primary $30 \%$ improvement strategies. It includes a range of recommendations to builders, including the following:

- Develop a continuous air barrier with interior gypsum board on walls and ceilings, giving attention to sealing at edges and joints, around penetrations and electrical boxes (including ceiling recessed downlights). Particularly important is to get sheathing continuity behind bathtubs and showers, at fireplaces, soffits, stairways, and at the band joist.

○ Develop an air barrier with exterior sheathing using taped and caulked joints.

○ Use foam seal (non-expansive) around window and doorframes.

○ Construct well-sealed attic access hatches.

- Take particular care to seal all contact surfaces between attached garages and the occupied house. This must include sealing at all penetrations and the provision of gasketed, self-closing doors between garage and house.

- Seal forced-air distribution systems. Leaky duct systems contribute to poor IAQ in several ways. Leaky ducts can cause pressure imbalances, which can draw air from the outdoors, building cavities, or attached garage spaces. In addition, pressure imbalances can move moisture laden air into building cavities where the water vapor can condense, causing a habitat for mold and mildew. Specific strategies and techniques associated with the proper design and construction of air distribution systems can be found elsewhere in this report.

- Control of radon and other soil gasses. The principal method of controlling the entry of these gases into a house is through the use of under-slab ventilation. House pressurization can be effective for this purpose as well, but is difficult to implement and control with current HVAC technologies. Under-slab ventilation typically takes the form of modest depth of uniformly graded crushed stone (i.e., with good void spaces) 4 in. to 8 in. deep, in which is embedded an array of perforated plastic drainpipe and covered with a poly air/vapor barrier. The piping is linked by a header, to which is connected a vertical vent pipe leading up through the house and out at the roof. This system is often installed as a precaution even when no evidence of radon has been shown, as it is far easier to do this than to come back later and retrofit an under-slab venting system. Usually, the vent goes through the roof and functions as a passive vent. It is designed, however, for the subsequent installation of an exhaust fan should the need for a more positive ventilating action be demonstrated. An electrical outlet for a possible future fan installation is located in the attic or basement adjacent to the vent pipe. Further information on sub-slab ventilation systems can be found in the EPA's Model Standards And Techniques For Control of Radon in New Residential Buildings ${ }^{31}$

- Combustion Safety. To avoid the possibility of the introduction of the by-products of combustion being brought into the house, several components associated with combustion safety must be addressed in the $30 \%$ improved house. Because these houses are generally quite air tight, natural-draft appliances are not recommended. The basic recommendations are as follows:

\footnotetext{
${ }^{31}$ Environmental Protection Agency. Model Standards and Techniques for Control of Radon in New Residential Buildings. Environmental Protection Agency Website. www.epa.gov/radon/pubs/newconst.html.
} 
- Furnaces. Use sealed-combustion units or draft-induced units with dedicated make-up air so that the combustion process is atmospherically decoupled from the house itself.

○ Tank or Tankless Domestic Hot Water (DHW) Heaters. Use sealed-combustion, direct-vent, or power-vented types that are atmospherically decoupled from the house.

- Fireplaces. If fireplaces are installed (gas-fired or solid-fuel-burning) are installed, use units that directly vent the by-products of combustion to the outdoors, are equipped with tight-fitting glass doors, and preferably use outside air for combustion.

○ Gas Appliances. Eliminate unvented gas appliances, except cooking appliance, which should be vented to the outdoors by a ducted-range hood.

- Finishes. Finishes such as paints, sealers, adhesives, fabrics, and surface-covering roll goods (i.e., vinyl wall coverings) are all potential sources of indoor air pollutants, including various volatile organic compounds (VOCs). Most of the liquid-applied materials dissipate rather rapidly as they dry. Leaving windows open as they are applied and dry removes the high initial concentrations. After this initial "dry-out" period, a properly designed ventilation system will continue to bring in fresh air and remove further off-gassing of pollutants. Thus, for any but highly sensitive occupants, the selection of special, low-VOC, materials and finishes is not seen as necessary to achieve the $30 \%$ whole-house energy-savings level. Should a homeowner have IAQ sensitivity needs, then the application of the American Lung Association (ALA) Health House Specifications ${ }^{32}$ or specifications to meet the EPA's Indoor Air Quality (IAQ) Label ${ }^{33}$ would be appropriate.

- Relative Humidity Control. The control of indoor relative humidity $(\mathrm{RH})$ is another key strategy to maintain good IAQ. The desirable range of indoor RH is from $20 \%$ in winter to $65 \%$ in summer, with a preferable range of $30 \%$ to $50 \%$. Ventilation strategies play a key role in maintaining these ranges and are discussed more fully in the ventilation section of this report. However, a variety of ventilation forms, including heat-recovery ventilators (HRVs) or energy recovery ventilation (ERVs), are used to remove excess humidity in the winter and ERVs, dehumidifying ventilators, dedicated dehumidifiers, and advanced HVAC control systems are used to control excess humidity in the summer. The importance of winter or summer humidity control, of course, varies with climate region.

- Pollutant Removal and/or Dilution. Ventilation and air cleaning are the principle methods of airborne pollutant removal or dilution. Ventilation system design and strategies are treated more fully in another section of this report, but key features relative to good IAQ in $30 \%$ improvement houses will be noted here.

○ Whole-house mechanical ventilation in accordance with ASHRAE Standard $62.2^{34}$ is recommended. Any of a number of system configurations can meet this requirement and include the following:

- Passive inlet direct to the return-air duct with appropriate dampers and controls

\footnotetext{
${ }^{32}$ American Lung Association. Builder Guidelines. American Lung Association ${ }^{\circledR}\left(\right.$ ALA) Health House ${ }^{\circledR}$. www.healthhouse.org/build/Guidelines.asp October 1, 2004.

${ }^{33}$ Environmental Protection Agency. Indoor Air Quality Label. Environmental Protection Agency Website. www.epa.gov/iaq/energystar/label_specifications.html. 2004.

${ }^{34}$ ANSI/ASHRAE 62.2-2004, Ventilation and Acceptable Indoor Air Quality in Low-Rise Residential Buildings
} 
- Dedicated supply fans designed for continuous operation

- HRVs or ERVs

- Dedicated central dehumidifier with ventilation.

- Whole-house ventilation air should be distributed to all the primary occupied spaces in the house, particularly bedroom and living areas. This is typically accomplished by ducting ventilation air into the heating/cooling duct system. For this distribution to be continually effective, however, the HVAC system must be periodically cycled, even in no heating/cooling periods. Dedicated ventilation distribution ductwork is occasionally used, particularly if no forced-air system exists, but it is a more costly option. Fresh-air intakes should be provided with nominal filtration to prevent the entry of insects and large particulates.

- For good IAQ, the HVAC return air stream should be filtered with a 4-in. standard filter or a new Minimum Efficiency Reporting Values (MERV) 35 or 8 normalthickness filters. Ventilation air should also pass through this filter, if possible. Filters should be easily accessible for cleaning or replacement and the filter slot should be designed so that there is no air bypass around the filter when the HVAC system is operating.

- It is important to provide local exhaust fans for bathrooms, range hoods in the kitchen, and exhaust fans in other areas where pollutants may be generated (utility, hobby rooms, etc.). All of these fans must be ducted to outdoors via the most direct path.

- Ventilation technology has developed significantly in recent years, but a few areas remain problematic:

- It is difficult to find low-airflow ventilation units, particularly HRVs and ERVs.

- Design of distribution systems is a challenge. Using HVAC ductwork requires cycling the central fan, which increases the electric consumption. Dedicated ventilation ductwork is quite small and must be well designed to function properly. The ventilation air from a dedicated ventilation fan (i.e., ERV, HRV) may not be fully distributed to all rooms when only the ventilation airflow is being moved through the larger ducts of the central space-conditioning system.

- Builders do not like the additional cost of installing a ventilation system and often have a difficult time explaining why it is needed to the consumer.

- Ventilation controls are often difficult to integrate with the HVAC system because the products are not usually designed for integration. A newer generation of integrated ventilation and space-conditioning controls are beginning to be introduced by major manufacturers, and it is anticipated that this trend will continue in the future with more options becoming available to builders.

- Ventilation should be accomplished in the most energy-efficient manner, balancing fan energy consumption with the cost of conditioning the ventilation air.

${ }^{35}$ See www.filters-for-home.com/mrev.htm for MERV definitions. 
- Physical Cleaning. Builders have very little control over occupant behavior and, as such, there are limited strategies a builder can incorporate in this area. One primary opportunity is in the installation of a whole-house vacuum system that exhausts to the outdoor, which limits the reintroduction of dust in the house. Another is the inclusion of a discussion of maintaining good indoor air quality in an owner's manual for the house, including cleaning practices as they relate to indoor air quality.

\section{Heating and Cooling Equipment and Distribution Strategies - Creating Conditioned Space for HVAC Systems}

For the $30 \%$ improvement house and all new home construction, it is highly recommended that the heating and cooling system be designed according to industry standard methodologies, most notably ACCA Manual J, ${ }^{36} \mathrm{~S},{ }^{37} \mathrm{D},{ }^{38}$ and $\mathrm{T} .{ }^{39}$ With the use of low-SHGC glass, it is practical to design each house model of a builder's line for the worst orientation without significant penalty in other orientation. The use of low-SHGC glazing reduces the solar component of the cooling load and helps to level the cooling load and minimize variations resulting from orientation. Whenever practical, the design should be specific to an individual house and its orientation. System implications based on variations with orientation are a result of the different solar loads and, for system design purposes, do not affect heating loads. The impact is primarily on the cooling system design as a result of solar load through windows.

Heating and Cooling Equipment. The preference is for a single heating/cooling unit to serve the entire house, frequently utilizing a zoning system with multiple fan speeds and variable output. This is an efficient approach and allows the closest tailoring of unit size to peak and part-load conditions. In some cases, especially homes of more than 2,500 $\mathrm{ft}^{2}$, two or more units may be needed to meet the load or to serve distinct zones in the house. With the better thermal envelope of the $30 \%$ improved house, a single HVAC unit may often be feasible where two were used before. A single HVAC unit with zoning dampers and controls is also better able to adapt to major load differences. It is strongly recommended that the airhandler unit be located within the conditioned space of the house. When located in unconditioned space, as in vented attic or garage locations, the units are exposed to full winter and summer temperature conditions and experience major thermal losses, because HVAC units are poorly insulated and have significant air leakage.

More detailed discussion of heating and cooling equipment selections are given in the section of this report entitled Space Conditioning and Ventilation. In the 30\% improvement house, the recommendation is to use a sealed-combustion furnace or draft-induced unit with dedicated make-up air so that the combustion process is atmospherically decoupled from the house itself and located in conditioned space, for efficiency and combustion safety reasons.

36 ACCA. 2003. Manual J: Residential Load Calculation 8th Edition. Arlington, VA: Air Conditioning Contractors of America.

37 ACCA. 1995. Manual S: Residential Heating and Cooling Equipment Selection. Arlington, VA: Air Conditioning Contractors of America, Washington, D.C.

38 ACCA. 1995. Manual D: Residential Duct Systems. Arlington, VA: Air Conditioning Contractors of America, Washington, D.C.

39 ACCA. 1993. Manual T: Air Distribution Basics. Arlington, VA: Air Conditioning Contractors of America, Washington, D.C. 
A high-efficiency electric heat pump may also be an effective choice for heating, although because of the source energy conversion a Heating Season Performance Factor (HSPF) of approximately 9.7 is necessary to match the source energy efficiency of a $92 \%$ AFUE furnace. Where the thermal envelope of the house has been significantly improved, the heating load may be dramatically reduced; therefore, the cost effectiveness of a gas furnace and all the associated piping and utility infrastructure costs need to be weighed against the potential increase in source energy consumption associated with using a heat pump with a HSPF lower than 9.7 .

Air conditioners in Hot-Dry/Mixed-Dry climates should have SEER ratings of 13 or greater, which will be code minimum starting in 2006. It should also be noted that there is a wide range of cooling requirements in the Hot-Dry/Mixed-Dry climate zone, and the SEER rating should be evaluated based on annual hours of operation. In general, the greater the cooling need, the higher the SEER rating should be. From a design standpoint, if the architecture of the home incorporates passive strategies for cooling-load reduction (such as shaded south-, west-, and east-facing glass, minimized unshaded west-facing glass, or a design that incorporates low-SHGC glazing and a small number of windows) cooling system run hours can be reduced, and smaller capacity equipment will be appropriate. In this climate zone, designers should also recognize that because of the minimal latent loads, some of the latent capacity in the equipment can be used for sensible load. In general, the sensible capacity equals the total capacity when the design wet-bulb temperature of the return air is less than $59^{\circ} \mathrm{F}$. Designers need to check the mean coincident wet-bulb temperature at outdoor design conditions and select equipment based on this. This strategy helps to prevent oversizing of the equipment.

Air Distribution Systems. To achieve a 30\% whole-house energy reduction, a number of requirements apply to design of the duct system:

- Design should be in accordance with ACCA Manual D.

- Ductwork should be located within the thermal envelope of the house; in some climate zones they may be buried in attic insulation.

- Ducts should not be located in exterior walls.

- Ducts must be air-sealed using UL 181-approved mastic or equivalent for the particular duct type

- "Panning" between joists and the use of stud cavities for supply or return air is not recommended.

- Ducts may be of galvanized sheet metal, duct board, or flex duct.

- There must be continuity of the vapor barrier on insulated ducts not running inside conditioned spaces.

Sometimes duct systems need to run in unconditioned spaces. For a discussion of the treatment of these ducts, see the section entitled Space Conditioning and Ventilation Systems.

To accommodate heating and cooling units and duct systems within the thermal envelope of the house, a number of techniques may be employed. This typically affects the architectural design of the house and should be considered at the early schematic phase of design. Keeping 
ducts inside the conditioned space may also involve framing systems that allow ducts to be run through it, such as an open-web floor-truss system. Alternately, dropped soffits, tray ceilings, and lower ceiling heights in "service" function rooms like baths, hallways, and closets can accommodate ducts inside the envelope. Strategies include the following:

- Locate ducts within an insulated, non-vented, conditioned crawl space or basement

- Locate within an insulated "cathedralized" attic

- Locate in open-web floor trusses

- Develop chase walls to accommodate duct risers

- Design closets inside the conditioned space for locating the air handler in houses using slab-on-grade construction.

More specific discussion of many of these recommendations is found in the Section entitled Space Conditioning and Ventilation Systems.

Where a boiler or water heater is used for space heating, a hydronic distribution system is necessary. These are particularly suited to cold-climate applications where there may not be a need for air conditioning and the associated duct-distribution system. Their most common configuration is a radiant floor or baseboard convection units. If a radiant floor system is selected in a slab-on-grade installation, it is required that the slab be insulated from the ground and at the slab edge with at least R-10 (2-in.) of rigid insulation. Slab edges need to be insulated because they are exposed to cold exterior conditions. If a boiler or water heater serves a fan coil and ducted system, all recommendations for ducts noted above apply. Hydronic systems are described in more detail in the section of this report entitled Space Conditioning and Ventilation Systems.

\section{First Costs, Cost Tradeoffs, and Owner Annualized PITI + Energy}

Useful and representative costs information for $30 \%$ improvements has not been easy to determine. In many cases, these are pilot homes and are the first of this level of energy performance that have been done by a builder. Thus, the energy-use-reduction construction strategies are new to the builder and costs do not represent a mature purchasing structure or experienced installation practices. Furthermore, there are often compensating or beneficial attributes of the improvement strategies that are not realized until multiple houses are built. An example is the ease of air sealing that is inherent with spray-foam insulation systems that replaces tedious hand-caulk and foam-gun sealing done by laborers. Until a builder experiences the change, it is usually not valued.

Some of the common cost tradeoffs that builders in the Building America program have used include the following:

- Reduced costs associated with advanced framing

- Reduced costs associated with downsizing space-conditioning equipment and simplifying air-distribution systems

- Increased costs for higher performance windows and insulation and air-sealing packages, that enable the reduction in HVAC system size 
- Substituting insulating sheathing for structural-panel sheathing increases wall-insulation levels at low or no incremental cost

- Increased cost of installing mechanical ventilation

- More usable floor space in slab-on-grade construction through the use of tankless water heaters instead of tank type water.

Builders who commits to evolving their organizations to the consistent production of quality high-performance homes face a transition period. Figure 9 illustrates how the organization will typically change through phases and the corresponding change in first costs.

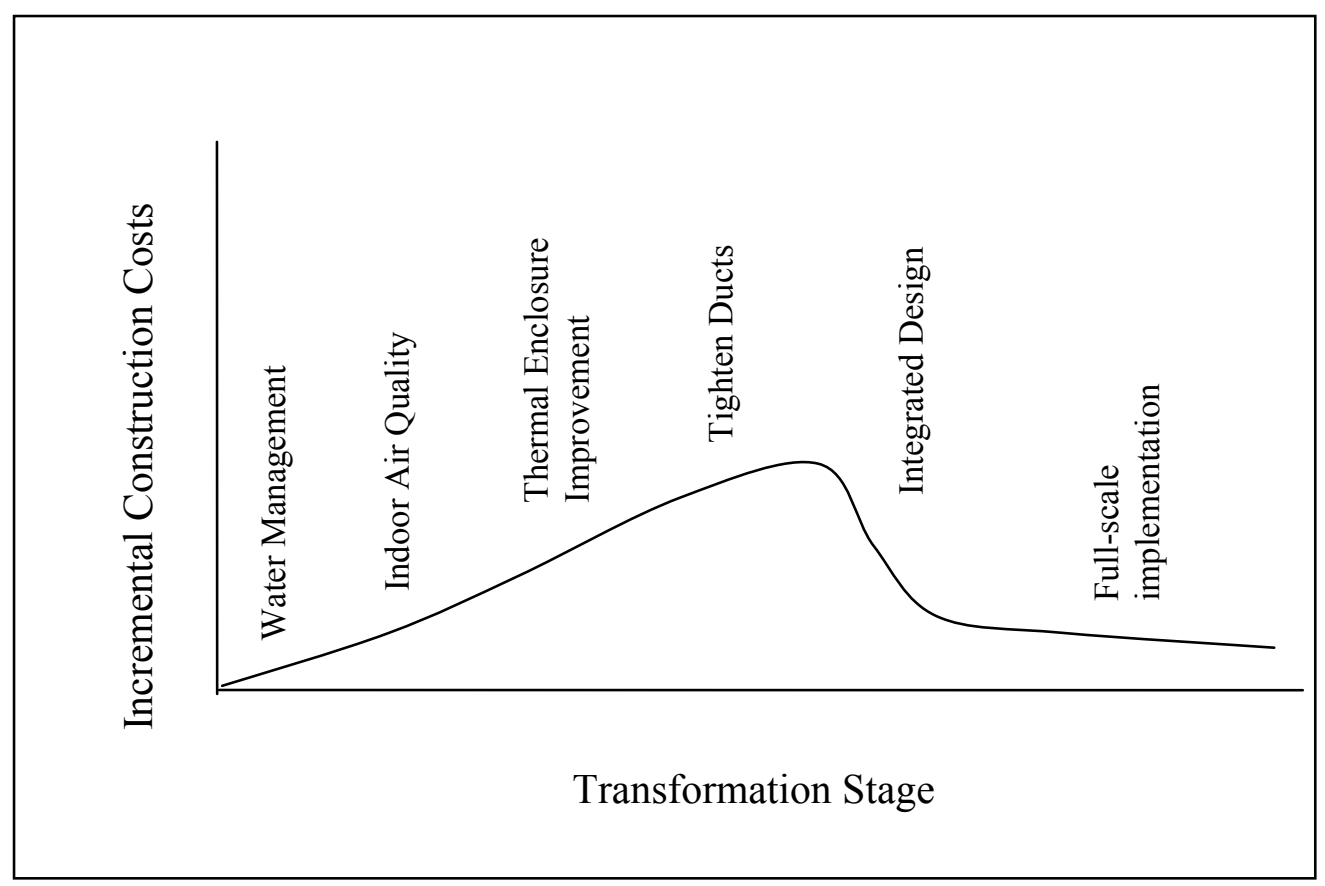

Figure 9. Incremental Cost versus Transformation Stage Curve 
The transition strategy outlined here provides a logical progression to higher-performance housing, but builders need to be prepared to make an investment in other costs associated with implementing a high-performance package, including staff and vendor training, product redesign, collateral development, and testing. Each of these issues will be discussed and suggestions made as to best practices in order to minimize costs.

If the steps taken to transform a company are followed, a builder will have a transitional period where higher costs will be incurred. It is only at the last step, where integrated designs are developed, that a builder can realize immediate construction cost savings. If the total operational costs of running a homebuilding business are considered, potential cost savings should begin to accrue from the first step.

\section{Water Management}

Many warrantee issues are associated with water intrusion; therefore, a solid watermanagement plan can reduce future costs, limiting the reserves builders need to put aside for future claims. Analysis of past history of water damage issues, both short-term and long-term, can help quantify the per-house costs associated with the "status quo" versus an improved water-management strategy.

The improvements to the indoor air quality, thermal enclosure, and duct sealing will all require additional expense. It is, therefore, important to successfully integrate these strategies as quickly as possible. This is where relationships with vendors are critical. Builders must be willing to support the trades during the transition; however, trades must take some level of responsibility for adapting and developing cost-effective solutions for delivering improved performance cost effectively. Examples of this include rethinking duct installations to allow for prefabrication and sealing of major components or panelization of structural systems to speed erection, cut cycle time, and reduce costs. In addition, vendors must have continuingeducation costs built into their overhead structure.

A diagrammatic Incremental Construction Cost versus Transformation Stage curve on a perhouse basis for a builder might be seen in Figure 9.

It should be noted that this curve is diagrammatic by nature and will vary from builder to builder and by region. For example, if a builder has already addressed water management, then there is no expected incremental cost associated with this practice. Also note that the tail end of the curve still shows some increase in costs. This represents the most conservative scenario, where a builder has already optimized many aspects of their houses (i.e., integrated advanced framing or does not significantly oversize HVAC equipment). For the consumer, this added cost is offset by reduction in utility bills and, as discussed in the section of this report entitled Systems Approach to Least Cost Energy Savings, should prove to be net cost neutral or even put the consumer at a net positive monthly cash flow.

To achieve the goals of a high-performance home transformation, builders and vendors must embark on a training program that engages all levels of the companies. Training must be provided for different levels of employees within the company and for the different departments within the company. 
The integrated design process comes with some inherent additional costs, especially if the builder takes responsibility for HVAC system design, as opposed to having the vendors do a "design build" system. The advantages of the builder doing the design are that a greater level of consistency can be achieved, and documentation exists for site supervisors to readily check work. It does involve additional costs, either through contracting with outside designers or by training and utilizing internal resources to cover systems integration, including HVAC, framing integration, and detailing. In addition, the cost of re-bidding work involves time and expense on the part of the builder's purchasing department, the trades, and their suppliers. For this reason, it is best that as a builder transitions to a high-performance approach, they do it as part of their ongoing product-redesign process, where many of these activities are already budgeted for. Unfortunately, this can lead to a disparity in the builder' marketing approach because some product may meet the new standards and others may not during the transition period. Builders must evaluate the volume they are building, the number of plan types, the current redesign cycle, and the uniformity of marketing message they wish to project when doing this cost-benefit analysis.

During the transformation, builders will need to be measuring how well they are doing compared to the performance goals they set. This measuring requires undertaking some level of performance testing. Typically, this performance testing will be $100 \%$ during the initial steps in order to gain insight into the effectiveness of various practices and techniques being used in the field. As vendors become adept at achieving performance targets, some builders have chosen to decrease testing activities, while others have chosen to maintain $100 \%$ testing as a quality-control measure. In either case, performance testing is a cost that needs to be budgeted for.

Some cost data have been developed from recent Building America 30\% improvement level projects. The extent of improvement work varies considerably depending on the thermal performance quality of a builder's basic model. These costs are also generally not representative of mature costs and, in some instances, are reduced because materials have been donated by manufacturers.

Table 6 is one example of the incremental costs associated with achieving 39\% energy savings in houses for one community in Sacramento, California. The case study for this project, Premier Gardens, is included later in this report.

The cost of the energy efficiency improvements less the cost of the photovoltaic system is $\$ 3,355$, and the monthly and annual utility savings are $\$ 38$ and $\$ 453$, respectively. The simple payback for these homes will be 7.41 years; however, the owners are realizing more than $\$ 34$ per month in positive cash flow. 


\section{Table 6. Illustrative Incremental Costs of a $39 \%$ Energy-Saving House}

Energy Features

Benchmark Building

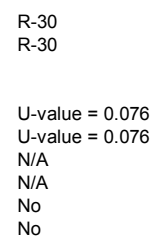

0.673
0.673
0.673

0.673
0.673
0.673

0.581
0.581
0.581

0.581

0.78
10 SEER

5.00
No
No

40 gal
0.54
Standard
R-12
None

3rd Party Inspections and Testing (In ComfortWise

Program)

Fluorescent lighting (screw-in lamps)

$2.4 \mathrm{~kW}$ PV System

CASH FLOW

Total Incremental Cost
Energy Features

Premier Gardens

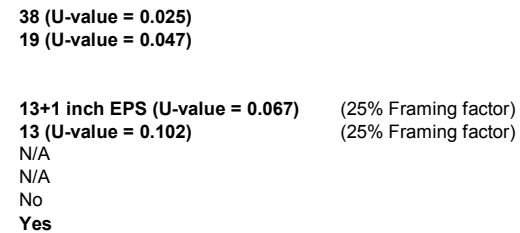

$38(\mathrm{U}$-value $=0.025)$
$19(\mathrm{U}$-value $=0.047)$

$\begin{array}{ll}13+1 \text { inch EPS }(\mathrm{U} \text {-value }=0.067) & (25 \% \text { Framing factor }) \\ 13(\mathrm{U} \text {-value }=0.102) & (25 \% \text { Framing factor })\end{array}$

$13(\mathrm{U}$-value $\mathbf{0} \mathbf{0 . 1 0 2 )}$

N/A

No

Dual Pane Vinyl Frame Windows w/

Spectrally Selective Glas

0.37

0.34

0.32

0.35

0.91

13.0 (buried in insulation)

Yes

Yes

Tankless System

Pipe Insulation
None

None

Yes

Yes, all downlight

GE Energ

Total Estimated Incremental Cost
with PV(after rebate)

Incremental Cost without PV

Estimated Monthly Energy Savings $\quad \$ 10,780.00$

Monthly Amortized Cost $\quad \$ 72.32$

At a $7 \%$ interest rate For 30 years 


\section{Reducing Construction Waste}

Research conducted by the National Association of Home Builders (NAHB) and the NAHB Research Center shows that $87.7 \%$ of the 1.7 million homes built in the United States in 1999 were stick-framed, that a "typical" home consumes slightly more than 13,100 board feet of framing lumber (about three-quarters of an acre of forest), and that the wood scrap pile for the construction of this "typical" home is approximately 2 tons.

The following combination of factors have worked to increase the consumption of wood in home building:

- Single-family detached units. A single-family detached home uses more wood per household than multi-family housing. According to NAHB, single-family detached units went from about $71 \%$ of overall housing starts to nearly $80 \%$ between 1978 and 2001 .

- Home size. In the past 40 years, the median new home size in the United States has increased from $1,365 \mathrm{ft}^{2}$ to well over $2,000 \mathrm{ft}^{2}$, this despite the fact that household size has actually decreased by $20 \%$.

- Complexity. Not many of today's homes are simple in form. Jogs, dormers, vaulted ceilings, convoluted roof lines, and elaborate staircases are common in new homes.

- Safety standards. We require more of our structures today, particularly in regions with seismic and wind considerations. Re-engineering for these loads has resulted in some increase in wood-se requirements, but has also spawned site practices that simply "throw more wood" at the problem.

- Lumber versus labor. Just as the relative value of materials versus labor seems to have reversed (today, materials are "cheap"-it's the labor that is "dear"), the typical skills set of both designers and framers has diminished, leading to waste at the front and tail ends of wood construction.

- The nature and structure of the industry. Home building is like no other production process in the 21 st century. Nearly all of the 1.7 million homes built each year are site-built, making home building one of the most fragmented of industries in the United States. It is the journeymen framers - not architects, engineers or even general contractors - who control what and how much wood goes where on the job site. And most training occurs informally, by word-of-mouth, during production.

\section{Two-Foot Module Design}

Starting with foundation layout, the house footprint should be based on 2-foot increments, often with significant savings in both framing members and sheathing and always with a lot less waste. Sheet goods come in $4 \mathrm{ft}$ by $8 \mathrm{ft}$ dimensions. Layouts should be based on the fundamental unit dimensions of the materials used. Work by the NAHB Research Center found that the wood savings are dependent on the starting dimension. 


\section{Value Engineered or "Advanced" Framing}

There are a number of substantial advantages to optimized framing: it saves time and money up front, it improves homebuyer satisfaction, its saves money and energy over the long term, and it improves builder image.

More than 7,000 homes built by Building Science Consortium production builders have used advanced framing. The resultant savings in waste are the products of "systems-thinking" and a breakdown of age-old myths about how wood framing works.

The following sections are descriptions of the major optimized framing techniques, with appropriate references from the International Residential Code, ${ }^{\circledR 40}$ cited in brackets.

Frame 24 in. on-center. The prevailing practice is to frame walls, floors, and often roofs at 16in. centers. However, 24-in. centers are structurally adequate for most residential applications. Even when the stud size must be increased from $2 \times 4$ to $2 \times 6$, changing spacing from 16 to 24 in. can reduce framing lumber needs significantly. See Figure 10 for an example.

Align framing members and use a single top plate. Double top plates are used principally to distribute loads from framing members that are not aligned above studs and joists. By aligning framing members vertically throughout the structure, the second plate can be eliminated. Plate sections are cleated together using flat-plate connectors. For multistory homes that are framed with $2 \times 4$ s, this may increase the stud size on lower floors to $2 \times 6$; however, there is still typically a net decrease in lumber used. [Section R602.3.2. of the Code: A single top plate is listed as an acceptable option for in-line framing and with properly tied joints.] Figure 11 illustrates the alignment of framing and use of single top plates.

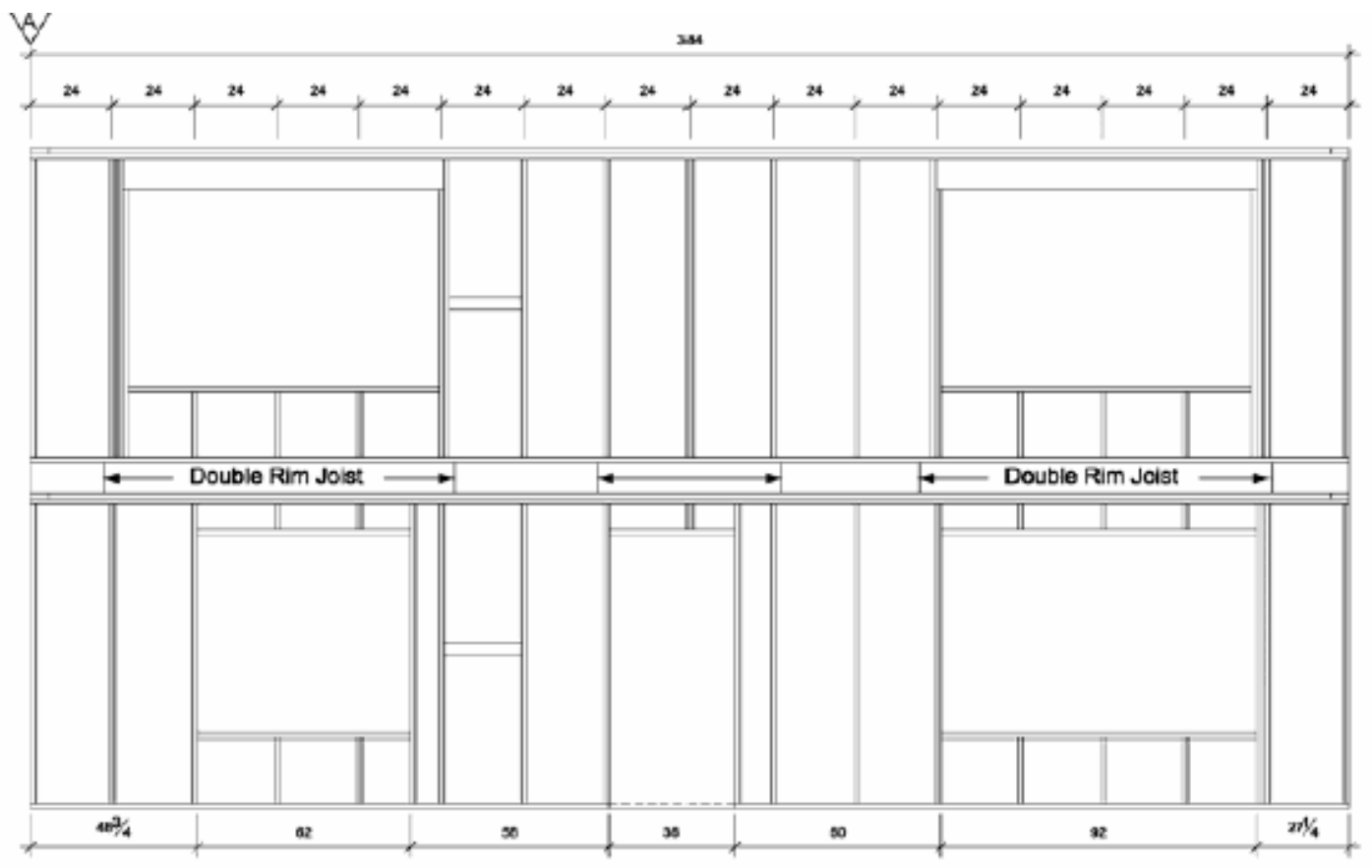

Figure 10. Advanced framing layout showing 24-in. stud centering

\footnotetext{
${ }^{40}$ International Residential Code®: 2003 Edition. Country Club Hills, IL: International Code Council, Inc. 2003.
} 


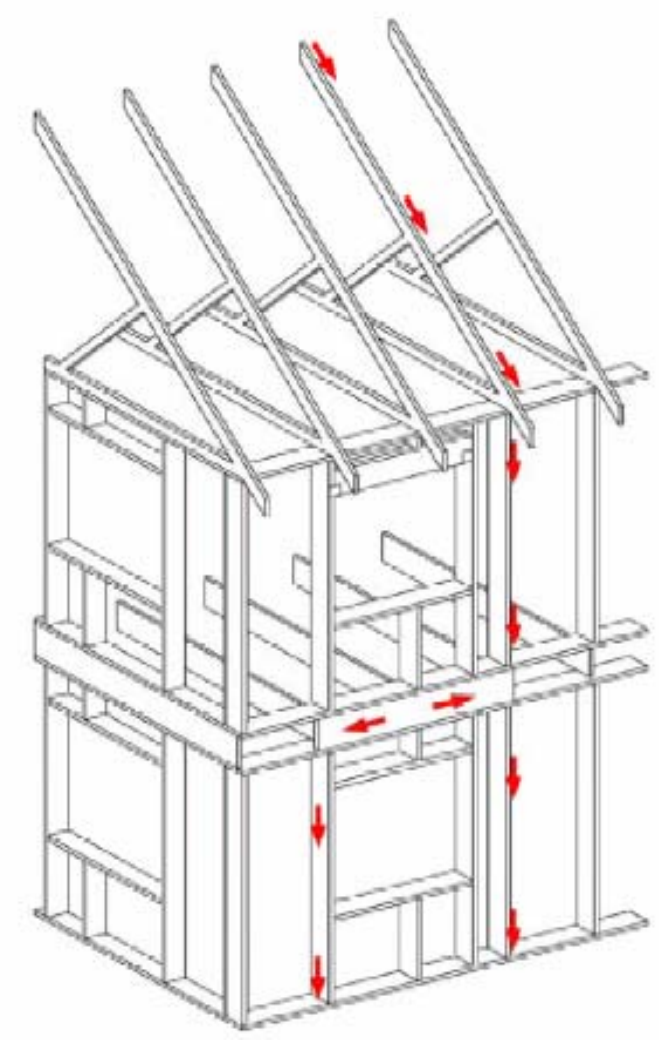

Figure 11. Advanced framing showing truss alignment with stud framing and single top plates

Size headers for actual loading conditions. Headers are often oversized for the structural work that they do. Doubled-up 2x6 (or 4x6) headers end up in non-load-bearing walls. Doubled-up $2 \times 12$ (or 4x12) headers end up in all-load-bearing walls, regardless of specific loading conditions. "Load-tuned" headers should be in the vocabulary and practice of all engineers, architects, builders, and framers. (Section R602.7.2 of the code. This section states that nonbearing walls do not need structural headers.)

Ladder-block exterior wall intersections. Where interior partitions intersect exterior walls, three-stud "partition post" or stud-block-stud configurations are typically inserted. Except where expressly engineered, these are unnecessary. Partitions can be nailed either directly to a single exterior wall stud or to flat blocks inserted between studs. This technique is called "ladder blocking" or "ladder framing." This also creates room for more insulation. Figure 12 shows a ladder-block configuration.

Use two-stud instead of three-stud corners. Exterior wall corners are typically framed with three studs. The third stud generally only provides a nailing edge for interior gypsum board and can be eliminated. Drywall clips, a 1x nailer strip or a recycled plastic nailing strip can be used instead. Using drywall clips also reduces opportunities for drywall cracking and nail popping, frequent causes of builder callbacks. [Figure R602.3(2) of the code shows let-in 1x4 bracing in place of sheathing and has a note at the bottom of the page for two-stud corners and drywall clips.] Figure 13 shows various stud corner arrangements. 


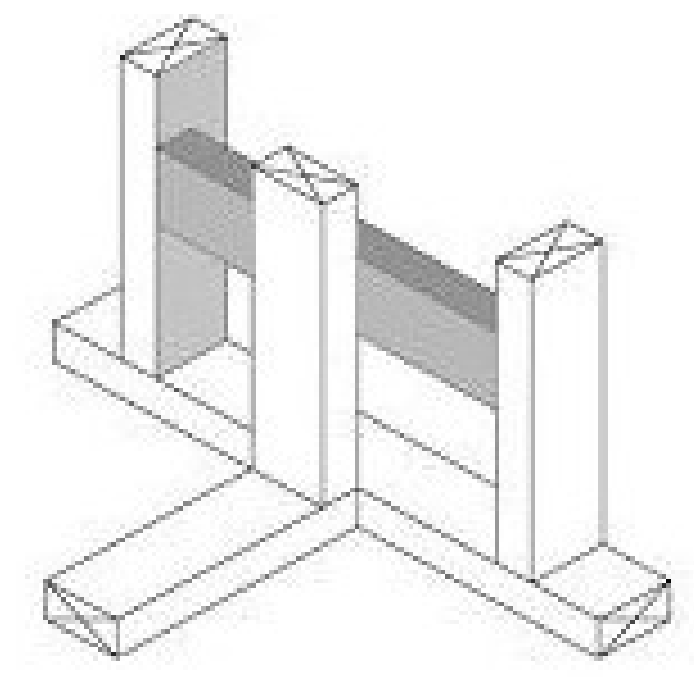

Figure 12. Example of ladder-block exterior wall intersections

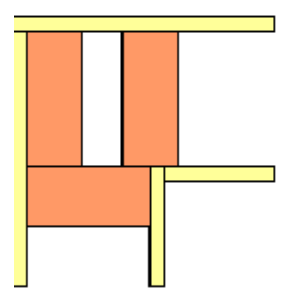

Conventional three-stud corner leaves a cavity that must be insulated by the framers - not good

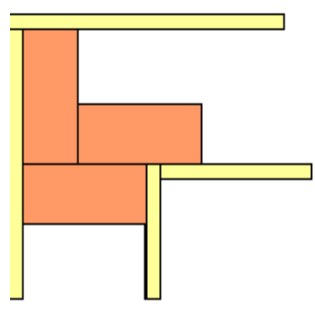

Improved three-stud corner allows insulation to be installed later, in sequence

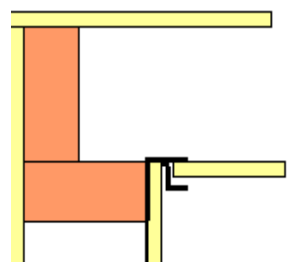

Two-stud corner with drywall clips uses least wood, gives best thermal performance

Figure 13. Wall stud corner configurations 
Eliminate redundant floor joists. Double floor joists are often installed unnecessarily below non-load-bearing partitions. Nailing directly to the sub-floor provides adequate attachment and support. Partitions parallel to overhead floor or roof framing can be attached to $2 \times 3$ or $2 \times 4$ flat blocking.

Use 2x3s for partitions. Interior, non-load-bearing partition walls can be framed with $2 \times 3 \mathrm{~s}$ at 24 in. on-center or $2 \times 4$ "flat studs" at 16 in. on-center. [Section R602.5 of the code.]

\section{Compact Duct Systems}

A framing plan can do more than just lay out floor joists. There are opportunities to valueengineer the floor system and obtain a proper joist count, to ensure that all plumbing is coordinated with the floor framing, to ensure that all HVAC is coordinated with the floor framing, and to ensure that the "stack framing" concept is followed on the job site. Most importantly, all these issues are resolved on paper prior to casting the foundation. Figures 14 and 15 show compact duct system layouts.

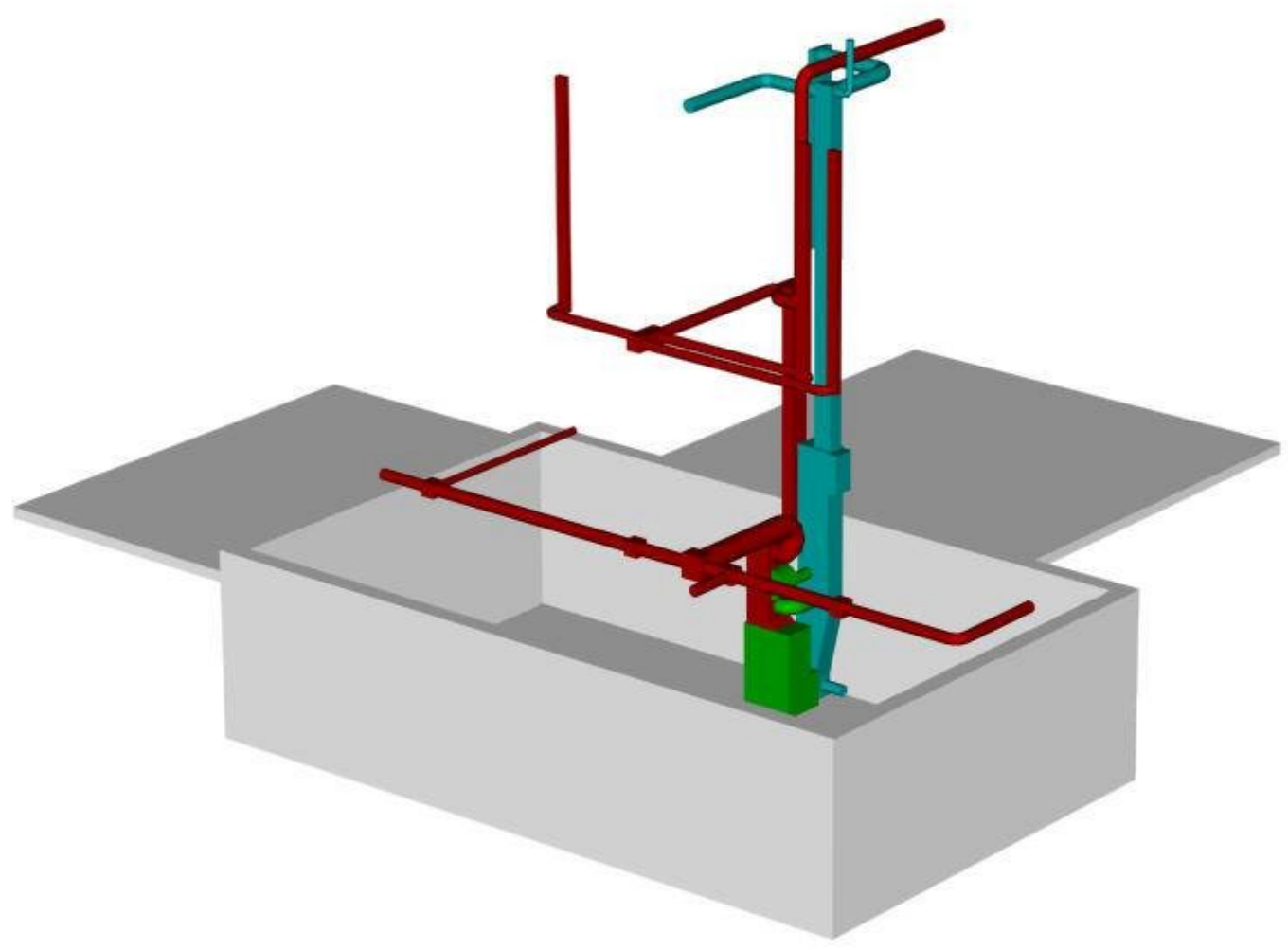

Figure 14. Three-dimensional example of compact duct system ${ }^{41}$

\footnotetext{
${ }^{41}$ Heating and cooling equipment shown in green, return duct shown in blue and supply ducts shown in brown.
} 


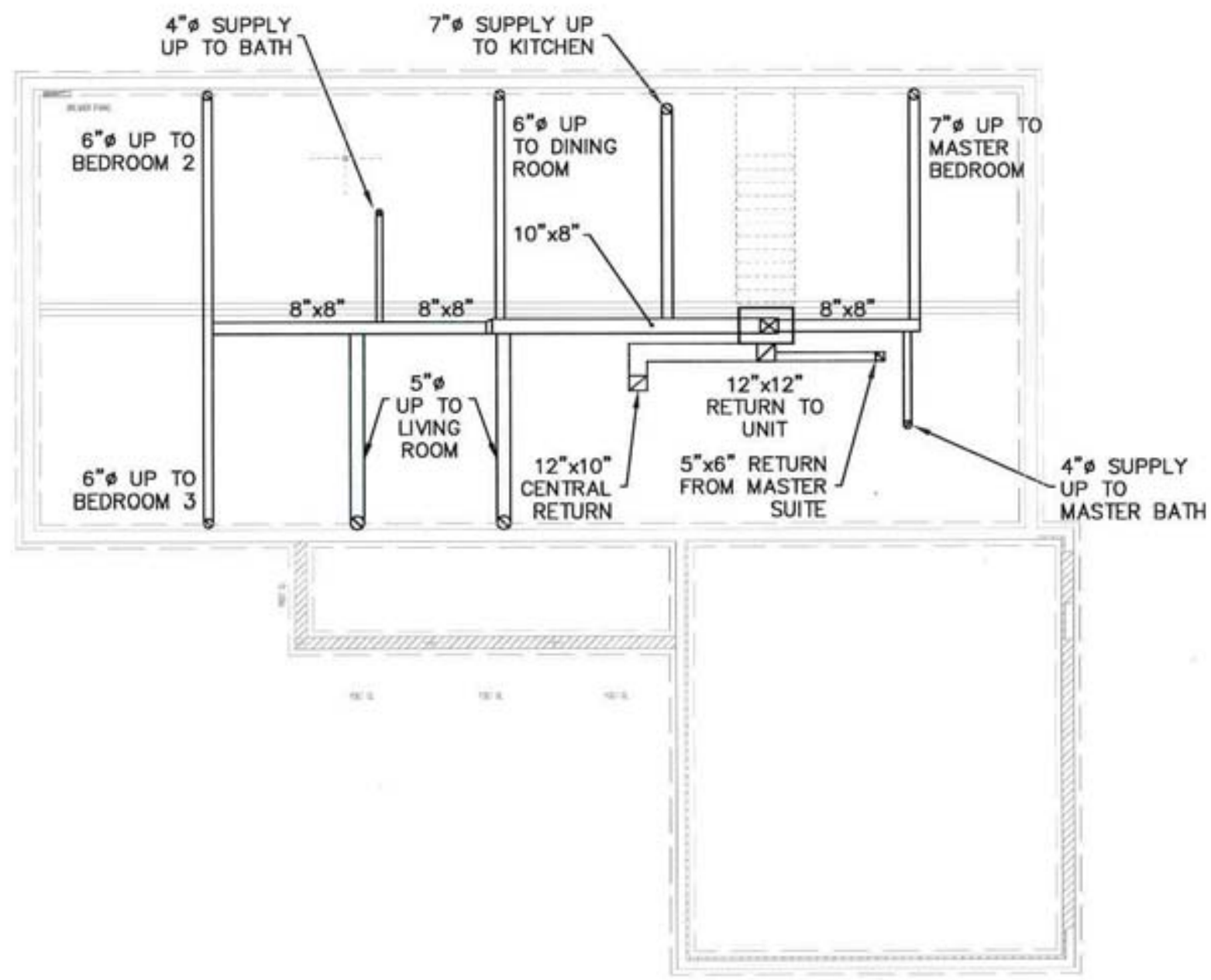

Figure 15. Example of a compact duct layout

\section{Recycling of Construction Materials}

No matter how efficient our use of wood, there will be some waste - cuts-offs from both solidsawn lumber and sheathing. Even for the most efficiently framed buildings, wood waste will be one of the largest components of the new construction waste stream.

Reduced wood purchase and disposal costs. Actual field counts for a production builder in California have found a $40 \%$ reduction in the cost of a wall-framing package after implementing optimized framing methods: a purchase savings for the builder of more than $\$ 1,100$ on each house. Another builder in Maryland reduces total wood waste disposal by $15 \%$ using efficient framing. Note that neither of these examples takes into account the labor savings from handling less wood and wood waste.

Reduced environmental impact. The annual toll for residential construction in the United States is 2 billion board feet of framing lumber and nearly 2.5 million tons of wood waste. That 
translates into 1.1 million acres of clear-cut forest and 30-yard dumpsters lined up end-to-end from Phoenix to Chicago! Clearly, builders can achieve and claim significantly reduced global and local environmental impact with optimized framing.

On-site grinding. If you can grind your waste into wood chips it makes a great soil erosion control mat at job site entrances or bermed at the base of silt fences.

\section{Quality Project Management Approach}

A key component of high-performance system design and any high-performance construction process is quality project management. Quality management is a well-traveled term, but its definition can be elusive. In terms of Building America high-performance homes, the following definition is useful:

Quality management is an ongoing effort to systematically and comprehensively improve methods and processes that yield an optimal combination of energy efficiency, comfort, durability, indoor air quality, and moisture management.

This definition recognizes quality management as an integral part of achieving $30 \%$ whole house energy savings. It emphasizes that improvements in energy efficiency must be accompanied by commensurate improvements or at least maintenance of other key performance attributes of the home to reflect a true systems-thinking approach. This definition also reflects the built-in costeffectiveness of high-performance quality management as a risk-reduction strategy (comfort, durability, indoor air quality, and moisture management) for the builder. And finally, the definition encompasses homebuyer expectations of performance-with energy efficiency as just one of five performance attributes that any home should provide.

This definition also establishes the inherent relationship between quality and high performance. It is essentially this: While a quality home need not necessarily be a high-performance home, any high-performance home MUST be a quality home. For any Building America high-performance home builder to truly incorporate a systems approach, he or she must also incorporate a quality management approach.

The quality-management approach is an essential element of the Building America approach to homebuilding because it is the main vehicle for moving from science and concepts of high performance to implementation. The package of tools within the Building America quality management approach includes the following:

- Training/Education

○ For builders

○ For individual trades

○ Certifications

- Operational Evaluation (Modified $\mathrm{NHQ}^{42}$ )

○ Paper Review

\footnotetext{
${ }^{42}$ The NHQ (National Housing Quality) is the NAHB Research Center's National Housing Quality Program, discussed in detail later in this report. Building America team leader, IBACOS, modified the NHQ system to include criteria specific to housing performance.
} 
○ Key Player Interviews

- Performance-Based Standards

○ Design

○ Specifications

○ Scopes

- Verification Tools

○ Performance Testing

○ Inspections (Checklists)

- Feedback Loops

Although this package has not been developed from a single source or as a comprehensive system, it certainly could be used as a comprehensive quality project management approach. Each of these is discussed in detail below.

\section{Education / Training}

\section{Builder and Subcontractor Training}

Training has been found to be needed throughout the Building America program. Ongoing efforts within the industry will be necessary to develop, deploy, and continually update training programs to disseminate information from the Building America program if widespread implementation is to take place. While Building America has not been specifically charged with the development and deployment of training programs, this section discusses some of the opportunities, activities, and issues involved with training at the residential construction industry level.

Builders. The starting point for the quality management approach has always been builder training. These have included pre-construction training meetings and site training of trade contractors. Each Building America team has conducted such trainings, and their work in the context of Building America has led to any number of building-science-based training programs in the industry:

- The Energy \& Environmental Building Association's Houses That Work training program. This public-private training partnership has trained hundreds of builders all across the country in the principles of climate-based high-performance building science. Several of the Building America teams have certified Houses That Work trainers. Although not explicitly portrayed as such, the Houses That Work trainings have many of the elements of quality management as listed above.

- The Environments for Living ${ }^{\circledR 3}$ (EFL) Diamond Class Training. Long-time Building America partner, Masco Contractor Services, has developed a new 3-day builder training

\footnotetext{
${ }^{43}$ Environments for Living is a building-science-based, high-performance home-building program of Masco Contractor Services. The program was developed approximately 5 years ago in a public-private partnership with Building America.
} 
program, a program that focuses on the principles of building science and their application in production homebuilding.

- Colorado Built Green ${ }^{\circledR} 2005$ training. The new three-tier version of this program has criteria based specifically on the Building America program and best practices, as well as Tier II and III training patterned after Houses That Work.

- Build IQ Best Practices. An online training company, Build IQ, has been incorporating best practices from the Building America program for inclusion in their free and for-fee coursework. Build IQ delivers online training to top 100 homebuilders throughout the United States, including Pulte Homes, John Laing Homes, Beazer, Morrison, and others.

- BECT (Building Energy Code Training). Since 1995, BECT has helped the building industry keep up with changes in energy codes. The Building Industry Institute (BII) and their subcontractor, ConSol, under contract to the California Energy Commission (CEC) began a training program for large production builders in California and Nevada. The program has improved compliance with energy standards by improving builders' understanding and implementation of the energy codes.

The BECT program has trained more than 3,000 contractors and subcontractors in the California and Nevada area since its beginnings in the mid 1990s. Through the BECT program, California is able to train builders in the following:

- Current codes and issues

- Upcoming code changes

- Construction techniques that improve quality of construction

- Common enforcement issues.

California's energy code has always been at the forefront of implementing energy-efficient standards in home building. The energy code's goal in the beginning was to increase energy efficiency of a home being built in California every 3 years by approximately $5 \%$. But since the energy crisis, the percentage has been increased to $12 \%$ in 2001 and $15 \%$ in 2005 . Having an infrastructure in place like the BECT program has greatly facilitated this dramatic change to the building industry.

Training - Trade Contractors. Each Building America team has conducted trade contractor training on climate-specific building science and systems thinking. Targeted trades have included framing, insulation, and HVAC. The EFL program conducts trade contractor building science training for framing and insulation contractors and is developing an HVAC training module. The BETC program in California also provides training to subcontractors.

Training - Certifications. The Building America program has led at least one of its builders to develop its own certification related to high performance. Artistic Homes of Albuquerque, New Mexico, certifies its entire sales staff under a high-performance training program. The program is called the High Performance Homes Sales Specialist.

It is not clear at this time if certification of high-performance homebuilding skills from a third party group such as the North American Technician Excellence (NATE) or the Building Performance Institute (BPI) would be used in the industry. There is time and expense on the part of the trade contractor and the individual technician to receive the certification, and this must 
then be built into the price of doing business, which ultimately gets transferred to the Builder. There may be a correlation with better-trained technicians and reduced callbacks; however, this direct link has not been thoroughly researched or documented.

Feedback from builders who have participated in the Building America program reveals that one of the most difficult aspects of sustaining the delivery of high-performance housing is the continuous need for trade training and re-emphasizing the performance targets each trade must meet. This, in part, can be attributed to the high turnover in the building industry; however, it may be that a certification program for high-performance delivery of various key trade activities will be necessary for true transformation of the housing industry. A list of key trade-based certifications associated with delivery of high-performance housing can be found in Appendix B.

\section{Operational Evaluation}

Modified from the National Association of Homebuilders Research Center's National Housing Quality program, the Building America operational evaluation is a two-step process to help builders evaluate their own operations. The first is a paper review of all the documentation a builder has that is associated with its operations and the actual housing being built. The second is an interview with key individuals in the company. A reasonable list of the builders' primary source information for the first part of this evaluation includes the following:

- Annual operating plan. This includes company mission, vision, organizational values, goals for each department, strategic objectives, and reporting and other operational guidelines. The annual operating plan supports the long-range strategic plan, by documenting specific actions and goals that will help the company achieve the strategic plan.

- Long-range strategic plan. This includes the direction the company is headed, what types of barriers might exist, and how these barriers might be overcome. This document is a roadmap, which is made more specific in each year's annual operating plan.

- Process maps. These include any diagrammatic or written representation of the workflows operationally within the company.

- Design documentation. This category includes construction drawings, scopes of work, written specifications, contracts, field guides, etc., that communicate what should be built by the vendors.

- Operational tools. These include any sort of departmental tools used to facilitate business processes. For example, construction schedules or other field tools used by site supervisors to assist in the day-to-day management of construction or template letters and reports to assist in the standardization of company processes.

- Training programs. This includes any internally developed or externally developed program for continuing education of staff within the builders operations. The intent here is not to specifically review the content of all training programs, but to evaluate the general attitude, approach, depth, and breadth of training activities in the builder's organization.

- Human resource manual. This includes company policy, safety programs, benefits, and items documenting company culture. 
- Marketing materials. This includes any type of material used to communicate the builder's message about their product to consumers.

- Survey mechanisms and results. These include any surveys done by the company or outside consultants, which can be for employees, customers, or vendors or can collect regional or local information on competitive information, such as sales prices or volume of construction.

A reasonable list of key builder staff to interview as part of the second step in an operational evaluation includes the following:

- Operations

- Marketing

- Sales

- Purchasing

- Construction

- Customer Service

- Human Resources

- Land Development.

This two-step process gives a comprehensive understanding of the builder's current operations. This evaluation process could be adopted internally by a builder or externally through the use of a consultant in order to identify what areas may need to be addressed if the builder is considering transforming their product line to achieve Building America high-performance home technology packages. The process is comprehensive, but not overly detailed-it takes approximately 20-30 hours for one person to work through, once all the data has been assembled. It can identify best practices and opportunities without dwelling on minutia. Appendix D contains the latest version of the modified NHQ two-step process as developed by IBACOS.

\section{Performance Standards—Design, Specifications, Scopes}

Quality is often compared to the three-legged stool (the stool is of little use without all three legs). In high-performance home building, quality is only achieved with performance standards for design AND materials (specifications) AND installation (scopes). Building America takes this premise one step further by stating that many performance standards must be climatespecific; indeed even lot-specific when local terrain and environments bring with them additional challenges, such as extreme slopes, expansive soils, coastal high winds and flooding, etc.

Design and Design Review. An effective means of assuring these goals are implemented during the planning stages of a project is through a design review of the project, this can be a key instrument in making sure the whole energy system is incorporated in the design. It is highly unlikely that a home will be designed singularly around the HVAC system, or window orientation, or its ability to resist heat. However, these are all factors that go into a home and are crucial in getting a house to achieve 30\% whole-house energy savings. For this purpose, value engineering techniques must be employed to ensure that all the systems in the home cannot only be designed to perform at optimum levels but also be coordinated with those involved with 
actual construction of the project to make sure that the homes are built practically and as intended when designed on paper.

Each of the Building America teams has conducted dozens of detailed design reviews, resulting in resources such as the Building America Houses That Work climate-specific Best Practices, the Houses That Work building profiles, the Noisette Home Performance Standards, the draft Risk Assessment Protocol, etc. The common ground among these design standards is that they respond to climate-specific protection of the energy efficiency, the comfort, the indoor air quality, the durability, and the moisture management of each high-performance home. Thus, they make up the first leg of the "quality stool"- - high performance design.

Specifications. Specifiers, and subsequently purchasers, rarely take into account the overall performance of the home and its systems when making crucial material/component/subsystem choices. Standard specifications don't take into account individual component performance variations, much less the impact of single-component choices on assemblies or systems. Various Building America projects have addressed this issue. High-performance specifications were developed for the EcoVillage Townhome project in Cleveland Ohio. ${ }^{44}$ These specifications could and should be modified and applied to other high-performance home projects.

Scopes of Work. Even with intelligent design and the right materials, quality can fall short of intended performance without the right installation. Production builders generally rely upon their scopes of work to achieve the installation required. But, as a rule, these scopes do not reflect systems thinking or climate-specific building science. More than one Building America team leader has developed project-specific mock-ups (for walls and window installation; for example BSC at EcoVillage, IBACOS at Summerset at Frick Park) or detailed installation procedures that could and should be used by high-performance builders in their scopes. BIRA, in conjunction with the Comfortwise program, has developed and posted high-performance specifications for several keytrades, including HVAC and insulation. It would not be difficult, for example, to take a well-known industry scopes resource, such as the NAHB BuilderBooks, The Scopes of Work Program, ${ }^{45}$ and develop a customized Building America set of scopes as a comprehensive resource that integrates performance and quality.

\section{Verification}

Verification tools for both performance and quality include performance testing and inspection checklists. Clearly the first choice is almost always a quantitative test, such as any of the following:

- Using a blower door for measuring air tightness

- Using a calibrated fan system for measuring for duct tightness

- Using a flow hood for measuring supply and return airflows at registers and grilles

- Using a manometer for room-to-room pressurization

\footnotetext{
${ }^{44}$ Building Science Corporation. 2002. EcoVillage Sample Spec Language. www.buildingscience.com/buildingamerica/casestudies/ecovillage specs.pdf.

${ }^{45}$ Haas Davenport, Linda. 2000. The Scopes of Work Program: Procedures and Standard to Increase Quality. Washington, D.C., BuilderBooks.com.
} 
- Using a digital thermometer to measure room-to-room temperature variation

- Using a low-e detector to verify glazing properties.

The beauty of these tests is that quantitative metrics can be established that summarize the quality of design, materials, and installation for one or more performance attribute. Most performance tests for the residential building industry deal with energy efficiency directly and then may be indirectly reflective of other performance attributes, such as indoor air quality and comfort. But quantitative tests for other performance attributes, such as moisture management and durability, are generally not available, at least not in a cost-effective application. For verification of these performance attributes, a detailed inspection checklist and visual inspections act as a proxy determination of both quality and performance.

An important consideration in any quality management approach is the cost of verification. The primary determinants of at least the initial costs are the number of homes tested - ranging from one initial model home to $100 \%$ testing of every home built — and what entity does the testingeither in-house testing, $3^{\text {rd }}$-party testing, or some combination of the two. In general, for production builders, Building America has recommended a testing strategy similar to the EPA ENERGY STAR strategy of 1-in-7 random testing after a period of $100 \%$ testing to verify that key performance metrics are met on a consistent basis. But more than one Building America production builder has determined that either the pace at which they build or their reputation for quality (or both) makes $100 \%$ in-house testing and random 1 -in- $73^{\text {rd }}$-party testing the most costeffective strategy in the long run and based on looking at the total costs and total benefits of a much more rigorous quality protocol. The Building America Best Practices Guides ${ }^{46}$ produced by Pacific Northwest National Laboratory (PNNL) contain recommendations for testing protocols for each climate. In addition, a "SNAPSHOT" performance testing protocol and report process has been documented by Building Science Corporation and is included as Appendix F.

Each Building America team has made up prescriptive checklists to handle non-quantitative performance assessment, particularly for performance attributes, such as durability and moisture management. While it is difficult to address ALL of the variables that lead to customization of these lists - climate, lot, aspect, surrounding local features, building type, etc. - these checklists can be referenced as examples of how quality management of high-performance attributes are assessed and verified for builders seeking to achieve the Building America "standard." One of the difficulties that builders face with non-quantitative metrics and verification are the questions, "How do I know when enough is enough? When is our practice a best practice, substandard, or overkill?" Builders MUST use their local conditions and past product history (in terms of callbacks, legal claims, 1- and 2-year warranty trends) to intelligently manage durability and moisture. Proxy, qualitative tools can be applied - such as infra-red imaging of assemblies, water testing, and moisture meter readings - but these approaches have not been documented as part of the Building America body of research.

\footnotetext{
${ }^{46}$ Baechler, M. C.; Taylor, Z. T.; Bartlett, R.; Gilbride, T.; Hefty, M.; Love, P. M. 2005. Building America Best Practices Series: Volume 2. Builders and Buyers Handbook for Improving New Home Efficiency, Comfort, and Durability in the Hot-Dry and Mixed-Dry Climates, Revised. NREL Report No. 38360.
} 


\section{Commissioning}

Building commissioning is a systematic process of ensuring that a building performs in accordance with the design intent, contract documents, and the owner's operational needs. Because of the sophistication of building designs and the complexity of building systems constructed today, commissioning is necessary, but not automatically included as part of the typical design and construction process. Commissioning is critical for ensuring that the design developed through the whole-building design process is successfully constructed and operated.

Building commissioning includes the following:

- Systematically evaluating all pieces of equipment to ensure that they are working according to specifications. This includes measuring temperatures and flow rates from all HVAC devices and calibrating all sensors to a known standard.

- Reviewing the sequence of operations to verify that the controls are providing the correct interaction between equipment.

In particular, building commissioning includes these activities:

- Engaging a commissioning authority and team

- Documentation

- Verification procedures, functional performance tests, and validation

- Training.

Building commissioning is not one of these:

- Construction observation (punch list)

- Start-up

- Testing, adjusting, and balancing (TAB)

- Final punch-out.

These activities are individual steps in the systematic process of commissioning, but by themselves these activities cannot meet the goals of building commissioning.

Commissioning HVAC systems is even more important in energy-efficient buildings because equipment is less likely to be oversized and must, therefore, run as intended to maintain comfort. Also, HVAC equipment in better-performing buildings may require advanced control strategies. Commissioning goes beyond the traditional HVAC elements. More and more buildings rely on parts of the envelope to ensure comfort.

Commissioning includes evaluating the building elements to ensure that shade management devices are in place, glazing was installed as specified, air-leakage standards have been metthese are the static elements of the building. Commissioning can also evaluate other claims about the construction materials, such as VOC emission content and durability. It is important that the products that were specified for the building meet the manufacturer's claims (and are appropriate for the project.) 
Continuous commissioning ensures that the building operates as efficiently as possible while meeting the occupants' comfort and functional needs throughout the life of the building. Continuous commissioning differs from building operation and maintenance.

Benefits of building commissioning include the following:

- Energy savings and persistence of savings

- Improved thermal comfort with proper environmental control

- Improved indoor air quality

- Improved operation and maintenance with documentation

- Improved system function that eases building turn-over from contractor to owner.

\section{Feedback Loops}

Quality is a process ideally supported by feedback within the corporate structure and across the full range of product. Every department - design, construction, purchasing, warranty, sales, and marketing - should report performance successes and failures to every department for each and every product type, taking full advantage of feedback loops. In reality, many production builders set up little incentive for quality of product, erring in favor of quantity of product. But some builders are beginning to understand that it is not just how much profit a company can make, but how much profit a company retains, once the set-asides for warranty and claims are factored in. More than one builder is asking its managers a question like this:

"If we are currently setting aside about \$5,000 for each home we build to cover warranty and claims, how much quality management can we afford?"

Production builders in today's hot housing market are generally not having trouble making profits, just keeping them. If financial incentives can be created for quality of product, the reduction in warranty and claims can be used to finance the quality incentive structure. Feedback loops are a key element of any such quality management approach.

\section{Quality Management Summary}

In order to achieve whole-house energy savings of $30 \%$ or more, we are managing energy flows on, in, and through the structure to such a degree that we must manage the flow of air and moisture with equal attention. The links among energy efficiency, comfort, indoor air quality, durability, and moisture are not optional, they are built into the physics that builders face and the expectations buyers bring. Likewise, quality management is not an option when building highperformance homes. It is a process inherent to systems-thinking and systems-engineering. Without the quality management tools to implement the principles of physics and building science, higher performance in housing is simply an technical exercise, not a business proposition. 


\section{Building Component Design Details}

\section{Building Enclosure Integrity}

A house is an environmental separator whose function is to separate the inside from the outside as required by the local environment and the wishes of its occupants. A house creates an interior environment that is different from the exterior environment. This interior environment should be controllable by the occupants in a manner that meets their needs.

In order to function as an environmental separator, the elements, components, assemblies, and sub-systems that comprise a house must meet specific objectives, including the following:

- Control of heat flow

- Control of airflow

- Control of rainwater

- Control of groundwater

- Control of water vapor flow.

Control of Heat Flow

The key strategy in the control of heat flow is the use of thermal insulation in a manner that continuously encloses the conditioned space. If a conditioned space is considered a cube, then all six surfaces enclosing the cube are encased by thermal insulation. In the typical home this means both the above- and below-grade walls are insulated: the attic ceiling/roof assembly and the foundation slab.

Fully insulating a basement slab is also not necessary to meet the $30 \%$ savings goal. However, it is a recommended approach for all new houses from a moisture-control perspective if basements are to be intended for occupancy. Installing carpets and other floor finishes over uninsulated concrete basement floor slabs often leads to problems with dust mites and mold in floor coverings.

With wood-frame construction, this means exterior walls framed with $2 \times 6$ framing where cavities are insulated with fiberglass batts, spray-applied cellulose, or low-density spray-applied foams. In addition, the exterior $2 \times 6$ framing is sheathed with rigid-foam insulating sheathing.

In general, insulating sheathing is not necessary to meet the $30 \%$ savings goal. However, insulating sheathing has other significant benefits, particularly in the areas of moisture control. Inwardly driven moisture from reservoir claddings, such as brick and stucco, can be controlled by insulating sheathing. Additionally, the use of insulating sheathing of sufficient thickness allows the removal of interior vapor barriers and vapor retarders, thereby enhancing the inward drying of the assembly. In other words "double vapor barriers" can be avoided.

Insulating sheathing also has cost advantages over oriented strand board (OSB) and plywood sheathings when coupled with innovative framing techniques for wind and seismic loadings.

Reducing heat-flow in wood frame construction can be accomplished by minimizing the amount of framing materials through which conductive heat transfer can occur, increasing the cavity 
thickness to accommodate more thermal insulation, and using sheathing materials that provide thermal resistance.

Materials can be reduced at corners and where interior partition walls intersect exterior walls. Thermal bridging can be reduced at door and window openings through the use of insulated headers and using hangers to eliminate king studs and cripple studs. Stud spacing can also be increased to 24-in. spacing and point-loading trusses.

Increasing cavity thickness to accommodate more thermal insulation can be facilitated in wall framing by using thicker framing materials and at the intersection of roof trusses and exterior walls through the use of specialized trusses. In all truss and roof assemblies, baffles should be installed to prevent the wind washing of thermal insulation and to prevent insulation from blocking ventilation in vented roof assemblies.

Fenestration has minimum U-values of 0.3 and SHGC values of 0.4 or lower.

\section{Control of Airflow}

One of the key strategies in the control of airflow is the use of air barriers. Air barriers are systems of materials designed and constructed to control airflow between a conditioned space and an unconditioned space. The air barrier system is the primary air enclosure boundary that separates indoor (conditioned) air and outdoor (unconditioned) air. In multiunit/townhouse/apartment construction, the air-barrier system also separates the conditioned air from any given unit and adjacent units. Air-barrier systems also typically define the location of the pressure boundary of the building enclosure.

The air-barrier system also separates garages from conditioned spaces. In this regard, the airbarrier system is also the "gas barrier" and provides the gas-tight separation between a garage and the remainder of the house or building.

Air-barrier systems keep outside air out of the building enclosure or inside air out of the building enclosure depending on climate or configuration. Sometimes, air-barrier systems do both.

Air-barrier systems can be located anywhere in the building enclosure - at the exterior surface, the interior surface, or at any location in between. In Cold Climates, interior air-barrier systems control the exfiltration of interior, often moisture-laden, air. Whereas exterior air-barrier systems control the infiltration of exterior air and prevent wind washing through cavity insulation systems.

Numerous approaches can be used to provide air-barrier systems in buildings. Rigid materials, such as gypsum board, exterior sheathing materials like plywood or OSB, and supported flexible barriers are typically effective air-barrier systems if joints and seams are sealed.

Spray-applied foam insulations can be used as interstitial (cavity) air-barrier systems. Damp spray-applied cellulose does not meet the performance requirements of air barrier materials or assemblies - it is an air retarder.

The significant advantage of exterior air-barrier systems is the ease of installation and the lack of detailing issues related to intersecting partition walls and service penetrations.

An additional advantage of exterior air-barrier systems is the control of wind washing that an exterior air seal provides with insulated-cavity frame assemblies. 
The significant disadvantage of exterior air-barrier systems is their inability to control the entry of air-transported moisture into insulated cavities from the interior. As a result, most exterior air-barrier systems are insulated on their exterior side with rigid or semi-rigid insulations that are not sensitive to wind washing.

An advantage of interior air-barrier systems over exterior systems is that they control the entry of interior moisture-laden air into insulated assembly cavities during heating periods. The significant disadvantage of interior air-barrier systems is their inability to control wind washing through cavity insulation.

Installing both interior and exterior air-barrier systems can address the weakness of each.

The practice of using framing elements in conjunction with the interior gypsum sheathing can meet the requirements of a building envelope air-barrier system. In this approach, the primary responsibility for reduction of air-leakage openings is shared by both the framer and the gypsumboard installer.

Air leakage at the platform frame floor assembly can be reduced by sealing the rim joist to the frame wall or plate below and the sub-floor sheathing above. This is typically accomplished by using a continuous bead of sub-floor adhesive to seal the sub-floor sheathing to the rim joist and caulking to seal the bottom of the rim joist assembly to the plate below. Gaskets and other seals can also be utilized. Where floor trusses or other manufactured wood-product floor-system components are used (wood I-beams), solid rim joist material installed in a continuous manner should be provided to prevent air leakage at the rim joist assembly.

Air leakage between the bottom plates of exterior walls and the sub-floor sheathing is controlled by sealing the bottom plate to the sub floor. This is typically accomplished by installing a continuous bead of sealant or caulk under wall plates.

Air leakage at floor assemblies where cantilevers occur is also controlled at rim joist locations. Blocking utilizing wood or rigid insulation can be used with both exterior and interior cantilever floor assemblies. Where floor-framing members are installed parallel to exterior walls (or garage walls), solid rim-joist material can be installed directly over wall plates to provide for air barrier continuity.

Air leakage through sub-floor sheathing installed over unconditioned spaces, such as vented crawl spaces, unconditioned garages, or cantilevered floors over exterior walls, can be controlled by sealing all panel joints.

Tubs, shower stalls, and one-piece manufactured tub/shower enclosures installed on exterior walls can provide the single largest source of air-leakage areas when uncontrolled. Rigid sheathing material should be installed on the interior surfaces of exterior walls and sealed to framing and sub-floor sheathing before the installation of tubs and shower enclosures. Thin, non-insulating sheathings can be installed in a manner that allows the installation of interior gypsum board sheathing over sheathing edges without noticeably altering wall thickness. With one-piece manufactured tub/shower enclosures, the entire height of the interior surface of exterior walls should be sheathed. This usually requires the installation of cavity insulation before the installation of the interior sheathing.

Where fireplaces are installed on exterior walls, air leakage can be as significant as air leakage at tubs and shower stalls. Fireplace enclosure framing should be lined on the interior with rigid sheathing material. Such enclosures should be considered as small rooms that are conditioned. 
Accordingly, they require a sealed top, bottom, and three sides. Gypsum board, plywood, wafer board, and foil-covered pressed paper can provide satisfactory performance when sealed. This will also greatly reduce callbacks from cold drafts coming from fireplaces.

Interior soffit assemblies above cabinetry on exterior walls or adjacent insulated ceilings and attics also require air sealing. Where the ends of soffit assemblies or framing boxing in mechanicals intersect exterior walls, the "footprint" of the soffit or framing against the exterior wall should be enclosed with sheathing.

Window and door openings can be sealed by the framer sealing the window or door unit to the rough framing with foam, caulk, or other sealant. Alternatively, the drywaller can return the gypsum-board interior finish to the window or door unit and seal the joint with caulk.

Interior utility chases or dead spaces between two closely spaced walls, dropped ceilings, and split levels require special attention. Sealing responsibilities are shared between framers and drywallers at dropped ceilings and split-levels. Blocking is installed and sealed by the framers; gypsum board is installed and sealed by the drywallers.

Attic access openings located within conditioned spaces should also be sealed as well as flue pipe penetrations.

Whole-house fans require a cover that can be installed during the heating season in an airtight manner. Some whole-house fan units come equipped with airtight covers. Those units that do not have covers $c$, an have removable covers site-manufactured in a similar manner to removable attic access covers.

\section{Control of Moisture}

Control of Rainwater. The fundamental principle of rainwater control is to shed water by layering materials in such a way that water is directed downwards and outwards from the building or away from the building. It applies to assemblies such as walls, roofs, and foundations, as well as to the components that can be found in walls, roofs, and foundations such as windows, doors, and skylights. It also applies to assemblies that connect to walls, roofs, and foundations such as balconies, decks, railings, and dormers.

Layering materials to shed water applies to the building as a whole. Overhangs can be used to keep water away from walls. Canopies can be used to keep water away from windows, and site grading can be used to keep water away from foundation perimeters.

All exterior claddings pass some rainwater. Siding leaks, brick leaks, stucco leaks, stone leaks, etc. Therefore, some control of this penetrating rainwater is required. In most walls, this penetrating rainwater is controlled by a drainage plane that directs the penetrating rainwater downwards and outwards.

Drainage planes are water-repellant materials (building paper, house wrap, foam insulation, etc.) that are located behind the cladding and are designed and constructed to drain water that passes through the cladding. They are interconnected with flashings, window and door openings, and other penetrations of the building enclosure to provide drainage of water to the exterior of the building. The materials that form the drainage plane overlap each other shingle fashion or are sealed so that water flow is down and out of the wall. 
Materials that absorb and store rainwater when it rains located on the outside of buildings can create problems. They can act like reservoirs or sponges absorbing and holding water when exposed to rain. Stored water can migrate elsewhere and cause problems. Common reservoirs are brick veneers, stuccos, wood siding, wood trim, and fiber cement cladding.

The best approach to dealing with reservoirs is to eliminate them or disconnect them from the building. Back priming (painting all surfaces, back, front, edges and ends of wood siding, cement siding and all wood trim) gets rid of the moisture storage issue with these materials.

Back-venting brick veneers and installing them over foam sheathings disconnects the brick veneer moisture reservoir from the building. Installing stucco over two layers of building paper or over an appropriate capillary break, such foam sheathing, similarly addresses stucco reservoirs.

Control of Groundwater. The fundamental principles of groundwater control are to keep rainwater away from the foundation wall perimeter and to drain groundwater with sub-grade perimeter drains before it gets to the foundation wall. This applies to slabs, crawlspaces, and basements.

Concrete and masonry are sponges - they can wick water because of capillarity. This is the main reason that damp-proofing (the black tar-like coating) is applied to exterior basement walls. The damp-proofing fills in the pores in the concrete and masonry to reduce ground-water absorption. The damp-proofing is a capillary break. Under concrete floor slabs, the stone layer combined with polyethylene serves a similar function (they act as capillary breaks). Unfortunately, the capillary rise through footings is typically ignored. This can be a major problem if foundation perimeter wall are finished or insulated.

In new construction, a capillary break should be installed on the top of the footing between the footing and the perimeter foundation wall. This can be done by damp-proofing the top of the footing or by installing a membrane at this location.

The interior insulation and finishing approach must take into account the moisture migrating up through the footing. This is best accomplished by installing rigid foam insulation on the interior of the assembly to protect the interior finishes.

The best foams to use have a perm rating of greater than 1 perm for the thickness used. This means limiting extruded polystyrene insulation to less than 1-in. thickness for walls (more than 1 in. thick, and they do not breathe sufficiently) and making sure that the rigid insulation is not faced with polypropylene skins or foil facings. Additionally, because foams need to be protected from fire, and this is often done with gypsum board, only latex paint should be used on interior gypsum finishes (because it breathes).

Capillary control also applies to slab-on-grade construction and crawlspaces. Monolithic slabs need plastic ground covers that extend under the perimeter grade beam and upwards to grade. Additionally, the exposed portion of slabs must be painted with latex paint to reduce water absorption and a capillary break must be installed under perimeter wall framing.

Control of Water Vapor Flow. The fundamental principle of control of water in the vapor form is to keep it out and to let it out if it gets in.

The following things are discouraged:

- The installation of vapor barriers on both sides of assemblies (i.e., "double vapor barriers"). 
- The installation of vapor barriers, such as polyethylene vapor barriers, foil-faced batt insulation, and reflective radiant-barrier foil insulation on the interior of air-conditioned assemblies.

- The installation of vinyl wall coverings on the inside of air-conditioned assemblies.

The following things are encouraged:

- The construction of assemblies that are able to dry by diffusion to at least one side and in many cases to both sides.

- The ability to use insulating sheathings without the creation of "double vapor barriers."

- The ability to use of damp spray insulations with insulating sheathings without the creation of "double vapor barriers."

\section{Specific Recommendations}

- Soil surfaces shall be graded away from below-grade envelope surfaces.

- Materials next to below-grade envelope surfaces shall be free-draining and shall connect to a sub-grade drainage system through a filter media that will prevent fines build-up in the drainage system.

- A clay cap or other water-flow-resistant surface layer shall be installed to prevent surface water from draining into the free-draining material next to below-grade envelope surfaces.

- Below-grade surfaces shall be provided with a damp-proofing layer or coating that will be effective as a capillary break.

- All surfaces subject to wind-driven rain or snow shall be provided with a drainage plane or layer that will prevent rain-wetting of internal materials.

- Indoor relative humidity shall be maintained at the center of the room or as low as necessary to keep the room air next to cool/cold surfaces at less than $70 \%$ relative humidity.

- All building envelope assemblies should include at least one air barrier and one vapor retarder surface.

- All crawl space assemblies should have a continuous impermeable ground cover that functions as both an air barrier and vapor retarder.

- Provide air-barrier systems that control air movement from the interior.

- Locate vapor diffusion retarders toward the interior of building assemblies and avoid vapor diffusion retarders toward the exterior of building assemblies. Where low-permeance exterior sheathings are used, temperature of condensing surfaces under heating conditions should be controlled (use of insulating sheathings, external insulation), as well as interior vapor pressures.

- Provide secondary air barriers that control wind washing from the exterior.

- Control interior relative humidities during the coldest portion of the heating season (maintain below 35\%). 
- Allow wet or moist materials used in construction to dry toward the exterior.

\section{Envelope Systems}

\section{Foundation Systems}

The function of a foundation system is to hold up the building. This involves facilitating the transfer of loads from above-grade to the ground. Foundation systems, depending on their configuration and location, may also have to control other factors, such as heat flow, airflow, rainwater, groundwater, and water vapor flow.

\section{Slab on Grade}

Structure. In Hot-Dry/Mixed-Dry climates, the primary slab-on-grade approach involves a monolithic slab-grade beam assembly. Post-tensioning in some cases occurs.

Insulation and Air Infiltration. In Mixed-Dry climates, the perimeter of the concrete must be thermally isolated from the ground. This thermal insulation extends from the bottom of the grade beam to the top of the slab. A sill gasket also provides an air seal between the foundation and the frame structure on top.

In Hot-Dry climates, the perimeter of the concrete remains uninsulated.

Water Management, Drainage, Vapor Diffusion. As in all foundation systems, the perimeter grade must slope away from the foundation to reduce the saturation of ground adjacent the structure. With monolithic slab-grade beam assemblies, the entire concrete assembly must be isolated from the ground with a capillary break. This involves installing a polyethylene sheet membrane under the grade beam extending to grade. The exposed portion of the foundation above grade is damp-proofed using latex paint. The sill gasket functions as the primary capillary break between the stem wall and the frame structure. A polyethylene sheet membrane vapor barrier should be installed in direct contract with the concrete slab - a sand layer should never be installed between the polyethylene sheet membrane and the concrete slab.

Interaction with Mechanical Systems. Excessively long-duration interior negative pressures should be avoided. A depressurization limit of 5 Pascals is recommended for continuously operating exhaust appliances. A depressurization limit of 20 Pascals is recommended for intermittent operating exhaust appliances. Only sealed-combustion appliances should installed within the pressure boundary of the building enclosure. Passive sub-slab ventilation is recommended to reduce atmospheric air pressure soil gas drivers.

\section{Crawl Space}

Structure. In Hot-Dry/Mixed-Dry climates the primary crawl space approach involves conditioned crawl space construction. Vented crawlspaces are energy inefficient compared to conditioned crawl spaces and interfere with ground coupling where the ground can act as a heat sink during air conditioning.

Insulation and Air Infiltration. The perimeter of crawl spaces must be insulated. Interior rigid insulation is the insulation system of choice because it is not water sensitive. The interior location is preferred from both a constructability perspective and insect-resistance perspective. 
This thermal insulation extends from the top of the footing to the underside of the floor framing. A sill gasket provides an air seal between the foundation and the frame structure.

Water Management, Drainage, Vapor Diffusion. As in all foundation systems, the perimeter grade must slope away from the foundation to reduce the saturation of ground adjacent the structure. All below-grade surfaces in ground contact should be damp-proofed. A continuoussealed air barrier and vapor-barrier ground cover should be installed. If the interior crawl space grade is below the exterior grade a perimeter drain system is required. This perimeter drain works best when located on the exterior of the foundation assembly.

Interaction with Mechanical Systems. Excessive long-duration interior negative pressures should be avoided. A depressurization limit of 5 Pascals is recommended for continuously operating exhaust appliances. A depressurization limit of 20 Pascals is recommended for intermittent operating exhaust appliances. Only sealed-combustion appliances should be installed within the pressure boundary of the building enclosure. Passive sub-ground cover ventilation is recommended to reduce atmospheric air pressure soil gas drivers.

Conditioning of the crawl space should be accomplished by supplying conditioned air to the crawl space either via a dedicated duct or via transfer air from the house where a continuously operating exhaust fan is used as the pressure driver.

\section{Building Enclosure Integration Strategies}

\section{Walls}

The function of wall systems is to provide environmental separation between the interior and exterior, as well as transfer wind and seismic loads to the foundation. And similarly transfer loads from the roof to the foundation. As part of the provision for environmental separation, wall systems have to control heat flow, airflow, rainwater, and water-vapor flow.

Structure. In Hot-Dry/Mixed-Dry climates, the primary structural approach is site-built woodframe-utilizing engineered elements, such as prefabricated lintels, headers, and sheet goods, such as OSB, plywood, and gypsum wallboard.

Resistance to shear loads as a result of wind and seismic events must be provided. The choice of construction or framing approaches addressing shear loads should reflect the local conditions. For example, houses constructed in low-wind zones can be constructed with wood frame assemblies with non-structural sheathings and metal cross braces or wood "let-in" braces. Whereas a similar home built in a higher wind zone, such as in a coastal wind zone, or built in a more severe seismic zone may have to be constructed with structural sheathing or inset shear panels.

The following are the principle means of controlling lateral loads:

- metal cross braces

- wood "let-in" braces

- structural sheathing such as plywood or OSB

- proprietary shear panels. 
Insulation and Air Infiltration. The optimum approach to insulation involves $2 \times 6$ advanced frame walls with insulating sheathing replacing OSB or plywood sheathing. Cavity insulation is either unfaced fiberglass batt insulation or damp-sprayed cellulose.

Air-infiltration control is provided by an air barrier. An interior air barrier is used, specifically the interior gypsum sheathing combined with using framing elements, such as draft-stopping and fire-stopping components.

Water Management, Drainage, Vapor Diffusion. Rainwater management is provided by using the insulating sheathing as a drainage plane and integrating window and doors with the insulating sheathing to provide drainage plane continuity.

Vapor diffusion is addressed by not installing vapor barriers on the interior of assemblies constructed in Hot-Dry/Mixed-Dry Climates.

Interaction with Mechanical Systems. The tighter the building enclosure, the greater the pressure differential created with exhaust appliances. The use of an air barrier results in a tighter building enclosure.

Excessive long-duration interior negative pressures should be avoided. A depressurization limit of 5 Pascals is recommended for continuously operating exhaust appliances. A depressurization limit of 20 Pascals is recommended for intermittent-operating exhaust appliances. Only sealedcombustion appliances should installed within the pressure boundary of the building enclosure.

\section{Floors}

The function of floor systems is to provide environmental separation between the interior and exterior where they intersect the exterior enclosure, as well as to transfer wind and seismic loads to the foundation by functioning as a diaphragm and similarly transfer loads from the roof to the foundation. As part of the provision for environmental separation, floor systems have to control heat flow, airflow, rainwater, and water-vapor flow.

Structure. In Hot-Dry/Mixed-Dry climates, the primary structural approach is site-built wood framing utilizing engineered elements, such as prefabricated I-joists and sheet goods, such as OSB.

Insulation and Air Infiltration. The optimum approach to insulation involves using spray foam insulation on the interior of the rim joist assembly.

Air-infiltration control is provided by an air barrier. The air barrier is the rim joist assembly itself sealed to the framing elements above and below using sealant or spray-foam insulation.

Water Management, Drainage, Vapor Diffusion. Rainwater management is provided by using insulating sheathing installed exterior to the rim joist as a drainage plane and integrating this with the insulating sheathing of the frame assembly, either above or below the floor system to provide drainage plane continuity.

Vapor diffusion is addressed by not installing vapor barriers on the interior of assemblies constructed in hot-dry/mixed-dry climates.

Interaction with Mechanical Systems. The tighter the building enclosure, the greater the pressure differential created with exhaust appliances. The use of an air-barrier rim-joist assembly results in a tighter building enclosure. 
Excessive long-duration interior negative pressures should be avoided. A depressurization limit of 5 Pascals is recommended for continuously operating exhaust appliances. A depressurization limit of 20 Pascals is recommended for intermittent-operating exhaust appliances. Only sealedcombustion appliances should be installed within the pressure boundary of the building enclosure.

\section{Roof/Ceiling/Attic}

The function of roof/attic systems is to provide environmental separation between the interior and exterior, as well as to transfer wind and seismic loads to the foundation by functioning as a diaphragm. As part of the provision for environmental separation, floor systems have to control heat flow, airflow, rainwater, and water vapor flow.

Structure. In hot-dry/mixed-dry climates, the primary structural approach is site-built woodframing utilizing engineered elements, such as prefabricated roof trusses and sheet goods, such as OSB and plywood.

Insulation and Air Infiltration. The optimum approach to insulation involves blowing insulation on the top surface of ceiling gypsum board. This ceiling insulation level is maintained throughout the entire plane of the ceiling extending to the perimeter walls. Roof trusses are constructed in such a manner as to maintain the thickness of ceiling insulation directly above the top plates of the exterior wall framing. Baffles are installed to control wind washing.

Air infiltration control is provided by an air barrier. The ceiling gypsum board is installed to function as an air barrier. Dropped ceiling areas are draftstopped, ceiling light fixtures are selected to be airtight, and all penetrations through plates are air sealed.

In some hot dry climates, conditioned roof/attic construction may be warranted.

Water Management, Drainage, Vapor Diffusion. Traditional roofing materials, such as shingles, are used to provide rainwater management at the roof deck.

Vapor diffusion is handled by providing roof/attic ventilation and by not installing an interior vapor barrier.

Figures 16, 17, and 18 are examples of building envelope details for Albuquerque, New Mexico; Sacramento, California; and Tucson, Arizona.

Interaction with Mechanical Systems. Excessively long-duration interior negative pressures should be avoided. A depressurization limit of 5 Pascals is recommended for continuously operating exhaust appliances. A depressurization limit of 20 Pascals is recommended for intermittent operating exhaust appliances. Only sealed-combustion appliances should installed within the pressure boundary of the building enclosure. Passive sub-slab ventilation is recommended to reduce atmospheric air pressure soil gas drivers. 


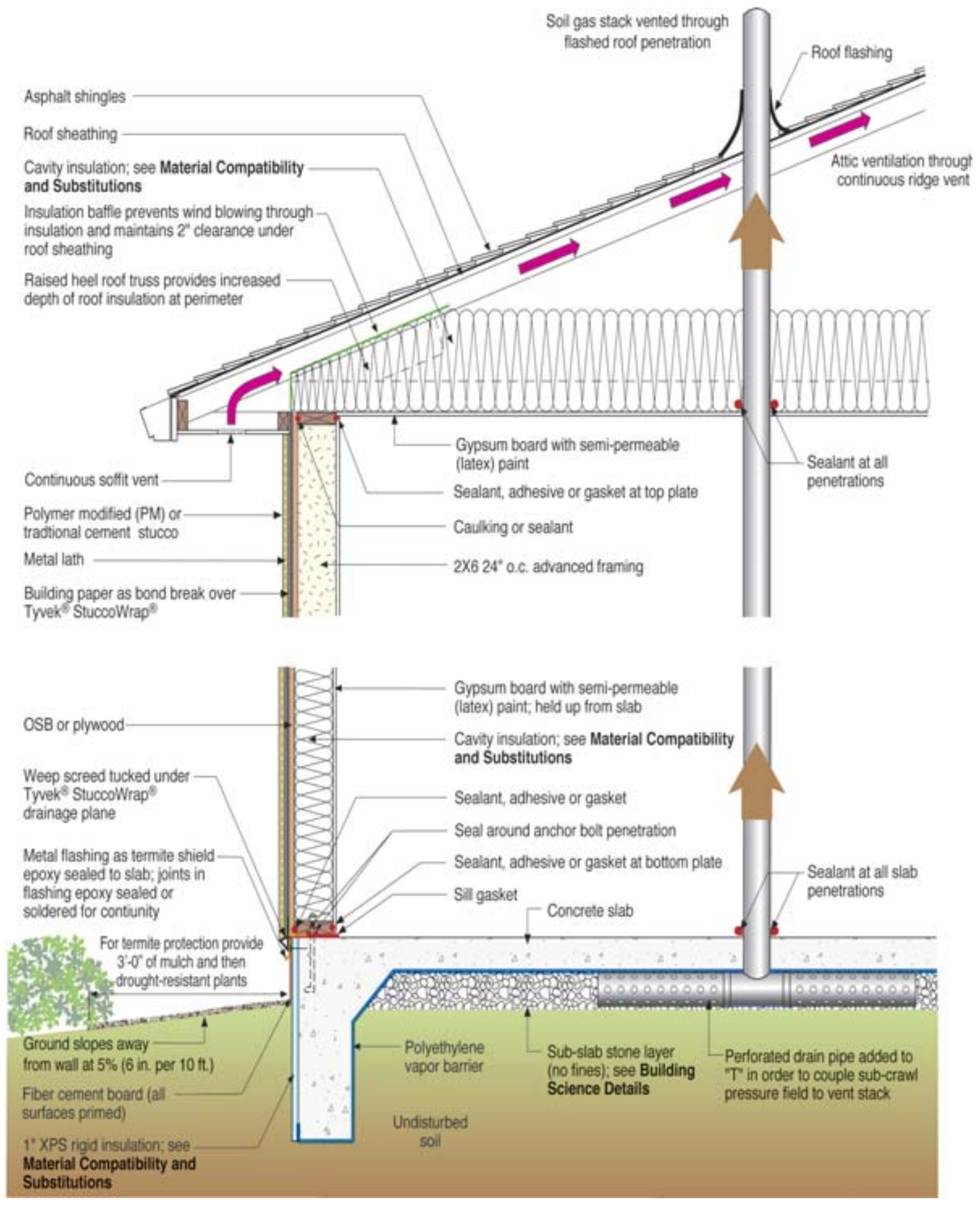

Figure 16. Example of building envelope details for Albuquerque, New Mexico 


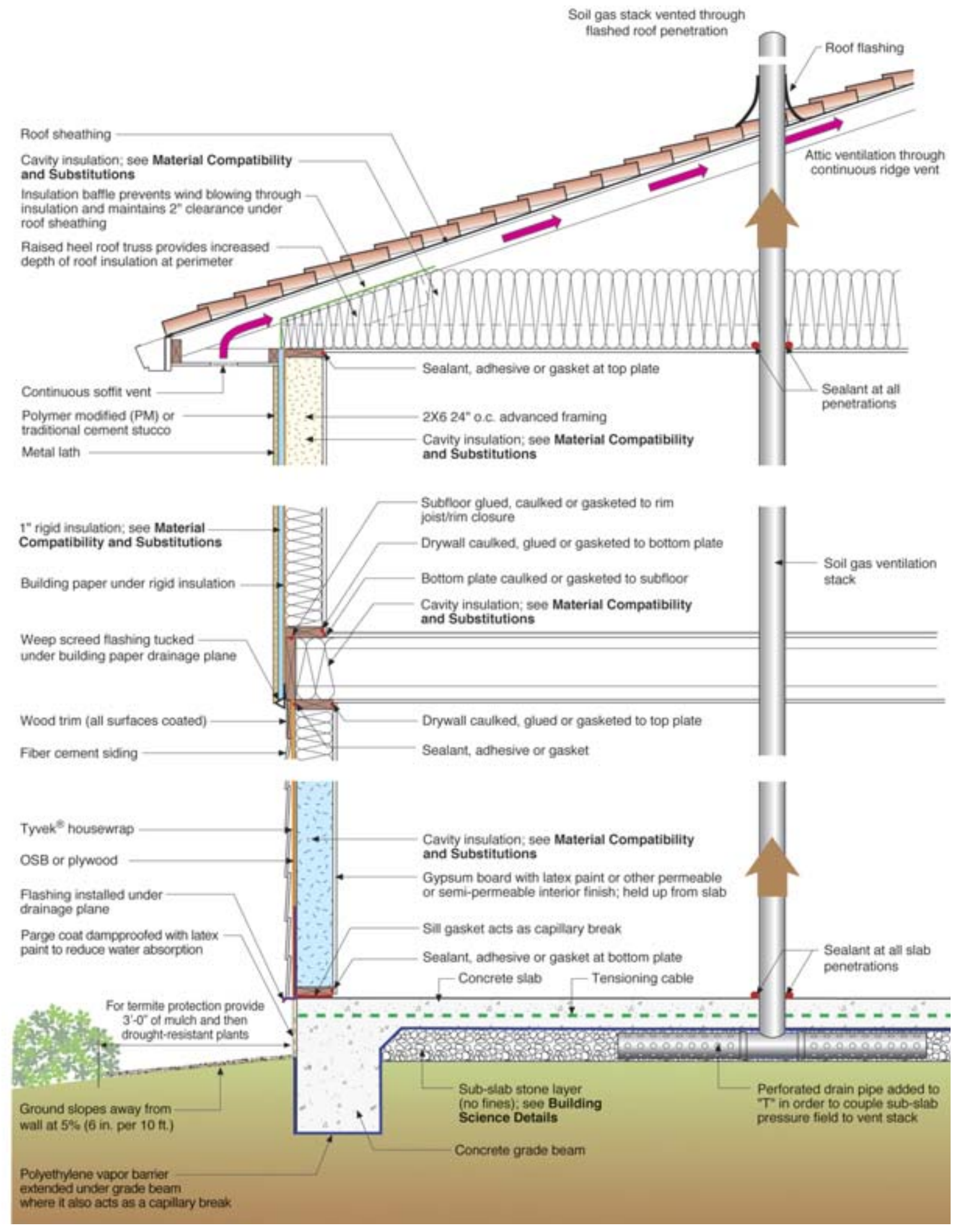

Figure 17. Example of building envelope details for Sacramento, California 


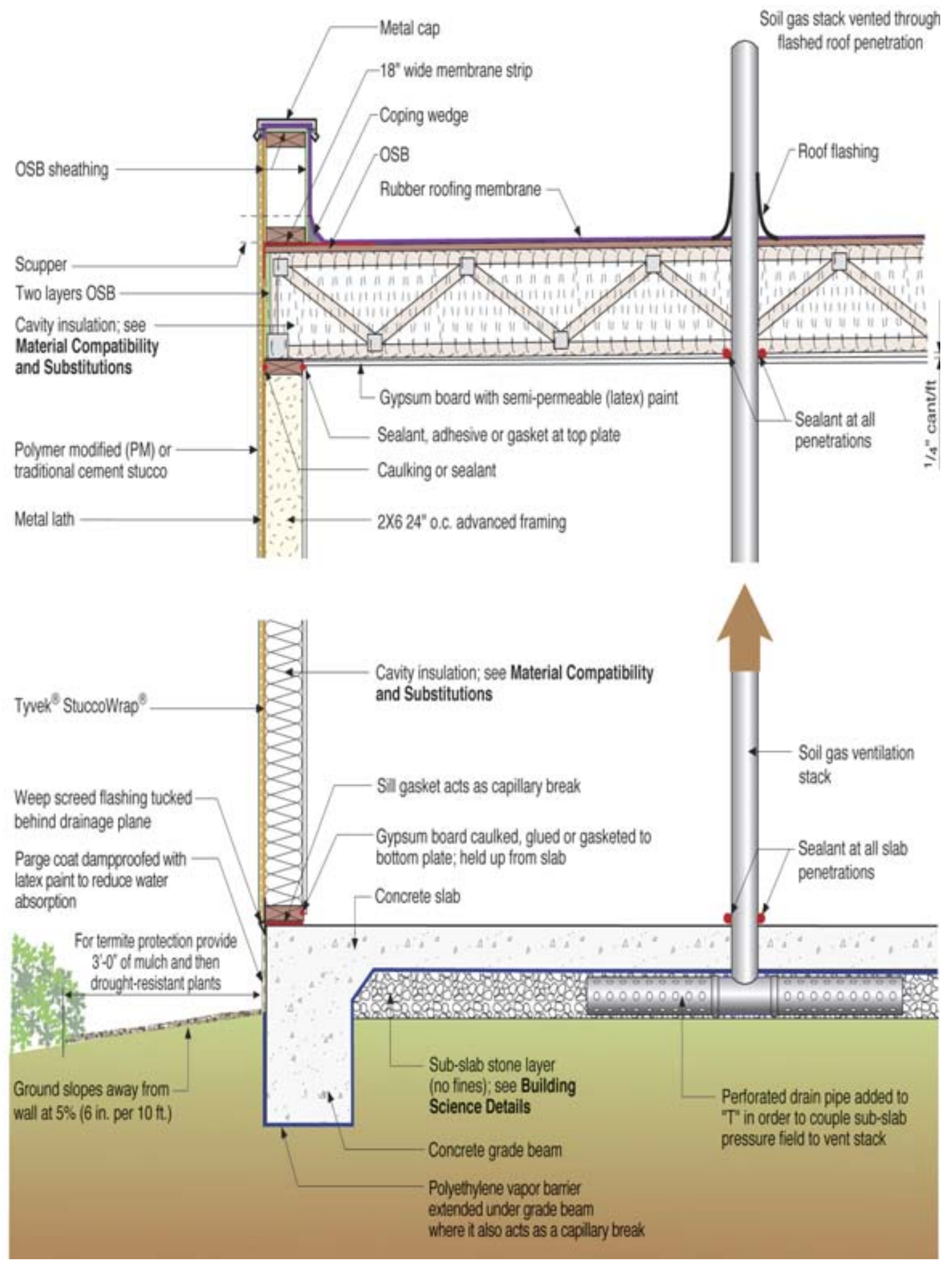

Figure 18. Example of building envelope details for Tucson, Arizona 


\section{Space Conditioning and Ventilation Systems}

\section{Forced Air}

Forced-air heating and cooling systems are the most predominant type of system in today's residential new-construction market. This is driven primarily by the market for central air conditioning. According to census data, $77 \%$ of the homes constructed from 1990 to $1997 \mathrm{had}$ central electric air conditioning. Central natural gas-fired furnaces were used in $47 \%$ of the new homes.

Cooling system efficiency is important in hot climates because air conditioning represents a larger share of annual building energy use than in other climates. However, the $30 \%$ performance goal is generally achievable by applying air conditioners that meet the 2006 federal (NAECA) standard of 13 SEER. This is particularly true if efficient duct systems are employed and if cooling loads are reduced by incorporating high performance (Low-E ${ }^{2}$ ) windows and architectural window shading in the design.

Selecting an efficient air conditioner is only part of the story. Right sizing of air conditioners (using ACCA Manuals J and S) will minimize operating efficiency losses resulting from cycling. Air conditioners and matching evaporator coils should be selected that have a sensible cooling capacity that meets or slightly exceeds the sensible cooling load from Manual J. Proper installation is required to ensure that air conditioners perform to their rated efficiencies. Fan speed taps should be adjusted to provide close to $400 \mathrm{cfm}$ per ton of cooling capacity; lower airflows will provide more latent cooling capacity than is generally needed in hot-dry/mixed-dry climates, and higher airflows will waste fan energy. Improper refrigerant charge can significantly compromise air-conditioner efficiency. Thermostat expansion valves (TXVs), which dynamically adjust refrigerant flow, can compensate for improper charge and should be used instead of orifice-type expansion devices.

Relatively low heating loads in hot-dry/mixed-dry climates mean that high-efficiency (condensing) furnaces are not required to achieve the $30 \%$ target, though with declining costs for $90+$ AFUE furnaces, they are an increasingly good value. Induced draft, direct-vent furnaces are desirable because they can be located in conditioned space, minimizing heat loss. Direct vent furnaces draw combustion air directly from outdoors rather than from the surrounding (unconditioned) space.

Air conditioning, heating, and, in some cases, ventilation systems, use the same fan to move air, so the efficiency of the furnace or heat pump indoor fan motor can have a large impact on yearround energy use. Nearly all furnace manufacturers offer "variable-speed" brushless permanent magnet (BPM) DC motors. Unlike permanent split-capacitor motors, BPM motors retain their high efficiency at reduced fan speeds, nearly attaining theoretical cube law reductions in energy use. Though they have more than a $\$ 200$ price premium, they are a recommended means of lowering HVAC energy use, particularly with two-stage heating and cooling systems.

Though not critical to meeting the $30 \%$ performance level, locating the forced-air system (furnace/air handler and ducts) within the conditioned space will substantially improve wholehouse performance. This approach minimizes the system inefficiencies associated with air leakage and thermal losses from the typically leaky system cabinets. Alternative locations for the furnace/air handler include a mechanical room, closet, or soffited area that is within conditioned space, or in an unvented or "cathedralized" attic. Few production homes are being 
built over basements in Hot-Dry/Mixed-Dry Climates, but basements are also a good alternative location.

Air-conditioner energy use can be reduced by ventilating homes at night with cool outdoor air to reduce the temperature of building thermal mass. This technique can reduce cooling energy use by up to $35 \%$ where summer diurnal temperatures vary by $30^{\circ} \mathrm{F}$ or more, but ventilation cooling is not necessary to achieve the $30 \%$ savings target.

\section{Ventilation}

Most new homebuilders in Hot-Dry/Mixed-Dry Climates still rely on building leakage, intermittent use of bathroom and range-hood ventilation fans, and occupant use of windows and doors for maintaining indoor air quality. A California study to determine the adequacy of this approach is currently underway.

Despite the fact that ventilation systems increase energy use, with new homes being built to tighter air-leakage standards, a whole-house mechanical ventilation system that is capable of meeting the specifications of ASHRAE Standard 62.2 is recommended to assure adequate indoor air quality. ${ }^{47}$ The relatively low indoor-outdoor temperature differences in Hot-Dry/Mixed-Dry climates do not justify the initial expense and operating cost of heat-recovery ventilators. The remaining choices for mechanical ventilation include systems that utilize the furnace fan to induce the flow of outdoor air into the HVAC system ducts and exhaust fans that operate continuously.

A supply-only system with a passive outside air inlet to the central air-handler's return with appropriate dampers and controls has been successfully employed in Building America homes. These systems have the disadvantage of using excessive fan energy during periods when there is no demand for heating or cooling, because most of the airflow is recirculated air and only a fraction is outside air. Advantages are that that the fresh-air volume can be adjusted to meet ASHRAE 62.2 requirements, outside air is filtered, and fresh air is delivered to every space.

Continuously operating exhaust fans located in a bathroom or central area of the house provide a lower cost solution. High-quality "low sone," efficient fans are typically used for this application. Because exhaust fans draw air from leaks in the building envelope, air is not filtered and may not be evenly distributed. A better solution that is in use by some contractors is to tie all bathroom exhaust ducts together and route them through a single, continuously operating, high-efficacy axial fan that is vented to the exterior. An approach that has also been used is to terminate a small fresh-air duct inside the return plenum, with a filter applied to the discharge opening. The filter is accessible through a hinged filter grill.

As with all mechanical systems, it is also important that ventilation systems be properly commissioned. Commissioning should include verification of fan operation and control settings and measurement of the outside air volume.

\section{Air Distribution}

For the $30 \%$ improvement, a number of requirements apply to design of the duct system:

\footnotetext{
${ }^{47}$ ASHRAE 62.2-2003. Ventilation and Acceptable Indoor Air Quality in Low-Rise Residential Buildings. Atlanta, GA: American Society of Heating, Refrigeration, and Air Conditioning Engineers.
} 
- Design should be in accordance with ACCA Manual D

- Ductwork should be located within the thermal envelope of the house or buried with insulation

- Ducts should not be located in exterior walls

- Ducts must be air-sealed using UL 181-approved mastic or equivalent for the particular duct type

- "Panning" between joists and the use of stud cavities for supply or return air is not recommended

- Ducts may be of galvanized sheet metal, duct board, or flex duct

- There must be continuity of the vapor barrier on insulated ducts not running inside conditioned spaces.

Sometimes duct systems need to run in unconditioned spaces.

To accommodate heating and cooling units and duct systems within the thermal envelope of the house, a number of techniques may be employed. This typically impacts the architectural design of the house and should be considered at the early schematic phase of design. Keeping ducts inside the conditioned space may also involve framing systems that allow ducts to be run through it, such as an open-web floor-truss system. Alternately, dropped soffits, tray ceilings, and lower ceiling heights in "service" function rooms like baths, hallways, and closets can accommodate ducts inside the envelope. Strategies include the following:

- Locate ducts within an insulated, non-vented, conditioned crawl space or basement

- Locate within an insulated "cathedralized" attic

- Locate in open-web floor trusses

- Develop chase walls to accommodate duct risers

- Design closets inside the conditioned space for locating the air handler in houses using slab on grade construction.

While the distribution system is important from an energy perspective, there are also health, safety, and indoor air quality issues to be considered. The following sections briefly discuss each, with recommended solutions.

Sealed Forced-Air Distribution Systems. Leaky duct systems, in addition to the energy losses introduced, may result in indoor-outdoor pressure imbalances that generate significant air leakage through the building envelope. For the $30 \%$ improvement house, extensive duct sealing is typically required. For metal ducts, UL 181-approved mastic is the only acceptable sealing method; for duct board, UL 181 tapes are accepted; and for flex duct, a combination of UL 181approved mastic and strap ties should be used. The targets for total duct leakage is $5 \%$ of the high-speed system-cooling airflow in CFM, as tested at 25-PA reference pressure. To further reduce duct leakage, do not pan joists or use stud cavities for supply or return air. It is virtually impossible to seal building cavities properly to achieve the target tightness for forced-air systems. 
Isolate the HVAC system from areas with potential pollutants. One of the most potentially hazardous IAQ problems arises when return ducts run through garage spaces where the opportunity exists to draw $\mathrm{CO}$ from automobile exhausts or other pollutants from hazardous chemicals often stored in the garage into the duct system and redistribute it throughout the house. Locating the HVAC unit in the garage is not recommended in the $30 \%$ improved houses, but it is not always possible to relocate the air-handling unit. If the air handler and return-air ducts must be located in the garage, any return-air ductwork and the air handler should be thoroughly sealed with UL 181-approved mastic, with a target leakage between the duct system and the garage of 0 CFM@25 PA. This yields the least possible opportunity for bringing garage air into the return system.

Pressure Balance the System. Pressure imbalances can cause air movement through the envelope when the HVAC system is operating, wasting energy and potentially causing moisture problems. Imbalanced airflows can also cause room-to-room or floor-to-floor temperature differences, leading to comfort complaints. Finally, imbalanced airflows can draw unwanted pollutants into the house, causing indoor air-quality problems. One key factor in eliminating room-room and indoor-outdoor pressure imbalances is the adequacy of the return air path. In homes with individual-room ducted returns, this is generally not a problem. Individual-room ducted return systems are historically typical in colder climates, but are losing favor because of their costs. From a cost-effectiveness standpoint, a well-designed central return system with individual room pressure relief is considered the standard for the 30\% improvement house. To qualify as well-designed, the return system must incorporate adequate relief from each room where entry doors may be closed. Thus, return air recommendations include the use of ceiling "jump ducts," or transfer grills located in the walls. Door under cuts are generally not considered to be acceptable because they are often inadequate in area and/or blocked by the installation of carpeting. One important consideration in the installation of "jump ducts" or transfer grilles is to maintain a satisfactory acoustic separation between spaces. This is typically accomplished by the use of flex duct, duct lining with sound-absorbent material, a slightly circuitous path, or some combination of these strategies to block sound transmission.

Supply-Air Register Selection and Placement. The distribution of the heating or cooling air stream from the supply register to the return point is critical to maintaining comfort conditions within the room. In the 30\% improvement house, envelope insulation, including window Uvalue and SHGC, and air sealing have been improved to such an extent that basic comfort needs are more easily met by the HVAC System. In particular, envelope surface temperatures are moderated to a considerable degree, which results in reduced radiant heat loss (or gain) to room occupants, improving comfort conditions. Similarly, solar gains through low-SHGC windows are reduced, considerably improving cooling season comfort conditions. With good air sealing, houses are much less drafty than those built to older construction standards.

All these reduced loads and improved comfort conditions mean room heating/cooling air volumes (at typical supply temperature) may be reduced. If typically sized registers are used, discharge velocities are reduced,and the air has less "throw" within the room. This is a new operating region for forced-air systems and presents a number of challenges to achieving a proper design for good comfort conditions.

In cooling-dominated climates, it has been typical to locate supply registers in the ceiling. This works well for cooling, but may present problems during heating periods. High sidewall and ceiling register placements have been used successfully in Building America projects. To attain 
optimal performance and comfort, it is critical to properly select registers based on throw characteristics and the volume of air being delivered to the room. This may require designing at the upper limits of recommended face velocities and the purchase of "non-standard" register sizes. It may also require the use of registers with manually operable vanes to fine tune airflow for optimal comfort.

In general, high-sidewall applications have been used where the register is directed at the wall of dominant heat loss or gain (usually the wall with windows or glass doors) and the register is no more that 12 to $13 \mathrm{ft}$ away. Ceiling diffusers with curved blades to help direct the airflow along the ceiling can be used where the wall opposite the dominant load exceeds $13 \mathrm{ft}$.

Research is currently underway in the Building America Program to understand the issues of air distribution in high-performances houses and to develop recommendations for supply and return apertures to achieve the best comfort conditions consistent with a highly energy-efficient system.

There are many issues to consider including the following:

- Register location and discharge pattern

- Discharge velocity

- Discharge temperature

- Effect of return location

- Stratification and mixing patterns

- Part-load operation, heating/cooling variation

- Impact of zoning systems

- Solar load variability

- Buoyancy issues

- Sound issues

- Register/nozzle configurations

- Register approach conditions - boots

- Dampening and control.

The recommendations that are developed from these ongoing investigations will enhance the current recommendations for houses achieving 30\% whole-house savings and will likely be critical for houses at the $40 \%$ and greater improvement levels.

Duct insulation. If ducts cannot be brought within conditioned spaced, supply ducts should be insulated to R-8 minimum and return ducts to R-4 minimum. Research by the Building America Team $\mathrm{CARB}^{48}$ has supported code credits for ducts in Hot-Dry and Mixed-Dry Climates that are buried in loose-fill attic insulation. This strategy should not be used in sections of this climate

${ }^{48}$ Dianne Griffiths et al. August 23, 2004. Insulation Buried Attic Ducts - Analysis and Field Evaluation Findings. American Council for Energy-Efficient Economy (ACEEE). 2004 ACEEE Summer Study on Energy Efficiency in Buildings. Pacific Grove, CA. 
zone with seasonally high levels of humidity with a corresponding need for cooling because condensation can form on the outside of the duct vapor barrier and cause moisture problems in the home. Similarly, it is critical to make sure all metal fittings are well insulated to avoid condensation.

\section{Mechanical, Electrical, and Plumbing Systems}

\section{Lighting}

Compact fluorescent lamps, smaller versions of standard fluorescent lamps, use $70 \%-75 \%$ less energy than their incandescent equivalents, and they have brightness and color rendition comparable to incandescent lights. They cost more, but last 10 to 13 times longer than incandescents, making them very cost effective if used at least 2-3 hours per day. A wide variety of sizes and shapes are available with varying color-spectrum characteristics. Consult your local lighting supplier/designer, and install them wherever practical.

The following are near-term energy-savings opportunities for new homes. In some cases, these involve newly commercialized products that are just now entering the market, while in other cases these represent systems show great promise but need further refinement and field-testing:

- High-quality, high-output residential grade CFL downlights for kitchens and hallways

- Linear fluorescent bathroom vanity strips (vertical and/or horizontally mounted)

- Bathroom occupancy sensors with integrated LED nightlight

- LED porch lighting

- LED exterior security luminaire

- High-output LED walkway lighting

- Evaluation of energy-savings potential from incandescent dimming.

Home Lighting Facts. Compact fluorescent lamp use 70\%-75\% less energy than their incandescent equivalents. When replacing a 100-watt incandescent lamp, a 28-watt CFL can be used. Here are some facts about CFLs:

- Compact fluorescents last approximately 10,000 hours, which is 10 to 13 times the life of an incandescent lamp (expected life approximately 750 hours).

- Compact fluorescents are most cost-effective when used at least 2-3 hours per day.

- Although compact fluorescent lamps may appear different than the common incandescent, they fit most standard fixtures found in homes today. The screw-in base is the same on both lamps.

- The typical incandescent lamp wastes $90 \%$ of the energy it uses, producing heat rather than light.

- The latest compact fluorescent lamps have improved color rendition. The light is a warm tone that is almost identical to that of an incandescent lamp. Most people can't tell the difference. 
Residential Lighting Controls. Residential lighting controls represents a significant opportunity for energy savings. Lighting controls generally refers to technologies that turn off (or turn down) lighting systems when they are not needed. Examples include occupancy sensors, photo sensors, dimmers, and timers.

Technologically, residential controls have improved greatly over the last several years, both in terms of the types of controls options available, as well as their quality and functionality. As the cost of these systems decrease because of increased demand for commercial applications, they become increasingly attractive for cost-effective residential applications.

Recognizing these technological and market advances, as well as the potential energy savings of these technologies, energy-code officials have begun to look more closely at residential lighting controls. The new 2005 Title 24 building code in California, which will go into effect on October 1, 2005, includes strong incentives for homebuilders to utilize occupancy sensors, photo sensors, and dimmers. In fact, many market watchers now anticipate that homebuilders will choose lighting control alternatives over energy-efficient luminaries to comply with this new code because the controls approaches are often more cost-effective.

\section{Major Appliances}

At the present time, the best practice recommendations for the $30 \%$ improvement house is to use ENERGY STAR-rated appliances. Within the ENERGY STAR-rated offerings, there are differences in performance levels, but these are probably not of significance at the $30 \%$ improvement level. It is also recommended that best-in-class appliance for non-ENERGY STAR-rated appliances be installed or recommended for purchase by the homeowner if not provided by the builder.

Program for Off-peak Operation. While not a mechanism for direct source energy reduction, peak-load shifting is a beneficial strategy from a consumer-utility cost perspective where time of use rates are in effect and can have electric utility system benefits by helping to reduce the need for peak power plants. The cost of energy consumption for appliances can be reduced by operating appliances during off-peak hours and refraining or minimizing their use, especially simultaneous use, during peak hours.

For example, using Whirlpool's energy management system for stand alone Time-of-Use (TOU) appliances delays the operation of the dishwasher, washing machine, and dryer can be delayed until the energy prices are lower (off-peak rate). An LED lets the consumer know if the rate is currently on- or off-peak. To delay until off-peak, the consumer can press a button and another LED illuminates to let them know that this appliance will start at a later time.

An alternative strategy is to minimize the amount of time that appliances are in the high-power mode by ensuring that the appliance is used in the lowest possible power mode when ever practical. $^{49}$

\footnotetext{
${ }^{49}$ International Energy Agency. 2001. Things That Go Blip in the Night: Standby Power and How to Limit it. www.iea.org/textbase/nppdf/free/2000/blipinthenight01.pdf.
} 


\section{Water Heating and Distribution Systems}

At the 30\% improvement level, energy use for hot water heating becomes a significant component of total energy use. Consequently, the following guidance has been developed for the design and installation of DHW Systems:

DHW heater sizing. The size of tank and first-hour draw pattern can have an impact on the overall energy consumption associated with hot water. Tank size is a function of first-hour rating, draw patterns, and incoming and outgoing water temperatures. The sizing method described below, takes into account the nominal population of a house, the main supply water temperature, and the efficiency of the DHW heating equipment.

Sizing Method for Tank-Type DHW Heater. Use this procedure for sizing tank-type domestic hot water heaters (Figure 19).

- Establish the design population of the house by taking the number of bedrooms +1 .

- Multiply this by the gallons/person for the climate zone where the house is located to get the first-hour rating for the water heater.

- Using the first-hour rating from Step 2, select a DHW heater that meets or exceeds this rating.

- For a tank-type gas heater, select a heater with an energy factor greater than 0.60. For a tanktype electric heater, select a heater that meets the current NAECA standard.

Heater Selection. The efficiency target for fuel-fired tank-type gas DHW heaters is 0.60 EF or higher. With the tight house construction of the 30\% improvement level, these heaters should be either power vented (which forcibly discharges the products of combustion and draws combustion air from the house), direct vent with dedicated outside air for combustion, or sealedcombustion units that draw combustion air from outdoors and fan discharge combustion gasses outdoors. If electricity is used for heating water, a high-efficiency tank or tankless unit should be used. 


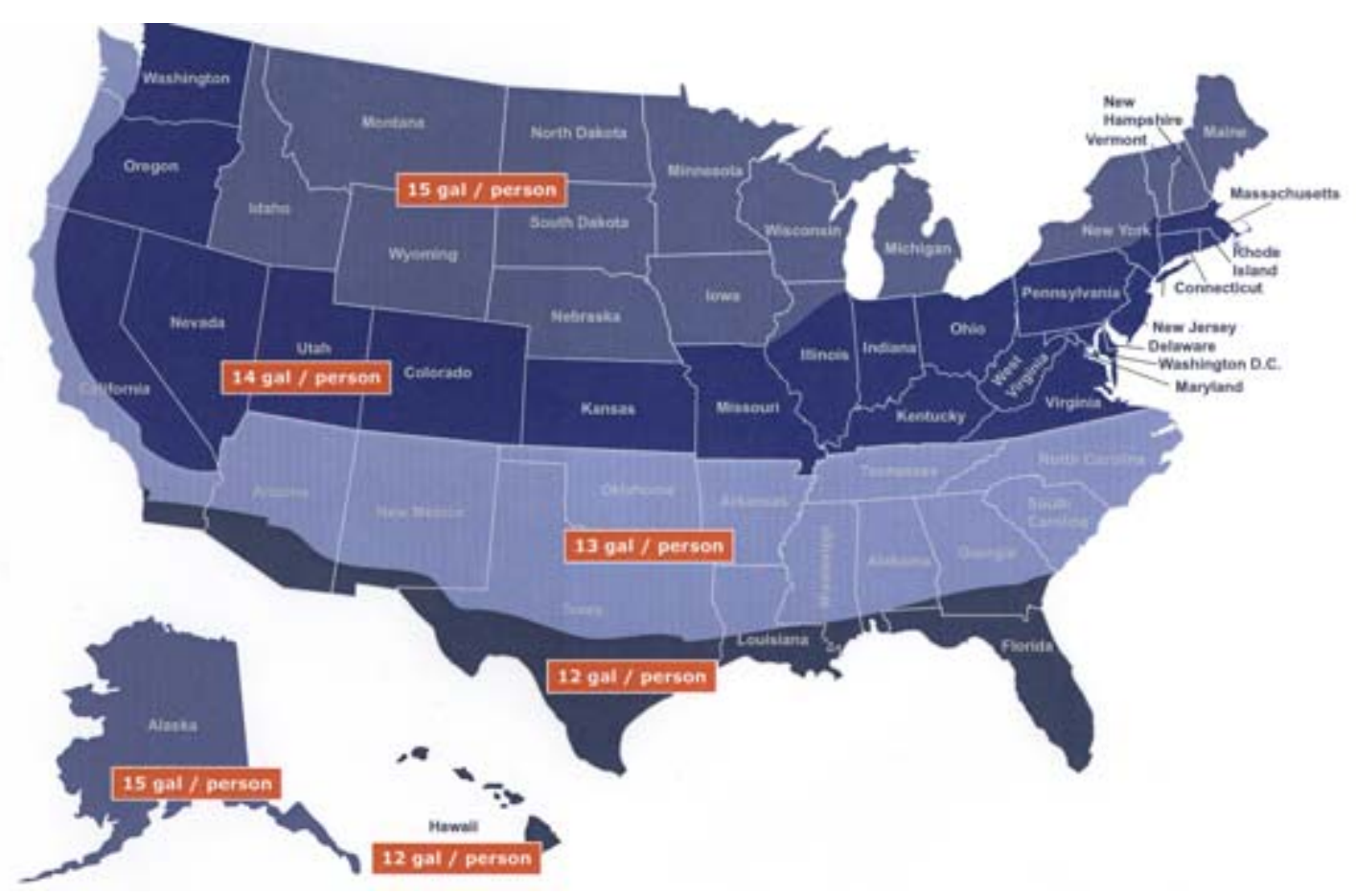

Figure 19. Domestic hot water tank sizing for $135^{\circ} \mathrm{F}$ tank temperature only

Tankless water heaters (about $0.84 \mathrm{EF)} \mathrm{can} \mathrm{provide} \mathrm{significant} \mathrm{advantages} \mathrm{over} \mathrm{the} \mathrm{traditional}$ storage tank water heaters for a number of reasons:

- Energy savings: Tankless water heaters have a higher energy factor compared to tank water heaters and are, therefore, a more energy-efficient option.

- Space savings: Tankless water heaters are dimensionally smaller and save space compared to storage tank water heater. This allows for installation in spaces with limited area or in locations closer to the point of use.

- Longer life expectancy and favorable life cycle costs: The tankless water heater has a life expectancy of 15 to 20 years compared to a typical 9 years for storage-tank water heaters. When the replacement of a tank water heater is combined with the lower operating costs, the life-cycle costs of a tankless water heater are generally lower than a tank-type water heater.

Some builders have chosen to install multiple gas-fired tankless units, which may require upsizing of the main gas service when coupled with other gas end-uses in the house (furnace, cooking appliances, dryer, etc.) This could be a significant barrier to widespread adoption, especially in areas with low gas pressures. By installing multiple units, builders are safeguarding against a call from homeowners that there isn't enough hot water, but may be overcompensating because of lack of experience with the tankless gas-fired technology.

Tank-type heaters offer the best efficiency with relatively steady, continuous-use patterns. If electricity is the energy source for water heating, additional improvements to other areas of the house will likely be needed to achieve the $30 \%$ savings levels, because there is very little room for improvement in electric water-heating efficiency compared to the possible efficiency gains using gas-fired technologies. 
Stand-alone electric heat-pump water heaters offer better efficiency than electric resistance heaters, but they are complex, costly, and still evolving as a standard commercial product. They provide the best efficiency when their cold-air discharge can be used to augment home air conditions, which can be a benefit in cooling-dominated climates. Conversely, they can contribute to an additional heating load during the winter. Optimizing these relationships along with this performance variation as a result of supply-water temperature and load pattern is quite challenging. Primarily because of the early state of technology deployment and reliability, stand-alone heat-pump water heaters are not considered a practical choice at the $30 \%$ level. Should these units improve in reliability, and if volume manufacturing brings costs down, then they would be worth considering as part of the overall package.

If a ground-source heat pump is chosen for space heating and cooling, it is possible to use it to generate hot water, either through a desuperheater on the basic water-to-air heat pump or by using a water-to-water system where the heat pump can generate heated or chilled water to be used for space conditioning and domestic hot water. These systems can be effective, but the pricing varies dramatically by region and can be more complex than a traditional gas furnace with DX air-conditioning systems. In an area where no natural gas is available, this system is an option in all climate zones; however, it requires a skilled and experienced installer base and favorable pricing.

While not necessarily required to achieve the $30 \%$ whole-house energy-savings target, there are a number of reliable solar DHW heaters in the market. They represent a range of operating philosophies:

- Storage/non-storage

- Freeze-protected/drain-back

- Passive thermosystem/pumped cycle, etc.

With good design, these solar systems can all be effective sources of hot water, particularly in sunny climates. What most degrades the performance of solar DHW systems are the details of design, construction, operation, and maintenance. Research has found that simple set of characteristics, such as long pipe run from the collector plate combined with a short, infrequent usage pattern, can render the solar contributions nearly negligible. Primarily because of their high cost, solar DHW systems are not considered practical at the 30\% improvement level.

Hot Water Distribution Systems. The hot water distribution system plays a surprisingly important role in the total energy efficiency of the DHW system. Thermal losses from the hot water distribution piping system while water is flowing and the losses associated with "stranded" hot water as it cools down once faucets are turned off can amount to a very substantial portion of total hot water energy use. Thus, guidance on the configuration of the system, its insulation, and patterns of use can help reduce the piping system component of DHW energy use.

Basic guidance on the layout of DHW piping suggests that the DHW source and major use points be as close to each other as practical. A good example of this would be the location of the DHW heater in a closet adjacent to the kitchen and laundry that are back-to-back. Short lines will minimize "stranded" losses, which can be considered detrimental during the cooling season. Locating tankless water heaters immediately adjacent to high-use clusters, such as a pair of bathrooms in a remote wing or a second floor, is an excellent way to reduce piping heat losses. 
All DHW supply piping should be insulated with standard R-4 pipe insulation. It is readily available, inexpensive, and effective. This includes any hot water lines located in concrete slabs or underground. Increasing tank insulation to a minimum of R-12 by adding a tank insulation wrap can also reduce energy consumption.

Research has also shown that "parallel piped" or "homerun" plumbing systems using PEX piping and a central manifold can reduce energy consumption compared to traditional copper "tree and branch" plumbing systems. ${ }^{50}$

To avoid the waste of water as one "waits for the hot water to arrive" and to provide instantaneous hot water, there is growing use of recirculation systems that continuously circulate hot water through the entire system. This continuous circulation of hot water results in high loss of heat from the piping system, even if insulated, and is strongly discouraged in an energyefficient house of any type.

If a recirculation system must be installed, a push-button type on-demand re-circulator will minimize the energy penalty associated with recirculation systems. The system circulates the water only when the hot water is needed. It is, thus, more energy efficient than the continuous recirculation system. The on-demand circulating pump briefly moves water out of the hot water pipe and back to the DHW heater down the cold water pipe until hot water is sensed at the faucet. This system eliminates the waste of water down the drain.

The on-demand circulator is primarily useful for use points that are a long way from the DHW source and represent a substantial water waste while waiting for the hot water to "arrive."

\section{Onsite Power Systems}

A number of on-site power production systems are currently available for Building America projects and others are in the research stage. Most have been used in Building America projects. These systems include the following:

- Photovoltaics

- Engine generator/combo systems

- Fuel cells.

The 30\% improvement level can be achieved most cost effectively through the improvement of the envelope; the heating, cooling, and domestic hot water systems; and possibly the application of some lighting and appliance improvements. On-site power systems are very costly and are not recommended as a strategy to achieve the $30 \%$ savings level.

\section{Cost Analysis}

\section{Life-cycle Cost Analysis}

From a purely economic point of view, building energy optimization involves finding the global optimum that balances investments in efficiency versus utility bill savings. However, there are

\footnotetext{
${ }^{50}$ NAHB Research Center, Inc. November 2002. Performance Comparison of Residential Hot Water Systems. Upper Marlboro, MD: NAHB Research Center, Inc.
} 
sometimes non-economic reasons for targeting a particular level of energy savings. Given a particular energy-savings target, economic optimization can be used to determine the optimal design (lowest cost) to achieve the energy-savings goal. The analysis presented below targets $30 \%-39 \%$ whole-house energy savings with respect to the Benchmark by using the BEopt analysis method to investigate cost tradeoffs associated with various residential energy efficiency and renewable energy technology options.

Building Characteristics Considered in This Study. For the Prototype building, a two-story $3,000-\mathrm{ft}^{2}$ and a single-story $1,500-\mathrm{ft}^{2}$ residential building were used for this study, with the front of the buildings facing east. While complex floor plan geometries can be analyzed, a simple square floor plan was implemented for the purposes of the current analysis. The buildings were modeled with a slab-on-grade foundation type. Both buildings were assumed to have three bedrooms and two bathrooms. The both buildings had 1-ft eaves. Window area was assumed to be $18 \%$ of floor area with $50 \%$ of the window area facing west, $25 \%$ of the window area facing east, $12.5 \%$ of the window area facing north, and $12.5 \%$ of the window area facing south. The non-uniform window distribution was utilized to represent a possible "worst case" window distribution from the available window distribution options currently included in the BEopt analysis method.. The energy options considered in the study include space-conditioning systems (up to SEER 18 and 92.5\% AFUE in the current study), envelope systems, hot water systems, lighting systems, major appliances, and residential PV. The buildings use natural gas for the following end uses: cooking, water heating, and clothes drying. No options that would potentially reduce miscellaneous electric loads other than major appliances were included in the study. For the Phoenix example cases, air-conditioner capacities less than 1.5 tons were not considered nor were furnace capacities less than $50 \mathrm{kBtu} / \mathrm{hr}$. SEER10 air-conditioning equipment was included in this analysis for discussion purposes; however, after January 1, 2006, Federal minimum equipment efficiencies will mandate the use of SEER13 air conditioners.

Occupancy/Operational Assumptions. Occupancy and operational assumptions are as defined in the Benchmark and include time-of-day profiles for occupancy, appliance and plug loads, lighting, domestic hot water use, ventilation, and thermostat settings.

Base-Case Building. Results are calculated relative to the Benchmark, which defines baseline features. These features include wall, ceiling, and foundation insulation levels and framing factors; window areas; U-values and solar heat gain factors; interior shading; overhangs; air infiltration rates; duct characteristics; and heating, cooling, and domestic hot water system efficiencies.

Cost Assumptions. Each option has an assumed first-cost and lifetime (Appendix B). Costs are retail and include national average estimated costs for hardware, installation labor, overhead, and profit. Some are input as unit costs that are then multiplied by a category constant (e.g., ceiling insulation costs are input per square foot and multiplied by ceiling area by BEopt). Some inputs are energy-option specific (e.g., cost of solar water heating systems). Inputs can also be based on total costs (e.g., cost of wall constructions with different insulation values) because BEopt will calculate the differences between option costs. 
Construction costs (wall insulation, ceiling insulation, foundation insulation, etc.) are typically based on R.S. Means ${ }^{51}$ cost estimates. Window and HVAC costs are based on quotes from manufacturers' distributors. Appliance costs are based on manufacturers' suggested retail prices.

Building construction options (wall insulation, ceiling insulation, foundation insulation, windows, etc.) are assumed to have 30-year lifetimes. Equipment and appliance options typically have 10- or 15-year lifetimes. Lifetimes for lighting options (incandescent and compact fluorescent lamps) are modeled based on cumulative hours of use.

Utility costs are assumed to escalate at the rate of inflation (i.e., to be constant in real terms). The mortgage interest rate is $5 \%$ above the rate of inflation. The onsite power option used for this study was a residential PV system with an installed cost of $\$ 7.50$ per peak Watt DC, including present value of future operation and maintenance costs. This cost is assumed to be independent of PV system size. Additional costs associated with mounting large PV arrays were not considered. For Phoenix, natural gas is assumed to cost $\$ 0.7986 /$ Therm, and the cost of electricity was modeled as $\$ 0.0778 / \mathrm{kWh}$.

Simulation Limitations. There are benefits that are not considered by the BEopt analysis method that will have an influence on the real-world design of a home, such as reduction in warrantee and liability exposure, increased customer satisfaction, and higher quality construction practices. The BEopt analysis method does not consider concerns with regard to indoor air quality, mold, and combustion safety. In a real-world design, these factors may lead the designer, engineer, builder, or architect to use equipment or construction practices that increase first cost without reducing utility bills in order to provide better indoor air quality, combustion safety, occupant comfort, or other design considerations that have high value to the builder or potential homebuyer. There are also some side effects that the simulations are not equipped to deal with, such as the costs of change in a builder's organization necessary to implement energyefficient design approaches, the costs of moving a trade base to a different place, or termination of long-term relationships with a trade because the trade would not adopt energy-efficient practices. There is currently no methodology available to account for these effects in the simulation. Further development of a methodology to account for these effects and collection of appropriate data to inform the simulation would be necessary if there is interest in considering these effects.

The BEopt analysis method is relatively new to the Building America program, the case studies included in the Building America Systems Research Results section were not initially simulated with BEopt nor was BEopt used to guide the design process of the case study homes included in the Building America Systems Research Results section. The case studies are the result of years of field experience and design work done by Building America teams. Currently, this analysis method is being used for general programmatic guidance in an effort to understand at what cost and performance specifications efficiency and renewable technologies begin to look attractive when compared to other efficiency and renewable technologies. In its current form, the BEopt analysis method is useful for programmatic studies in terms of weighing the merits of certain efficiency and renewable technologies versus standard construction practices or other technologies using national average cost data, retail cost data, or projected costs for emerging technologies; however, cost of these technologies may be very different on a production-scale or

\footnotetext{
${ }^{51}$ Residential Cost Data $-18^{\text {th }}$ Annual Edition. 1999. Kingston, MA: R.S. Means, Company, Inc.
} 
custom-builde-scale, and the results shown here should not be taken as representative of all builders in this climate region.

As an example of what building efficiency options would lead to a combination of options that would achieve 30-39\% whole-house energy efficiency relative to the Benchmark, an optimization was performed with the Phoenix TMY2 $2^{52}$ weather file. Figure 20 shows the 35\% whole-house energy efficiency point that falls on the cost optimal curve for Phoenix.

${ }^{52}$ Typical Meteorological Year weather data, http://rredc.nrel.gov/solar/old_data/nsrdb/tmy2/ 


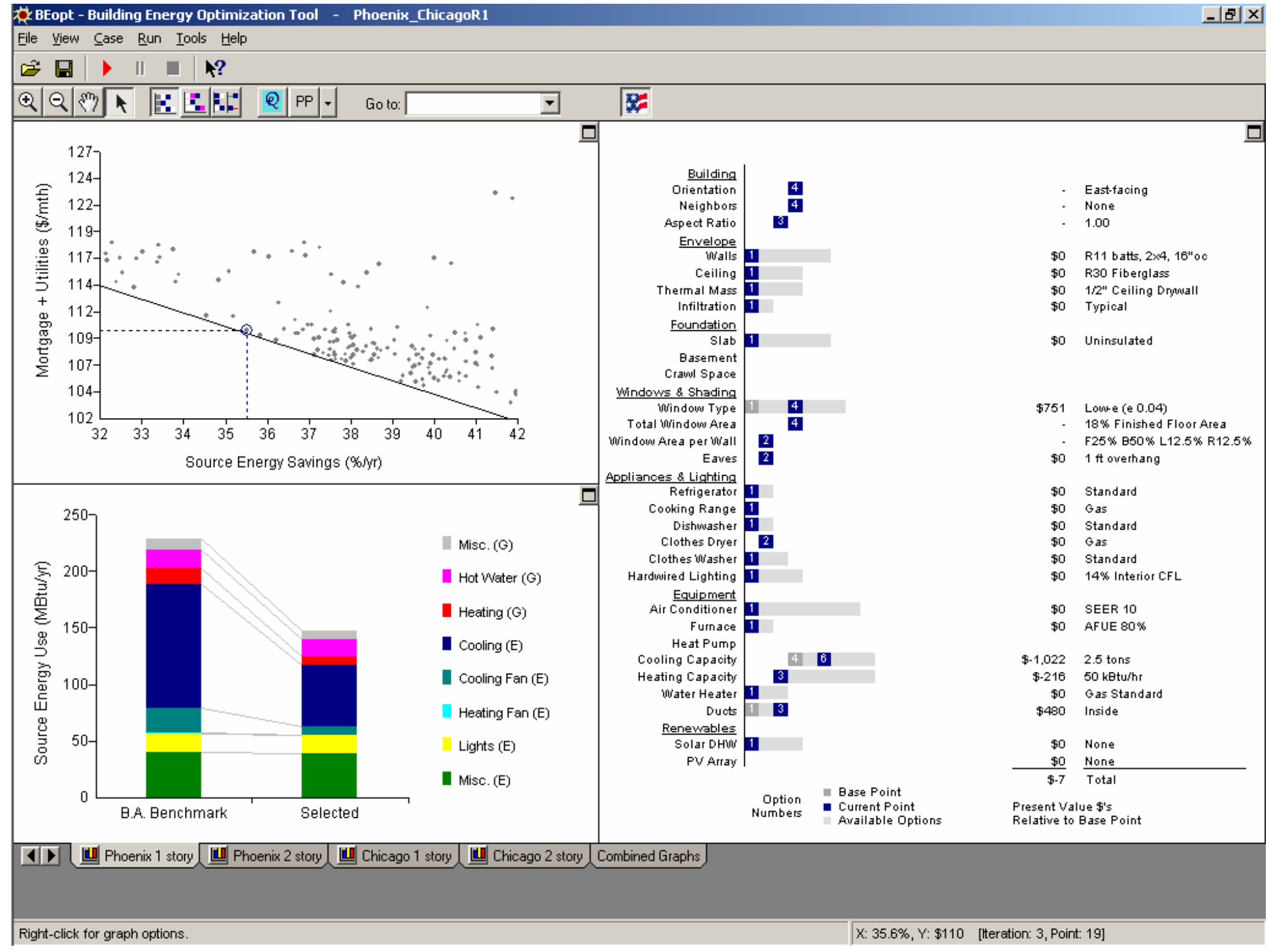

Figure 20. The $35 \%$ point for a single-story Phoenix example case 
Based on the costs assumed as shown in Appendix B and within the limitations of the analysis method and the previously mentioned assumptions, the options selected in Figure 21 would represent a possible least-cost combination for 35\% whole-house energy savings for a singlestory residence in Phoenix, Arizona. Because costs may vary significantly across the Hot-Dry /Mixed-Dry Climate region, from builder to builder, and over time, the above is only an example that may not reflect the actual least-cost set of options that would apply to a specific home, builder and location.

At the high end of the whole-house energy-performance range considered here $-39 \%$ wholehouse energy savings - the total monthly cost is slightly lower than the $35 \%$ example. Figure 21 shows an example combination that meets $39 \%$ whole-house energy savings compared to the $35 \%$ combination. 


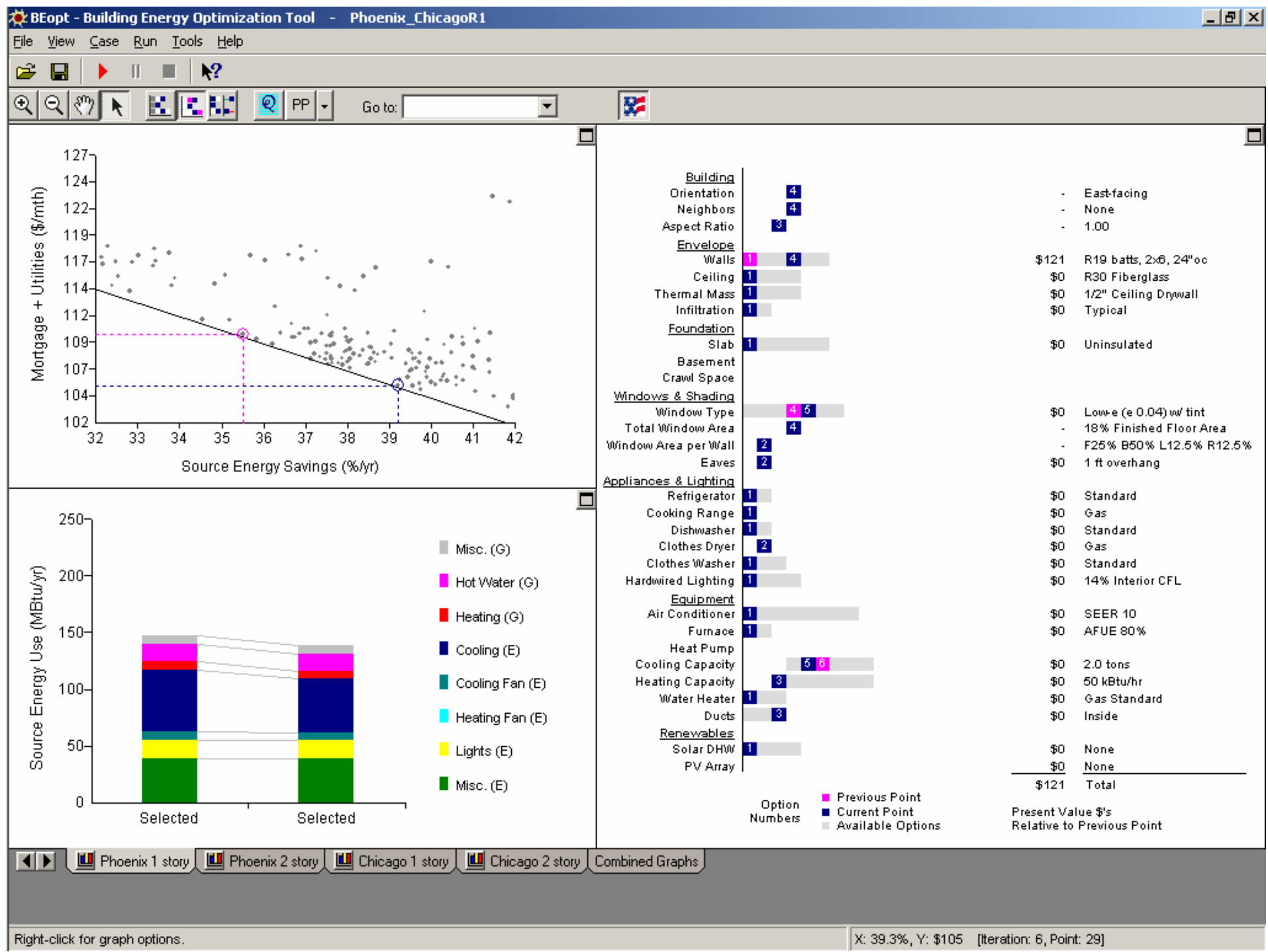

Figure $21 .^{53}$ Comparison of $39 \%$ point to $30 \%$ point, one-story Phoenix example case

\footnotetext{
${ }^{53}$ Note that costs shown in this figure are incremental relative to the $30 \%$ energy-savings point (shown in magenta)
} 
The comparison of the $35 \%$ combination (represented in magenta) to the $39 \%$ combination (blue only) shown in Figure 22 demonstrates that by using additional exterior wall insulation and a lower-SHGC, low-e glass, the 39\% combination is less expensive in terms of total cost per month than the $35 \%$ single-story example. There are some savings associated with the downsizing of the cooling equipment as a result of the envelope improvements.

Figures 22 and 23 look at the same points for the two-story case.

The comparison of the $35 \%$ combination (represented in magenta) to the $39 \%$ combination (blue only) shown in Figure 23 demonstrates that by utilizing a SEER-14 air conditioner, the 39\% combination is not only more efficient but costs less per month than the $35 \%$ two-story example. A more specific comparison of the features of the $35 \%$ and $39 \%$ examples are shown in Table 7 for single- and two-story cases.

Table 7 shows some differences in the options selected between the one- and two-story cases for the energy-savings levels and points selected. The differences between one- and two-story examples at the $35 \%$ and $39 \%$ energy-savings level are limited to exterior wall construction, glazing types, and air-conditioner SEER rating. Within the limitations of the economic model included in the BEopt analysis method, the above example cases would represent a reduction in total monthly cost (mortgage cost - utility cost) when compared to the neutral cost line shown in Figure 6. 


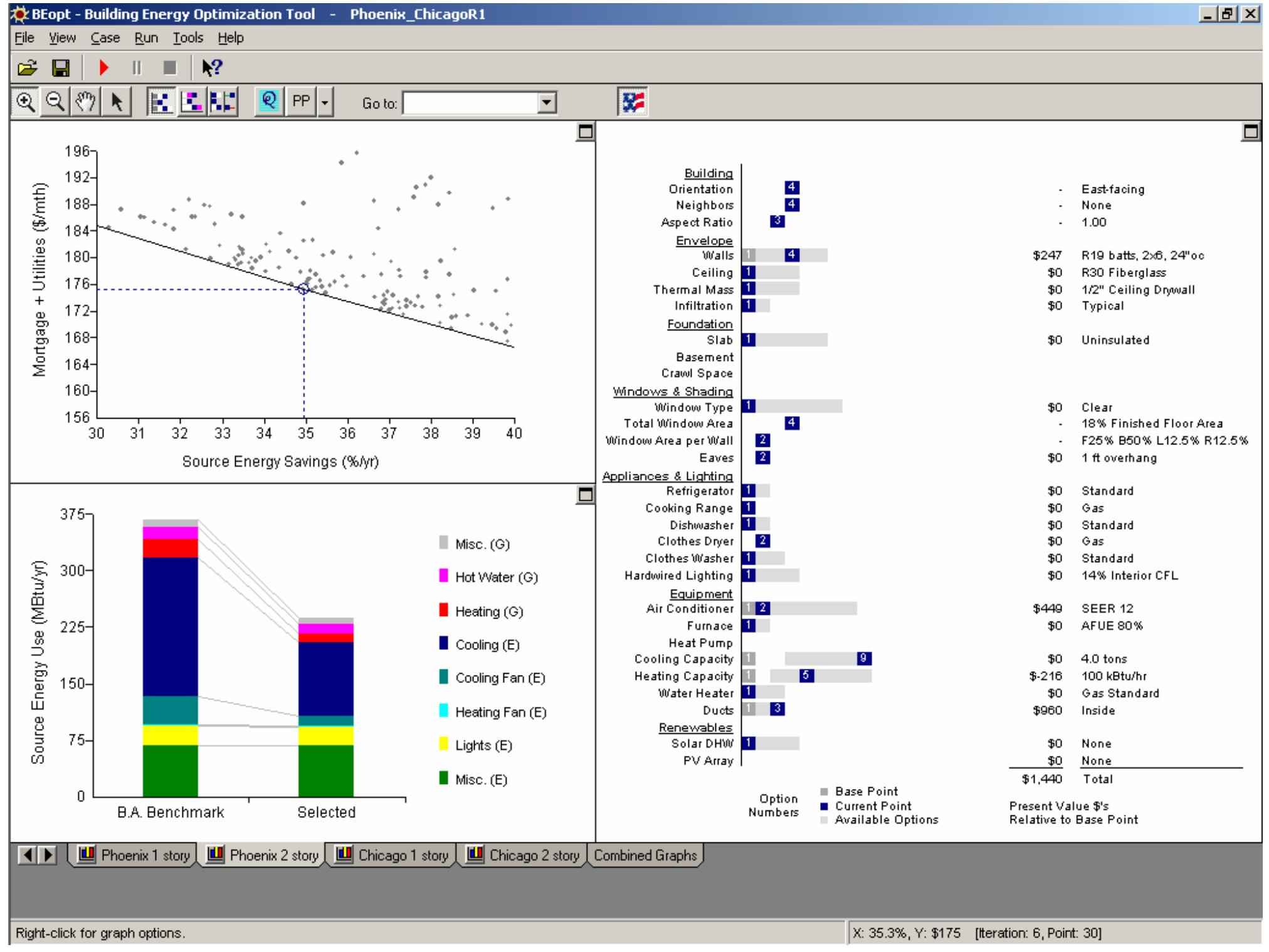

Figure 22. The $35 \%$ point for two-story Phoenix example case 


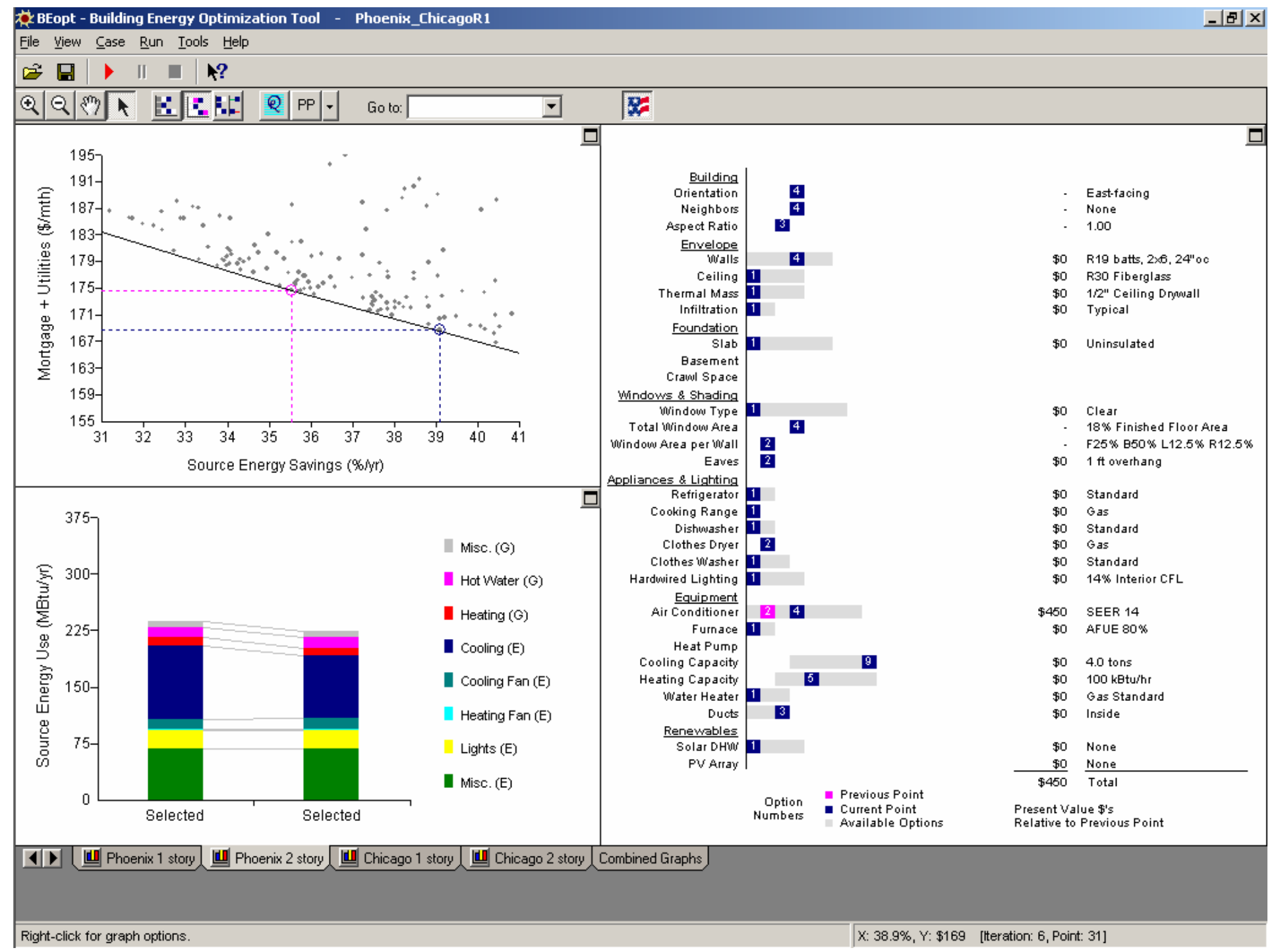

Figure $23 .{ }^{54}$ Comparison of $39 \%$ point to $35 \%$ point, two-story Phoenix example case

\footnotetext{
${ }^{54}$ Note that costs shown are incremental relative to the $30 \%$ energy-savings point.
} 
Table 7. Comparison of Single- and Two-Story Example Cases

\begin{tabular}{|c|c|c|c|c|}
\hline CATEGORY & \multicolumn{2}{|c|}{$35 \%$ EXAMPLE } & \multicolumn{2}{|c|}{$39 \%$ EXAMPLE } \\
\hline Number of Floors & One Story & Two Stories & One Story & Two Stories \\
\hline Walls & $\mathrm{R}-11,2 \times 4,16$ in. oc & R-19, 2x6, 24 in. oc & R-19, 2x6, 24 in. oc & R-19, 2x6, 24 in. oc \\
\hline Ceiling & R-30 fiberglass & R-30 fiberglass & R-30 fiberglass & R-30 fiberglass \\
\hline Thermal Mass & $1 / 2$-in. ceiling drywall & $1 / 2$-in. ceiling drywall & $1 / 2$-in. ceiling drywall & $1 / 2$-in. ceiling drywall \\
\hline Infiltration & SLA $=0.0005$ & SLA $=0.0005$ & SLA $=0.0005$ & SLA $=0.0005$ \\
\hline Basement & Uninsulated & Uninsulated & Uninsulated & Uninsulated \\
\hline Glass Type & $\begin{array}{l}\text { Two-pane, Low-e, } U=0.3 \text {, } \\
\text { SHGC = } 0.44 \text { center of glass, } \\
\text { insulated spacer, vinyl frame }\end{array}$ & $\begin{array}{l}\text { Two-pane clear, } U=0.49 \text {, } \\
\text { SHGC = } 0.76 \text { center of glass, } \\
\text { insulated spacer, vinyl frame }\end{array}$ & $\begin{array}{l}\text { Two-pane, Low-e, } \\
U=0.29, \text { SHGC = } 0.29 \text { center } \\
\text { of glass, insulated spacer, vinyl } \\
\text { frame }\end{array}$ & $\begin{array}{l}\text { Two-pane clear, } U=0.49 \text {, } \\
\text { SHGC = } 0.76 \text { center of glass, } \\
\text { insulated spacer, vinyl frame }\end{array}$ \\
\hline $\begin{array}{l}\text { Window Area per } \\
\text { Wall }\end{array}$ & $\begin{array}{l}270 \mathrm{ft}^{2}, 12.5 \% \mathrm{~N} \& \mathrm{~S}, 50 \% \mathrm{~W}, \\
25 \% \mathrm{E}\end{array}$ & $\begin{array}{l}540 \mathrm{ft}^{2}, 12.5 \% \mathrm{~N} \& \mathrm{~S}, 50 \% \mathrm{~W}, \\
25 \% \mathrm{E}\end{array}$ & $\begin{array}{l}270 \mathrm{ft}^{2}, 12.5 \% \mathrm{~N} \& S \\
50 \% \mathrm{~W}, 25 \% \mathrm{E}\end{array}$ & $\begin{array}{l}540 \mathrm{ft}^{2}, 12.5 \% \mathrm{~N} \& \mathrm{~S} \\
50 \% \mathrm{~W}, 25 \% \mathrm{E}\end{array}$ \\
\hline Refrigerator & Standard: 671 kWh/yr & $671 \mathrm{kWh} / \mathrm{yr}$ & Standard - $671 \mathrm{kWh} / \mathrm{yr}$ & $671 \mathrm{kWh} / \mathrm{yr}$ \\
\hline Cooking Range & 45 Therms/yr & 45 Therms/yr & 45 Therms/yr & 45 Therms/yr \\
\hline Dishwasher & $\begin{array}{l}\text { Standard, } 462 \mathrm{kWh} \text {, eight } \\
\text { place-setting capacity, } \\
131.6 \mathrm{kWh} / \mathrm{yr} \text { machine energy, } \\
\text { 5.39-gal/day DHW }\end{array}$ & $\begin{array}{l}\text { Standard, } 462 \mathrm{kWh} \text {, eight } \\
\text { place-setting capacity, } \\
131.6 \mathrm{kWh} / \mathrm{yr} \text { machine } \\
\text { energy, 5.39-gal/day DHW }\end{array}$ & $\begin{array}{l}\text { Standard, } 462 \mathrm{kWh} \text {, eight- } \\
\text { place setting capacity, } \\
131.6 \mathrm{kWh} / \mathrm{yr} \text { machine energy, } \\
\text { 5.39-gal/day DHW }\end{array}$ & $\begin{array}{l}\text { Standard, } 462 \mathrm{kWh}, 8 \text { place } \\
\text { setting capacity, } 131.6 \mathrm{kWh} / \mathrm{yr} \\
\text { machine energy, 5.39-gal/day } \\
\text { DHW }\end{array}$ \\
\hline Clothes Dryer & $\begin{array}{l}\text { Gas: } 5.7 \mathrm{ft}^{3}, 2.75 \mathrm{EF} \text {, } \\
70.1 \mathrm{kWh} / \mathrm{yr}, 31.8 \text { therms/yr }\end{array}$ & $\begin{array}{l}\text { Gas: } 5.7 \mathrm{ft}^{3}, 2.75 \mathrm{EF} \\
70.1 \mathrm{kWh} / \mathrm{yr}, 31.8 \text { therms/yr }\end{array}$ & $\begin{array}{l}\text { Gas: } 5.7 \mathrm{ft}^{3}, 2.75 \mathrm{EF} \text {, } \\
70.1 \mathrm{kWh} / \mathrm{yr}, 31.8 \text { therms/yr }\end{array}$ & $\begin{array}{l}\text { Gas: } 5.7 \mathrm{ft}^{3}, 2.75 \mathrm{EF}, 70.1 \\
\mathrm{kWh} / \mathrm{yr} \text {, } \\
31.8 \text { therms/yr }\end{array}$ \\
\hline Clothes Washer & $\begin{array}{l}\text { Standard, } 3.15 \mathrm{ft}^{3}, 533 \mathrm{kWh} / \mathrm{yr}, \\
1.16 \mathrm{MEF}, 65.6 \mathrm{kWh} / \mathrm{yr} \\
\text { machine energy, } \\
4.63 \mathrm{gal} / \text { day DHW }\end{array}$ & $\begin{array}{l}\text { Standard, } 3.15 \text { cuft, } \\
533 \mathrm{kWh} / \mathrm{yr}, 1.16 \mathrm{MEF}, \\
65.6 \mathrm{kWh} / \mathrm{yr} \text { machine energy, } \\
4.63 \mathrm{gal} / \mathrm{day} \mathrm{DHW}\end{array}$ & $\begin{array}{l}\text { Standard, } 3.15 \mathrm{ft}^{3}, \\
533 \mathrm{kWh} / \mathrm{yr}, 1.16 \mathrm{MEF}, \\
65.6 \mathrm{kWh} / \mathrm{yr} \text { machine energy, } \\
4.63-\mathrm{gal} / \mathrm{day} \mathrm{DHW}\end{array}$ & $\begin{array}{l}\text { Standard, } 3.15 \mathrm{ft}^{3} \text {, } \\
533 \mathrm{kWh} / \mathrm{yr}, 1.16 \mathrm{MEF} \text {, } \\
65.6 \mathrm{kWh} / \mathrm{yr} \text { machine energy, } \\
\text { 4.63-gal/day DHW }\end{array}$ \\
\hline Lighting & $\begin{array}{l}14 \% \text { CFL, } 1574 \mathrm{kWh} / \mathrm{yr} \\
\text { Hardwired, } 331 \mathrm{kWh} / \mathrm{yr} \text { Plug in }\end{array}$ & $\begin{array}{l}\text { 14\% CFL, 2534-kWh/yr } \\
\text { Hardwired, } 571 \mathrm{kWh} / \mathrm{yr} \text { Plug } \\
\text { in }\end{array}$ & $\begin{array}{l}14 \% \text { CFL, } 1574 \text { kWh/yr } \\
\text { Hardwired, } 331 \mathrm{kWh} / \mathrm{yr} \text { Plug in }\end{array}$ & $\begin{array}{l}\text { 14\% CFL, } 2534 \text { kWh/yr } \\
\text { Hardwired, } 571 \text { kWh/yr Plug in }\end{array}$ \\
\hline Air Conditioner & $\begin{array}{l}\text { SEER 10, } 2.5 \text { Tons, } \\
0.365 \text { W/CFM AH Fan }\end{array}$ & $\begin{array}{l}\text { SEER 12, } 4 \text { Tons, } \\
0.365-W / C F M ~ A H ~ F a n\end{array}$ & $\begin{array}{l}\text { SEER 10, } 2 \text { Tons, } \\
0.365 \text { W/CFM AH Fan }\end{array}$ & $\begin{array}{l}\text { SEER 14, } 4 \text { Tons, } 0.383 \\
\text { W/CFM AH Fan }\end{array}$ \\
\hline Furnace & $80 \%$ AFUE, $50 \mathrm{kBtu} / \mathrm{hr}$ & $80 \%$ AFUE, $100 \mathrm{kBtu} / \mathrm{hr}$ & $80 \%$ AFUE, $50 \mathrm{kBtu} / \mathrm{hr}$ & $80 \%$ AFUE, $100 \mathrm{kBtu} / \mathrm{hr}$ \\
\hline Ducts & $\begin{array}{l}\text { Inside Conditioned Space, } \\
\text { SA leakage }=1 \% \text {, } \\
\text { OA leakage }=0.23 \% \text { of fan } \\
\text { flow }\end{array}$ & $\begin{array}{l}\text { Inside Conditioned Space, } \\
\text { SA leakage }=1 \% \\
\text { OA leakage }=0.23 \% \text { of fan flow }\end{array}$ & $\begin{array}{l}\text { Inside Conditioned Space, SA } \\
\text { leakage }=1 \% \text {, OA leakage }= \\
0.23 \% \text { of fan flow }\end{array}$ & $\begin{array}{l}\text { Inside Conditioned Space, SA } \\
\text { leakage }=1 \% \text {, OA leakage = } \\
0.23 \% \text { of fan flow }\end{array}$ \\
\hline Water Heater & $\begin{array}{l}\text { Gas Standard, } 40 \text { gallons, } \\
0.55 \mathrm{EF}, 0.76 \mathrm{RE}\end{array}$ & $\begin{array}{l}\text { Gas Standard, } 40 \text { gallons, } \\
0.55 \mathrm{EF}, 0.76 \mathrm{RE}\end{array}$ & $\begin{array}{l}\text { Gas Standard, } 40 \text { gallons, } 0.55 \\
\text { EF, 0.76RE }\end{array}$ & $\begin{array}{l}\text { Gas Standard, } 40 \text { gallons, } \\
0.55 \mathrm{EF}, 0.76 \mathrm{RE}\end{array}$ \\
\hline
\end{tabular}




\section{First-Cost Impacts}

For all of the $30 \%$ energy-savings level example cases, first costs are increased. Many builders are reluctant to design first-cost increases into their standard products. To many potential homebuyers, the first cost of a home can make or break a home sale. To address first-cost concerns associated with energy-efficient home designs, some builders have implemented guaranteed energy-bill programs that may influence some potential homebuyers, such that they would be more willing to absorb the additional first cost into a 30-year mortgage knowing that their monthly cash flow will ultimately be reduced when the utility bill is considered.

Builders who guarantee their homes are willing to tell buyers how much energy the home should use, and they guarantee these levels will not be exceeded. These guarantees are backed up with payments if limits are exceeded. Builders can work with insulation companies or other partners to offer guarantees or caps on their home's energy costs, or they may develop their own programs. Some cover room comfort by guaranteeing that the temperature at the thermostat will not vary by more than 3 degrees at the center of any room served by that thermostat. A Building America team helped to develop these programs.

Information on three of these programs can be found at:

○ Environments for Living - www.eflhome.com/index.jsp

$\circ$ Engineered for Life - www.us-gf.com/engineered.asp

○ The Energy Use and Comfort Guarantee -www.artistichomessw.com/guarantee.htm." ${ }^{, 55}$

In some cases, homebuyers may be eligible for energy-efficient mortgages that allow potential home buyers to qualify for larger loans to compensate for additional first costs associated with energy-efficient options that are designed into a home. The Armory Park Del Sol in Tuscon, Arizona, case study featured later in this report is an example of a guaranteed energy bill program.

The following features for energy-efficient loans are taken from Fannie Mae, the nation's largest source of funding for mortgages. You can learn more about Fannie Mae at www.fanniemae.com.

o Energy-efficient mortgages (EEM) are available for both purchase and refinance in conjunction with most Fannie Mae first-mortgage products, including conventional fixed-rate and adjustable-rate mortgages.

o Monthly savings resulting from energy efficiency can be used to qualify borrowers for a larger mortgage. This means consumers can buy more home in the form of energy efficiency or other upgrades.

O The EEM can be used with many Fannie Mae mortgage products. The guidelines of the selected Fannie Mae mortgage apply, with the EEM allowing for the projected energy

\footnotetext{
${ }^{55}$ Building America Best Practices Volume 2, Builders and Buyers Handbook for Improving New Home Efficiency, Comfort, and Durability in the Hot-Dry and Mixed Dry Climates, September 2005, NREL/TP-550-36360, Page HOM-5.
} 
savings to provide an adjustment to the loan-to-value and qualifying ratios that favor the borrower." 56

Table 8 shows that the first cost associated with the 39\% example case are larger than the first cost associated with the $35 \%$ example case. The first-cost increase (relative to the $35 \%$ example) is a result of the use of a SEER-14 air conditioner. At a 7\% mortgage interest rate, an additional $\$ 1,738$ first cost associated with energy-efficiency measures only represents an additional $\$ 12$ per month for a 30-year loan term. It is important to note that the cost data used in this analysis may not be representative of actual builder or consumer costs in the Phoenix area or other HotDry/Mixed-Dry climate areas. The actual first costs for a particular builder and potential homeowner in the Hot-dry/Mixed-dry climate area may vary substantially from Table 8. Variations in costs would affect the outcome of the optimization. Other examples of actual first costs associated with the construction of homes that meet the $30 \%-39 \%$ savings criteria are found in the case studies section and in the First Costs, Cost Tradeoffs, and Owner Annualized PITI + Energy section.

\section{Key Cost Tradeoffs}

The analysis for a single- and two-story home in the Phoenix climate shows that the main trends that result in a home that saves 30\% - 39\% whole-house energy relative to the Benchmark show improved exterior wall constructions, ducts in conditioned space, and higher efficiency air conditioners. The results indicate that the main driver for energy and cost savings in the Phoenix climate are cooling load reduction strategies (better wall insulation, low-e glazing, and ducts in conditioned space) coupled with higher SEER air conditioners to reduce cooling energy use. One of the tradeoffs shown in most of the example cases is that the improved envelope allows for a smaller-capacity furnace to be installed, which offsets the first-cost.

Table 8. Incremental First Cost for the Two-Story Phoenix Example Cases

\begin{tabular}{lcc}
\hline \hline & \multicolumn{2}{c}{ PHOENIX, TWO-STORY } \\
\hline \hline Category & Incremental First-Cost 35\% Example & Incremental First-Cost 39\% Example \\
Walls & $\$ 317.00$ & $\$ 317.00$ \\
Air Conditioner & $\$ 303.00$ & $\$ 607.00$ \\
Furnace & $-\$ 146.00$ & $-\$ 146.00$ \\
Ducts & $\$ 960.00$ & $\$ 960.00$ \\
Total & $\$ 1,434.00$ & $\$ 1,738.00$ \\
\hline
\end{tabular}

\footnotetext{
${ }^{56}$ Building America Best Practices Volume 2, Builders and Buyers Handbook for Improving New Home Efficiency, Comfort, and Durability in the Hot-Dry and Mixed Dry Climates, September 2005, NREL/TP-550-36360, Page HOM-4.
} 


\section{Research Results and Conclusions}

Through the use of systems engineering and operations research, the Building America program has shown that homes that save 30\% whole-house source energy in Hot-Dry and Mixed-Dry Climates can be built on a cost-neutral basis by production builders. Table 9A shows a summary for energy-related features for the case studies included in the following section of this report and examples of results from use of the BEopt analysis method for Hot-Dry and Mixed-Dry Climates. While the specific combinations of technologies used in the case studies or shown in BEopt results may not be cost-optimal solutions for all areas and housing types covered by the Hot-Dry and Mixed-Dry Climate, the key features of the approaches demonstrated in each of these examples can be adapted as needed to provide homes that save $30 \%$ whole-house energy savings.

It should be also noted that the BEopt analysis method is subject to the limitations as described in the Cost Analysis - Life-cycle Cost Analysis section of this report and the case studies are the result of 3 years of field experience and design work done by Building America's research teams. 
Table 9A. Summary of Energy Features for Case Studies and BEopt Results

\begin{tabular}{|c|c|c|c|c|c|c|c|c|c|c|}
\hline \multirow[b]{2}{*}{ Category } & \multirow[b]{2}{*}{$\begin{array}{c}\text { Merlin } \\
\text { Contracting } \\
\text { New American } \\
\text { Home }\end{array}$} & \multirow[b]{2}{*}{$\begin{array}{c}\text { JWM } \\
\text { Armory Park } \\
\text { Del Sol }\end{array}$} & \multirow{2}{*}{$\begin{array}{c}\text { Case Studies } \\
\text { Artistic Homes } \\
\text { Gamlen } \\
\text { Residence }\end{array}$} & \multirow[b]{2}{*}{$\begin{array}{l}\text { Premier } \\
\text { Homes } \\
\text { Premier } \\
\text { Gardens }\end{array}$} & \multirow[b]{2}{*}{$\begin{array}{l}\text { Morrison } \\
\text { Homes } \\
\text { Lakeside }\end{array}$} & \multirow[b]{2}{*}{$\begin{array}{c}\text { Centex } \\
\text { Windemere } \\
\text { Adventura/ } \\
\text { Lunaria }\end{array}$} & \multirow[b]{2}{*}{$35 \%$ point } & \multicolumn{2}{|c|}{ BEopt results } & \multirow[b]{2}{*}{ Neighbor 5} \\
\hline & & & & & & & & $\begin{array}{c}\text { Neighbor } \\
4\end{array}$ & $35 \%$ point & \\
\hline Floor Area & Not Described & 1916 & 2700 & 1503 & $2126-3672$ & $2250-3800$ & 1500 & 1500 & 3000 & 3000 \\
\hline \# of Floors & 3 & 1 & 1 & 1 & $1-2$ & 2 & 1 & 1 & 2 & 2 \\
\hline $\begin{array}{l}\text { Number of } \\
\text { Bedrooms }\end{array}$ & 4 & 2 & 4 & 3 & 4 & Not Described & 3 & 3 & 3 & 3 \\
\hline $\begin{array}{l}\text { Number of } \\
\text { Bathrooms }\end{array}$ & 4 & 2 & 3 & 2 & 3 & Not Described & 2 & 2 & 2 & 2 \\
\hline Walls & $\begin{array}{c}\text { Insulated } \\
\text { Concrete Forms, } \\
\text { 10-in. concrete } \\
\text { with 2-5/8-in. XPS } \\
\text { each side, R22 }\end{array}$ & $\begin{array}{l}\text { 8-in. CMU, } \\
\text { R-12 exterior } \\
\text { rigid foam }\end{array}$ & $\begin{array}{l}2 \times 624 \text { in. oc, } \\
\text { R23 cellulose + } \\
\text { R-1.2 asphalt } \\
\text { impregnated } \\
\text { sheathing }\end{array}$ & $\begin{array}{c}\text { 2x4, R-13 Batt } \\
+1 \text {-in. EPS } \\
\text { sheathing }\end{array}$ & $\mathrm{R}-19$ & $\begin{array}{l}2 \times 416 \text {-in. oc, } \\
\text { R-15 blown-in } \\
\text { fiberglass }\end{array}$ & $\begin{array}{l}\text { R-11, 2x4, } \\
\text { 16-in. oc }\end{array}$ & $\begin{array}{l}\text { R-13, 2x4, } \\
\text { 16-in. oc }\end{array}$ & $\begin{array}{l}\text { R-19, 2x6, } \\
\text { 24-in. oc }\end{array}$ & $\begin{array}{l}\text { R-13, 2x4, } \\
\text { 16-in. oc }\end{array}$ \\
\hline Ceiling & $\begin{array}{c}\text { SIP, 8-1/4-in. } \\
\text { thick, R-30 }\end{array}$ & $\begin{array}{l}\text { R-38 fiberglass } \\
\text { batt/l joists, } \\
\text { flat roof }\end{array}$ & $\begin{array}{l}\text { R-38 loose fill } \\
\text { fiberglass }\end{array}$ & $\mathrm{R}-38$ & $\begin{array}{c}\text { R-30 (two- } \\
\text { story) / R-38 } \\
\text { (1 Story) }\end{array}$ & $\begin{array}{l}\text { R-48 blown in } \\
\text { fiberglass }\end{array}$ & $\begin{array}{c}\mathrm{R}-30 \\
\text { fiberglass }\end{array}$ & $\begin{array}{c}\mathrm{R}-30 \\
\text { fiberglass }\end{array}$ & $\begin{array}{c}\mathrm{R}-30 \\
\text { fiberglass }\end{array}$ & $\begin{array}{c}\mathrm{R}-30 \\
\text { fiberglass }\end{array}$ \\
\hline $\begin{array}{l}\text { Thermal } \\
\text { Mass }\end{array}$ & $\begin{array}{l}\text { ICF exterior walls } \\
\text { and ICF basement } \\
\text { walls }\end{array}$ & 8-in. CMU & Not Described & Not Described & Not Described & Not Described & $\begin{array}{l}\text { 1/2-in. Ceiling } \\
\text { Drywall }\end{array}$ & $\begin{array}{l}\text { Two 5/8-in. } \\
\text { Ceiling } \\
\text { Drywall } \\
\text { Layers }\end{array}$ & $\begin{array}{l}1 / 2 \text {-in. } \\
\text { Ceiling } \\
\text { Drywall }\end{array}$ & $\begin{array}{l}1 / 2 \text {-in. } \\
\text { Ceiling } \\
\text { Drywall }\end{array}$ \\
\hline Infiltration & $\begin{array}{l}\text { Sealing at SIP to } \\
\text { ICF joints, roof } \\
\text { penetrations and } \\
\text { all gaps }\end{array}$ & $2.9 \mathrm{ACH}_{50}$ & $\begin{array}{l}2.5 \mathrm{in}^{2} \text { per } 100 \mathrm{ft}^{2} \\
\text { of envelope }\end{array}$ & 3.5 SLA & Not Described & 3.9 SLA & $\begin{array}{l}\text { SLA }= \\
0.0005\end{array}$ & $\begin{array}{l}\text { SLA }= \\
0.0005\end{array}$ & $\begin{array}{l}\text { SLA }= \\
0.0005\end{array}$ & $\begin{array}{l}\text { SLA }= \\
0.0005\end{array}$ \\
\hline
\end{tabular}


Table 9A (continued). Summary of Energy Features for Case Studies and BEopt Results

\begin{tabular}{|c|c|c|c|c|c|c|c|c|c|c|}
\hline \multirow[b]{2}{*}{ Category } & \multirow[b]{2}{*}{$\begin{array}{c}\text { Merlin } \\
\text { Contracting } \\
\text { New American } \\
\text { Home }\end{array}$} & \multirow[b]{2}{*}{$\begin{array}{c}\text { JWM } \\
\text { Armory Park } \\
\text { Del Sol }\end{array}$} & \multirow{2}{*}{$\begin{array}{l}\text { Case Studies } \\
\text { Artistic Homes } \\
\text { Gamlen } \\
\text { Residence }\end{array}$} & \multirow[b]{2}{*}{$\begin{array}{l}\text { Premier } \\
\text { Homes } \\
\text { Premier } \\
\text { Gardens }\end{array}$} & \multirow[b]{2}{*}{$\begin{array}{l}\text { Morrison } \\
\text { Homes } \\
\text { Lakeside }\end{array}$} & \multirow[b]{2}{*}{$\begin{array}{c}\text { Centex } \\
\text { Windemere } \\
\text { Adventura/ } \\
\text { Lunaria }\end{array}$} & \multirow[b]{2}{*}{$35 \%$ point } & \multicolumn{2}{|c|}{ BEopt results } & \multirow[b]{2}{*}{ Neighbor 5} \\
\hline & & & & & & & & Neighbor 4 & $35 \%$ point & \\
\hline $\begin{array}{l}\text { Basement/Slab/ } \\
\text { Crawlspace }\end{array}$ & $\begin{array}{c}\text { Basement - } \\
\text { Insulated Concrete } \\
\text { Forms, 10-in. } \\
\text { concrete with 2- } \\
\text { 5/8-in. XPS each } \\
\text { side + waterproof } \\
\text { coating and } \\
\text { membrane, R-22 }\end{array}$ & $\begin{array}{c}\text { Slab = R-12 } \\
\text { slab edge } \\
\text { insulation }\end{array}$ & $\begin{array}{c}\text { Conditioned } \\
\text { Crawlspace = } \\
\text { R-14, 2-in. } \\
\text { Polyisocyanurate } \\
\text { Rigid Insulation }\end{array}$ & Slab & Slab & Slab & Uninsulated & Uninsulated & Uninsulated & Uninsulated \\
\hline Glass Type & $\begin{array}{c}\text { Low-e, } \\
U=0.36, \\
\text { SHGC }=0.35 \\
\text { Eight French } \\
\text { Doors, } \\
U=0.38, \\
\text { SHGC }=0.21, \\
45 \mathrm{ft}^{2} \text { of single } \\
\text { glazing, } \\
U=1.11, \\
\mathrm{SHGC}=0.86\end{array}$ & $\begin{array}{c}\text { Low-e, } \\
U=0.32 \\
S H G C=0.30\end{array}$ & $\begin{array}{c}\text { Double-glazed } \\
\begin{array}{c}\text { Low- } E^{2} \text { vinyl frame, } \\
U=0.35 \\
\text { SHGC }=0.35\end{array}\end{array}$ & $\begin{array}{c}\text { Slider: } \\
U=0.36, \\
\text { SHGC }=0.30 \\
\text { Single Hung: } \\
U=0.33, \\
\text { SHGC }=0.32 \\
\text { Fixed: } \\
U=0.30, \\
\text { SHGC }=0.33 \\
\text { Sliding Patio } \\
\text { Door: } \\
U=0.34, \\
\text { SHGC }=0.30 \\
\text { French Door: } \\
U=0.33, \\
\text { SHGC }=0.28\end{array}$ & $\begin{array}{c}\text { Spectrally } \\
\text { Selective } \\
U=0.36 \\
\text { sliders, } \\
0.33 \text { fixed, } \\
0.354 \text { patio } \\
\text { door, } \\
\text { SHGC }=0.33 \\
\text { sliders, } \\
0.36 \text { fixed, } \\
0.35 \text { patio } \\
\text { door }\end{array}$ & $\begin{array}{c}\text { Low-E2 Vinyl, } \\
U=0.35 \\
\text { SHGC }=0.37\end{array}$ & $\begin{array}{c}2 \text { pane Low-e, } \\
U=0.3 \\
\text { SHGC }=0.44 \\
\text { Center of } \\
\text { Glass, } \\
\text { insulated } \\
\text { spacer, Vinyl } \\
\text { frame }\end{array}$ & $\begin{array}{c}2 \text { pane Low-e, } \\
U=0.32, \\
\text { SHGC }=0.64 \\
\text { Center of } \\
\text { Glass, } \\
\text { insulated } \\
\text { spacer, Vinyl } \\
\text { frame }\end{array}$ & $\begin{array}{c}2 \text { pane clear, } \\
U=0.49, \\
\text { SHGC }=0.76 \\
\text { Center of } \\
\text { Glass, } \\
\text { insulated } \\
\text { spacer, Vinyl } \\
\text { frame }\end{array}$ & $\begin{array}{c}2 \text { pane Low-e, } \\
U=0.32, \\
\text { SHGC = } 0.64 \\
\text { Center of } \\
\text { Glass, } \\
\text { insulated } \\
\text { spacer, Vinyl } \\
\text { frame }\end{array}$ \\
\hline $\begin{array}{l}\text { Window Area } \\
\text { per Wall }\end{array}$ & Not Described & Not Described & Not Described & $\begin{array}{c}\text { Not } \\
\text { Described }\end{array}$ & $\begin{array}{c}\text { Not } \\
\text { Described }\end{array}$ & Not Described & $\begin{array}{c}270 \mathrm{ft}^{2} \\
12.5 \% \mathrm{~N} \& \mathrm{~S} \\
50 \% \mathrm{~W} \\
25 \% \mathrm{E}\end{array}$ & $\begin{array}{c}270 \mathrm{ft}^{2} \\
12.5 \% \mathrm{~N} \& \mathrm{~S} \\
50 \% \mathrm{~W} \\
25 \% \mathrm{E}\end{array}$ & $\begin{array}{c}540 \mathrm{ft}^{2} \\
12.5 \% \mathrm{~N} \& \mathrm{~S} \\
50 \% \mathrm{~W} \\
25 \% \mathrm{E}\end{array}$ & $\begin{array}{c}540 \mathrm{ft}^{2} \\
12.5 \% \mathrm{~N} \& \mathrm{~S} \\
50 \% \mathrm{~W} \\
25 \% \mathrm{E}\end{array}$ \\
\hline
\end{tabular}


Table 9A (continued). Summary of Energy Features for Case Studies and BEopt Results

\begin{tabular}{|c|c|c|c|c|c|c|c|c|c|c|}
\hline \multirow[b]{2}{*}{ Category } & \multicolumn{6}{|c|}{ Case Studies } & \multicolumn{4}{|c|}{ BEopt results } \\
\hline & $\begin{array}{c}\text { Merlin } \\
\text { Contracting } \\
\text { New American } \\
\text { Home }\end{array}$ & $\begin{array}{c}\text { JWM } \\
\text { Armory Park Del Sol }\end{array}$ & $\begin{array}{l}\text { Artistic } \\
\text { Homes } \\
\text { Gamlen } \\
\text { Residence }\end{array}$ & $\begin{array}{l}\text { Premier } \\
\text { Homes } \\
\text { Premier } \\
\text { Gardens }\end{array}$ & $\begin{array}{c}\text { Morrison } \\
\text { Homes } \\
\text { Lakeside }\end{array}$ & $\begin{array}{l}\text { Centex } \\
\text { Windemere } \\
\text { Adventura/ } \\
\text { Lunaria }\end{array}$ & $35 \%$ point & Neighbor 4 & $35 \%$ point & Neighbor 5 \\
\hline Refrigerator & Not Described & ENERGY STAR & $\begin{array}{c}\text { Not } \\
\text { Described }\end{array}$ & $\begin{array}{c}\text { Not } \\
\text { Described }\end{array}$ & $\begin{array}{l}\text { ENERGY } \\
\text { STAR }\end{array}$ & $\begin{array}{c}\text { Not } \\
\text { Described }\end{array}$ & $\begin{array}{l}\text { Standard - } \\
671 \mathrm{kWh} / \mathrm{yr}\end{array}$ & $\begin{array}{c}\text { Standard - } 671 \\
\mathrm{kWh} / \mathrm{yr}\end{array}$ & $671 \mathrm{kWh} / \mathrm{yr}$ & $671 \mathrm{kWh} / \mathrm{yr}$ \\
\hline $\begin{array}{l}\text { Cooking } \\
\text { Range }\end{array}$ & Not Described & Not Described & $\begin{array}{c}\text { Not } \\
\text { Described }\end{array}$ & $\begin{array}{c}\text { Not } \\
\text { Described }\end{array}$ & $\begin{array}{c}\text { Not } \\
\text { Described }\end{array}$ & $\begin{array}{c}\text { Not } \\
\text { Described }\end{array}$ & 45 Therms/yr & 45 Therms/yr & 45 Therms/yr & 45 Therms/yr \\
\hline Dishwasher & Not Described & ENERGY STAR & $\begin{array}{c}\text { Not } \\
\text { Described }\end{array}$ & $\begin{array}{c}\text { Not } \\
\text { Described }\end{array}$ & $\begin{array}{l}\text { ENERGY } \\
\text { STAR }\end{array}$ & $\begin{array}{c}\text { Not } \\
\text { Described }\end{array}$ & $\begin{array}{l}\text { Standard, } \\
462 \mathrm{kWh}, \\
\text { eight place } \\
\text { setting } \\
\text { capacity, } \\
131.6 \mathrm{kWh} / \mathrm{yr} \\
\text { machine } \\
\text { energy, } \\
5.39-\mathrm{gal} / \mathrm{day} \\
\mathrm{DHW}\end{array}$ & $\begin{array}{c}\text { Standard, } \\
462 \mathrm{kWh} \text {, eight } \\
\text { place setting } \\
\text { capacity, } \\
131.6 \mathrm{kWh} / \mathrm{yr} \\
\text { machine } \\
\text { energy, } \\
5.39-\mathrm{gal} / \mathrm{day} \\
\mathrm{DHW}\end{array}$ & $\begin{array}{l}\text { Standard, } \\
462 \mathrm{kWh}, \\
\text { eight place } \\
\text { setting } \\
\text { capacity, } \\
131.6 \mathrm{kWh} / \mathrm{yr} \\
\text { machine } \\
\text { energy, } \\
5.39-\text { gal/day } \\
\text { DHW }\end{array}$ & $\begin{array}{l}\text { Standard, } \\
462 \mathrm{kWh} \\
\text { eight place } \\
\text { setting } \\
\text { capacity, } \\
131.6 \mathrm{kWh} / \mathrm{yr} \\
\text { machine } \\
\text { energy, } \\
5.39-\text { gal/day } \\
\text { DHW }\end{array}$ \\
\hline Clothes Dryer & Not Described & Not Described & $\begin{array}{c}\text { Not } \\
\text { Described }\end{array}$ & $\begin{array}{l}\text { Gas Dryer } \\
\text { stub }\end{array}$ & $\begin{array}{c}\text { Not } \\
\text { Described }\end{array}$ & Not Described & $\begin{array}{c}\text { Gas - } 5.7 \mathrm{ft}^{3} \\
2.75 \mathrm{EF} \\
70.1 \mathrm{kWh} / \mathrm{yr} \\
31.8 \text { therms/yr }\end{array}$ & $\begin{array}{c}\text { Gas }-5.7 \mathrm{ft}^{3} \\
2.75 \mathrm{EF} \\
70.1 \mathrm{kWh} / \mathrm{yr} \\
31.8 \text { therms/yr }\end{array}$ & $\begin{array}{c}\text { Gas - } 5.7 \mathrm{ft}^{3}, \\
2.75 \mathrm{EF}, \\
70.1 \mathrm{kWh} / \mathrm{yr}, \\
31.8 \text { therms/yr }\end{array}$ & $\begin{array}{c}\text { Gas }-5.7 \mathrm{ft}^{3} \\
2.75 \mathrm{EF} \\
70.1 \mathrm{kWh} / \mathrm{yr}, \\
31.8 \text { therms/yr }\end{array}$ \\
\hline $\begin{array}{l}\text { Clothes } \\
\text { Washer }\end{array}$ & Not Described & Not Described & $\begin{array}{c}\text { Not } \\
\text { Described }\end{array}$ & $\begin{array}{c}\text { Not } \\
\text { Described }\end{array}$ & $\begin{array}{l}\text { ENERGY } \\
\text { STAR }\end{array}$ & Not Described & $\begin{array}{c}\text { Standard, } \\
3.15 \mathrm{ft}^{3}, \\
533 \mathrm{kWh} / \mathrm{yr}, \\
1.16 \mathrm{MEF}, \\
65.6 \mathrm{kWh} / \mathrm{yr} \\
\text { machine energy, } \\
\text { 4.63-gal/day } \\
\mathrm{DHW}\end{array}$ & $\begin{array}{c}\text { Standard, } \\
3.15 \mathrm{ft}^{3}, \\
533 \mathrm{kWh} / \mathrm{yr}, \\
1.16 \mathrm{MEF}, 65.6 \\
\mathrm{kWh} / \mathrm{yr} \text { machine } \\
\text { energy, } 4.63- \\
\text { gal/day DHW }\end{array}$ & $\begin{array}{c}\text { Standard, } \\
3.15 \mathrm{ft}^{3}, \\
533 \mathrm{kWh} / \mathrm{yr}, \\
1.16 \mathrm{MEF}, \\
65.6 \mathrm{kWh} / \mathrm{yr} \\
\text { machine } \\
\text { energy, } \\
4.63-\mathrm{gal} / \mathrm{day} \\
\mathrm{DHW}\end{array}$ & $\begin{array}{c}\text { Standard, } \\
3.15 \mathrm{ft}^{3}, \\
533 \mathrm{kWh} / \mathrm{yr}, \\
1.16 \mathrm{MEF}, \\
65.6 \mathrm{kWh} / \mathrm{yr} \\
\text { machine energy, } \\
\text { 4.63-gal/day } \\
\text { DHW }\end{array}$ \\
\hline
\end{tabular}


Table 9A (continued). Summary of Energy Features for Case Studies and BEopt Results

\begin{tabular}{|c|c|c|c|c|c|c|c|c|c|c|}
\hline \multirow[b]{2}{*}{ Category } & \multicolumn{6}{|c|}{ Case Studies } & \multicolumn{4}{|c|}{ BEopt results } \\
\hline & $\begin{array}{c}\text { Merlin } \\
\text { Contracting } \\
\text { New American } \\
\text { Home }\end{array}$ & $\begin{array}{c}\text { JWM } \\
\text { Armory Park Del Sol }\end{array}$ & $\begin{array}{l}\text { Artistic Homes } \\
\text { Gamlen } \\
\text { Residence }\end{array}$ & $\begin{array}{l}\text { Premier Homes } \\
\text { Premier } \\
\text { Gardens }\end{array}$ & $\begin{array}{l}\text { Morrison } \\
\text { Homes } \\
\text { Lakeside }\end{array}$ & $\begin{array}{c}\text { Centex } \\
\text { Windemere } \\
\text { Adventura/ } \\
\text { Lunaria }\end{array}$ & $35 \%$ point & Neighbor 4 & $35 \%$ point & Neighbor 5 \\
\hline Lighting & Not Described & $\begin{array}{l}\text { Incandescent / } \\
\text { flourescent }\end{array}$ & Not Described & $100 \%$ fluorescent & $\begin{array}{c}100 \% \\
\text { fluorescent }\end{array}$ & $\begin{array}{l}\text { CFLs on all } \\
\text { permanent } \\
\text { fixtures } \\
\text { except dining } \\
\text { chandelier }\end{array}$ & $\begin{array}{c}14 \% \mathrm{CFL}, \\
1574 \mathrm{kWh} / \mathrm{yr} \\
\text { Hardwired, } \\
331 \mathrm{kWh} / \mathrm{yr} \\
\text { Plug in }\end{array}$ & $\begin{array}{c}14 \% \text { CFL, } \\
1574 \text { kWh/yr } \\
\text { Hardwired, } 331 \\
\text { kWh/yr Plug in }\end{array}$ & $\begin{array}{c}14 \% \text { CFL, } \\
2534 \mathrm{kWh} / \mathrm{yr} \\
\text { Hardwired, } 571 \\
\text { kWh/yr Plug in }\end{array}$ & $\begin{array}{c}14 \% \text { CFL, } \\
2534 \mathrm{kWh} / \mathrm{yr} \\
\text { Hardwired, } 571 \\
\text { kWh/yr Plug in }\end{array}$ \\
\hline Cooling & $\begin{array}{l}\text { Four systems, } \\
\text { SEER } 16 \text { Heat } \\
\text { Pump, SEER } \\
14.8,15.9 \text {, and } \\
15 \text { condensing } \\
\text { units, Total of } 18 \\
\text { tons }\end{array}$ & SEER 12 heat pump & SEER 13 & SEER14 w/ TXV & SEER14 & SEER10 & $\begin{array}{l}\text { SEER } 10, \\
2.5 \text { Tons, } \\
0.365 \text { W/CFM } \\
\text { AH Fan }\end{array}$ & $\begin{array}{l}\text { SEER 10, } \\
3 \text { Tons, } \\
0.365 \text { W/CFM } \\
\text { AH Fan }\end{array}$ & $\begin{array}{l}\text { SEER } 12, \\
4.00 \text { Tons, } \\
0.365 \text { W/CFM } \\
\text { AH Fan }\end{array}$ & $\begin{array}{l}\text { SEER } 12, \\
4.00 \text { Tons, } \\
0.365 \text { W/CFM } \\
\text { AH Fan }\end{array}$ \\
\hline Heating & $\begin{array}{c}\text { One heat pump, } \\
\text { COP = 3.6 @ } \\
47^{\circ} \mathrm{F}, \\
\text { Two } 94 \% \text { AFUE } \\
\text { furnaces w/ two- } \\
\text { speed air } \\
\text { handlers, One } \\
94 \% \text { AFUE } \\
\text { furnace with two- } \\
\text { zone control } \\
\text { dampers }\end{array}$ & 8.6 HSPF heat pump & $\begin{array}{l}\text { Combo System - } \\
90 \% \text { CA }_{\text {AFUE }} \text { in } \\
\text { conditioned space }\end{array}$ & $91 \%$ AFUE & $92 \%$ AFUE & $\begin{array}{c}80 \% \text { AFUE, } \\
\text { variable- } \\
\text { speed AH fan }\end{array}$ & $\begin{array}{l}80 \% \text { AFUE, } \\
50 \mathrm{kBtu} / \mathrm{hr}\end{array}$ & $\begin{array}{l}80 \% \text { AFUE, } \\
75 \mathrm{kBtu} / \mathrm{hr}\end{array}$ & $\begin{array}{l}80 \% \text { AFUE, } \\
100 \mathrm{kBtu} / \mathrm{hr}\end{array}$ & $\begin{array}{l}80 \% \text { AFUE, } \\
100 \mathrm{kBtu} / \mathrm{hr}\end{array}$ \\
\hline Ducts & $\begin{array}{l}\text { Inside conditioned } \\
\text { space with UL181 } \\
\text { mastic sealed } \\
\text { joints }\end{array}$ & $\begin{array}{c}15 \text { CFM Total Leakage } \\
@ 25 \mathrm{~Pa} \text {, in conditioned } \\
\text { space }\end{array}$ & $\begin{array}{l}\text { Sheet metal and } \\
\text { flex duct in crawl } \\
\text { space, } 5 \% \text { or less } \\
\text { to outside }\end{array}$ & $\begin{array}{l}\text { R-4.2 ducts } \\
\text { insulation buried in } \\
\text { attic } \sim \mathrm{R}-13 \\
\text { equivalent }\end{array}$ & $\mathrm{R}-6$ & $\begin{array}{l}\text { R-4.2 flex } \\
\text { ducts buried } \\
\text { in } \mathrm{R}-48 \text { attic } \\
\text { insulation }\end{array}$ & $\begin{array}{c}\text { Inside } \\
\text { Conditioned } \\
\text { Space, } \\
\text { SA leakage = } \\
1 \%, \\
\text { OA leakage = } \\
0.23 \% \text { of fan } \\
\text { flow }\end{array}$ & $\begin{array}{c}\text { Inside } \\
\text { Conditioned } \\
\text { Space, } \\
\text { SA leakage = } \\
1 \%, \\
\text { OA leakage = } \\
0.23 \% \text { of fan } \\
\text { flow }\end{array}$ & $\begin{array}{c}\text { Inside } \\
\text { Conditioned } \\
\text { Space, } \\
\text { SA leakage = } \\
1 \%, \\
\text { OA leakage = } \\
0.23 \% \text { of fan } \\
\text { flow }\end{array}$ & $\begin{array}{c}\text { Inside } \\
\text { Conditioned } \\
\text { Space, } \\
\text { SA leakage = } \\
1 \%, \\
\text { OA leakage = } \\
0.23 \% \text { of fan } \\
\text { flow }\end{array}$ \\
\hline
\end{tabular}


Table 9A (continued). Summary of Energy Features for Case Studies and BEopt Results

\begin{tabular}{|c|c|c|c|c|c|c|c|c|c|c|}
\hline \multirow[b]{2}{*}{ Category } & \multicolumn{6}{|c|}{ Case Studies } & \multicolumn{4}{|c|}{ BEopt results } \\
\hline & $\begin{array}{c}\text { Merlin } \\
\text { Contracting } \\
\text { New } \\
\text { American } \\
\text { Home }\end{array}$ & $\begin{array}{c}\text { JWM } \\
\text { Armory Park Del Sol }\end{array}$ & $\begin{array}{c}\text { Artistic Homes } \\
\text { Gamlen } \\
\text { Residence }\end{array}$ & $\begin{array}{c}\text { Premier Homes } \\
\text { Premier } \\
\text { Gardens }\end{array}$ & $\begin{array}{l}\text { Morrison } \\
\text { Homes } \\
\text { Lakeside }\end{array}$ & $\begin{array}{c}\text { Centex } \\
\text { Windemere } \\
\text { Adventura/ } \\
\text { Lunaria }\end{array}$ & $35 \%$ point & Neighbor 4 & $35 \%$ point & Neighbor 5 \\
\hline $\begin{array}{l}\text { Water } \\
\text { Heater }\end{array}$ & $\begin{array}{l}\text { 75-gallon power } \\
\text { vented, } \\
55 \mathrm{MBH} \text { input, } \\
0.50 \mathrm{EF}\end{array}$ & $\begin{array}{l}\text { Batch Solar Water } \\
\text { Heater with Tankless } \\
\text { backup }\end{array}$ & $\begin{array}{c}\text { Combo System - } \\
0.86 \mathrm{CA}_{\mathrm{EF}} \\
34 \mathrm{gal} \text { in garage }\end{array}$ & $\begin{array}{l}\text { Tankless } 0.82 \mathrm{EF}, \\
\text { R4 insulation on } \\
\text { trunk lines }\end{array}$ & $\begin{array}{c}\text { Tankless } \\
0.82 \mathrm{EF}+ \\
\text { pipe } \\
\text { insulation }\end{array}$ & $\begin{array}{l}\text { Tankless } \\
0.82 \mathrm{EF}, \\
\text { PEX home } \\
\text { run piping }\end{array}$ & $\begin{array}{c}\text { Gas Standard, } \\
40 \text { gallons, } \\
0.55 \mathrm{EF} \\
0.76 \mathrm{RE}\end{array}$ & $\begin{array}{c}\text { Gas Standard, } \\
40 \text { gallons, } \\
0.55 \mathrm{EF} \\
0.76 \mathrm{RE}\end{array}$ & $\begin{array}{c}\text { Gas } \\
\text { Standard, } \\
40 \text { gallons, } \\
0.55 \mathrm{EF}, \\
0.76 \mathrm{RE}\end{array}$ & $\begin{array}{c}\text { Gas Standard } \\
40 \text { gallons, } \\
0.55 \mathrm{EF} \\
0.76 \mathrm{RE}\end{array}$ \\
\hline $\begin{array}{l}\text { On-site } \\
\text { Power } \\
\text { system }\end{array}$ & & $\begin{array}{c}1.5-k W \text { grid-tied PV } \\
\text { system }\end{array}$ & & $\begin{array}{l}\text { 2.4-kW DC system, } \\
\text { building integrated }\end{array}$ & $\begin{array}{l}\text { 2-kW roof } \\
\text { integrated } \\
\text { PV tiles }\end{array}$ & Optional & & & & \\
\hline $\begin{array}{l}\text { Space } \\
\text { Heating }\end{array}$ & $77 \%$ & $69 \%$ & $47 \%$ & $50 \%$ & $44 \%$ & $37 \% / 19 \%$ & $48 \%$ & $65 \%$ & $58 \%$ & $57 \%$ \\
\hline $\begin{array}{l}\text { Space } \\
\text { Cooling }\end{array}$ & $50 \%$ & $62 \%$ & $55 \%$ & $76 \%$ & $78 \%$ & $20 \% / 43 \%$ & $53 \%$ & $48 \%$ & $50 \%$ & $53 \%$ \\
\hline DHW & $-7 \%$ & $0 \%$ & $33 \%$ & $43 \%$ & $37 \%$ & $54 \% / 58 \%$ & $11 \%$ & $12 \%$ & $57 \%$ & $56 \%$ \\
\hline Lighting & $0 \%$ & $25 \%$ & $0 \%$ & $74 \%$ & $50 \%$ & $67 \% / 67 \%$ & $0 \%$ & $0 \%$ & $0 \%$ & $0 \%$ \\
\hline $\begin{array}{c}\text { Appliances + } \\
\text { MEL }\end{array}$ & $0 \%$ & $1 \%$ & $0 \%$ & $3 \%$ & $1 \%$ & $0 \% / 0 \%$ & $6 \%$ & $6 \%$ & $4 \%$ & $4 \%$ \\
\hline $\begin{array}{l}\text { Total } \\
\text { Energy } \\
\text { Use }\end{array}$ & $31 \%$ & $37 \%$ & $29 \%$ & $39 \%$ & $36 \%$ & $30 \% / 33 \%$ & $35.6 \%$ & $33.8 \%$ & $35.3 \%$ & $37.2 \%$ \\
\hline
\end{tabular}


Table 9B is a summary of the case studies presented in this report. Figure 24 shows the location of the case studies presented in this report. Locations are indicated with stars.

Table 9B. Summary of Source Energy Savings by End-use as a Percentage of Total Energy Use for the Seven Hot-Dry/Mixed-Dry Case Studies

\begin{tabular}{|c|c|c|c|c|c|c|c|}
\hline \multirow[b]{4}{*}{ End Use } & \multicolumn{7}{|c|}{ Percent Source Energy Savings } \\
\hline & \multirow{3}{*}{$\begin{array}{c}\text { Merlin } \\
\text { Contracting } \\
\text { New } \\
\text { American } \\
\text { Home }\end{array}$} & \multirow{3}{*}{$\begin{array}{l}\text { JWM } \\
\text { Armory } \\
\text { Park Del } \\
\text { Sol }\end{array}$} & \multirow{3}{*}{$\begin{array}{c}\text { Artistic } \\
\text { Homes } \\
\text { Gamlen } \\
\text { Residence }\end{array}$} & \multirow{3}{*}{$\begin{array}{l}\text { Premier } \\
\text { Homes } \\
\text { Premier } \\
\text { Gardens }\end{array}$} & \multirow{3}{*}{$\begin{array}{l}\text { Morrison } \\
\text { Homes } \\
\text { Lakeside }\end{array}$} & \multicolumn{2}{|c|}{ Centex - Windemere } \\
\hline & & & & & & Adventura & Lunaria \\
\hline & & & & & & & \\
\hline Space Heating & $77 \%$ & $69 \%$ & $47 \%$ & $50 \%$ & $44 \%$ & $37 \%$ & $19 \%$ \\
\hline Space Cooling & $50 \%$ & $62 \%$ & $55 \%$ & $76 \%$ & $78 \%$ & $20 \%$ & $43 \%$ \\
\hline DHW & $-7 \%$ & $0 \%$ & $33 \%$ & $43 \%$ & $37 \%$ & $54 \%$ & $58 \%$ \\
\hline Lighting & $0 \%$ & $25 \%$ & $0 \%$ & $74 \%$ & $50 \%$ & $67 \%$ & $67 \%$ \\
\hline Appliances + MEL & $0 \%$ & $1 \%$ & $0 \%$ & $2.5 \%$ & $1 \%$ & $0 \%$ & $0 \%$ \\
\hline Total Energy Use & $31 \%$ & $37 \%$ & $29 \%$ & $39 \%$ & $36 \%$ & $30 \%$ & $33 \%$ \\
\hline Number of Homes & 1 & 6 & 1 & $\begin{array}{c}71 \\
\text { complete, } \\
475 \text { total } \\
\text { buildout }\end{array}$ & $\begin{array}{l}1 \text { complete, } \\
120 \text { total } \\
\text { buildout }\end{array}$ & 6 & 19 \\
\hline
\end{tabular}




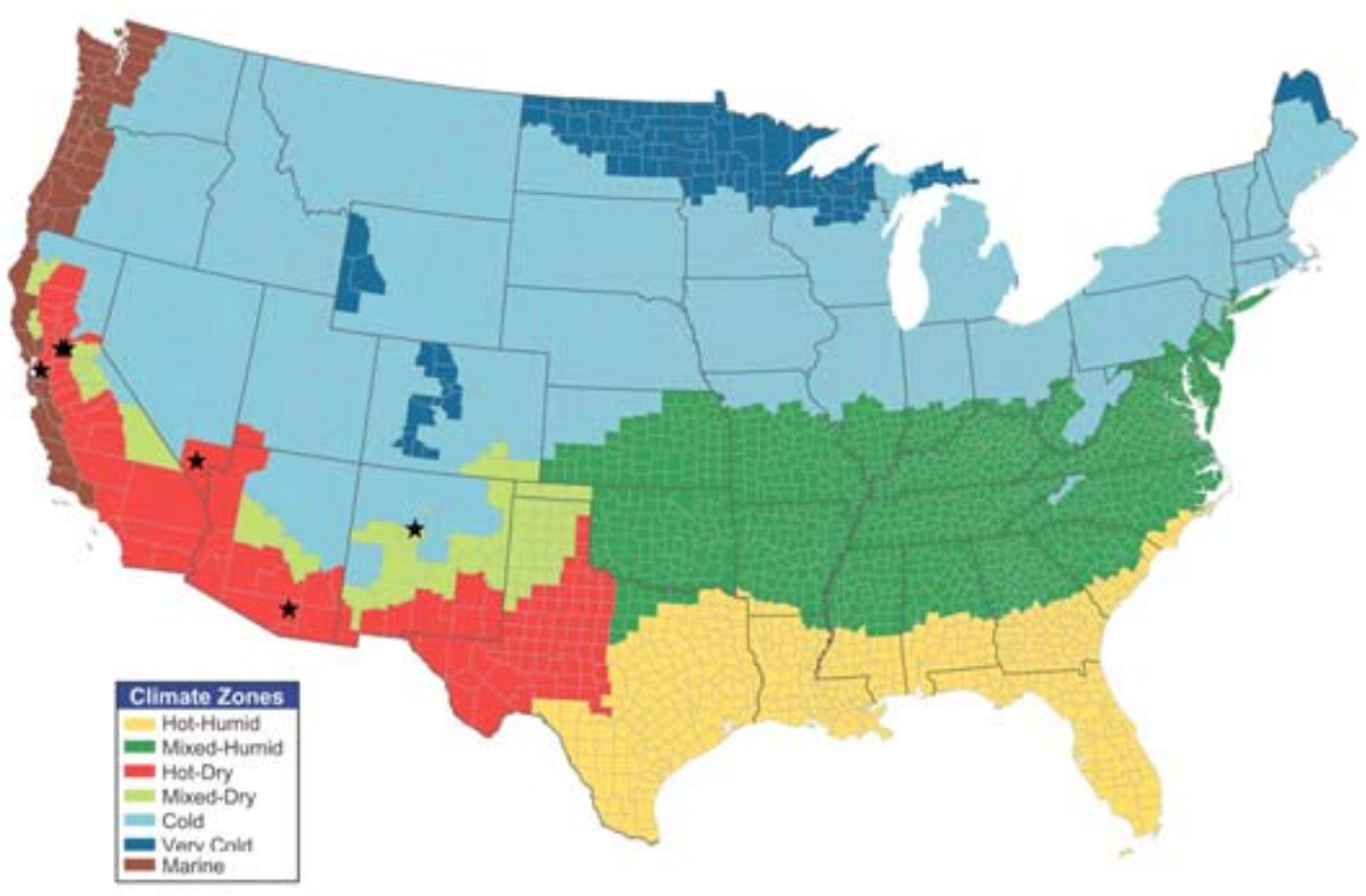

Figure 24. Location of $30 \%$ Hot-Dry and Mixed-Dry Climate case studies 


\section{House Case Studies}

Development: Sahara Lake

Builder: Merlin Contracting

Location: $\quad$ Las Vegas, Nevada

Within a high-pressure situation, the builders who construct The New American Home ${ }^{\circledR}$ (TNAH®) each year face unique obstacles: a frustratingly short and tight timeframe, designers and manufacturers they may have never worked with, products and practices they may be unfamiliar with, and materials that may not get specified right. On top of all this, The National Association of Home Builders (NAHB) requires that TNAH's builders construct houses to extremely high performance requirements, which adds its own set of challenges.

TNAH ${ }^{\circledR}$ is an annual showcase project co-sponsored by the NAHB's National Council of the Housing Industry and Builder Magazine. The NAHB began requiring that each home, beginning with TNAH® 2001, be built to extremely high energy-efficiency goals and other highperformance targets because they know it's important in the industry. IBACOS, through the Department of Energy's Building America program, has worked with the builders in the design and construction to ensure that each home meets specific performance goals.

Merlin Contracting built TNAH ${ }^{\circledR} 2004$ in the Sahara Lake community, just west of downtown Las Vegas. TNAH ${ }^{\circledR} 2004$ was designed to reach a Home Energy Rating System (HERS) score of 90 , a score well above the current ENERGY STAR ${ }^{\circledR}$ rating requirement of 86 , and uses a number of high-performance technologies.

The rear elevation of the pilot home is the most dramatic face because it is looking over the lake and highlights the glazing for the high-ceiling living room. The rear of the house faces south.

Figures 25 and 26 are floor plans for this house at Sahara Lake in Las Vegas, Nevada (Figure 27) 


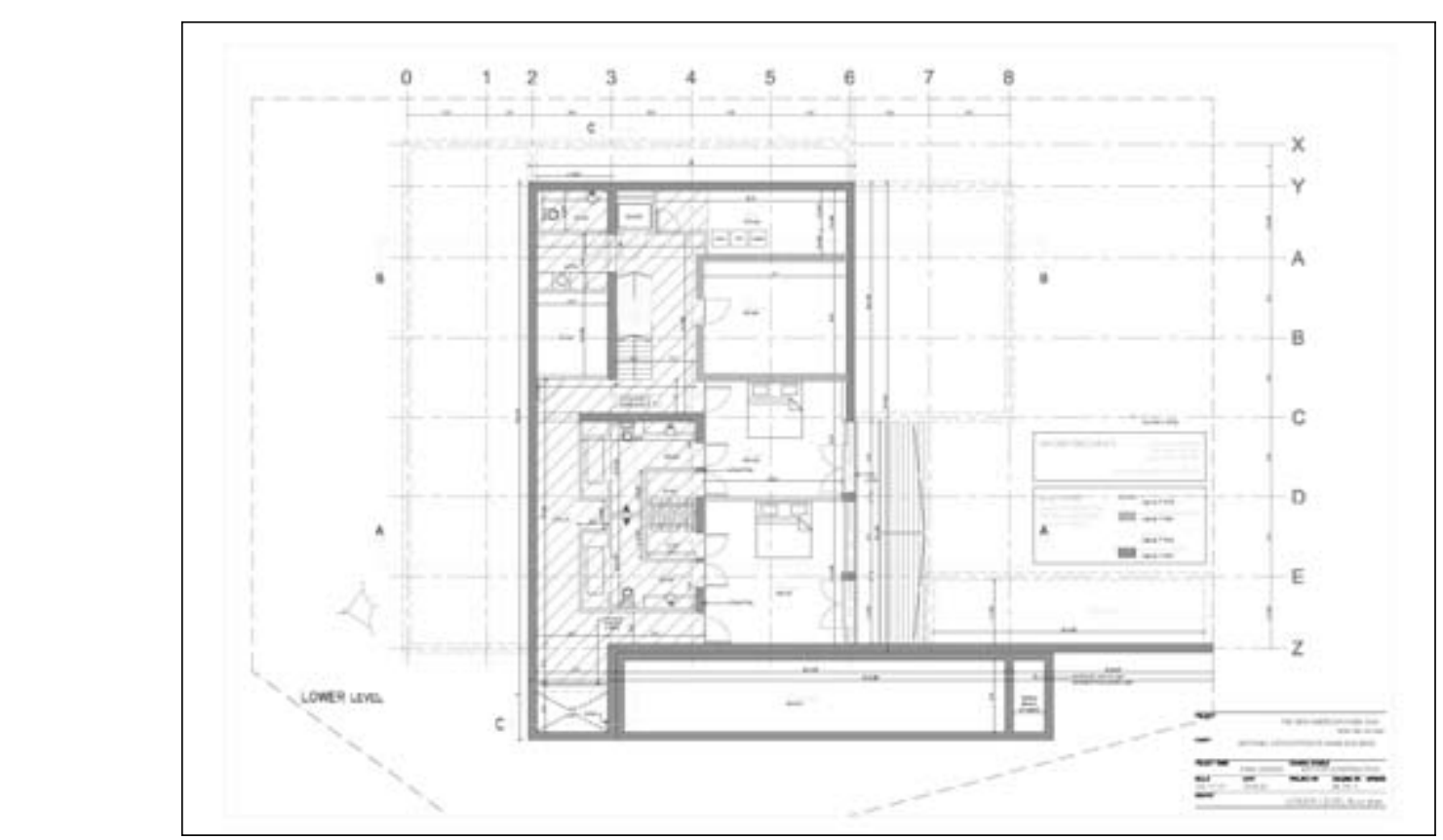

$1^{\text {st }}$ Floor

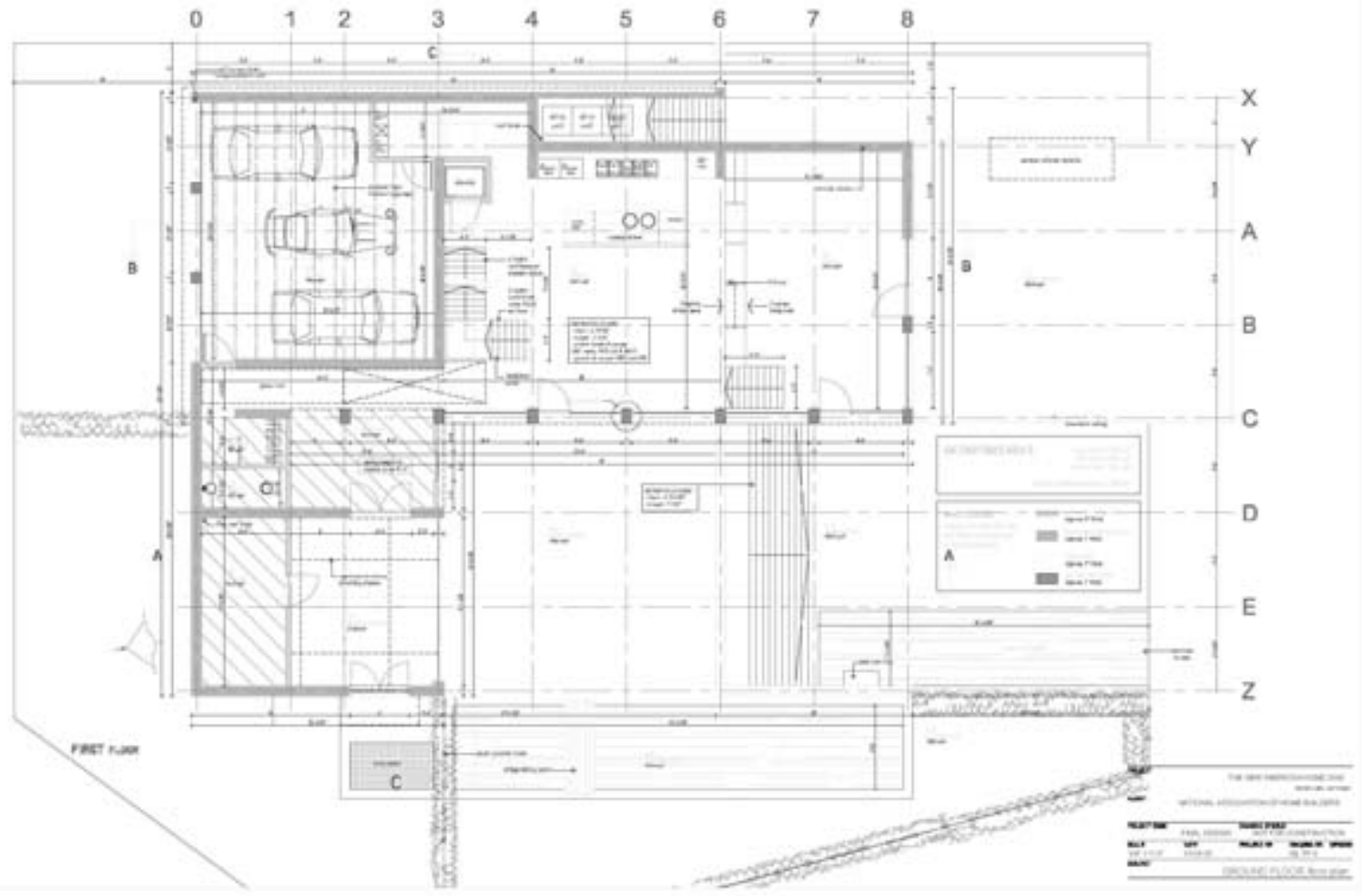

2nd Floor

Figure 25. Merlin Contracting house floor plan, $1^{\text {st }}$ and $2^{\text {nd }}$ floor 


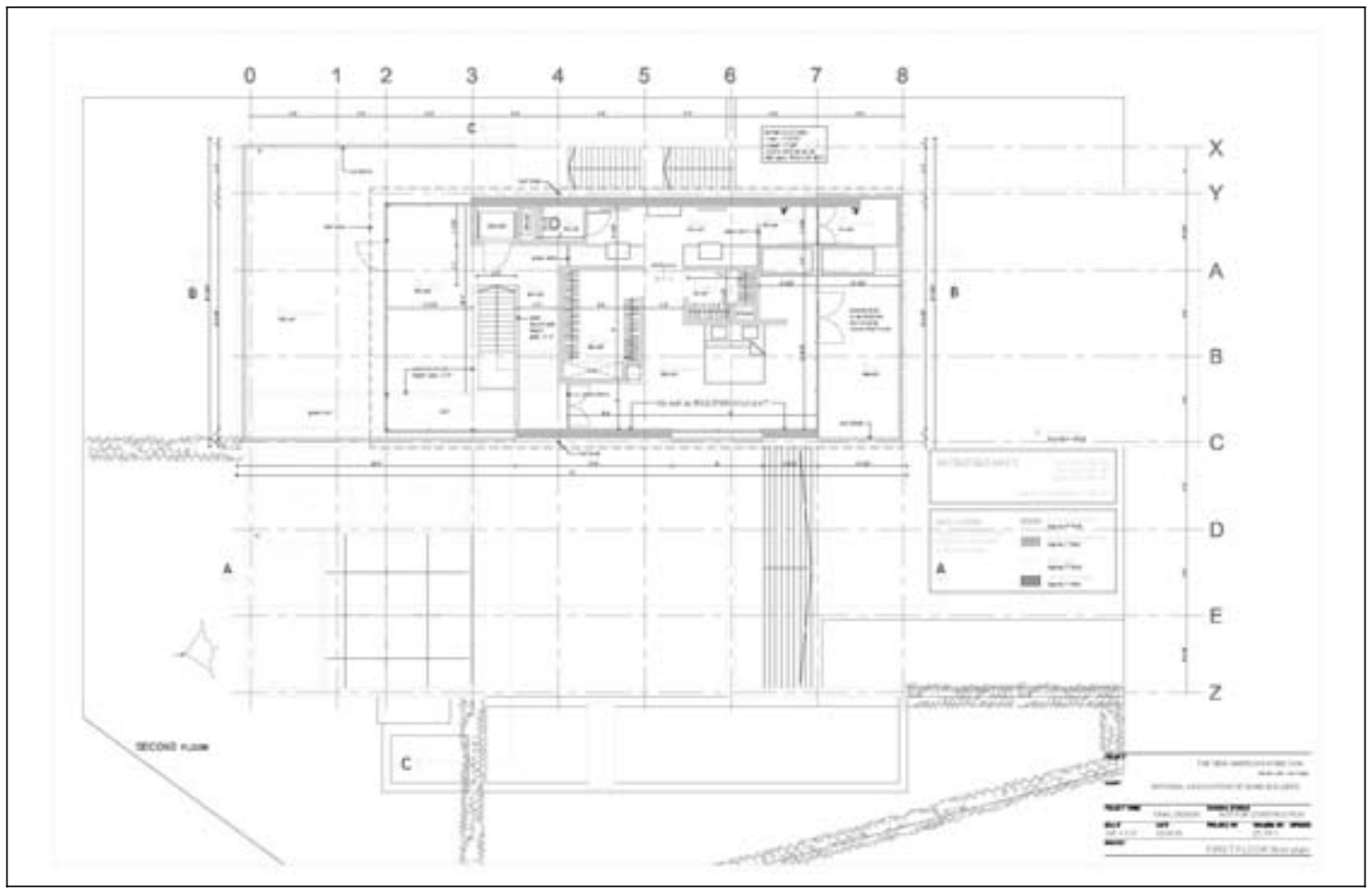

Figure 26. Merlin Contracting house floor plan, $3^{\text {rd }}$ floor

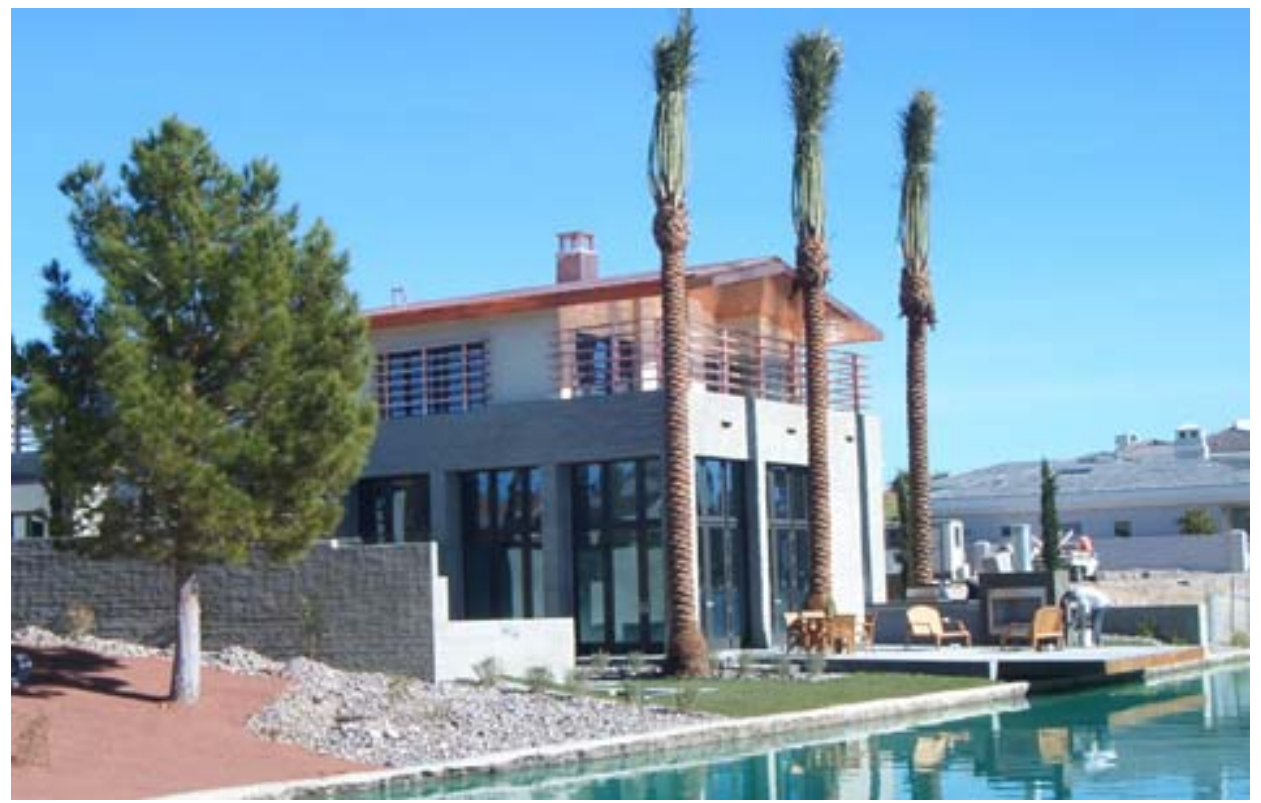

Figure 27. The New American Home at Sahara Lake, Nevada 


\section{House Specifications}

The house is located on a lot on Sahara Lake, an exclusive community about 6 miles west of downtown Las Vegas. The 5,180- $\mathrm{ft}^{2}$ home features a loft design that offers greater versatility for interior design and layout options.

\section{As-Built Specifications}

- Picture windows are from Loewen and are aluminum-clad, wood-framed, double-glazed, with a spectrally selective low-emissivity coating, U-value of 0.36 , SHGC of 0.35 . Eight sets of French doors, with U-values of 0.38 and SHGC of 0.21 , were installed. The master shower has approximately $45 \mathrm{ft}^{2}$ of single glazing. A U-value of 1.11 and SHGC of 0.86 is assumed for these windows (Carmody 1996).

- Second-floor fenestration is shaded externally by 9-in. by 2-in. copper-clad wooden sunshades. External, operable, and electronically controlled shading covers first-floor westside fenestration.

- All exterior walls above grade consisted of insulated concrete forms (ICF). The ICF system includes a 10-in. concrete core sandwiched by two 2-5/8-in. layers of extruded polystyrene (EPS) to give a thermal resistance of R-22 (Figures 28 and 29)

- Basement walls consisted of the ICF system covered by a waterproof coating and membrane (Figure 30)

- To improve building airtightness, a great deal of emphasis was placed on sealing the numerous penetrations through the building enclosure and any gaps at the roof-wall connection.

- Structural panels made up of an expanded polystyrene core bonded between two layers of OSB were used as the roof deck. Panels were $8-1 / 4$ in. thick and provided R-30 thermal performance (Figure 31).

\section{Mechanical Equipment}

- A total of four Lennox HVAC systems were installed to handle the five zones in the house; the second-floor system has a mechanical damper-zone control system. Three direct-vent natural-gas furnaces and a heat pump will be used for space heating, and each has a variablespeed blower. The three air handlers have a minimum 94\% AFUE, and all of them are located in conditioned space. The condensing units provide two-stage operation and have efficiencies of SEER 14.8, 15, and 15.9. The heat pump has two speeds, is located in conditioned space, and has a COP rating of 3.6 at $47^{\circ} \mathrm{F}$ and 16 SEER.

- A 75-gallon power-vented domestic water heater, $55 \mathrm{MBH}$ input, with an assumed EF of 0.50 , was used because manufacturer's data was unavailable. Also included was an electronically controlled pump-and-valve assembly that provides rapid delivery of hot water to plumbing fixtures without the loss of cold water down the drain.

- All ductwork, which consists of flex and spiral galvanized metal, is within the conditioned space of the home. Ductwork was sealed with UL-181 approved water-based mastic sealant or appropriate caulking. 
- A heat-recovery ventilator (HRV) provides mechanical ventilation on a balanced basis to first-floor HVAC systems.

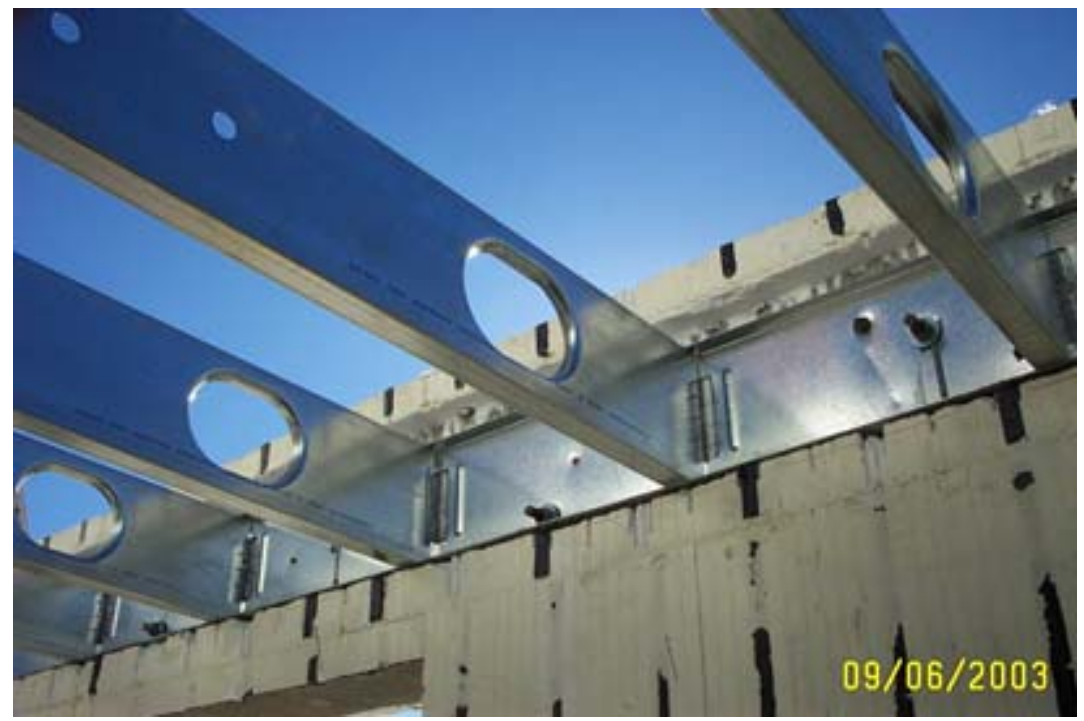

Figure 28. Steel beams were used for structural framing and are anchored into the insulated concrete form wall.

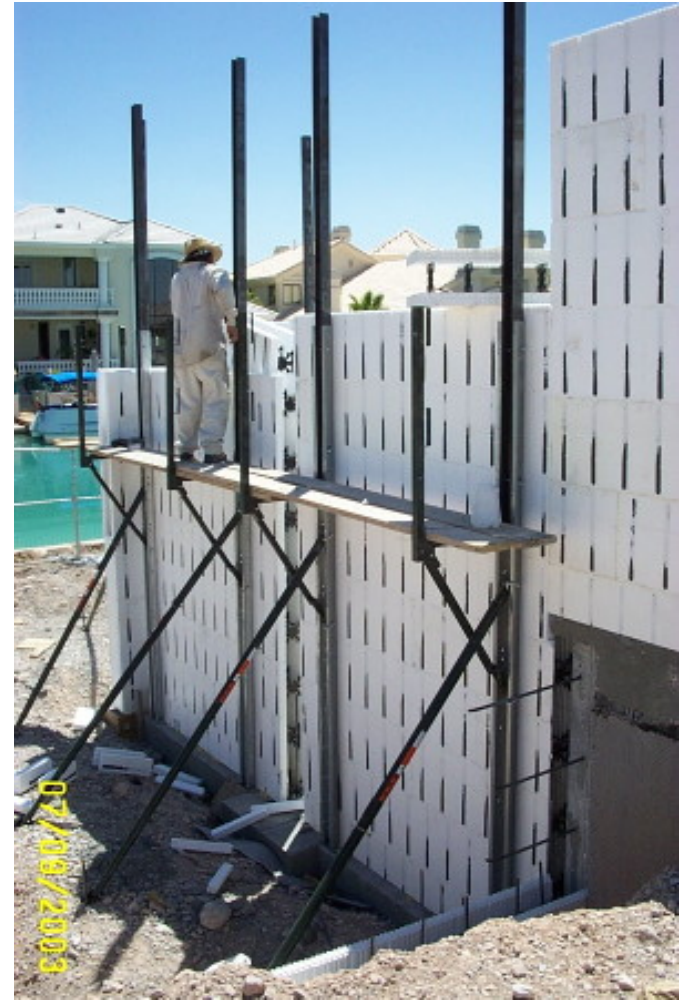

Figure 29. Insulated concrete forms make up the exterior shell of the home. 


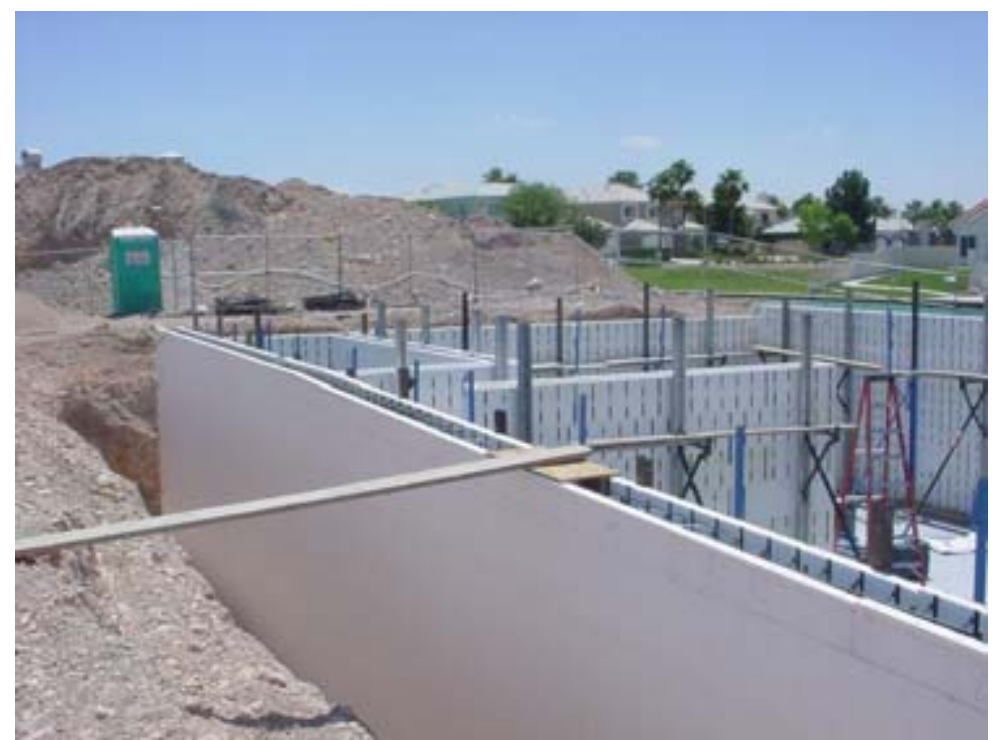

Figure 30. Insulated concrete forms were used to form the walls of the basement

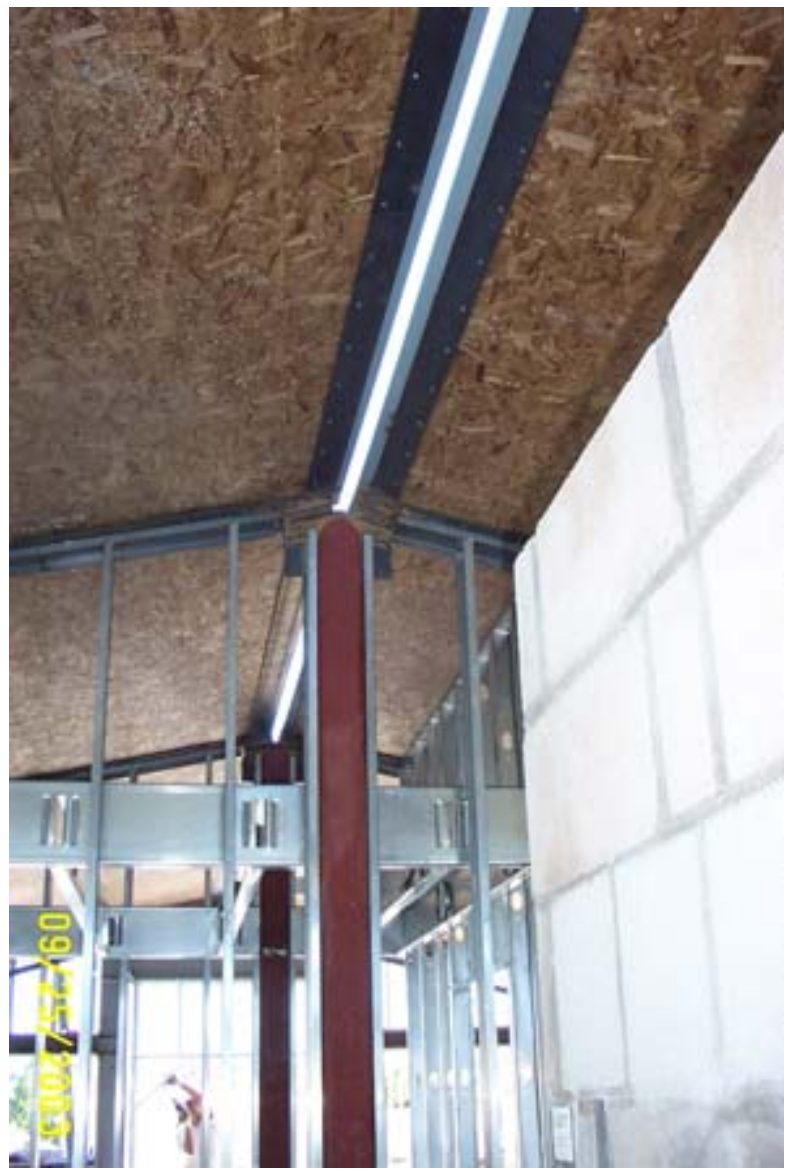

Figure 31. Structural insulated panels provide the air and thermal barrier for the roof 


\section{Innovations}

Specific technologies used in TNAH® 2004 include a foundation system and above-ground exterior walls of insulated concrete forms; windows that limit solar heat gain; a roof system built with structural insulated panels; a heat-recovery ventilator for the ventilation system; and superior efficiency condensing units. The insulated concrete forms provide excellent insulation for the basement. Structural insulated panels provide the roof system with good insulation and airtightness characteristics. The heat-recovery ventilator ensures good indoor air quality in an efficient manner by tempering incoming hot outdoor air with cooler indoor air. The condensing units have a seasonal energy efficiency ratio (SEER) between 14.7 and 16 and provide excellent cooling capacity while using minimal energy.

As a result of these improvements and advanced technologies, the home will use $46 \%$ less energy for space heating and cooling, hot water, and lighting than the typical Las Vegas new home.

\section{The Bottom Line}

Through this project, builders get a unique opportunity to learn new ways to build quality homes, without worrying about the costs involved with a learning curve. This is something very valuable to Merlin Contracting, the builder of TNAH ${ }^{\circledR} 2004$. As a custom homebuilder, their own bottom line doesn't matter as much as their customer's bottom line. "It's important for us to use their customer's money as wisely as possible," says Bart Jones, a principal in Merlin Contracting.

With their customer's bottom line in mind, they can't gamble on products or practices they're not familiar with. Knowing that something they tried through the TNAH® project works—or doesn't - eliminates guesswork and enables them to confidently make cost-effective recommendations to their customers. For example, based on their experience using Insulated Concrete Forms (ICFs) in TNAH ${ }^{\circledR} 2204$, Merlin would recommend ICFs to their customers. "In fact, recently we did recommend that one client use ICFs for the wall system and are currently building his 20,000- $\mathrm{ft}^{2}$ "French Country Cottage-style Compound" in Las Vegas using ICFs . This is something we wouldn't have done before because we'd never used it," said Bart Jones.

The NAHB's commitment to quality challenges builders to push the envelope further in the already high-pressure situation of building TNAH ${ }^{\circledR}$. With the help of the DOE's Building America Program, builders are successfully meeting the challenge and learning valuable lessons in the process. The builders, and the industry as a whole, are seeing that the value added to their business - reduced warranty and callback expenses, reduced liability risk, and increased customer satisfaction - is worth the effort. 


\section{Key Features}

- Low-emissivity solar-control windows

- Foundation and above-grade walls of insulated concrete forms that provide airtightness and R-22 thermal performance

- All air-handling equipment within conditioned space

- High-efficiency furnaces (minimum 94\% AFUE) and condensing units (between 14.7 and 16 SEER)

- One heat pump with coefficient of performance (COP) of 3.6 and 16 SEER

- Heat-recovery ventilator delivers fresh air to return plenum

- Air-distribution system leakage to the outside target is $3 \%$ of system airflow or $216 \mathrm{cfm}$ at 25 Pa.

\section{Advanced Systems and Construction Methods}

The builder was interested in the home at least reaching the ENERGY STAR ${ }^{\circledR}$ level of energy efficiency. In order to meet Building America objectives, IBACOS proceeded to design the home to achieve, at a minimum, a HERS 90 level. This level of energy efficiency matches that of the last three New American Homes ${ }^{\circledR}$. The design featured several advanced systems including improved building enclosure insulation, enhanced building airtightness, higher-performance windows, external shading devices, high-efficiency heating and cooling equipment, and mechanical ventilation. Optimized HVAC and energy-efficient lighting strategies were recommended. The reasons behind each not being implemented are also discussed.

\section{Construction Challenges}

\section{Building Enclosure Insulation}

A 15-in.-wide ICF system, including 10-in.-wide concrete core and a thermal resistance value of R-22, was chosen as the structural and insulating system for the exterior walls and basement.

Figure 28 and Figure 29 show the ICF systems under construction. The builder made this choice after a presentation by the Portland Cement Association on the system's merits, namely reduced construction time and increased durability, airtightness, and thermal performance over framedwall systems. The mass of the ICF wall will also have an effect the impact of solar radiation. We suspect that this will result in a more gradual distribution of heat through the wall assembly, thereby lowering cooling load peaks and allowing for a more-uniform distribution of heat gain.

At first, the builder was considering using a poured-concrete foundation system insulated on the exterior with a rigid or semi-rigid insulation board to a minimum level of R-10. After an examination of the connection details that would be required at the top of the foundation wall with the ICF system, the logistics of having another subcontractor and the aforementioned benefits of ICFs, the builder choose to use the ICF system as the only structural system for the home. 
Structural insulated panels (SIPS) made up of an EPS core bonded between two layers of OSB were used as the roof deck (Figure 30). Panels are 8.25 in. thick and provide R-30 thermal performance. The panels were placed within a structural steel skeleton and then fastened to the steel. The roofing material used is copper. The copper roofing was placed over two layers of 7/8in.-thick plywood, which sat directly on the panels. We recommended that the roofing sit on battens, thereby allowing for the creation of an air space, which would limit heat gain to the roofing panels, limit the temperature of the copper, and allow the roofing and the panel to cool during cooler periods.

\section{Building Enclosure Air-tightness}

A great deal of emphasis was placed on sealing gaps in the building enclosure and the connections between the different components. The most prominent connection point between component systems was at the SIPS roof to ICF wall intersection. The air tightness of the roof system was also considered. The numerous penetrations through the building enclosure were sealed as well.

Recommendations on Building Enclosure. The site superintendent for the pilot home believed that construction time savings could be realized when using insulated concrete forms, especially if the house is designed structurally from the start based on this system. He noted that the less the design is architecturally complicated, the faster the installation of the ICF system. The EnergyGauge software estimated that the mass effect alone of the ICF system has a noticeable reduction in energy consumption, particularly the amount of energy in therms used for heating.

The use of SIPS was also well received because of its quick installation. Merlin may use this product again in vaulted-ceiling applications. Turning an attic into semi-conditioned space creates a haven for air handlers and ductwork away from the extremely hot temperatures associated with a vented attic. Leaky return-system ductwork in the attic no longer draws very hot air in the summer, which raises the temperature of air being delivered to the home. The result is that the air handler has to work longer for the setpoint temperature to be reached. Therefore, even where roof plans do not call for a vaulted or cathedralized ceiling, SIPS for the roof are recommended to create a conditioned space in the attic.

Because many of the homes Merlin builds sell for more than a million dollars and cost hundred of thousands of dollars to construct, they can more easily absorb any additional costs associated with advanced-building enclosure systems, such as ICF or SIPS. The energy-efficiency value of building-enclosure improvements, as presented in Tables 10 and 11, was the second highest of all improvements.

\section{High-Performance Windows}

Aluminum-clad, wood-framed windows with double glazing and a spectrally selective lowemissivity coating and U-values of 0.36 and SHGC of 0.35 were used for the project. The low $U$ and SHGC values of these windows will result in reduced cooling and heating loads compared to the builders' standard window, which have U-values of 0.47 and SHGC of 0.50. Eight sets of French doors with U values of 0.38 and SHGCs of 0.21 were installed. Approximately $45 \mathrm{ft}^{2}$ of single glazing, with $25 \mathrm{ft}^{2}$ facing south and the rest facing west, exists in the second-floor master shower. A U-value of 1.11 and SHGC of 0.86 is assumed for these windows. Privacy control is an issue for the master shower. 
Table 10. Summary of Predicted End-use Site Energy for Merlin Contracting Project

\begin{tabular}{|c|c|c|c|c|c|c|}
\hline \multirow[b]{2}{*}{ End-Use } & \multicolumn{2}{|c|}{$\begin{array}{l}\text { Building America } \\
\text { Benchmark }\end{array}$} & \multicolumn{2}{|c|}{$\begin{array}{l}\text { Builder Standard } \\
\text { Home }\end{array}$} & \multicolumn{2}{|c|}{$\begin{array}{l}\text { Pilot Home } \\
\text { As Built }\end{array}$} \\
\hline & $\mathrm{KWh}$ & therms & KWh & Therms & KWh & Therms \\
\hline $\begin{array}{l}\text { Space } \\
\text { Heating }\end{array}$ & 451 & 638 & 518 & 730 & 87 & 144 \\
\hline $\begin{array}{l}\text { Space } \\
\text { Cooling }\end{array}$ & 12,114 & & 19,556 & & 6,075 & \\
\hline DHW & & 139 & & 139 & & 150 \\
\hline Lighting & 4,599 & & 4,599 & & 4,599 & \\
\hline Subtotal & 17,164 & 777 & 24,673 & 869 & 10,761 & 294 \\
\hline Equipment & 669 & 150 & 669 & 150 & 669 & 150 \\
\hline Miscellaneous & 8,962 & & 8,962 & & 8,962 & \\
\hline Total & 26,795 & 927 & 34,304 & 1,019 & 20,392 & 444 \\
\hline
\end{tabular}


Table 11. Summary of Estimated End-use Source Energy

\begin{tabular}{|c|c|c|c|c|c|c|c|}
\hline \multirow[b]{3}{*}{ End-Use } & \multirow{2}{*}{\multicolumn{3}{|c|}{ Annual Source Energy }} & \multicolumn{4}{|c|}{ Estimated Source Energy Savings } \\
\hline & & & & \multicolumn{2}{|c|}{$\%$ of End Use } & \multicolumn{2}{|c|}{$\%$ of Total } \\
\hline & $\begin{array}{c}\text { BA } \\
\text { Benchmark } \\
\text { (MBTU) }\end{array}$ & $\begin{array}{l}\text { Builder } \\
\text { Standard } \\
\text { (MBTU) }\end{array}$ & $\begin{array}{c}\text { Pilot } \\
\text { Home } \\
\text { (MBTU) }\end{array}$ & $\begin{array}{c}\text { BA } \\
\text { Benchmark }\end{array}$ & $\begin{array}{l}\text { Builder } \\
\text { Standard }\end{array}$ & $\begin{array}{c}\text { BA } \\
\text { Benchmark }\end{array}$ & $\begin{array}{l}\text { Builder } \\
\text { Standard }\end{array}$ \\
\hline Space Heating & 70 & 80 & 16 & $77 \%$ & $80 \%$ & $14 \%$ & $13 \%$ \\
\hline Space Cooling & 131 & 211 & 65 & $50 \%$ & $69 \%$ & $17 \%$ & $31 \%$ \\
\hline DHW & 14 & 14 & 15 & $-7 \%$ & $-7 \%$ & $0 \%$ & $0 \%$ \\
\hline Lighting & 50 & 50 & 50 & $0 \%$ & $0 \%$ & $0 \%$ & $0 \%$ \\
\hline Subtotal & 265 & 355 & 146 & $45 \%$ & $79 \%$ & $31 \%$ & $44 \%$ \\
\hline Equipment & 23 & 23 & 23 & $0 \%$ & $0 \%$ & $0 \%$ & $0 \%$ \\
\hline Miscellaneous & 97 & 97 & 97 & $0 \%$ & $0 \%$ & $0 \%$ & $0 \%$ \\
\hline Total & 385 & 475 & 266 & $31 \%$ & $44 \%$ & $31 \%$ & $44 \%$ \\
\hline
\end{tabular}


Recommendation. In the hot climate of Las Vegas, the energy savings are obvious when using windows that have a low-emissivity coating compared to those that do not. Merlin should consider using these windows on all their homes and can sell the added benefit that upholstery fabrics are less likely to fade and that the temperature in the home will be more uniform from room to room. Upgrading to these windows will mean an additional cost, but the load reduction from the windows is key to optimizing the entire HVAC system and, thereby, reducing overall construction costs and increasing system efficiency. Window performance values of $U=0.35$ and $\mathrm{SHGC}=0.35$, or better, are recommended for Las Vegas.

\section{External Shading}

Second-floor areas with fenestration are shaded externally by 9-in. by 2 -in. copper-clad wooden sunshades. The roofing system was designed by the architect to extend over most of second-floor outdoor decks, thereby providing relief from the summer sun. On the west side of the first floor, externally mounted shade covers can roll down in front of glazing from its soffit location. The covers can be controlled to roll down as far as necessary to prevent solar heat gain. Internal shade covers are in place on south- and west-facing glazing.

\section{HVAC Equipment Efficiencies}

Four pieces of high-efficiency equipment serve the house through five zones, all situated within conditioned space. An air-source heat pump with a COP 3.6 at $47^{\circ} \mathrm{F}$ and 16 SEER serves the basement, which includes two bedrooms. A heat pump was selected for this zone in order to highlight Lennox's new system. Two two-speed air handlers with 94\% AFUE and 14.8 and 15.9 SEER condensing units serve the first floor, with one unit dedicated only for the living room. For these units, an airtight mechanical room was built. Lastly, one air handler with 94\% AFUE and 15 SEER and two zone-control dampers serve the second floor.

Recommendations. Merlin gained experience with using high-efficiency furnaces and condensing units in the pilot home. According to the builder's HVAC subcontractor, to upgrade to a high-efficiency 93\% AFUE furnace costs about $\$ 400$ more. To upgrade to a high-efficiency 16 SEER condensing unit from a 12 SEER unit costs about four times more - a significant price increase. Clearly, such a pricing structure by condensing unit manufacturers creates an obstacle to the use of 16 SEER equipment. Another reason Merlin does not use higher efficiency HVAC equipment is that their clientele are wealthy and are not usually concerned about spending less in utility costs. In any case, we recommend that subcontractors use higher efficiency HVAC equipment, 93\% AFUE furnaces and 14 SEER condensing units.

\section{Air Distribution}

All ductwork in the home is inside the conditioned enclosure. In addition, to improve HVAC system airtightness, UL 181-approved mastic sealant was applied on all joints between all pieces of ductwork, as well as joints in the furnace and joints between ductwork and the furnace. Caulking material, specifically for galvanized ducts, was used on the joints in the second-floor air-distribution system. This approach was specifically used because of the exposed nature of the ductwork and the more presentable finish provided by the caulking-over-mastic sealant. 
A detailed duct layout based on calculated loads and predicted air movement was developed to ensure that correctly sized ductwork could efficiently move air from the three air handlers and the heat pump. The builder chose instead to use the design from a local HVAC engineering firm that they use for all of their HVAC design services.

\section{Mechanical Ventilation}

The builder installed a heat recovery ventilator (HRV) to provide a balanced source of mechanical ventilation. The ventilator delivers air to the return plenum of the two first-floor air handlers. Our initial recommendation was to have an HRV installed on each floor. According to manufacturers' specification, the unit will deliver a total of $200 \mathrm{cfm}$ of outdoor air on a continuous basis.

Recommendations. As Merlin increases the airtightness of their homes, mechanical ventilation will be needed. By explaining the benefits of such a system to enhancing indoor air quality, this need has become apparent to Merlin. The heat-recovery ventilator is a good choice for the Las Vegas climate, and we recommend that Merlin use them in future homes.

\section{HVAC Optimization}

An engineered HVAC system design was developed for the pilot home by IBACOS. The design determined that with the use of spectrally selective high-performance windows, good thermal performance in the foundation walls, exterior walls and roof, and an airtight building enclosure, the HVAC equipment did not need to have the capacity suggested by a conventional design based on ACCA Manual J (1992) calculations performed by the local HVAC engineering firm. The conventional design estimated that 18 tons of cooling capacity would be needed for the home, while our final design estimated that 13.5 tons would be sufficient. In addition, our design is based on a $70^{\circ} \mathrm{F}$ setpoint temperature used for cooling system design as requested by the builder and a lighting load of 2 watts per square foot of floor area, which is reflective of show home conditions in Las Vegas based on information obtained from a lighting survey conducted at TNAH ${ }^{\circledR} 2003$. In addition, our design was based on smaller airflows occurring over a longer period of time and, thereby, minimized the start-up frequency of HVAC equipment and allowed units to reach the best operating efficiency.

In an effort to use the equipment we specified while still using the conventional design for the air distribution system, we recommended a plan to the local HVAC engineering firm to make some of the registers temporarily inactive and, thereby, reduce airflow to the particular room. The plan would allow for equipment change-outs to occur if larger capacity units were necessary, while allowing for the use of the conventional air-distribution system design. This plan was rejected as being too complicated and hard to implement.

The builder indicated that over-sizing of cooling equipment capacity was standard practice for their homes because it ensured that homeowners could always be adequately cooled. Apparently custom home purchasers are sometimes inclined to set temperatures very low in the summer, as low as $63^{\circ} \mathrm{F}$. In the end, the builder choose to follow the complete conventional design approach, because it had a track record of keeping customers satisfied and was guaranteed in their eyes by the local HVAC engineering firm, even though it was stressed to them to have excessive capacity would be inefficient. If any of Merlin's customers had comfort complaints in their homes, the local HVAC engineering firm would do what was necessary, including replacing equipment, to 
ensure the customer was satisfied. As the project neared completion, the builder had misgivings regarding not following our design approach, having had adequate time to consider the benefits of an optimized HVAC system design.

With respect to air distribution, our analysis determined that if the conventional design was followed, air movement would be noticeable by the occupants, and they would possibly experience discomfort as a result of drafts and frequent start-ups. For example, in the living room we recommended that $805 \mathrm{cfm}$ of air be delivered, while the conventional design specified 1600 $\mathrm{cfm}$.

Recommendation. According to heating and cooling load calculations, which took into account the improved thermal performance of the home through higher-performance windows, increased building airtightness and improved thermal enclosure, it was determined that 13.5 tons of cooling capacity could adequately condition the home. Instead of following our design, Merlin chose to follow the conventional design offered by their HVAC engineer and installed 18 tons of cooling equipment. Long-term monitoring equipment is being used to evaluate if temperature and humidity conditions are being maintained at a comfortable level. We expect that the frequency of HVAC equipment start-ups will be noticeable and that anecdotes from homeowners will reflect drafty and possible uncomfortable conditions in several rooms. We plan on sharing this monitoring information with Merlin and their HVAC engineer in an attempt to get them to optimize their HVAC design in future homes.

\section{Energy-Efficient Lighting}

IBACOS, in conjunction with a lighting designer from the General Electric Lighting Center, developed an energy-efficient lighting design for consideration by the architect. The design highlighted the use of compact fluorescent lamps and lighting distribution that improved the quality of lighting in each room. But, because of the showcasing aspects for this home, the architect opted to only work with a lighting manufacturer and their designers on the lighting design and the fixture and lamp selection. Consequently, many fixtures were selected for their aesthetic appeal only rather than considering their energy use and lamp longevity.

Recommendations. The houses built by Merlin contain many lighting fixtures. To reduce peak cooling loads and reduce energy use, we recommend that they use energy-efficient lighting where possible. The recommendations made in the energy-efficient lighting design developed for the pilot home should be followed in future projects.

The analysis determined that the pilot home as built will save $45 \%$ with respect to the Benchmark and 79\% with respect to the Builder Standard Home for end-use source energy related to space heating, space cooling, domestic hot water production, and lighting. Total savings are $31 \%$ with respect to the Benchmark and $44 \%$ with respect to the Builder Standard Home. The total savings values reflect the fact that lighting and appliance energy use was constant between the three comparison homes. 
Development: Armory Park del Sol

Builder: $\quad$ John Wesley Miller Companies

Location: $\quad$ Tucson, Arizona
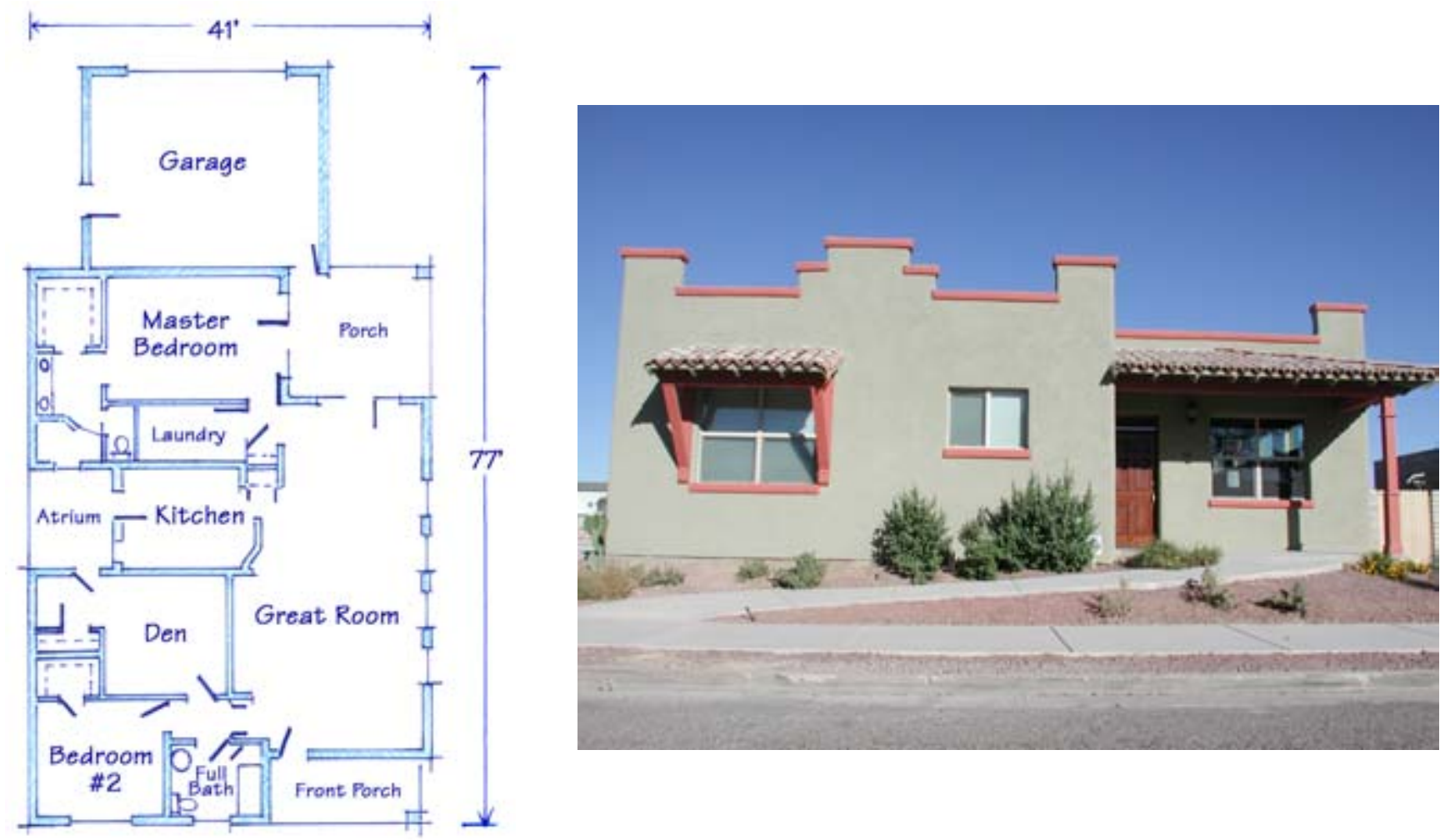

Figure 32. Floor plan (left) of Amory Park del Sol (right)

\section{An Award-Winning Community}

As the 2005 EnergyValue Housing Award Builder of the Year, John Wesley Miller (JWM) Companies' mission is energy efficiency. John Wesley Miller Said, "Our mission is to design and build the most energy efficient development in the world by incorporating the latest energy saving technologies...in all of the homes we build." The Armory Park del Sol development (Figure 32) in downtown Tucson combines desert-climate appropriate designs with roof solar energy production to win Sonoran Institute's Livable Community Award (2005), SAHBA Builder of the Year (2003), and City of Tucson's Most Energy Efficient Builder (2003). 
Table 12. Energy Simulation of John Wesley MIller Compared to Benchmark

\begin{tabular}{lccc}
\hline \hline & $\begin{array}{c}\text { Tucson } \\
\text { Benchmark } \\
\text { (kWh) }\end{array}$ & $\begin{array}{c}\text { Armory } \\
\text { Park del } \\
\text { Sol } \\
\mathbf{( k W h )}\end{array}$ & $\begin{array}{c}\text { Energy } \\
\text { Savings }\end{array}$ \\
\hline \hline Cooling & 7,958 & 2,487 & $-69 \%$ \\
Heating & 2,146 & 811 & $-62 \%$ \\
Hot Water & 2,410 & 2,410 & $-0.0 \%$ \\
Lighting & 2,351 & 1,776 & $-25 \%$ \\
Appliances & 1,969 & 1,942 & $-1 \%$ \\
Miscellaneous & 3,471 & 3,471 & $0.0 \%$ \\
Total (without solar) & $\mathbf{2 0 , 3 0 5}$ & $\mathbf{1 2 , 8 9 7}$ & $\mathbf{- 3 7 \%}$ \\
Solar Hot Water & & 9,20 & \\
Solar PV System & & 2,491 & \\
Total (with solar) & $\mathbf{2 0 , 3 0 5}$ & $\mathbf{9 , 4 8 6}$ & $-\mathbf{5 3} \%$ \\
\hline
\end{tabular}

\section{Measuring Up}

An analysis of energy use for the prototype home in comparison to the Benchmark for Tucson shows that the Armory Park del Sol homes were estimated to consume 37\% less energy, not including the solar systems savings. The energy continues to reduce to $53 \%$ when including the solar hot water and PV systems. Table 12 shows a breakdown of the primary energy uses.

When analyzing utility bills for a number of homes similar to the prototype, an average of 9,730 $\mathrm{kWh}$ was shown as being purchased. These data includes the solar hot water and PV system supply to the home - proof that a well-designed and constructed energy-efficient home does live up to its reputation.

\section{A Solar Community Develops}

As a builder and developer, John Wesley Miller Companies arranged the lots in the Armory Park del Sol subdivision so that each home could have optimal orientation for a solar PV and hotwater system. The covenants, codes, and restrictions for the development govern the placement and maximum height of trees to avoid shading on the rooftop solar systems. Desert-style parapet walls are ideal in keeping solar hot water and PV panels out of sight. 


\section{Solid Construction}

In the Tucson climate, Miller feels, masonry construction adds a lot of value to the company's homes. JWM Companies' wall system, which consists of CMUs with solid grout, R-12 exterior rigid foam, and interior steel-framed walls, produces a tight house $\left(2.9 \mathrm{ACH}_{50}\right)$ with little additional air sealing required. Because plumbing and electrical lines run through the interior steel-framed walls and all ducts are in the conditioned space, no additional air sealing is needed for mechanical penetrations.

Concrete construction provides a thermal mass to temper the extreme heat and cold of the desert climate. Miller explains that the thermal mass property of solid-grout concrete block, combined with exterior insulation, helps temper the indoor environment from the extreme outdoor conditions. In addition, people are willing to pay for the quality of the company's masonry construction. "The resale value is much higher for masonry," Miller says.

\section{Selective about Windows}

Spectrally selective coatings on the windows offer protection from the brutal Tucson heat and sun. Having a low U-value of 0.32 prevents conduction of heat indoors and heat loss during the cool nights. The low SHGC of 0.30 helps mitigate direct solar heat gain during the summer months.

\section{Engineering the HVAC System}

As part of the design team, a local professional engineer conducts an analysis on all plans for proper sizing of HVAC equipment and location of ductwork. Miller relies on the engineer, who he describes as a "practical guy who grew up in the tin-bending business."

The high ceilings and architectural features, combined with a knowledgeable HVAC engineer, make it possible for the company to bring all the ductwork into a conditioned space. The ducts are enclosed in soffits below the insulation along the central core of the house plan. All ducts are sealed with mastic and tested for leakage. A central return, as well as transfer grilles across interior doorways, helps equalize the pressure throughout the house.

\section{Exploring and Experimenting}

JWM Companies is constantly seeking new and interesting building techniques and materials. Consideration is given to the cost of new features. However, according to John Wesley Miller, it isn't always the only consideration. Miller said, "A lot of what we do is trying something to see if it works instead of adopting only what is proven. We don't always look at the cost-benefit analysis. I like to explore and experiment and try things to see what happens. It's research and it's fun." In addition, practicality often factors into Miller's decision to use a new product; products must be locally available and must fit neatly into the construction schedule.

To this end, JWM Companies relies heavily on the subcontractors with which it has loyal and longstanding relationships. The company works closely with the trade contractors to determine the best materials, production, and processes to minimize energy use and take advantage of the abundant solar resource. Periodic meetings with staff and trades are held to review building practices, identify problems, and implement solutions. 


\section{Builders as Environmentalists}

As John Wesley Miller summarizes, "Builders are the environmentalists because we construct the built environment. We have the opportunity to improve that built environment every day and every year, to provide a higher quality of life. We are the ones that can raise the bar to which all of us strive. That's what we, as builders, can do to improve people's quality of life."

\section{Utility Inspiration and Perspiration}

Efficiency features make the cost of heating and cooling very low. According to an independent study, the utilities for an average home in the Armory Park del Sol subdivision run about half of what a typical new home in the city costs. Through a synergistic partnership with Tucson Electric Power (TEP), the home's heating and cooling bills are guaranteed not to exceed $\$ 0.76$ per day for 5 years.

Under the TEP program, periodic quality inspections are performed - at the framing, insulation, and HVAC phases - plus a final inspection. The builder can be assured that the house was constructed as designed; TEP adds a new house to its customer base that sends power to the utility grid at times when TEP needs it most; and the customer's utility bills are guaranteed to fall below a certain amount each month.

Inspections include performance testing to check whole-house air leakage, duct leakage, and pressure in each room with the doors closed. Reducing the pressure difference across interior doorways facilitates air circulation to all rooms and results in a more comfortable home.

\section{A Good Deal}

Each home in the subdivision features a solar electric and solar hot-water system. John Wesley Miller Companies has the advantage of working with a progressive utility company that is aggressively encouraging the installation of renewable energy power systems. Currently, the rebate for solar systems is $\$ 3$ per installed watt. Therefore, all new homes in Armory Park del Sol are getting a $\$ 4,500$ rebate from the power company, in addition to lower energy bills, for their $1.5-\mathrm{kW}$ photovoltaic system. In turn, Arizona provides a $\$ 1,000$ tax credit for solar water heating and solar electric systems.

\section{Builder Innovation, Challenges, and Lessons Learned}

Though constructing homes for more than 50 years, JWM continues to search for new opportunities to improve his product and process. While most homes constructed in the area have switched to light-frame materials, the Armory Park del Sol homes are constructed of solid grout block, with the insulation attached to the exterior of the block leaving the interior surface to be finished with a skim coat of plaster, and a stable exterior surface that reduces stucco cracks. The comfortable and solid feel to the wall are major selling points that differentiate JWM from the competition. In addition, the homes use a parallel-piping system for the hot-water plumbing, one of the lessons learned from early homes to improve hot water delivery time and reduce water use. And although popular with some customers, the builder has stopped the use of recessed light fixtures because of the energy penalties that are difficult to overcome. 
For builders in a sunny desert climate looking to improve energy efficiency, Miller feels that builders should install a solar hot water system. Next, he recommends looking at windows with low U-factors and low SHGC. He suggests that builders should look at the value of thermal mass storage with masonry walls and exterior insulation. Finally, he adds, "Everyone should be insulating concrete slab foundations. A tremendous amount of heat goes out through the slab in the winter."

\section{Snapshot of Energy Features}

Floor Area

Construction Cost

Number of floors

Foundation Insulation

Wall Construction and Insulation

Ceiling/Roof Construction and Insulation

Windows

Air Sealing

Blower Door Test

Ducts

Duct Losses

Ventilation

Heating Equipment

Cooling Equipment

Hot Water System

Solar PV System

Lighting

Appliances

HERS Score
$1,916 \mathrm{ft}^{2}$

$\$ 148$ per $\mathrm{ft}^{2}$

one-story; slab-on-grade

R-12 slab-edge insulation

8-in. solid-grout CMU;

$\mathrm{R}-12$ exterior rigid foam

I-joists/flat roof;

R-38 fiberglass batt insulation

Low-E, gas-filled; $U=0.32$;

SHGC $=0.30$

Foam around rough openings of windows and doors

$2.9 \mathrm{ACH}_{50}$

$100 \%$ conditioned space;

$\mathrm{R}-6$ insulation

$15 \mathrm{cfm}$ total at 25 Pascals

Passive inlet to return side of air handler

HPSF 8.6 heat pump with programmable thermostat

12 SEER heat pump

Batch-type solar water heating system with tankless back-up

1.5-kW grid-connected photovoltaic system

Combination incandescent and fluorescent

ENERGY STAR ${ }^{\circledR}$ refrigerator (643 $\mathrm{kWh} / \mathrm{yr}$ ) and dishwasher (449 kWh/yr)

91.8 
Development: Gamlen House

Builder: $\quad$ Artistic Homes

\section{Location: $\quad$ Albuquerque, New Mexico}

The home is a $2700-\mathrm{ft}^{2}$, four-bedroom, three-bathroom, single-story home with an unvented conditioned crawlspace below (Figures 33, 34, 35). Key features include well-insulated building envelope, low-e windows, ducts and air handler in conditioned space, ENERGY STAR dishwasher, supply ventilation system, and a condensing gas furnace for water and space heating.

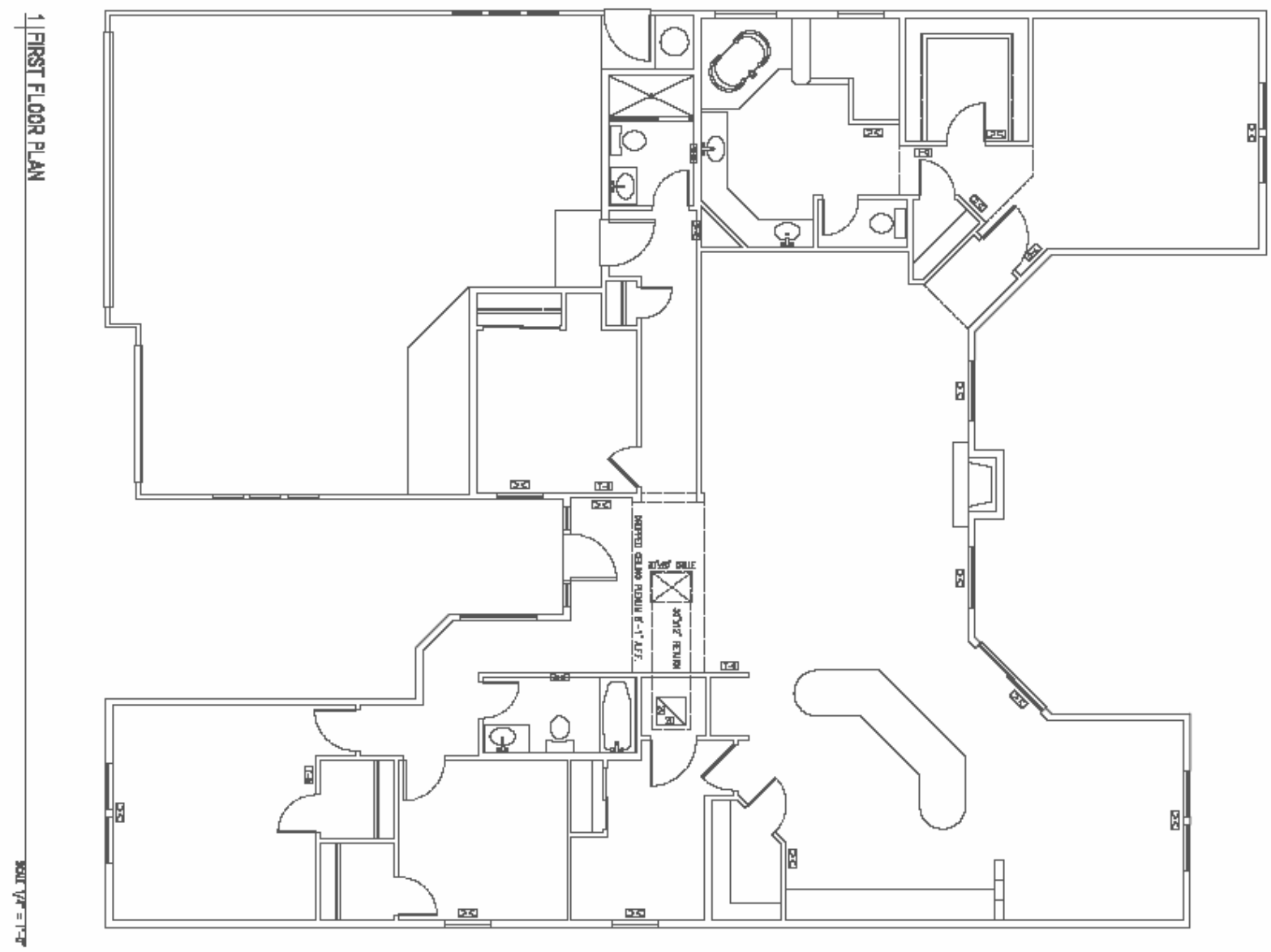

Figure 33. Gamlen House floor plan 


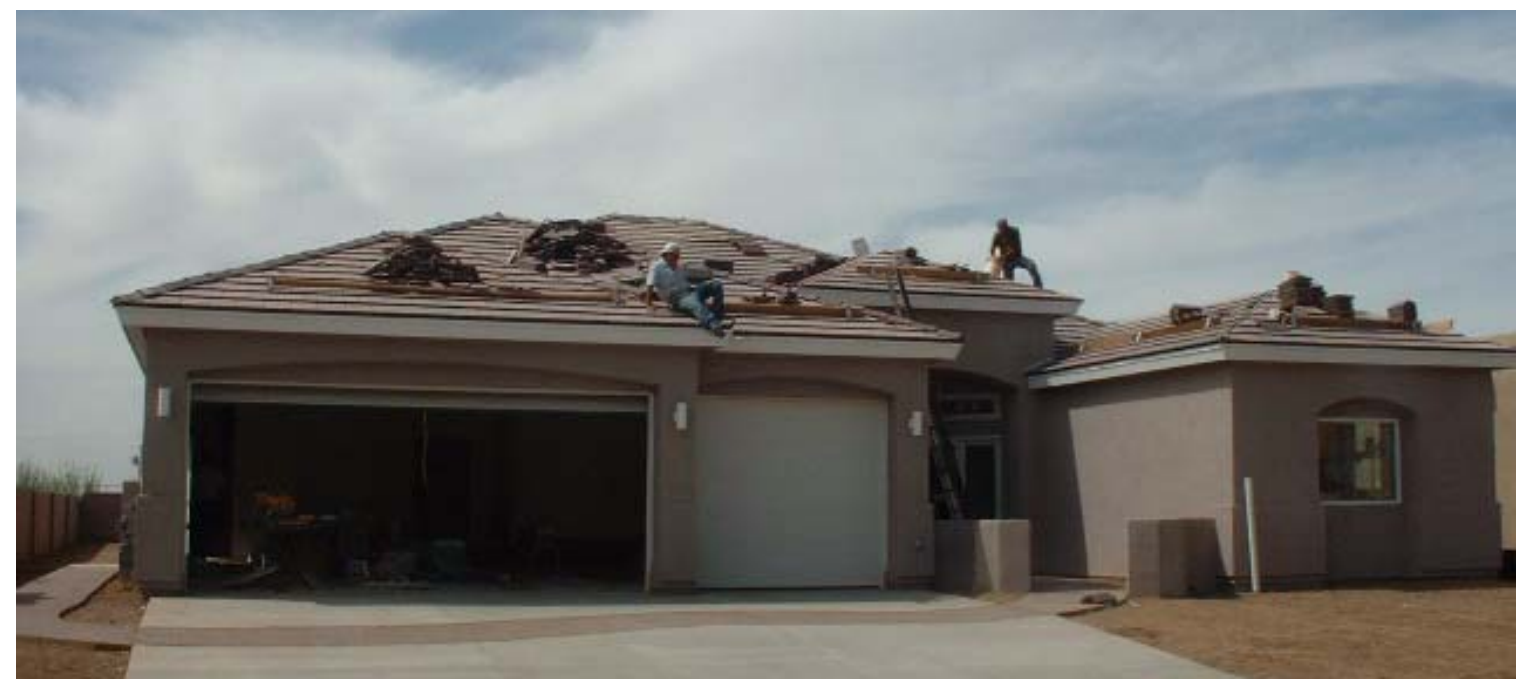

Figure 34. Gamlen House front elevation

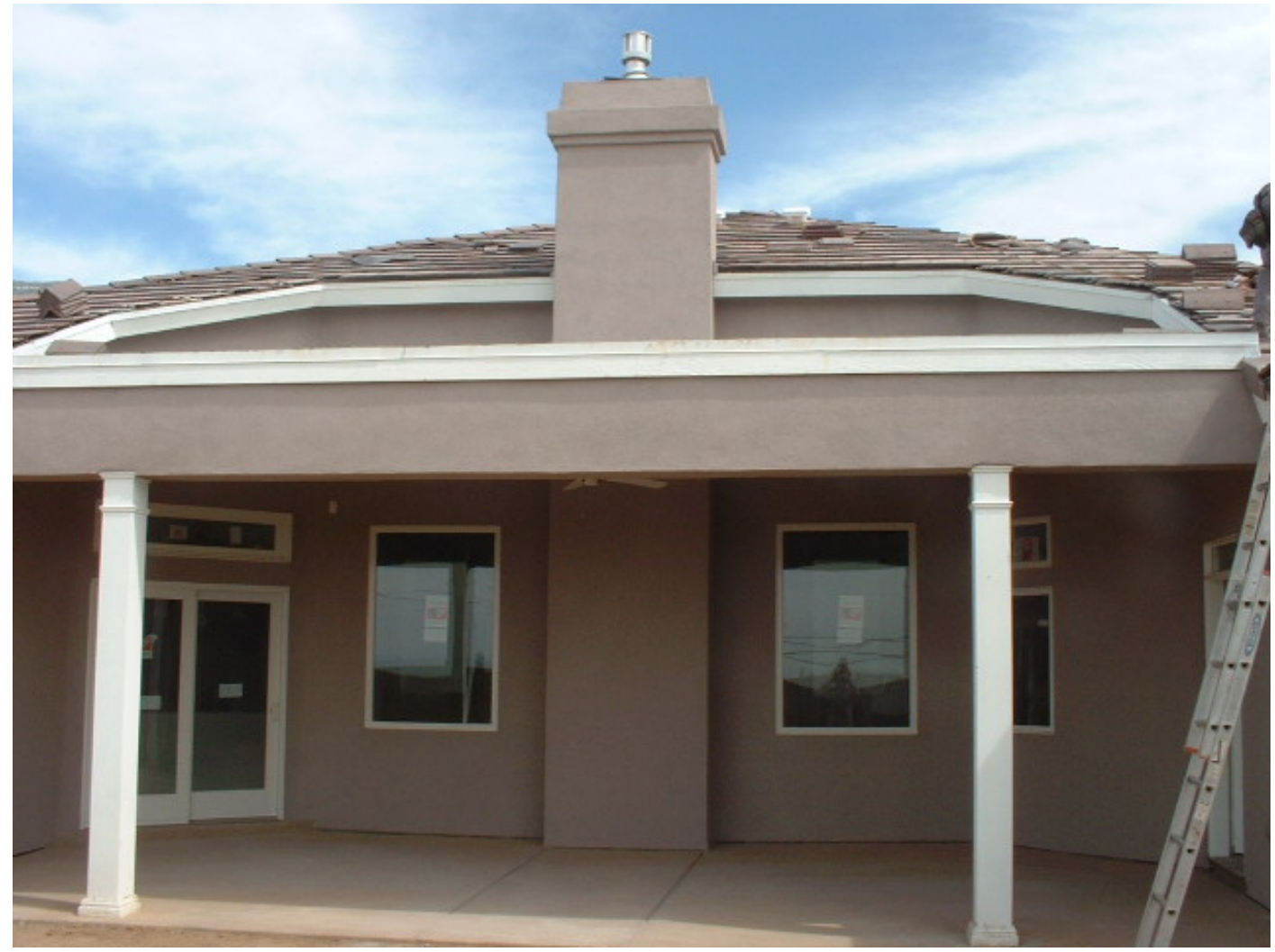

Figure 35. Gamlen House rear elevation 


\section{House Specifications}

Specifications are provided in Table 13.

Table 13. Specifications for Artistic Homes: Gamlen Residence, Albuquerque, New Mexico

\section{Benchmark Construction}

\section{Building America/EFL ${ }^{\mathrm{TM}}$} Platinum
Estimated Cost \$

\section{Building}

envelope

Ceiling $\quad \mathrm{R}-33$ on flat vented attic

$\mathrm{R}-38$ attic loose fill fiberglass

R-23 2x6 24 oc +

Walls

R-11.7 16 oc

$\mathrm{R}-1.2$ asphalt impregnated

$\$ 0 *$

sheathing to exterior,

OSB on corners

cavity insulation Optima

dry-blown fiberglass

R-23 2x6 24 oc

Crawl Space

Walls

$\mathrm{R}-13.7$ on walls

R-14 2-in. Polyisocyanurate

Rigid Insulation

$\$ 150$

Windows

Single-pane TIM frame

Double-glazed Low-E ${ }^{2}$ vinyl

$\$ 1,000$

$U=0.44$, SHGC $=0.55$

vinyl frame; $U=0.35$,

$$
\mathrm{SHGC}=0.35
$$

2.5 in. $^{2}$ leakage area per

Infiltration

186 ELA 
Table 13 (continued). Specifications for Artistic Homes:

Gamlen Residence, Albuquerque, New Mexico

\begin{tabular}{|c|c|c|c|}
\hline & $\begin{array}{l}\text { Benchmark } \\
\text { Construction }\end{array}$ & $\begin{array}{c}\text { Building America/EFL } \\
\text { Platinum }\end{array}$ & $\begin{array}{c}\text { Estimated } \\
\text { Cost } \$\end{array}$ \\
\hline \multicolumn{4}{|l|}{$\begin{array}{l}\text { Mechanical } \\
\text { systems }\end{array}$} \\
\hline Heat & $\begin{array}{l}\text { 78\% AFUE in vented } \\
\text { attic }\end{array}$ & $\begin{array}{l}90 \%+\text { AFUE in } \\
\text { conditioned floor area }\end{array}$ & $\$ 1,000$ \\
\hline Cooling & 10 SEER A/C & 13 SEER A/C & - \\
\hline DHW & $\begin{array}{c}0.54 \text { naturally } \\
\text { aspirating gas water } \\
\text { heater in garage }\end{array}$ & $\begin{array}{l}0.86 \text { EF condensing gas } \\
\text { furnace in garage }\end{array}$ & - \\
\hline Ducts & $\begin{array}{c}\text { metal ducts in } \\
\text { conditioned crawl }\end{array}$ & $\begin{array}{l}\text { metal ducts in } \\
\text { conditioned crawl }\end{array}$ & $\$ 0$ \\
\hline Leakage & $15 \%$ of flow & $\begin{array}{c}\text { None }(5 \% \text { or less of } \\
\text { nominal flow to outside) }\end{array}$ & $\$ 0$ \\
\hline \multirow[t]{3}{*}{ Ventilation } & none & $\begin{array}{l}\text { Aircycler FR-V with } \\
\text { manual damper }\end{array}$ & $\$ 150$ \\
\hline & & $\begin{array}{l}\text { Resulting } 2 \text { ton } \\
\text { Downsizing }\end{array}$ & $-\$ 1,000$ \\
\hline & & Total & $\$ 1,450$ \\
\hline
\end{tabular}




\section{Specifications}

\section{Building envelope}

Ceiling

Walls

Crawl Space Walls

Windows

Infiltration

Mechanical systems

Heat

Cooling

DHW

Ducts

Leakage

Ventilation

\section{Building America}

$\mathrm{R}-38$ attic loose fill fiberglass R-23 2x6 24 oc + R-1.2 asphalt impregnated sheathing to exterior, OSB on corners cavity insulation Optima dry-blown fiberglass R-23 2x6 24 oc.

R-14 2" Polyisocyanurate Rigid Insulation Double glazed $\mathrm{LoE}^{2}$ vinyl vinyl frame; $U=0.35, S H G C=0.35$ $2.5 \mathrm{sq}$ in leakage area per $100 \mathrm{sf}$ envelope

\author{
Lennox CompleteHeat $₫$ Combo System AM30Q2/3-70 \\ 90\% $\mathrm{CA}_{\text {AFUE }}$ in conditioned space \\ 13 SEER A/C (First Air-Lennox) \\ Lennox CompleteHeat ${ }^{\circledR}$ Combo System HN30-100 \\ $0.86 \mathrm{CA}_{\mathrm{EF}} 34 \mathrm{gal}$ in garage \\ sheet metal \& flex in conditioned crawlspace \\ None (to outside; $5 \%$ or less) \\ AirCycler ${ }^{\mathrm{TM}}$ Supply-only system \\ 10 minutes on; 20 minutes off
}




\section{Innovative Features}

\section{Supply Ventilation System}

A supply-only ventilation system is specified. An outside air duct is run from the outside (through a gable end) to the return side of the air handler. The running air handler pulls outside air into the return system. A flow regulator or adjustable damper provides fixed outside air supply quantities independent of air-handler blower speed, and the HVAC system provides circulation and tempering. In addition to the flow regulator, an electrically operated damper will be installed to prevent excess ventilation during peak-load usage. This damper will automatically close the fresh-air duct to prevent outside air from diluting the conditioned air too much. This unit should be available through most HVAC contractors.

Continuous running of the air handler in order to draw ventilation air is not recommended. An AirCycler ${ }^{\mathrm{TM}} \mathrm{FR}-\mathrm{V}$ controller is suggested to run air handler periodically; it operates the fan only after a selected amount of time following last operation. Furthermore, this system reduces stagnation in the house by providing mixing of house air and controls the electrically operated damper to prevent over mixing.

\section{Conditioned Crawl Space}

This was Artistic Homes' first conditioned crawlspace. The design's intent was to ensure that the home would have the same outside appearance as the slab-on-grade product. This meant that the top of the floor had to be within 8 in. of grade. The detail shown below was the one chosen to accomplish this. The absence of a rim joist contributed to the tightness of the conditioned crawl as noticed in the blower-door tests (Figure 36).

\section{Builder Cost Summary}

Builder costs have been individually priced and the associated downsizing savings have been included to show net cost.

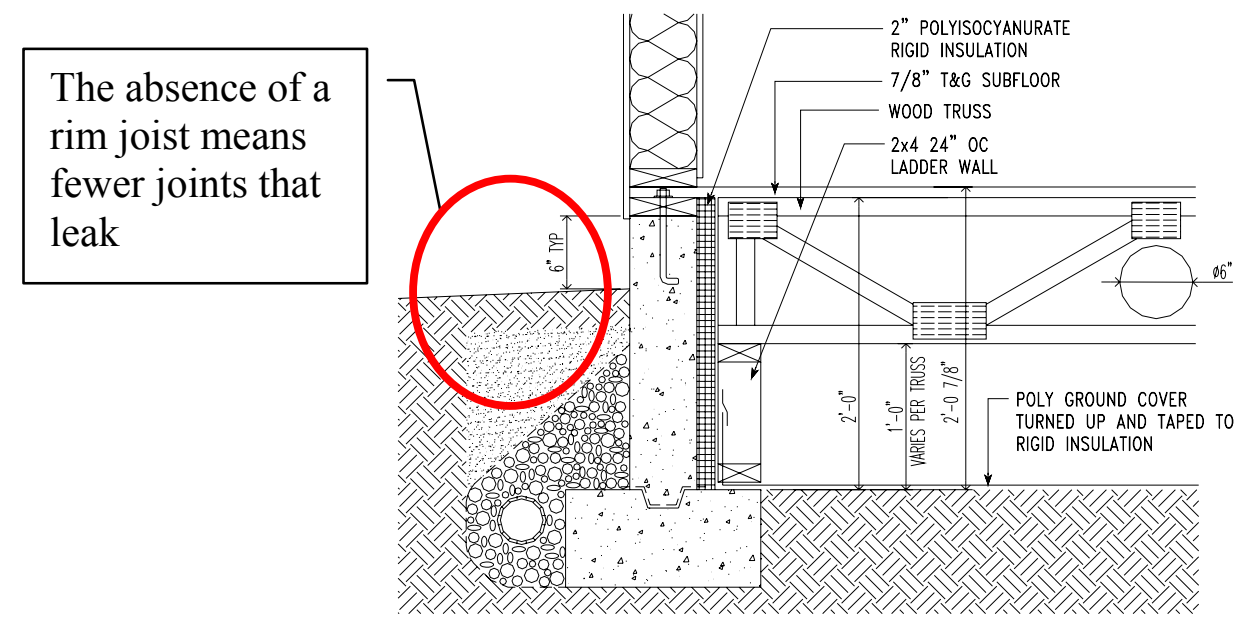

Figure 36. Rim joist 


\section{Utility Information}
Gas
PNM
$\$ 0.4226$ per therm $+\$ 9.00 /$ month
Electricity
PNM
$0-200=\$ 0.0720$ per $\mathrm{kWh}$
$200+=\$ 0.0843$ per $\mathrm{kWh}+\$ 3.00 /$ month

\section{Source Energy Consumption Summary}

The simulations have been updated with a multi-point blower door and single-point duct blaster, as well as a measured outside air intake flow. The savings increased by $5 \%$ as a result of the improved tightness and negligible duct leakage to outside. Note that the "Percent of End-Use" column shows how effective the prototype building is at reducing energy use in each end-use category. The "Percent of Total" column shows how the energy reductions in each end-use category contribute to the overall savings (Table 14 and Table 15).

Table 14. Source Energy Consumption Summary

\begin{tabular}{|l|c|c|c|c|}
\cline { 3 - 5 } \multicolumn{1}{c|}{} & \multicolumn{2}{c|}{} & \multicolumn{2}{c|}{ Source Energy Savings } \\
\cline { 3 - 5 } \multicolumn{1}{c|}{} & Estimated Annual Source Energy & Percent of End-Use & Percent of Total \\
\cline { 3 - 5 } \multicolumn{1}{c|}{} & $\begin{array}{c}\text { Benchmark } \\
\text { End-Use }\end{array}$ & $\begin{array}{c}\text { Proto } \\
10^{6} \text { BTU/yr }\end{array}$ & Proto savings & Proto savings \\
\hline Space Heating & 109 & 58 & $\mathbf{4 7 \%}$ & $\mathbf{1 9 \%}$ \\
\hline Space Cooling & 29 & 13 & $\mathbf{5 5 \%}$ & $\mathbf{6 \%}$ \\
\hline DHW & 31 & 21 & $\mathbf{3 3 \%}$ & $\mathbf{4 \%}$ \\
\hline Lighting & 27 & 27 & $\mathbf{0 \%}$ & $\mathbf{0 \%}$ \\
\hline Appliances + Plug & 76 & 76 & $\mathbf{0 \%}$ & $\mathbf{0 \%}$ \\
\hline OA Ventilation & & 0 & $\mathbf{0 \%}$ & $\mathbf{0 \%}$ \\
\hline Total Usage & 0 & 195 & $\mathbf{2 9} \%$ & $\mathbf{2 9} \%$ \\
\hline Site Generation & 0 & 0 & & $0 \%$ \\
\hline Net Energy Use & 274 & 195 & $29 \%$ & $29 \%$ \\
\hline
\end{tabular}


Table 15. Measured Data

\begin{tabular}{|c|c|c|c|}
\hline & & $\mathrm{TT}^{\mathrm{C}}$ "Th & \\
\hline Lot \#: 9 & Subdivision: & Address: & Date and time: \\
\hline Model: Gamlen & Primerose & 8609 Royaglo & 9/24/03 2:15 PM \\
\hline
\end{tabular}

\section{INITIALIZATION}

\begin{tabular}{|c|c|}
\hline Square feet & $2700 \mathrm{ft}^{2}$ \\
\hline Surface area (all outside surfaces, including foundation) & $9226 \mathrm{ft}^{2}$ \\
\hline Volume & 32997 cu. ft. \\
\hline Windspeed (approximate mph) & $\sim 0 \mathrm{mph}$ \\
\hline Outside temperature (estimated) & $80^{\circ} \mathrm{F}$ \\
\hline Check that all registers and bedroom doors are open & Yes $\backslash$ No $\square$ \\
\hline Static pressure in Supply and Return & $\mathrm{S}+5 \mathrm{~Pa} / \mathrm{R}-32 \mathrm{~Pa}$ \\
\hline Is there a ventilation system? & Yes $\$ No $\square$ \\
\hline Type of ventilation system (e.g., exhaust-only, HRV, ERV) & $\begin{array}{l}\text { Air Cycler Supply } \\
\text { Only }\end{array}$ \\
\hline If there is an AirCycler ${ }^{T M}$, enter the off / on times & on 8 \\
\hline Enter outside air duct pressure & $-35.4 \mathrm{pa}$ \\
\hline Type of outside air duct (flex/sheet metal; diameter) & 6-in. insulated flex \\
\hline Is there an adjustable outside air damper? & Yes $\triangle \mathrm{No} \square$ \\
\hline Is there a fireplace or wood stove? & Yes $\$ No $\square$ \\
\hline $\begin{array}{l}\text { Duct location (approximate \% in attic, conditioned space, } \\
\text { basement, etc.) }\end{array}$ & $\begin{array}{l}100 \% \text { Conditioned } \\
\text { Crawl }\end{array}$ \\
\hline
\end{tabular}

\section{PRESSURE TESTING}

\begin{tabular}{|c|c|c|}
\hline \multicolumn{2}{|c|}{ Stack Pressure (baseline with blower door installed; covers on) } & $-0.1 \mathrm{pa}$ \\
\hline \multicolumn{2}{|c|}{ Dominant Duct Leak Effect (baseline with HVAC system running) } & $\mathrm{pa}$ \\
\hline \multicolumn{2}{|c|}{$\begin{array}{l}\text { Master Bedroom Door Closure Effect ( } \triangle P \text { from main space to } \\
\text { outdoors) }\end{array}$} & $\mathrm{pa}$ \\
\hline \multicolumn{2}{|c|}{ All Doors Closed Effect ( $\Delta P$ from main space to outdoors) } & $\mathrm{pa}$ \\
\hline \multicolumn{2}{|c|}{ Fireplace/Wood Stove Zone HVAC Test } & $\mathrm{pa}$ \\
\hline \multirow{2}{*}{$\begin{array}{l}\text { Pressure In Each Closed Room. Not } \\
\text { available on initial test; no doors were } \\
\text { installed. }\end{array}$} & $\begin{array}{l}p \\
a\end{array}$ & $\begin{array}{l}p \\
a\end{array}$ \\
\hline & $\begin{array}{l}p \\
a\end{array}$ & $\begin{array}{l}p \\
a\end{array}$ \\
\hline
\end{tabular}


Table 15 (continued). Measured Data

\section{BLOWER DOOR TESTING (BDT)}

\begin{tabular}{|c|c|}
\hline Blower Door Location and Test Goal & Front Door (Goal = 2310 CFM 50) \\
\hline $\begin{array}{l}\text { Test 1: Transfer grilles open, hatches } \\
\text { closed }\end{array}$ & $\begin{array}{c}C F M 50=1217, L R=0.13, C=82.6, n=0.688, \\
R^{2}=0.99965\end{array}$ \\
\hline $\begin{array}{l}\text { Test 2: Transfer grilles open, hatches } \\
\text { open }\end{array}$ & $\begin{aligned} C F M 50=1214, L R & =0.13, C=80.0, n=0.695, \\
R^{2} & =0.99953\end{aligned}$ \\
\hline $\begin{array}{l}\text { Test 3: Transfer grilles closed, } \\
\text { hatches closed }\end{array}$ & $\begin{aligned} C F M 50=1216, L R & =0.13, C=87.7, n=0.672, \\
R^{2} & =0.99928\end{aligned}$ \\
\hline
\end{tabular}

\section{DUCT AIRTIGHTNESS TESTING (DAT)}

\begin{tabular}{|l|lr|c|}
\hline & DAT CFM25 TOTAL & $125 \mathrm{~Pa} 25$ Ring 2 & 170 CFM 25 \\
\hline & DAT CFM25 OUTSIDE & 0 Pa 25 Ring 3 & $\sim 0$ CFM 25 \\
\hline
\end{tabular}

AIR HANDLER FLOW MEASUREMENT (TRUEFLOW located at return)

\begin{tabular}{|c|c|c|}
\hline DG700 Reading & \multicolumn{2}{|c|}{ NSOP $=\sim 5.4 \mathrm{~Pa}$, TFSOP $=\sim 4.5 \mathrm{~Pa}$, Cooling Flow $=995$ CFM } \\
\hline DG700 Reading & \multicolumn{2}{|c|}{ NSOP $=\sim 5.0 \mathrm{~Pa}$, TFSOP $=\sim 4.7 \mathrm{~Pa}$, Heating Flow $=775 \mathrm{CFM}$} \\
\hline \multicolumn{3}{|l|}{ MECHANICALS } \\
\hline \begin{tabular}{|l} 
Furnace or air \\
handler
\end{tabular} & Make: Lennox CompleteHeat $(\subset$ & Model: AM30Q2/3-70 \\
\hline Air Conditioning & Make: Lennox & Model: HS26-030-4P \\
\hline Cooling Coil & Make: & $\begin{array}{l}\text { Model: BV } 124 \text { 36-BPA23 } \\
\text { 9GL58 }\end{array}$ \\
\hline Domestic hot water & Make: Lennox CompleteHeat $(\subset)$ & Model: HM61-100-1 \\
\hline
\end{tabular}




\section{Community-Scale Case Studies}

Development: Premier Gardens

Builder: Premier Homes

Location: Rancho Cordova, California

\section{Introduction}

The Zero Energy Homes (ZEH) in the Premier Homes development - "Premier Gardens" (Figures 37, 38, 39) is located in Rancho Cordova, California. The Sacramento Municipal Utility District (SMUD) is a primary sponsor and research partner with the Building America Program on this project. SMUD cost shared a portion of the incremental costs of the energy efficiency and renewable energy upgrades for the Premier homes. In addition, SMUD has instrumented 19 homes in the ZEH development and a nearby non-ZEH subdivision and is collecting and analyzing performance data on these homes to help evaluate the relative impact of ZEH features on peak and total energy consumption of the homes. A 2.4-kW DC buildingintegrated photovoltaic system is installed in each ZEH home. With building energy-efficient features, appliances, other appliance/plug loads and fluorescent lighting alone, the homes have achieved around 35\% energy savings without PV system and around $60 \%$ energy savings with PV system.

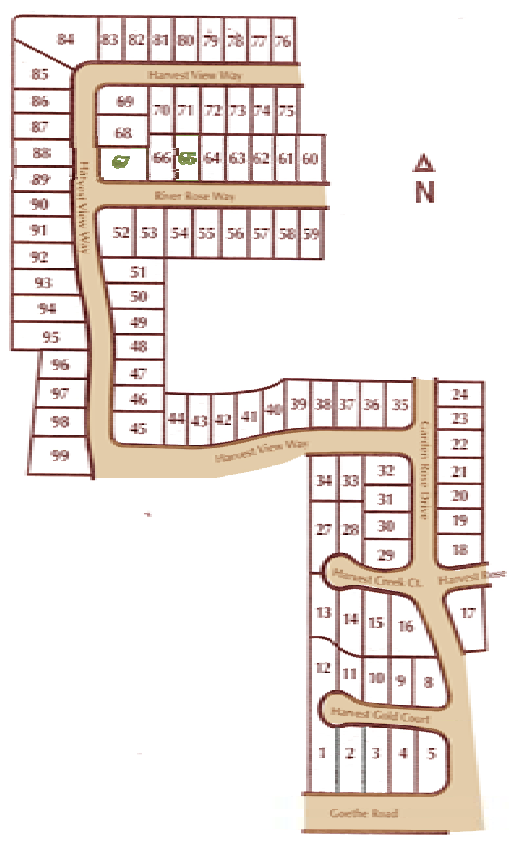

Figure 37. Premier Garden Homes site plan and elevation 


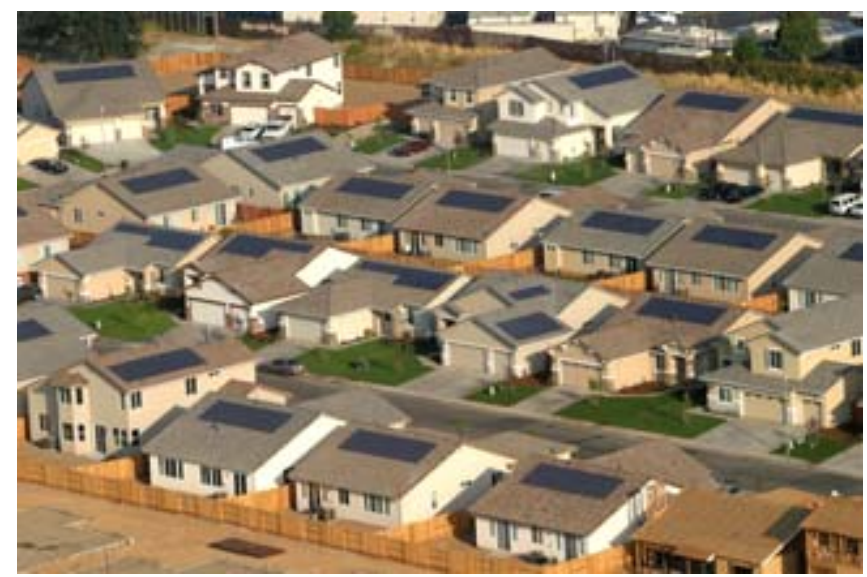

Figure 38. Aerial view of Premier Gardens (Premier Homes photograph courtesy of SMUD)

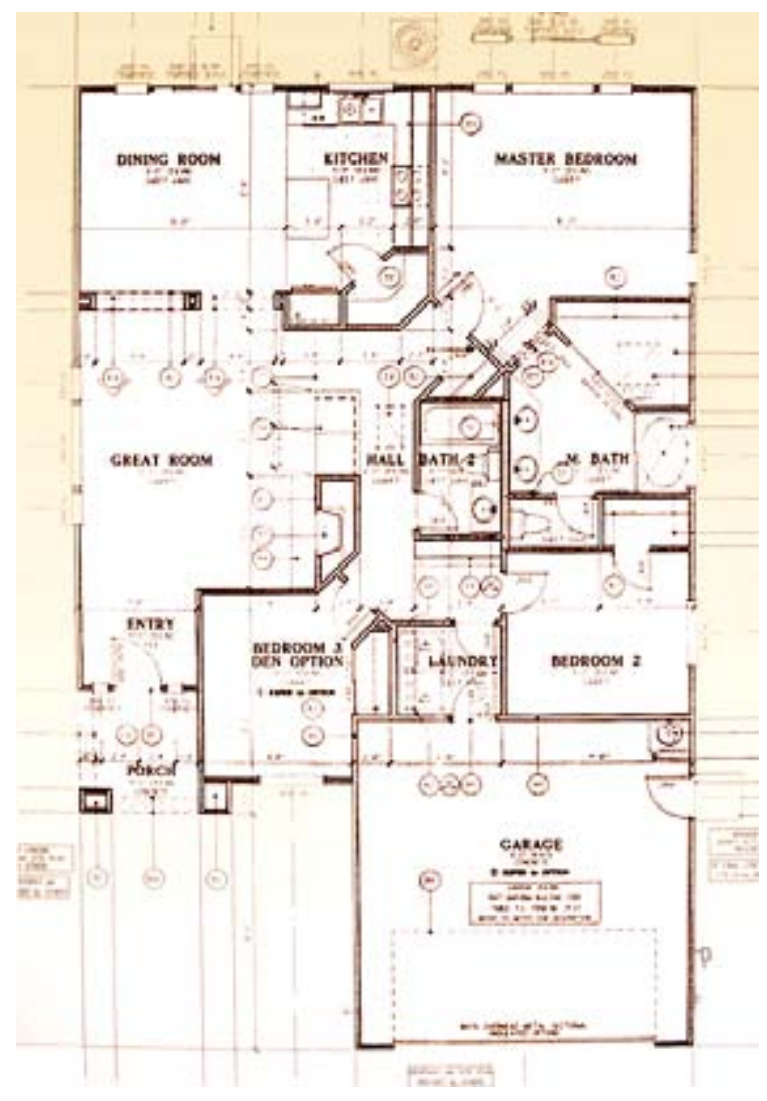

Figure 39. Floor Plan $1503 \mathrm{ft}^{2}$ (Lot 68) - (three bedroom, two baths, and one-car garage) 


\section{House Specifications}

To achieve $60 \%$ energy savings below the base case house, the Prototype BAP House requires the following advanced systems:

- $\quad$ R-38 attic insulation $(\mathrm{U}$-value $=0.031)$. High insulation reduces heat gain in summer and reduces heat loss in winter.

- R-13 fiberglass batts +1 -in. EPS foam $(U$-value $=0.067)$. This U-value reflects $25 \%$ framing factor.

- 3.5 SLA or low air infiltration rate. Tight building envelope to help minimize outside/inside air from entering/exiting the home. With lower infiltration of unconditioned air and exfiltration of conditioned air, less conditioning is required, making the home more efficient. Homes with low air infiltration/exfiltration are often quieter and cleaner.

- Dual-pane non-metal frame windows with spectrally selective glass with U- factor and SHGC no greater than that listed in Table 16.

These types of glazing help increase the comfort level of the home by reducing solar insolation into the house. In the summer, spectrally selective glass lets in visible sunlight while blocking $80 \%$ of both the infrared and ultraviolet solar energy (that drives up cooling costs and degrades curtains, window treatments, carpeting and furnishings). In the winter, these glazing products offer reduced heating costs by reflecting room-side radiant heat back into the room. ${ }^{57}$ In hot climates this type of glazing typically enables builders to reduce the size of air conditioners and decrease other building energy related features.

- Engineered System with Heating Ventilating and Air Conditioning (HVAC) efficiencies of 91\% AFUE for furnace and 14 SEER for air conditioning with thermal expansion valve (TXV). Licensed mechanical engineers size and select HVAC systems, design duct sizes, and register locations. The final engineered systems will have properly sized and balanced

Table 16. U-values and SHGC values for doors

\begin{tabular}{lcc}
\hline \hline & U-value & SHGC \\
\hline \hline Slider & 0.36 & 0.30 \\
Single Hung & 0.33 & 0.32 \\
Fixed & 0.30 & 0.33 \\
Sliding Patio Door & 0.34 & 0.30 \\
French Door & 0.33 & 0.28 \\
\hline
\end{tabular}

\footnotetext{
${ }^{57}$ Supplemental Catalogue for Cardinal IG: LoE ${ }^{2}$ Glass Products "The Choice for Year-Round Energy Savings and Comfort"
} 
HVAC systems with correct duct sizes and placement of registers, this will assure the conditioned air to be evenly distributed throughout the whole house. They will also provide improve efficiency and comfort. The TXV is a metering device for refrigerant flow into the evaporator of an air conditioner. A TXV improves efficiency.

- R-4.2 buried in insulation (R-13 equivalent) with tight duct and ACCA Manual D designed by a licensed mechanical engineer. Duct leakage can have a significant impact on HVAC performance, household infiltration/exfiltration rates, moisture levels in the house, water heater and furnace safety, and overall occupant comfort. A tight duct system is one that does not leak more than $6 \%$ of the fan airflow (at 50 Pascal). Excessive air leakages in duct systems make HVAC systems work harder, using more time and energy to cool or heat the home as a result of insufficient air delivery. This results in higher energy bills and less comfort for homeowners/occupants, which often triggers callbacks. Duct leakage typically occurs at these locations:

- Poorly fitted and improperly sealed joints and seams in the ductwork

- Disconnected and partially disconnected boot connections

- Holes in the ducts

- Use of improperly sealed building cavities for supply and return ducts

- Poor connections between room registers and register boots

- Poorly fitted air handler doors, filter doors and air handler cabinets.

Tight duct systems increase forced-air distribution efficiency, resulting in improved comfort and lower utility bills for homeowners. Tight ducts are required to be tested by a third party.

- One tankless water heater with a minimum Energy Factor (EF) of 0.82. R-4 insulation on all trunk lines. This includes any hot water lines located in concrete slabs or underground. A tankless water heater has high efficiencies. Hot water is heated upon demand and has no storage tank.

- All-fluorescent lighting. The wide variety of improved quality, more efficient lighting that are on the market today warrant more careful lighting design. Lighting plans are recommended and fluorescent lamps used wherever possible. Where possible, bayonetmount fluorescent should be used in compact-fluorescent fixtures. Where this is not possible, medium-base CFLs are permitted. Minimum recommended downlight specifications of fluorescent lamps should be $2700 \mathrm{~K}$ in cooler temperature, 23-26 watts, and 1300 lumens (used 26 watts). Vanity lighting requirements may vary.

- Gas dryer stub. This is provided to encourage the use of gas dryers, which are less expensive to operate than electric.

- Photovoltaic System. The 2.4-kW DC system by GE Energy produces on average 3420 $\mathrm{kWh} /$ year (or $285 \mathrm{kWh} / \mathrm{month}$ ). The building-integrated PV system not only produces electricity, but is also aesthetically pleasing by blending in with the roof tiles. 


\section{Calculated Energy Performance}

Table 17 lists the energy savings of the base case house compared to the prototype house.

Table 17. Lot $68\left(1503 \mathrm{ft}^{2}\right)$ Summary of Energy Savings (Micropas Simulation)

\begin{tabular}{|c|c|c|c|}
\hline & $\begin{array}{c}\text { Base Case } \\
\text { House }\end{array}$ & $\begin{array}{l}\text { Prototype } \\
\text { House }\end{array}$ & $\begin{array}{l}\text { Energy } \\
\text { savings }\end{array}$ \\
\hline Heating (from Micropas simulation) & $33,863 \mathrm{kBtu} / \mathrm{yr}$ & $16,849 \mathrm{kBtu} / \mathrm{yr}$ & $50 \%$ \\
\hline Cooling (from Micropas simulation) & $21,252 \mathrm{kBtu} / \mathrm{yr}$ & $5,095 \mathrm{kBtu} / \mathrm{yr}$ & $76 \%$ \\
\hline $\begin{array}{l}\text { Water Heating (from Micropas } \\
\text { simulation) }\end{array}$ & $22,951 \mathrm{kBtu} / \mathrm{yr}$ & $13,076 \mathrm{kBtu} / \mathrm{yr}$ & $43 \%$ \\
\hline Lighting & $20,550 \mathrm{kBtu} / \mathrm{yr}$ & $5,345 \mathrm{kBtu} / \mathrm{yr}$ & $74 \%$ \\
\hline Other Uses/Appliances/Plug Loads & $51,009 \mathrm{kBtu} / \mathrm{yr}$ & $49,659 \mathrm{kBtu} / \mathrm{yr}$ & $2.5 \%$ \\
\hline Whole House Energy Savings & 149,624 & 90,023 & $39 \%$ \\
\hline $\begin{array}{l}\text { Site Generation } \\
(2.4-k W D C P V \text { system) }\end{array}$ & & $\begin{array}{l}-35,017 \\
k B t u / y r\end{array}$ & \\
\hline Total & $\begin{array}{l}149,624 \\
\text { kBtu/yr }\end{array}$ & $\begin{array}{l}55,006 \\
\text { kBtu/yr }\end{array}$ & $63 \%$ \\
\hline
\end{tabular}




\section{Development: Lakeside}

\section{Builder: Morrison Homes \\ Location: $\quad$ Elk Grove, California}

Morrison Homes at Lakeside is located within the master-planned community of Lakeside in the "hometown" of Elk Grove, 25 miles south of Sacramento, California (Figure 40). Lakeside is one of the first homes under the U.S. Department of Energy's Zero Energy Homes (ZEH) initiative, in the Sacramento area. SMUD and ConSol were both invited by Morrison Homes to help them with the Lakeside project. This is a 120-home development with 12 homes being ZEH. Five home plans are available - and all are available with the ZEH package. Floor plans range from $2,126 \mathrm{ft}^{2}$ up to $3,672 \mathrm{ft}^{2}$. The community was originally designed with $\mathrm{ZEH}$ in mind, but no special architectural design was required for the reduced-energy homes. In addition, $\mathrm{ZEH}$ is an option available on most of the remainder of the regular homes, with a few exceptions where the roof's solar exposure is not optimal. Monitoring equipment has been installed on the model home. The Sacramento Municipal Utility District (SMUD) installed sensors for determining solar insolation and PV panel temperatures (Figure 41). SMUD provided considerable expertise aiding Morrison with solar features as well as providing hookup fee discounts related to home energy efficiency measures, incentives for efficient lighting and Energy Star home certification as well as PV buydowns. ConSol provided technical expertise to develop the efficiency package that, combined with the solar was agreeable to all to meet DOE, SMUD and Morrison objectives. ConSol and SMUD provided marketing support for the project.

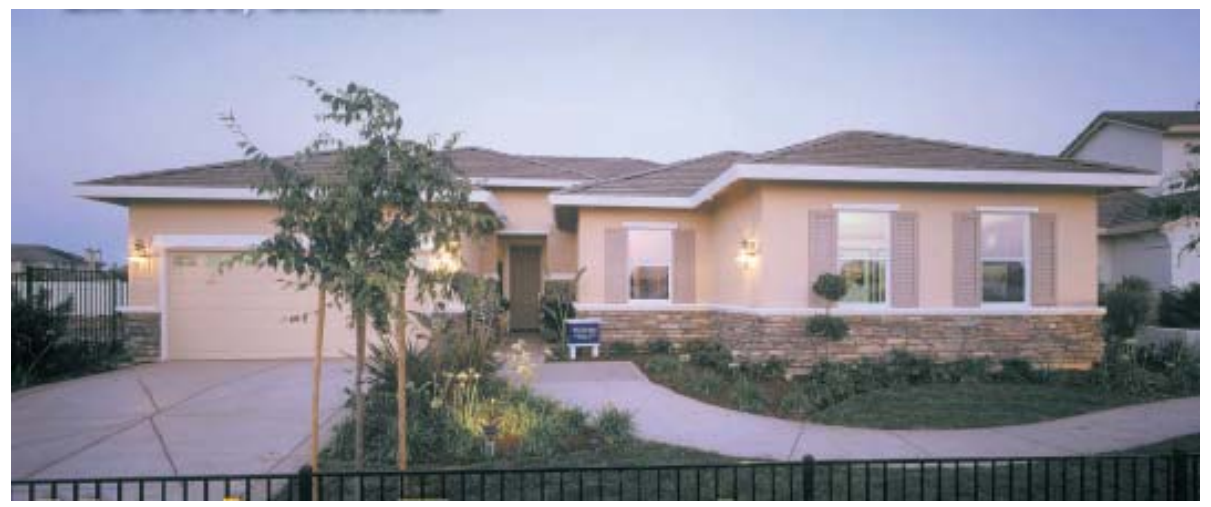

Figure 40. Morrison Homes in Elk Grove, California 

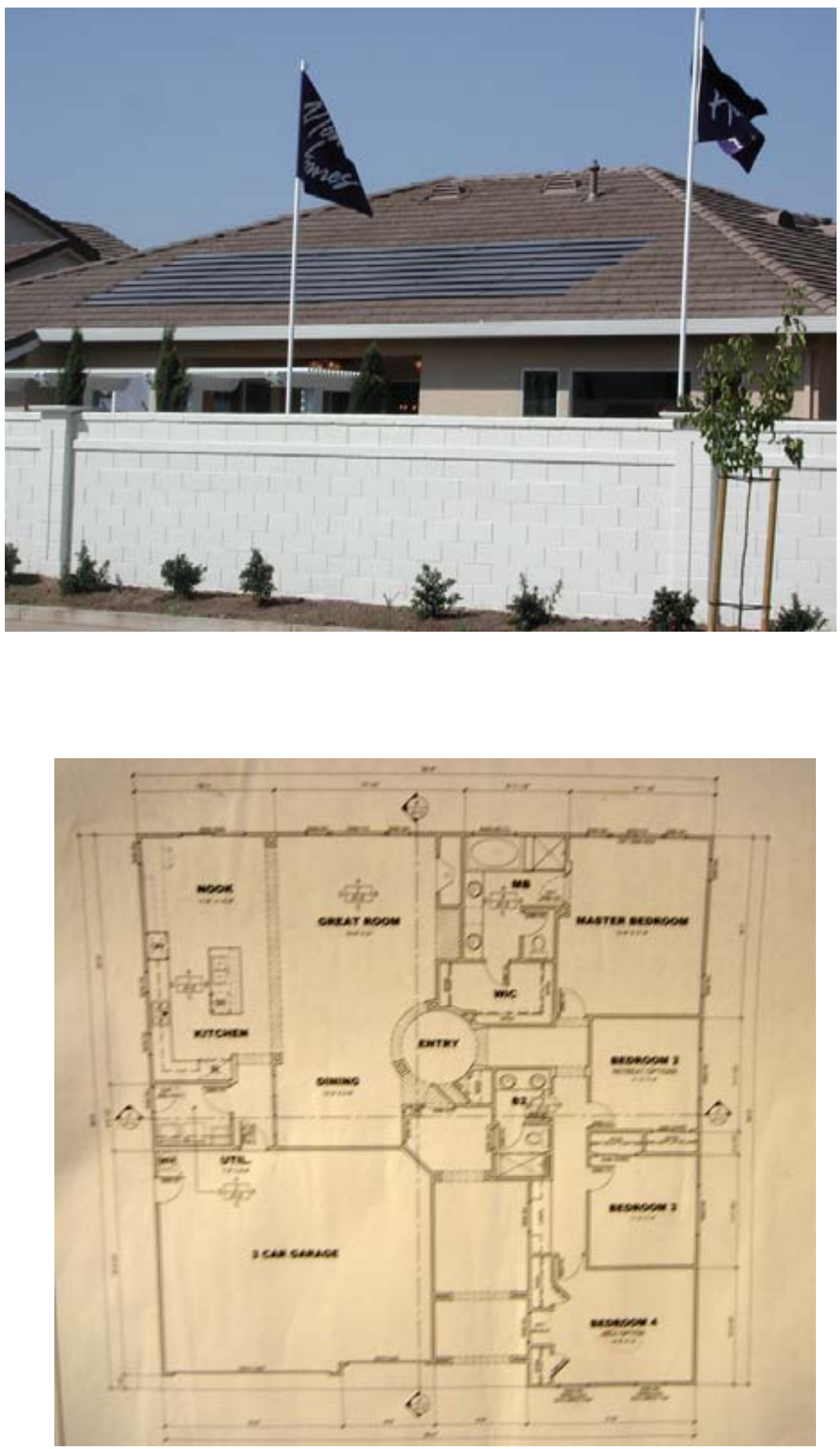

Figure 41. Typical plan floor plan, Lakeside, California 


\title{
Innovative Energy-Efficient Features
}

The following is a list of all the energy efficient features deployed in the ZEH home:

Appliances

\author{
ENERGY STAR ${ }^{\circledR}$
}

Air Sealing Caulking and sealing measures ensure low air infiltration

Insulation R-19 wall insulation

R-30 second-story floor insulation (two-story plans)

$\mathrm{R}-38$ attic insulation

R-6 duct insulation - Plans 1 and 4

Windows $\quad$ Spectrally selective glass, high-performance windows, U-factor: 0.36 for sliders, 0.33 for fixed, 0.35 for patio door; SHGC: 0.33 for sliders, 0.36 for fixed, 0.35 for patio door

Heating/Cooling 0.92 AFUE furnace

14 SEER A/C

Lighting

All fluorescent lighting

Water Heating Tankless water heater with 0.82 energy rating

Hot water pipe insulation

Photovoltaics 2-kW roof-integrated photovoltaic tile system 


\section{Energy and Cost Savings}

Tables 18 and 19 list the energy and cost savings for Plan 2 with an area of $2513 \mathrm{ft}^{2}$.

Table 18. Energy Savings for Base Case and Prototype House

\begin{tabular}{|c|c|c|c|}
\hline & $\frac{\frac{\text { Base Case / BA }}{\text { Benchmark House }}}{\text { (kBtu/yr) }}$ & $\frac{\text { Prototype House - }}{\frac{40 \% \text { Energy Savings }}{\text { Features (kBtu/yr) }}}$ & $\begin{array}{l}\frac{\text { Reduction in }}{\text { Energy Use }} \\
\text { (kBtu/yr) }\end{array}$ \\
\hline Heating & 62,951 & 35,458 & \\
\hline Cooling & 34,554 & 7,665 & \\
\hline Water Heating & 27,744 & 17,516 & \\
\hline Total & 125248 & 60639[ & $51.6 \%$ \\
\hline Lighting & 28,823 & 14,335 & \\
\hline Total (Heat, Cool, WH and Lighting) & 154,071 & 74,973 & $51 \%$ \\
\hline Other Uses & 71,835 & 70,039 & \\
\hline Total (Heat, Cool, WH, Lighting \& Other Uses) & 225,905 & 145,012 & $36 \%$ \\
\hline & & - & \\
\hline Energy Savings & 225,905 & 145,012 & $36 \%$ \\
\hline
\end{tabular}


Table 19. Energy Savings for Base Case and Building America Benchmark House

Energy Code Related Space Heating Space Cooling Water Heating

Other Uses cooking dishwasher

electric or gas dryer refrigerator

Miscellaneous (Appliances

+ Plug)

Lighting

reduce $\mathrm{kWh}$ by solar contribution

Total use

\begin{tabular}{|c|c|c|c|c|c|}
\hline \multicolumn{3}{|c|}{$\begin{array}{c}\text { Base Case / BA Benchmark } \\
\text { House }\end{array}$} & \multicolumn{3}{|c|}{$\begin{array}{l}\text { BA Prototype House - } 40 \% \text { Energy } \\
\text { Savings (Upgraded Features, } \\
\text { Fluorescent, Gas Dryer Stub and } \\
\text { Tankless Hot Water) }\end{array}$} \\
\hline \multicolumn{2}{|c|}{1} & Dollars & \multicolumn{2}{|c|}{ Energy Use } & Dollars \\
\hline Therms & kWh & $\$$ & Therms & kWh & $\$$ \\
\hline 630 & & 629.51 & 355 & & 354.58 \\
\hline & 3,375 & $\$ 506.21$ & & 749 & $\begin{array}{ll}112.29 \\
\end{array}$ \\
\hline 277 & & $\$ \quad 277.44$ & 175 & & 175.16 \\
\hline & & & & & \\
\hline 78 & & 78.00 & 78 & & 78.00 \\
\hline & 275 & 41.25 & & 275 & 41.25 \\
\hline & 1,113 & 166.95 & 96 & & 96.00 \\
\hline & 669 & $\$ \quad 100.35$ & & 669 & $\$ \quad 100.35$ \\
\hline & 4,197 & 629.51 & & 4,197 & 629.51 \\
\hline & 2,815 & 422.25 & & 1,400 & 210.00 \\
\hline & $\mathrm{n} / \mathrm{a}$ & $\mathrm{n} / \mathrm{a}$ & & $(3,420)$ & $\$ \quad(513.00)$ \\
\hline 985 & 12,443 & $\$ 2,851.46$ & 704 & 3,869 & $1,284.13$ \\
\hline
\end{tabular}

Total Annual Energy Use

$225,902 \mathrm{kBtu} / \mathrm{yr}$

$109,992 \mathrm{kBtu} / \mathrm{yr}$

Reduction in Energy Use

$100 \%$

$29 \%$

$69 \%$

$55 \%$

Total for Column in kBtu/yr

$98,494 \quad 127,408$

70,374

39,618

Total kBtu/yr for BA

Benchmark House

Total kBtu/yr for Prototype

House

Percent End Use Energy

Savings

$225,902 \mathrm{kBtu} / \mathrm{yr}$
$109,992 \mathrm{kBtu} / \mathrm{yr}$
$\mathbf{5 1 . 3 \%}$

Estimated Montly Energy Bill

\$ $237.62 / \mathrm{mo}$

\$ $107.01 / \mathrm{mo}$

Reduction in Energy Cost

$45 \%$

price of gas/therm

$\$ 1.00$

price of electricity/kWh

$\$ 0.15$ 


\section{Development: Windemere}

\section{Builder: $\quad$ Centex Homes, Northern California Division}

\section{Location: $\quad$ San Ramon, California}

Windemere development contains two neighborhoods that are included in the program; Aventura and Lunaria (Figures 42 and 43). Two energy package options were developed for Centex Homes: basic PowerSave and PowerSave Plus. A model home in each of the neighborhoods was selected to demonstrate the PowerSave Plus option, and a total of 25 homes were pre-plotted with the basic PowerSave features within both neighborhoods. The basic PowerSave option meets the 30\% Building America goal and are described in this section. Details of the PowerSave Plus home are not included here because source energy savings exceed $39 \%$ on efficiency measures. All of the homes in these two neighborhoods are two stories and range in size from 2,250 $\mathrm{ft}^{2}$ to $3,800 \mathrm{ft}^{2}$. Construction of the models began in September 2003, and all homes will be completed by October 2005. There are two additional neighborhoods, Torello and Montevego, with models in construction that will offer these same options.

Table 20 lists the final group of measures included in the final PowerSave option package. Two measures that were being considered for inclusion in the PowerSave designs were implemented throughout the two communities, leading to spin-off energy savings for all homes. These measures, zero defect insulation and insulated headers, were adopted for both the Aventura and Lunaria communities. Zero defect wall insulation was achieved by employing a blown-in fiberglass insulation product. The small incremental cost compared to fiberglass batts encouraged Centex to use it on all homes.

Insulated headers were initially rejected because the manufacturer did not make headers in the sizes used by Centex. After the manufacturer accommodated Centex by expanding their product line, they were rejected a second time because the recess between the stud face and the header made nailing of siding difficult. The manufacturer then offered to use scrap material to fill in the recess, and Centex adopted the header for universal application. The cost of the insulated headers proved to be less than the cost of linear strand lumber (LSL) wood headers.

\section{Source Energy Consumption Summary}

Tables 21 and 22 list source energy use and savings for the Aventura and Lunaria neighborhoods. Savings are relative to the Benchmark. The standard Centex models meet Title 24 and ComfortWise performance requirements. Note that the "Percent of End-Use" column shows how effective the prototype building is at reducing energy use in each end-use category. The "Percent of Total" column shows how the energy reductions in each end-use category contribute to the overall savings. 
Table 20. House Specifications Centex - Building America PowerSave Home

Building Envelope

Ceiling

$\mathrm{R}-48$ blown fiberglass in attic

Walls

Zero defect wall insulation: R-15 blown fiberglass $2 \mathrm{X} 4$

16 in. oc. with insulated window and door headers

Floor

Windows

Slab-on-grade, uninsulated

$$
\text { Double-glazed vinyl windows Low- } \mathrm{E}^{2}
$$

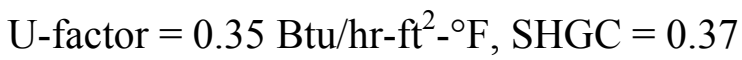

Infiltration

Tight construction, including draft stops, caulking of top plate penetrations and windows, and bottom plate gaskets. Tested to be less than 3.9 SLA

\section{Mechanical Systems}

Heating

Cooling

Ducts

Water Heating

Lighting

Carrier 80\% AFUE variable-speed furnace

$$
\text { Carrier } 10 \text { SEER condensing unit }
$$

R-4.2 flex ducts buried in R-49 attic insulation.

Tested tight ducts $<\%$ leakage

Takagi Instantaneous water heater $(0.82 \mathrm{EF})$

PEX Home-run piping design

CFL's on all permanent fixtures except dining chandelier

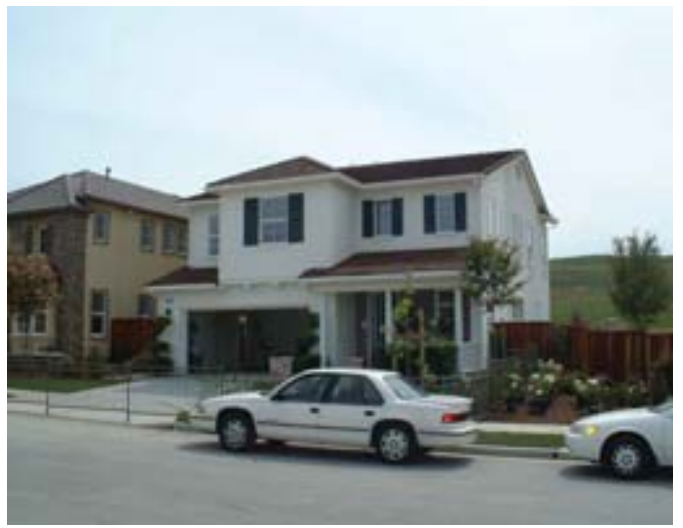

Figure 42. Aventura - front elevation

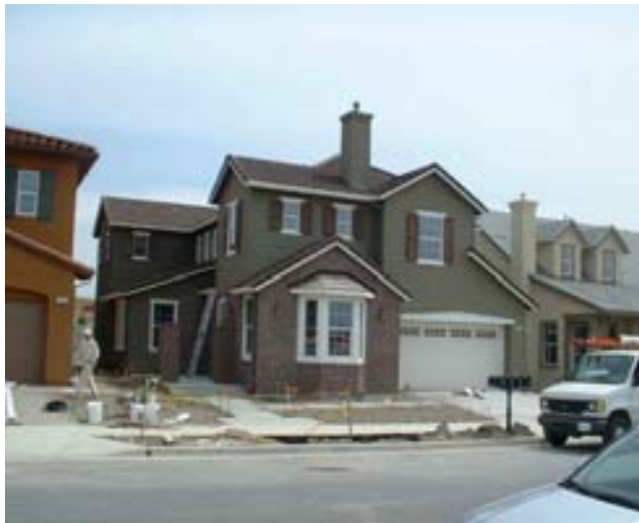

Figure 43. Lunaria - front elevation 
Table 21. Aventura Summary of Estimated End-Use Source Energy

\begin{tabular}{|c|c|c|c|c|c|c|c|}
\hline \multirow[b]{3}{*}{ End Use } & \multicolumn{3}{|c|}{ Estimated Annual Source Energy } & \multicolumn{4}{|c|}{ Source Energy Savings } \\
\hline & \multirow{2}{*}{$\begin{array}{c}\text { Benchmark } \\
\text { (MBtu/yr) }\end{array}$} & \multirow{2}{*}{$\begin{array}{l}\text { Centex } \\
\text { Standard } \\
\text { (MBtu/yr) }\end{array}$} & \multirow{2}{*}{$\begin{array}{l}\text { Prototype } \\
\text { (MBtu/yr) }\end{array}$} & \multicolumn{2}{|c|}{ Percent of End-Use } & \multicolumn{2}{|c|}{ Percent of Total } \\
\hline & & & & $\begin{array}{c}\text { vs. } \\
\text { Benchmark }\end{array}$ & vs. Standard & $\begin{array}{c}\text { vs. } \\
\text { Benchmark }\end{array}$ & $\begin{array}{l}\text { vs. } \\
\text { Standard }\end{array}$ \\
\hline Space Heating & 38 & 27 & 24 & $37 \%$ & $12 \%$ & $8 \%$ & $2 \%$ \\
\hline Space Cooling & 47 & 43 & 38 & $20 \%$ & $13 \%$ & $5 \%$ & $3 \%$ \\
\hline DHW & 32 & 32 & 14 & $54 \%$ & $54 \%$ & $9 \%$ & $10 \%$ \\
\hline Lighting & 21 & 21 & 7 & $67 \%$ & $67 \%$ & $8 \%$ & $8 \%$ \\
\hline $\begin{array}{l}\text { Appliances+ } \\
\text { Plug }\end{array}$ & 42 & 42 & 42 & $0 \%$ & $0 \%$ & $0 \%$ & $0 \%$ \\
\hline OA Ventilation & 0 & 0 & 0 & $0 \%$ & $0 \%$ & $0 \%$ & $0 \%$ \\
\hline Total Usage & 180 & 165 & 125 & $30 \%$ & $24 \%$ & $30 \%$ & $24 \%$ \\
\hline
\end{tabular}


Table 22. Lunaria Summary of Estimated End-Use Source Energy

\begin{tabular}{|c|c|c|c|c|c|c|c|}
\hline \multirow[b]{3}{*}{ End Use } & \multicolumn{3}{|c|}{ Estimated Annual Source Energy } & \multicolumn{4}{|c|}{ Source Energy Savings } \\
\hline & \multirow{2}{*}{$\begin{array}{c}\text { Benchmark } \\
\text { (MBtu/yr) }\end{array}$} & \multirow{2}{*}{$\begin{array}{c}\text { Centex } \\
\text { Standard } \\
\text { (MBtu/yr) }\end{array}$} & \multirow{2}{*}{$\begin{array}{l}\text { Prototype } \\
\text { (MBtu/yr) }\end{array}$} & \multicolumn{2}{|c|}{ Percent of End-Use } & \multicolumn{2}{|c|}{ Percent of Total } \\
\hline & & & & $\begin{array}{c}\text { vs. } \\
\text { Benchmark }\end{array}$ & vs. Standard & $\begin{array}{c}\text { vs. } \\
\text { Benchmark }\end{array}$ & vs. Standard \\
\hline Space Heating & 72 & 64 & 59 & $19 \%$ & $8 \%$ & $5 \%$ & $2 \%$ \\
\hline Space Cooling & 68 & 46 & 39 & $43 \%$ & $15 \%$ & $12 \%$ & $3 \%$ \\
\hline DHW & 38 & & 16 & $58 \%$ & $58 \%$ & $9 \%$ & $10 \%$ \\
\hline Lighting & 28 & 28 & 9 & $67 \%$ & $67 \%$ & $7 \%$ & $8 \%$ \\
\hline $\begin{array}{l}\text { Appliances+ } \\
\text { Plug }\end{array}$ & 44 & 44 & 44 & $0 \%$ & $0 \%$ & $0 \%$ & $0 \%$ \\
\hline OA Ventilation & 0 & 0 & 0 & $0 \%$ & $0 \%$ & $0 \%$ & $0 \%$ \\
\hline Total Usage & 250 & & 167 & $33 \%$ & $24 \%$ & $33 \%$ & $24 \%$ \\
\hline
\end{tabular}




\section{Builder Cost Summary}

The basic PowerSave package was pre-plotted on 25 lots in the two neighborhoods; six in Aventura and 19 in Lunaria. The package was also offered as an option for the remaining homes. Centex offered the basic PowerSave option for $\$ 3,600$ for Aventura and $\$ 3,850$ for the bigger homes in Lunaria. Table 23 summarizes the incremental costs to the builder, and Table 24 summarizes the PowerSave cash-flow analysis for the buyer. Estimated incremental costs in Table 24 were obtained from the builder. Amortized costs are based on a 30-year mortgage at $6 \%$ interest. Buyer surveys indicated some interest in the PowerSave package, but it appears that interested parties purchased the pre-plotted homes instead of purchasing a standard home with the PowerSave option.

Table 23. Centex Windemere PowerSave Pricing

\begin{tabular}{|c|c|c|c|c|}
\hline & Standard Construction & $\begin{array}{c}\text { Building America - } \\
\text { PowerSave }\end{array}$ & & $\begin{array}{c}\text { Estimated } \\
\text { Cost } \$\end{array}$ \\
\hline \multicolumn{5}{|c|}{ Building envelope } \\
\hline Ceiling & R-38 batt in vented attic & R-49 blown fiberglass & & $\$ 700-\$ 800$ \\
\hline Walls & $\mathrm{R}-132 \times 416$ in. oc & $\begin{array}{l}\text { R-15 blown } \\
\text { fiberglass. }\end{array}$ & & $\$ 100$ \\
\hline Headers & LSL Headers & Insulated headers & & $\$ 0$ \\
\hline \multicolumn{5}{|c|}{$\begin{array}{l}\text { Mechanical } \\
\text { systems }\end{array}$} \\
\hline DHW & $\begin{array}{l}0.54 \mathrm{EF} \text { storage gas } \\
\text { water heater in garage }\end{array}$ & $\begin{array}{c}0.82 \mathrm{EF} \\
\text { instantaneous gas } \\
\text { water heater in } \\
\text { garage }\end{array}$ & & $\$ 1,200$ \\
\hline Ducts & $\begin{array}{c}\mathrm{R}-4.2 \text { suspended from } \\
\text { trusses }\end{array}$ & $\begin{array}{l}\mathrm{R}-4.2 \text { buried in ceiling } \\
\text { insulation }\end{array}$ & & $\$ 0$ \\
\hline \multirow[t]{2}{*}{ Lighting } & Incandescent Lighting & Full CFL Package & & $\$ 375$ \\
\hline & & Total & $=$ & $\begin{array}{l}\$ 2,375- \\
\$ 2475\end{array}$ \\
\hline
\end{tabular}


Table 24. PowerSave Cash Flows

\begin{tabular}{lll}
\hline \hline Package & Aventura & Lunaria \\
Total Cost & $\$ 3,600$ & $\$ 3,850$ \\
Annual Amortized & $\$ 259$ & $\$ 277$ \\
Cost & & \\
Annual Energy Savings & $\$ 452$ & $\$ 598$ \\
Net Savings & $\$ 193$ & $\$ 321$ \\
\hline
\end{tabular}




\section{Appendix A: Passive Solar Design Considerations}

There are three primary passive design systems: direct gain, indirect gain, and sunrooms.

Direct Gain. In direct gain (Figure A-1), the sun shines directly into the house through windows, skylights, and clerestories. Depending on the amount and orientation of glazing, thermal mass materials may be needed to be incorporated in walls and floors to absorb the solar radiation and re-release it during the evening. Direct gain can also utilize a strategy called "sun tempering" where glazing is favored on the south side, but limited so that additional thermal mass is not necessary to prevent overheating of south-facing rooms.

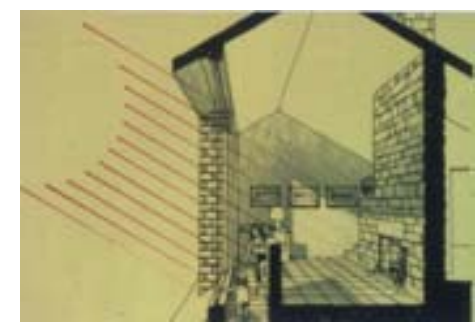

Figure A-1. Direct Solar Gain

Indirect Gain. Indirect gain (Figure A-2), also called thermal storage wall and Trombe Wall, consists of a thermal mass wall, with direct southern exposure. For example, a thermal storage wall could be a poured-in-place concrete wall or a concrete masonry block wall with the cores filled with concrete. One or more panes of glazing are located immediately on the outside of these mass walls. The outside surface of the mass wall is painted a dark color or coated with a selective surface, such as those used in active solar collectors.

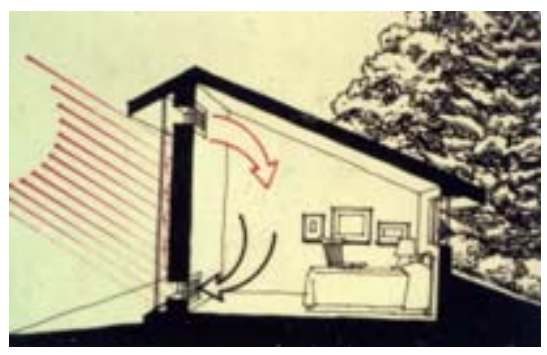

Figure A-2. Indirect Solar Gain 
Sunroom. Passive solar sunrooms (Figure A-3) can either be isolated or open to the rest of the home. Because of the large areas of glass, it is usually recommended that they include doors and windows that can be closed to isolate them from the rest of the house. In this configuration, the temperature in the sunroom can be permitted to go higher and lower than would be permitted within the home.

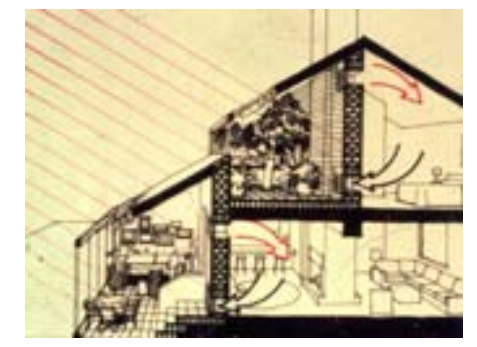

Figure A-3. Passive Solar Gain

To optimize the solar design of the house, which includes size of aperture, glazing performance characteristics (U-value and Solar Heat Gain Coefficient [SHGC]), by orientation, inclusion of mass, and house configuration, it is recommended that detailed energy simulations be undertaken. In general, if passive solar design is to be implemented, the following issues should be addressed, in the following order of importance:

- Site planning to allow for optimizing house orientation

- Orienting the house to optimize solar gains for heating and limiting solar gains during the cooling season. Simply by orienting homes with longer sides with larger glazing areas facing north-south helps to minimize unwanted heat gain in summer and maximize beneficial solar heat gains in winter (Figure A-4).

Builders seeking to optimize individual home and lot orientation can follow these guidelines.

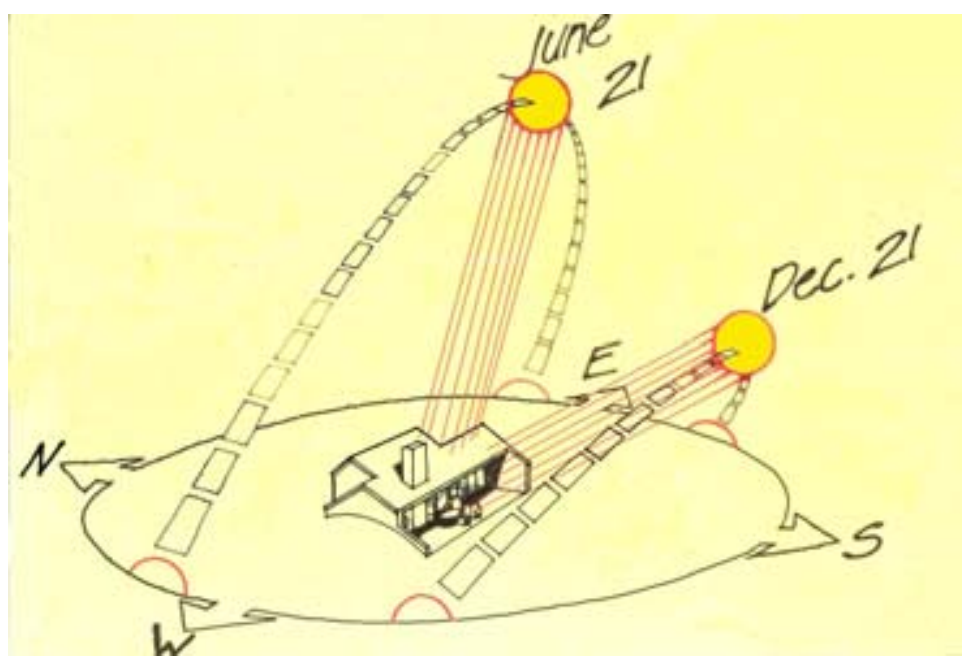

Figure A-4. The paths of the sun in winter and summer over a home with long sides facing north and south 
- Minimize East and West Glazing. Orienting homes so that the sides with the least glazing face east and west can significantly reduce cooling loads and reduce glare. Typically, afternoon sun shining in west windows is most important to minimize or to shade.

- North-south Orientation. Having the longer sides of homes facing north-south is beneficial for reducing both heating and cooling loads. In Cold Climates, having more glazing face south with adequate shading can minimize cooling and heating loads significantly; however, this must be carefully designed to prevent overheating and comfort complaints. South windows can most easily be shaded with overhangs.

- Architectural Design. Shape the architectural form and solar apertures of the houses to optimize passive solar heating, including appropriate mass to avoid localized overheating, and summertime shading to mitigate cooling loads. This is best done in conjunction with hourly energy and room temperature modeling to assure energy savings and occupant comfort. Passive designs typically employ increased use of dense materials like concrete slab floors with tile and increased thickness of drywall or interior brick or concrete walls that have high conductivity to heat and high heat capacities. The increased mass can be as simple as replacing carpeted floors with inexpensive tile floors in slab-on-grade construction. If mass materials are warmed by winter sun and cooled with night ventilation systems in summer, they can add to comfort and reduce use of and consumption by conventional heating and cooling systems.

- Night Cooling: Locate openings to optimize airflow during temperate conditions and to facilitate "night flushing" of heat built up over the day during the relatively cooler evening hours.

Passive design may have a significant impact on the architectural character of the house and may be viewed in a positive or negative manner by builders and homebuyers. Passive strategies may be pursued as a trade-off for other energy improvements; however, careful consideration of occupant comfort must be taken into account. Effective passive solar heat gain can be very beneficial during the heating season, but it is challenging to design well and requires proper linkage of aperture and thermal storage in order to be useful and to avoid discomfort.

Overheating is a significant problem. Passive cooling, both by window shading and glass transmission characteristics, is very beneficial during the cooling season. Window shading can be very effective, but its proper design is critical, and the shading elements may have a strong visual impact on the exterior of the house. Thus, it is not a strategy that is thought to be universally appropriate at the $30 \%$ improvement level. For more information on passive design strategies, see the Passive Solar Industries Council's passive solar design guidelines. ${ }^{58}$

Architectural Shading Considerations. Shading, like orientation, is not required to achieve $30 \%$ savings, particularly with low-SHGC glazing. However, studies have shown that shading can cut solar heat gain by anywhere from $10 \%$ to $50 \%$. Blocking the sun's rays from striking glazing areas and heating up a home is much more efficient than using air conditioning to cool down an already overheated house.

"Architectural shading" is simple, does not need any maintenance, and may reduce costs compared to sophisticated shading devices. Incorporating shading methods into the home during

\footnotetext{
${ }^{58}$ Sustainable Building Industries Council. Passive Solar Design Strategies: Guidelines for Home Building. Sustainable Building Industries Council Website. www.psic.org
} 
the design phase ensures that a home receives the most effective shading. For example, providing properly designed overhangs shading the south glass adequately can reduce the heat gain during the summers while allowing for heat gain during the winters. Shading the west glass can also minimize the unwanted heat gains. A wide range of shading options is available, including the following:

- Overhangs on South Sides. Extending the roofline a few feet can create shade for a home's south-facing windows. Because sun angles drop in the winter months, south-facing overhangs will let the warming sun into the home when it is needed. Because of low sun angles in summer mornings and afternoons, overhangs on the east or west have little to no affect. Shades for east- or west-facing windows must have some vertical dimension, such as awnings or shade screens.

Decks and Porches. Adding a covered deck or porch is an excellent way to shade a home and to add living space, too. Porches and covered decks should have enough of an overhang to shield the area from the high sun and still offer a view outside from the interior spaces.

- Awnings. Awnings provide excellent shading for south-, east-, and west-facing windows; awnings will block as much as $65 \%$ of the summer sun's heat $(77 \%$ on an east- or west-facing window), but they have the disadvantage of blocking the top half of the view from the window and reducing ventilation when windows are opened. Retractable canvas awnings can overcome this problem to some extent because they can be extended only when they are needed. This is especially helpful in winter months, when occupants want to let the sun in to warm their home.

- Louvers. Exterior louvers are attractive because their adjustable slats control the level of sunlight entering the building and, depending on the design, can be manually adjusted from inside or outside. The slats can be vertical or horizontal. Louvers remain fixed and are attached to the exteriors of window frames. Careful attention to the louver angle can allow significant winter sun penetration whilst still excluding all sun in summer.

- Exterior Shade Screens. Retractable shade screens are a good choice for windows that receive direct sunlight. They work much like an inside window shade, except that they are attached to the outside of the window. Most shade screen manufacturers offer automatic controls for these products. The screens are installed at the top of the window and can be lowered during sunny days and retracted when not needed. Shade screens are generally custom-made. They are a good choice for a homeowner who wants to retrofit for energy efficiency but still wants to see out of a window that gets lots of sun throughout the day. The downside of shade screens is that they can darken the view when pulled down.

Designing Shading Systems. The following design recommendations generally hold true for properly designed shading devices:

- Use fixed overhangs on south-facing glass to control direct-beam solar radiation. Indirect (diffuse) radiation should be controlled by other measures, such as low-e glazing.

- To the greatest extent possible, limit the amount of east and west glass because it is harder to shade than south glass. Consider the use of landscaping to shade east and west exposures, awnings, exterior shade screens, or interior highly reflective shades.

- Do not worry about shading north-facing glass because it receives very little direct solar gain. 
- Shading effects daylighting; consider both simultaneously. For example, a light shelf bounces natural light deeply into a room through high windows while shading lower windows.

- Do not expect interior shading devices such as Venetian blinds or vertical louvers to reduce cooling loads because the solar gain has already been admitted into the work space. However, these interior devices do offer glare control and can contribute to visual acuity and visual comfort.

- An understanding of sun angles is critical to selecting shading devices.

- Carefully consider the durability of shading devices. Over time, operable shading devices can require a considerable amount of maintenance and repair.

- When relying on landscape elements for shading, be sure to consider the cost of landscape maintenance and upkeep on life-cycle cost.

- Shading strategies that work well at one latitude, may be completely inappropriate for other sites at different latitudes. Be careful when applying shading ideas from one project to another. 


\section{Appendix B: Detailed BEopt Analysis Results}

Table B.1. BEopt Option Results for Single-Story Case

\begin{tabular}{|c|c|c|c|c|c|c|c|c|c|}
\hline CATEGORY & BENCHMARK & 35\% POINT & NEIGHBOR 1 & NEIGHBOR 2 & NEIGHBOR 3 & NEIGHBOR 4 & NEIGHBOR 5 & $\begin{array}{l}\text { NEXT POINT } \\
\text { ON OPT. } \\
\text { CURVE }\end{array}$ & $39 \%$ POINT \\
\hline Walls & $\begin{array}{l}U=0.085, \\
23 \% \text { FF, } \\
\text { R-11 batt, } \\
2 \times 416 \text { in. oc + } \\
\text { R-2.5 } \\
\text { sheathing }\end{array}$ & $\begin{array}{l}\text { R-11, } 2 \times 4, \\
16 \text { in. oc }\end{array}$ & $\begin{array}{l}\text { R-19, } 2 \times 6, \\
24 \text { in. oc }\end{array}$ & $\begin{array}{l}\text { R-19, } 2 \times 6, \\
24 \text { in. oc }\end{array}$ & $\begin{array}{l}\text { R-19, } 2 \times 6, \\
24 \text { in. oc }\end{array}$ & $\begin{array}{l}\text { R-13, } 2 \times 4, \\
6 \text { in. oc }\end{array}$ & $\begin{array}{l}\text { R-19, } 2 \times 6, \\
24 \text { in. oc }\end{array}$ & $\begin{array}{l}\text { R-13, } 2 \times 4, \\
16 \text { in. oc }\end{array}$ & $\begin{array}{l}\text { R-19, } 2 \times 6, \\
24 \text { in. oc }\end{array}$ \\
\hline Ceiling & $\begin{array}{l}U=0.042 \\
11 \% F F, R-24\end{array}$ & R-30 fiberglass & R-30 fiberglass & R-30 fiberglass & R-30 fiberglass & $\mathrm{R}-30$ fiberglass & R-30 fiberglass & R-30 fiberglass & R-30 fiberglass \\
\hline $\begin{array}{l}\text { Thermal } \\
\text { Mass }\end{array}$ & $\begin{array}{l}8 \mathrm{lbs} / \mathrm{ft}^{2} \text { - } \\
\text { furniture, } \\
\text { standard light } \\
\text { frame } \\
\text { construction }\end{array}$ & $\begin{array}{l}1 / 2 \text {-in. Ceiling } \\
\text { Drywall }\end{array}$ & $\begin{array}{l}1 / 2 \text {-in. Ceiling } \\
\text { Drywall }\end{array}$ & $\begin{array}{l}1 / 2 \text {-in. Ceiling } \\
\text { Drywall }\end{array}$ & $\begin{array}{l}\text { Two 5/8-in. } \\
\text { Ceiling Drywall } \\
\text { Layers }\end{array}$ & $\begin{array}{l}\text { Two 5/8-in. } \\
\text { Ceiling Drywall } \\
\text { Layers }\end{array}$ & $\begin{array}{l}\text { Two 5/8-in. } \\
\text { Ceiling Drywall } \\
\text { Layers }\end{array}$ & $\begin{array}{l}\text { 1/2-in. Ceiling } \\
\text { Drywall }\end{array}$ & $\begin{array}{l}\text { 1/2-in. Ceiling } \\
\text { Drywall }\end{array}$ \\
\hline Infiltration & $S L A=0.00057$ & $S L A=0.0005$ & $S L A=0.0005$ & $S L A=0.0005$ & $S L A=0.0005$ & $S L A=0.0005$ & $S L A=0.0005$ & $S L A=0.0005$ & $S L A=0.0005$ \\
\hline Slab & Uninsulated & Uninsulated & Uninsulated & Uninsulated & Uninsulated & Uninsulated & Uninsulated & Uninsulated & Uninsulated \\
\hline Glass Type & $\begin{array}{l}U=0.79 \\
S H G C=0.65\end{array}$ & $\begin{array}{l}\text { Two-pane Low- } \\
\text { e, U = 0.3, } \\
\text { SHGC = } 0.44 \\
\text { Center of } \\
\text { Glass, insulated } \\
\text { spacer, } \\
\text { Vinyl frame }\end{array}$ & $\begin{array}{l}\text { Two-pane } \\
\text { Low-e, } \\
U=0.29, \\
\text { SHGC = } 0.29 \\
\text { Center of } \\
\text { Glass, } \\
\text { insulated } \\
\text { spacer, } \\
\text { Vinyl frame }\end{array}$ & $\begin{array}{l}\text { Heat Mirror, } \\
U=0.18, \\
S H G C=0.48 \\
\text { Center of Glass, } \\
\text { insulated } \\
\text { spacer, } \\
\text { Vinyl frame }\end{array}$ & $\begin{array}{l}\text { Two-pane clear, } \\
U=0.49, \\
S H G C=0.76 \\
\text { Center of Glass, } \\
\text { insulated } \\
\text { spacer, } \\
\text { Vinyl frame }\end{array}$ & $\begin{array}{l}\text { Two-pane Low- } \\
\text { e, U = 0.32, } \\
\text { SHGC = 0.64 } \\
\text { Center of } \\
\text { Glass, insulated } \\
\text { spacer, } \\
\text { Vinyl frame }\end{array}$ & $\begin{array}{l}\text { Two-pane Low- } \\
\text { e, U = 0.32, } \\
\text { SHGC = } 0.64 \\
\text { Center of } \\
\text { Glass, } \\
\text { insulated } \\
\text { spacer, } \\
\text { Vinyl frame }\end{array}$ & $\begin{array}{l}\text { Two-pane Low- } \\
\text { e, U = 0.3, } \\
\text { SHGC = } 0.44 \\
\text { Center of Glass, } \\
\text { insulated } \\
\text { spacer, } \\
\text { Vinyl frame }\end{array}$ & $\begin{array}{l}\text { Two-pane Low- } \\
\text { e, U = 0.29, } \\
\text { SHGC = 0.29 } \\
\text { Center of Glass, } \\
\text { insulated } \\
\text { spacer, } \\
\text { Vinyl frame }\end{array}$ \\
\hline
\end{tabular}


Table B.1 (continued). BEopt Option Results for Single-Story Case

\begin{tabular}{|c|c|c|c|c|c|c|c|c|c|}
\hline CATEGORY & BENCHMARK & $35 \%$ POINT & NEIGHBOR 1 & NEIGHBOR 2 & NEIGHBOR 3 & NEIGHBOR 4 & NEIGHBOR 5 & $\begin{array}{c}\text { NEXT POINT } \\
\text { ON OPT. } \\
\text { CURVE }\end{array}$ & $39 \%$ POINT \\
\hline $\begin{array}{l}\text { Window Area } \\
\text { per Wall }\end{array}$ & $\begin{array}{l}270 \mathrm{ft}^{2}, \text { Equal } \\
\text { distance on } \\
\text { four sides }\end{array}$ & $\begin{array}{l}270 \mathrm{ft}^{2} \\
12.5 \% \mathrm{~N} \& \mathrm{~S}, \\
50 \% \mathrm{~W}, 25 \% \mathrm{E}\end{array}$ & $\begin{array}{l}270 \mathrm{ft}^{2} \\
2.5 \% \mathrm{~N} \& \mathrm{~S}, \\
50 \% \mathrm{~W}, 25 \% \mathrm{E}\end{array}$ & $\begin{array}{l}270 \mathrm{ft}^{2} \\
12.5 \% \mathrm{~N} \& \mathrm{~S}, \\
50 \% \mathrm{~W}, 25 \% \mathrm{E}\end{array}$ & $\begin{array}{l}270 \mathrm{ft}^{2} \\
12.5 \% \mathrm{~N} \& \mathrm{~S}, \\
50 \% \mathrm{~W}, 25 \% \mathrm{E}\end{array}$ & $\begin{array}{l}270 \mathrm{ft}^{2} \\
12.5 \% \mathrm{~N} \& \mathrm{~S}, \\
50 \% \mathrm{~W}, 25 \% \mathrm{E}\end{array}$ & $\begin{array}{l}270 \mathrm{ft}^{2} \\
12.5 \% \mathrm{~N} \& \mathrm{~S}, \\
50 \% \mathrm{~W}, 25 \% \mathrm{E}\end{array}$ & $\begin{array}{l}270 \mathrm{ft}^{2} \\
12.5 \% \mathrm{~N} \& \mathrm{~S}, \\
50 \% \mathrm{~W}, 25 \% \mathrm{E}\end{array}$ & $\begin{array}{l}270 \mathrm{ft}^{2} \\
12.5 \% \mathrm{~N} \& \mathrm{~S}, \\
50 \% \mathrm{~W}, 25 \% \mathrm{E}\end{array}$ \\
\hline Refrigerator & $669 \mathrm{kWh} / \mathrm{yr}$ & $\begin{array}{l}\text { Standard - } 671 \\
\mathrm{kWh} / \mathrm{yr}\end{array}$ & $\begin{array}{l}\text { Standard - } 671 \\
\mathrm{kWh} / \mathrm{yr}\end{array}$ & $\begin{array}{l}\text { Standard - } 671 \\
\mathrm{kWh} / \mathrm{yr}\end{array}$ & $\begin{array}{l}\text { Standard - } 671 \\
\mathrm{kWh} / \mathrm{yr}\end{array}$ & $\begin{array}{l}\text { Standard - } 671 \\
\mathrm{kWh} / \mathrm{yr}\end{array}$ & $\begin{array}{l}\text { Standard - } 671 \\
\mathrm{kWh} / \mathrm{yr}\end{array}$ & $\begin{array}{l}\text { Standard - } 671 \\
\mathrm{kWh} / \mathrm{yr}\end{array}$ & $\begin{array}{l}\text { Standard - } 671 \\
\mathrm{kWh} / \mathrm{yr}\end{array}$ \\
\hline Cooking Range & 45 Therms/yr & 45 Therms/yr & 45 Therms/yr & 45 Therms/yr & 45 Therms/yr & 45 Therms/yr & 45 Therms/yr & 45 Therms/yr & 45 Therms/yr \\
\hline Dishwasher & $\begin{array}{l}206 \mathrm{kWh} / \mathrm{yr}, \\
\text { 5-gal DHW/day }\end{array}$ & $\begin{array}{l}\text { Standard, } 462 \mathrm{kWh} \text {, } \\
\text { eight place setting } \\
\text { capacity, } 131.6 \\
\text { kWh/yr machine } \\
\text { energy, } 5.39-\text { gal/day } \\
\text { DHW }\end{array}$ & $\begin{array}{l}\text { Standard, } 462 \\
\text { kWh, eight place } \\
\text { setting capacity, } \\
131.6 \mathrm{kWh} / \mathrm{yr} \\
\text { machine energy, } \\
5.39-\text { gal/day } \\
\text { DHW }\end{array}$ & $\begin{array}{l}\text { Standard, } 462 \\
\text { kWh, eight place } \\
\text { setting capacity, } \\
131.6 \mathrm{kWh} / \mathrm{yr} \\
\text { machine energy, } \\
5.39-\text { gal/day } \\
\text { DHW }\end{array}$ & $\begin{array}{l}\text { Standard, } 462 \\
\text { kWh, eight } \\
\text { place setting } \\
\text { capacity, } 131.6 \\
\text { kWh/yr machine } \\
\text { energy, } 5.39- \\
\text { gal/day DHW }\end{array}$ & $\begin{array}{l}\text { Standard, } 462 \\
\text { kWh, eight } \\
\text { place setting } \\
\text { capacity, } 131.6 \\
\text { kWh/yr machine } \\
\text { energy, } 5.39- \\
\text { gal/day DHW }\end{array}$ & $\begin{array}{l}\text { Standard, } 462 \\
\text { kWh, eight } \\
\text { place setting } \\
\text { capacity, } 131.6 \\
\text { kWh/yr } \\
\text { machine } \\
\text { energy, 5.39- } \\
\text { gal/day DHW }\end{array}$ & $\begin{array}{l}\text { Standard, } 462 \\
\text { kWh, eight } \\
\text { place setting } \\
\text { capacity, } 131.6 \\
\text { kWh/yr machine } \\
\text { energy, } 5.39- \\
\text { gal/day DHW }\end{array}$ & $\begin{array}{l}\text { Standard, } 462 \mathrm{kWh} \text {, } \\
\text { eight place setting } \\
\text { capacity, } 131.6 \\
\mathrm{kWh} / \mathrm{yr} \text { machine } \\
\text { energy, 5.39-gal/day } \\
\text { DHW }\end{array}$ \\
\hline Clothes Dryer & $\begin{array}{l}\text { Gas - } \\
\text { 71.6kWh/yr, } \\
\text { 31.3 Therms/yr }\end{array}$ & $\begin{array}{l}\text { Gas }-5.7 \mathrm{ft}^{3}, 2.75 \\
\mathrm{EF}, 70.1 \mathrm{kWh} / \mathrm{yr} \\
31.8 \text { therms/yr }\end{array}$ & $\begin{array}{l}\text { Gas }-5.7 \mathrm{ft}^{3}, 2.75 \\
\mathrm{EF}, 70.1 \mathrm{kWh} / \mathrm{yr} \\
31.8 \text { therms/yr }\end{array}$ & $\begin{array}{l}\text { Gas }-5.7 \mathrm{ft}^{3} \\
2.75 \mathrm{EF}, \\
70.1 \mathrm{kWh} / \mathrm{yr}, \\
31.8 \mathrm{therms} / \mathrm{yr}\end{array}$ & $\begin{array}{l}\text { Gas }-5.7 \mathrm{ft}^{3}, \\
2.75 \mathrm{EF}, \\
70.1 \mathrm{kWh} / \mathrm{yr}, \\
31.8 \mathrm{therms} / \mathrm{yr}\end{array}$ & $\begin{array}{l}\text { Gas }-5.7 \mathrm{ft}^{3} \\
2.75 \mathrm{EF}, \\
70.1 \mathrm{kWh} / \mathrm{yr}, \\
31.8 \mathrm{therms} / \mathrm{yr}\end{array}$ & $\begin{array}{l}\text { Gas }-5.7 \mathrm{ft}^{3} \\
2.75 \mathrm{EF}, \\
70.1 \mathrm{kWh} / \mathrm{yr} \\
31.8 \text { therms/yr }\end{array}$ & $\begin{array}{l}\text { Gas }-5.7 \mathrm{ft}^{3}, \\
2.75 \mathrm{EF}, \\
70.1 \mathrm{kWh} / \mathrm{yr}, \\
31.8 \mathrm{therms} / \mathrm{yr}\end{array}$ & $\begin{array}{l}\text { Gas }-5.7 \mathrm{ft}^{3}, 2.75 \\
\mathrm{EF}, \\
70.1 \mathrm{kWh} / \mathrm{yr}, 31.8 \\
\text { therms/yr }\end{array}$ \\
\hline $\begin{array}{l}\text { Clothes } \\
\text { Washer }\end{array}$ & $\begin{array}{l}105 \mathrm{kWh} / \mathrm{yr}, 15 \\
\text { gal/day }\end{array}$ & $\begin{array}{l}\text { Standard, } 3.15 \mathrm{ft}^{3} \text {, } \\
533 \mathrm{kWh} / \mathrm{yr}, 1.16 \\
\mathrm{MEF}, 65.6 \mathrm{kWh} / \mathrm{yr} \\
\text { machine energy, } \\
\text { 4.63-gal/day DHW }\end{array}$ & $\begin{array}{l}\text { Standard, } 3.15 \\
\mathrm{ft}^{3}, 533 \mathrm{kWh} / \mathrm{yr}, \\
1.16 \mathrm{MEF}, 65.6 \\
\mathrm{kWh} / \mathrm{yr} \text { machine } \\
\text { energy, } 4.63- \\
\text { gal/day DHW }\end{array}$ & $\begin{array}{l}\text { Standard, } 3.15 \\
\mathrm{ft}^{3}, 533 \mathrm{kWh} / \mathrm{yr}, \\
1.16 \mathrm{MEF}, 65.6 \\
\mathrm{kWh} / \mathrm{yr} \text { machine } \\
\text { energy, } 4.63- \\
\text { gal/day DHW }\end{array}$ & $\begin{array}{l}\text { Standard, } 3.15 \\
\mathrm{ft}^{3}, 533 \mathrm{kWh} / \mathrm{yr}, \\
1.16 \mathrm{MEF}, 65.6 \\
\mathrm{kWh} / \mathrm{yr} \text { machine } \\
\text { energy, } 4.63- \\
\text { gal/day DHW }\end{array}$ & $\begin{array}{l}\text { Standard, } 3.15 \\
\mathrm{ft}^{3}, 533 \mathrm{kWh} / \mathrm{yr} \text {, } \\
1.16 \mathrm{MEF}, 65.6 \\
\mathrm{kWh} / \mathrm{yr} \text { machine } \\
\text { energy, } 4.63- \\
\text { gal/day DHW }\end{array}$ & $\begin{array}{l}\text { Standard, } 3.15 \\
\mathrm{ft}^{3}, 533 \mathrm{kWh} / \mathrm{yr}, \\
1.16 \mathrm{MEF}, 65.6 \\
\mathrm{kWh} / \mathrm{yr} \\
\text { machine } \\
\text { energy, } 4.63- \\
\text { gal/day DHW }\end{array}$ & $\begin{array}{l}\text { Standard, } 3.15 \\
\mathrm{ft}^{3}, 533 \mathrm{kWh} / \mathrm{yr}, \\
1.16 \mathrm{MEF}, 65.6 \\
\mathrm{kWh} / \mathrm{yr} \text { machine } \\
\text { energy, } 4.63- \\
\text { gal/day DHW }\end{array}$ & $\begin{array}{l}\text { Standard, } 3.15 \mathrm{ft}^{3} \text {, } \\
533 \mathrm{kWh} / \mathrm{yr}, 1.16 \\
\mathrm{MEF}, 65.6 \mathrm{kWh} / \mathrm{yr} \\
\text { machine energy, } \\
\text { 4.63-gal/day DHW }\end{array}$ \\
\hline
\end{tabular}


Table B.1 (continued). BEopt Option Results for Single-Story Case

\begin{tabular}{|c|c|c|c|c|c|c|c|c|c|}
\hline CATEGORY & BENCHMARK & 35\% POINT & NEIGHBOR 1 & NEIGHBOR 2 & NEIGHBOR 3 & NEIGHBOR 4 & $\begin{array}{c}\text { NEIGHBOR } \\
5\end{array}$ & $\begin{array}{l}\text { NEXT } \\
\text { POINT ON } \\
\text { OPT. } \\
\text { CURVE }\end{array}$ & $39 \%$ POINT \\
\hline $\begin{array}{l}\text { Interior } \\
\text { Lighting }\end{array}$ & $\begin{array}{l}1574 \mathrm{kWh} / \mathrm{yr} \\
\text { Hardwired, } 331 \\
\text { kWh/yr Plug in }\end{array}$ & $\begin{array}{l}14 \% \text { CFL, } 1574 \\
\text { kWh/yr } \\
\text { Hardwired, } 331 \\
\text { kWh/yr Plug in }\end{array}$ & $\begin{array}{l}76 \% \text { CFL, } 749 \\
\text { kWh/yr } \\
\text { Hardwired, } 571 \\
\text { kWh/yr Plug in }\end{array}$ & $\begin{array}{l}14 \% \text { CFL, } 1574 \\
\text { kWh/yr Hardwired, } \\
331 \mathrm{kWh} / \mathrm{yr} \text { Plug } \\
\text { in }\end{array}$ & $\begin{array}{l}14 \% \text { CFL, } 1574 \\
\mathrm{kWh} / \mathrm{yr} \text { Hardwired, } \\
331 \mathrm{kWh} / \mathrm{yr} \text { Plug } \\
\text { in }\end{array}$ & $\begin{array}{l}14 \% \text { CFL, } \\
1574 \mathrm{kWh} / \mathrm{yr} \\
\text { Hardwired, } 331 \\
\text { kWh/yr Plug in }\end{array}$ & $\begin{array}{l}14 \% \text { CFL, } \\
1574 \\
\mathrm{kWh} / \mathrm{yr} \\
\text { Hardwired, } \\
331 \mathrm{kWh} / \mathrm{yr} \\
\text { Plug in }\end{array}$ & $\begin{array}{l}14 \% \text { CFL, } \\
1574 \\
\mathrm{kWh} / \mathrm{yr} \\
\text { Hardwired, } \\
331 \mathrm{kWh} / \mathrm{yr} \\
\text { Plug in }\end{array}$ & $\begin{array}{l}14 \% \text { CFL, } \\
1574 \\
\text { kWh/yr } \\
\text { Hardwired, } \\
331 \mathrm{kWh} / \mathrm{yr} \\
\text { Plug in }\end{array}$ \\
\hline Air Conditioner & $\begin{array}{l}\text { SEER 10, } 0.55 \\
\text { W/CFM AH Fan }\end{array}$ & $\begin{array}{l}\text { SEER 10, } 2.5 \\
\text { Tons, } 0.365 \\
\text { W/CFM AH Fan }\end{array}$ & $\begin{array}{l}\text { SEER 12, } 2.5 \\
\text { Tons, } 0.365 \\
\text { W/CFM AH Fan }\end{array}$ & $\begin{array}{l}\text { SEER } 10,2.5 \\
\text { Tons, } 0.365 \\
\text { W/CFM AH Fan }\end{array}$ & $\begin{array}{l}\text { SEER 12, } 3 \text { Tons, } \\
0.365 \text { W/CFM AH } \\
\text { Fan }\end{array}$ & $\begin{array}{l}\text { SEER 10, } 3 \\
\text { Tons, } 0.365 \\
\text { W/CFM AH } \\
\text { Fan }\end{array}$ & $\begin{array}{l}\text { SEER 10, } 3 \\
\text { Tons, } 0.365 \\
\text { W/CFM AH } \\
\text { Fan }\end{array}$ & $\begin{array}{l}\text { SEER } 10, \\
2.5 \text { Tons, } \\
0.365 \\
\text { W/CFM AH } \\
\text { Fan }\end{array}$ & $\begin{array}{l}\text { SEER } 10,2 \\
\text { Tons, } 0.365 \\
\text { W/CFM AH } \\
\text { Fan }\end{array}$ \\
\hline Furnace & $78 \%$ AFUE & $\begin{array}{l}80 \% \text { AFUE, } 50 \\
\mathrm{kBtu} / \mathrm{hr}\end{array}$ & $\begin{array}{l}80 \% \text { AFUE, } 75 \\
\text { kBtu/hr }\end{array}$ & $\begin{array}{l}80 \% \text { AFUE, } 50 \\
\mathrm{kBtu} / \mathrm{hr}\end{array}$ & $\begin{array}{l}80 \% \text { AFUE, } 75 \\
\mathrm{kBtu} / \mathrm{hr}\end{array}$ & $\begin{array}{l}80 \% \text { AFUE, } 75 \\
\mathrm{kBtu} / \mathrm{hr}\end{array}$ & $\begin{array}{l}80 \% \text { AFUE, } \\
50 \mathrm{kBtu} / \mathrm{hr}\end{array}$ & $\begin{array}{l}80 \% \text { AFUE, } \\
50 \mathrm{kBtu} / \mathrm{hr}\end{array}$ & $\begin{array}{l}80 \% \text { AFUE, } \\
50 \mathrm{kBtu} / \mathrm{hr}\end{array}$ \\
\hline Ducts & $\begin{array}{l}100 \% \text { Attic, } 5 \% \\
\text { AH fan flow } \\
\text { leakage to the } \\
\text { outside }\end{array}$ & $\begin{array}{l}\text { Inside } \\
\text { Conditioned } \\
\text { Space, SA } \\
\text { leakage }=1 \% \text {, } \\
\text { OA leakage }= \\
0.23 \% \text { of fan flow }\end{array}$ & $\begin{array}{l}\text { Typical, SA } \\
\text { leakage }=10 \%, \\
\text { OA leakage }= \\
5 \% \text { of fan flow }\end{array}$ & $\begin{array}{l}\text { Inside } \\
\text { Conditioned } \\
\text { Space, SA } \\
\text { leakage }=1 \%, \mathrm{OA} \\
\text { leakage }=0.23 \% \\
\text { of fan flow }\end{array}$ & $\begin{array}{l}\text { Inside } \\
\text { Conditioned } \\
\text { Space, SA } \\
\text { leakage }=1 \%, \text { OA } \\
\text { leakage }=0.23 \% \\
\text { of fan flow }\end{array}$ & $\begin{array}{l}\text { Inside } \\
\text { Conditioned } \\
\text { Space, SA } \\
\text { leakage = } 1 \% \text {, } \\
\text { OA leakage = } \\
0.23 \% \text { of fan } \\
\text { flow }\end{array}$ & $\begin{array}{l}\text { Inside } \\
\text { Conditioned } \\
\text { Space, SA } \\
\text { leakage }= \\
1 \%, \mathrm{OA} \\
\text { leakage = } \\
0.23 \% \text { of } \\
\text { fan flow }\end{array}$ & $\begin{array}{l}\text { Inside } \\
\text { Conditioned } \\
\text { Space, SA } \\
\text { leakage = } \\
1 \%, \text { OA } \\
\text { leakage = } \\
0.23 \% \text { of } \\
\text { fan flow }\end{array}$ & $\begin{array}{l}\text { Inside } \\
\text { Conditioned } \\
\text { Space, SA } \\
\text { leakage = } \\
1 \%, \text { OA } \\
\text { leakage = } \\
0.23 \% \text { of } \\
\text { fan flow }\end{array}$ \\
\hline Water Heater & $\begin{array}{l}\text { Gas, } 40 \text { gal, } \\
0.54 \mathrm{EF}, 0.76 \mathrm{RE}\end{array}$ & $\begin{array}{l}\text { Gas Standard, } 40 \\
\text { gallons, } 0.55 \mathrm{EF} \text {, } \\
0.76 \mathrm{RE}\end{array}$ & $\begin{array}{l}\text { Gas Standard, } \\
40 \text { gallons, } 0.55 \\
\text { EF, } 0.76 \text { RE }\end{array}$ & $\begin{array}{l}\text { Gas Standard, } 40 \\
\text { gallons, } 0.55 \mathrm{EF} \text {, } \\
0.76 \mathrm{RE}\end{array}$ & $\begin{array}{l}\text { Gas Standard, } 40 \\
\text { gallons, } 0.55 \mathrm{EF} \text {, } \\
0.76 \mathrm{RE}\end{array}$ & $\begin{array}{l}\text { Gas Standard, } \\
40 \text { gallons, } \\
0.55 \mathrm{EF}, \\
0.76 \mathrm{RE}\end{array}$ & $\begin{array}{l}\text { Gas } \\
\text { Standard, } \\
40 \text { gallons, } \\
0.55 \mathrm{EF}, \\
0.76 \mathrm{RE}\end{array}$ & $\begin{array}{l}\text { Gas } \\
\text { Standard, } \\
40 \text { gallons, } \\
0.55 \mathrm{EF}, \\
0.76 \mathrm{RE}\end{array}$ & $\begin{array}{l}\text { Gas } \\
\text { Standard, } \\
40 \text { gallons, } \\
0.55 \mathrm{EF}, \\
0.76 \mathrm{RE}\end{array}$ \\
\hline
\end{tabular}


Table B.2. BEopt Energy and Savings Results for Single-Story Case

\begin{tabular}{|c|c|c|c|c|c|c|c|c|c|}
\hline & BENCHMARK & $\begin{array}{c}35 \% \\
\text { POINT }\end{array}$ & $\begin{array}{c}\text { NEIGHBOR } \\
1 \\
\end{array}$ & $\begin{array}{c}\text { NEIGHBOR } \\
2 \\
\end{array}$ & $\begin{array}{c}\text { NEIGHBOR } \\
3 \\
\end{array}$ & $\begin{array}{c}\text { NEIGHBOR } \\
4 \\
\end{array}$ & $\begin{array}{c}\text { NEIGHBOR } \\
5 \\
\end{array}$ & $\begin{array}{l}\text { NEXT POINT ON } \\
\text { OPT. CURVE }\end{array}$ & $\begin{array}{l}39 \% \\
\text { POINT }\end{array}$ \\
\hline \multicolumn{10}{|c|}{$\begin{array}{c}\text { Energy End Use (MBtu/yr) } \\
\end{array}$} \\
\hline Misc. (E) & 39.84 & 38.74 & 38.74 & 38.74 & 38.74 & 38.74 & 38.73 & 38.74 & 38.74 \\
\hline Lights $(\mathrm{E})$ & 16.13 & 16.13 & 8.99 & 16.13 & 16.13 & 16.13 & 16.13 & 16.13 & 16.13 \\
\hline Heating Fan (E) & 0.95 & 0.34 & 0.42 & 0.20 & 0.21 & 0.22 & 0.17 & 0.32 & 0.30 \\
\hline Cooling Fan (E) & 22.44 & 7.21 & 9.24 & 7.08 & 7.86 & 7.94 & 7.76 & 7.17 & 6.41 \\
\hline Cooling (E) & 108.95 & 54.67 & 55.46 & 53.33 & 51.21 & 60.49 & 58.87 & 54.26 & 47.95 \\
\hline Heating (G) & 14.40 & 7.60 & 10.10 & 4.60 & 5.00 & 5.20 & 4.00 & 7.30 & 6.70 \\
\hline Hot Water (G) & 16.32 & 14.54 & 14.54 & 14.54 & 14.54 & 14.54 & 14.54 & 14.54 & 14.54 \\
\hline Misc. (G) & 9.79 & 8.10 & 8.10 & 8.10 & 8.10 & 8.10 & 8.10 & 8.10 & 8.10 \\
\hline Total & 228.82 & 147.33 & 145.60 & 142.74 & 141.79 & 151.37 & 148.31 & 146.56 & 138.88 \\
\hline \multicolumn{10}{|c|}{ End Use Savings } \\
\hline Misc. (E) & & $2.8 \%$ & $2.8 \%$ & $2.7 \%$ & $2.7 \%$ & $2.8 \%$ & $2.8 \%$ & $2.8 \%$ & $2.8 \%$ \\
\hline Lights $(E)$ & & $0.0 \%$ & $44.3 \%$ & $0.0 \%$ & $0.0 \%$ & $0.0 \%$ & $0.0 \%$ & $0.0 \%$ & $0.0 \%$ \\
\hline Heating Fan (E) & & $64.1 \%$ & $55.2 \%$ & $79.2 \%$ & $77.5 \%$ & $76.5 \%$ & $82.4 \%$ & $65.8 \%$ & $68.1 \%$ \\
\hline Cooling Fan (E) & & $67.8 \%$ & $58.8 \%$ & $68.4 \%$ & $65.0 \%$ & $64.6 \%$ & $65.4 \%$ & $68.1 \%$ & $71.4 \%$ \\
\hline Cooling (E) & & $49.8 \%$ & $49.1 \%$ & $51.0 \%$ & $53.0 \%$ & $44.5 \%$ & $46.0 \%$ & $50.2 \%$ & $56.0 \%$ \\
\hline Heating (G) & & $47.2 \%$ & $29.9 \%$ & $68.1 \%$ & $65.3 \%$ & $63.9 \%$ & $72.2 \%$ & $49.3 \%$ & $53.5 \%$ \\
\hline Hot Water (G) & & $10.9 \%$ & $10.9 \%$ & $10.9 \%$ & $10.9 \%$ & $10.9 \%$ & $10.9 \%$ & $10.9 \%$ & $10.9 \%$ \\
\hline $\operatorname{Misc}(\mathrm{G})$ & & $17.2 \%$ & $17.2 \%$ & $17.2 \%$ & $17.2 \%$ & $17.2 \%$ & $17.2 \%$ & $17.2 \%$ & $17.2 \%$ \\
\hline $\begin{array}{l}\text { Total Energy } \\
\text { Savings }\end{array}$ & & $35.6 \%$ & $36.4 \%$ & $37.6 \%$ & $38.0 \%$ & $33.8 \%$ & $35.2 \%$ & $35.9 \%$ & $39.3 \%$ \\
\hline
\end{tabular}


Table B.3. BEopt Option Results for Two-Story Case

\begin{tabular}{|c|c|c|c|c|c|c|c|c|c|}
\hline CATEGORY & BENCHMARK & $35 \%$ POINT & NEIGHBOR 1 & NEIGHBOR 2 & NEIGHBOR 3 & NEIGHBOR 4 & NEIGHBOR 5 & $\begin{array}{c}\text { NEXT POINT } \\
\text { ON OPT. } \\
\text { CURVE }\end{array}$ & $39 \%$ POINT \\
\hline Walls & $\begin{array}{c}U=0.085, \\
23 \% \mathrm{FF}, \\
\text { R11 batt, } 2 \times 4 \\
16 \text { in. oc }+ \\
\text { R2.5 sheathing }\end{array}$ & $\begin{array}{l}\text { R19, 2x6, } \\
24 \text { in. oc }\end{array}$ & $\begin{array}{l}\text { R19, } 2 \times 6, \\
24 \text { in. oc }\end{array}$ & $\begin{array}{l}\text { R19, } 2 \times 6, \\
24 \text { in. oc }\end{array}$ & $\begin{array}{l}\text { R19, } 2 \times 6, \\
24 \text { in. oc }\end{array}$ & $\begin{array}{l}\text { R13, } 2 \times 4, \\
16 \text { in. oc }\end{array}$ & $\begin{array}{l}\mathrm{R} 13,2 \times 4, \\
16 \text { in. oc }\end{array}$ & $\begin{array}{c}\text { R19, } 2 \times 6,24 \\
\text { in. oc }\end{array}$ & $\begin{array}{c}\mathrm{R} 19,2 \times 6,24 \\
\text { oc }\end{array}$ \\
\hline Ceiling & $\begin{array}{c}U=0.042 \\
11 \% \mathrm{FF}, \mathrm{R}-24\end{array}$ & $\mathrm{R}-30$ fiberglass & $\mathrm{R}-30$ fiberglass & $\mathrm{R}-30$ fiberglass & $\mathrm{R}-30$ fiberglass & $\mathrm{R}-60$ fiberglass & $\mathrm{R}-30$ fiberglass & $\begin{array}{c}\mathrm{R} 30 \\
\text { fiberglass }\end{array}$ & R30 fiberglass \\
\hline $\begin{array}{l}\text { Thermal } \\
\text { Mass }\end{array}$ & $\begin{array}{c}8 \mathrm{lbs} / \mathrm{ft}^{2}- \\
\text { furniture, } \\
\text { standard light } \\
\text { frame } \\
\text { construction }\end{array}$ & $\begin{array}{l}\text { 1/2-in. Ceiling } \\
\text { Drywall }\end{array}$ & $\begin{array}{l}1 / 2 \text {-in. Ceiling } \\
\text { Drywall }\end{array}$ & $\begin{array}{l}1 / 2 \text {-in. Ceiling } \\
\text { Drywall }\end{array}$ & $\begin{array}{l}1 / 2 \text {-in. Ceiling } \\
\text { Drywall }\end{array}$ & $\begin{array}{l}1 / 2 \text {-in. Ceiling } \\
\text { Drywall }\end{array}$ & $\begin{array}{l}1 / 2 \text {-in. Ceiling } \\
\text { Drywall }\end{array}$ & $\begin{array}{l}1 / 2 \text {-in. Ceiling } \\
\text { Drywall }\end{array}$ & $\begin{array}{l}1 / 2 \text {-in. Ceiling } \\
\text { Drywall }\end{array}$ \\
\hline Infiltration & $S L A=0.00057$ & $S L A=0.0005$ & $S L A=0.0005$ & $S L A=0.0003$ & $S L A=0.0005$ & $S L A=0.0005$ & $S L A=0.0005$ & $S L A=0.0005$ & $S L A=0.0005$ \\
\hline Slab & Uninsulated & Uninsulated & Uninsulated & Uninsulated & Uninsulated & Uninsulated & Uninsulated & Uninsulated & Uninsulated \\
\hline Glass Type & $\begin{array}{c}U=0.79 \\
S H G C=0.65\end{array}$ & $\begin{array}{c}\text { Two-pane clear, } \\
U=0.49 \\
\text { SHGC }=0.76 \\
\text { Center of Glass, } \\
\text { insulated } \\
\text { spacer, Vinyl } \\
\text { frame }\end{array}$ & $\begin{array}{c}\text { Two-pane } \\
\text { clear, U = 0.49, } \\
\text { SHGC }=0.76 \\
\text { Center of } \\
\text { Glass, } \\
\text { insulated } \\
\text { spacer, Vinyl } \\
\text { frame }\end{array}$ & $\begin{array}{c}\text { Two-pane } \\
\text { clear, U = 0.49, } \\
\text { SHGC =0.76 } \\
\text { Center of } \\
\text { Glass, } \\
\text { insulated } \\
\text { spacer, Vinyl } \\
\text { frame }\end{array}$ & $\begin{array}{c}\text { Two-pane clear, } \\
U=0.49 \\
\text { SHGC = } 0.76 \\
\text { Center of Glass, } \\
\text { insulated } \\
\text { spacer, Vinyl } \\
\text { frame }\end{array}$ & $\begin{array}{c}\text { Two-pane clear, } \\
U=0.49 \\
\text { SHGC }=0.76 \\
\text { Center of Glass, } \\
\text { insulated } \\
\text { spacer, Vinyl } \\
\text { frame }\end{array}$ & $\begin{array}{c}\text { Two-pane Low- } \\
\text { e, U = 0.32, } \\
\text { SHGC = 0.64 } \\
\text { Center of Glass, } \\
\text { insulated } \\
\text { spacer, Vinyl } \\
\text { frame }\end{array}$ & $\begin{array}{c}\text { Two-pane } \\
\text { clear, } \\
U=0.49 \text {, } \\
\text { SHGC }=0.76 \\
\text { Center of } \\
\text { Glass, } \\
\text { insulated } \\
\text { spacer, Vinyl } \\
\text { frame }\end{array}$ & $\begin{array}{c}\text { Two-pane clear, } \\
U=0.49 \\
\text { SHGC }=0.76 \\
\text { Center of } \\
\text { Glass, insulated } \\
\text { spacer, Vinyl } \\
\text { frame }\end{array}$ \\
\hline $\begin{array}{l}\text { Window } \\
\text { Area per } \\
\text { Wall }\end{array}$ & $\begin{array}{l}540 \mathrm{ft}^{2} \text {, Equal } \\
\text { distANCE On } \\
\text { four sides }\end{array}$ & $\begin{array}{c}540 \mathrm{ft}^{2} \\
12.5 \% \mathrm{~N} \& \mathrm{~S} \\
50 \% \mathrm{~W}, 25 \% \mathrm{E}\end{array}$ & $\begin{array}{c}540 \mathrm{ft}^{2} \\
12.5 \% \mathrm{~N} \& \mathrm{~S} \\
50 \% \mathrm{~W}, 25 \% \mathrm{E}\end{array}$ & $\begin{array}{c}540 \mathrm{ft}^{2} \\
12.5 \% \mathrm{~N} \& \mathrm{~S}, \\
50 \% \mathrm{~W}, 25 \% \mathrm{E}\end{array}$ & $\begin{array}{c}540 \mathrm{ft}^{2} \\
12.5 \% \mathrm{~N} \& \mathrm{~S} \\
50 \% \mathrm{~W}, 25 \% \mathrm{E}\end{array}$ & $\begin{array}{c}540 \mathrm{ft}^{2} \\
12.5 \% \mathrm{~N} \& \mathrm{~S} \\
50 \% \mathrm{~W}, 25 \% \mathrm{E}\end{array}$ & $\begin{array}{c}540 \mathrm{ft}^{2} \\
12.5 \% \mathrm{~N} \& \mathrm{~S}, \\
50 \% \mathrm{~W}, 25 \% \mathrm{E}\end{array}$ & $\begin{array}{c}540 \mathrm{ft}^{2}, 12.5 \% \\
\mathrm{~N} \& \mathrm{~S}, 50 \% \mathrm{~W} \\
25 \% \mathrm{E}\end{array}$ & $\begin{array}{c}540 \mathrm{ft}^{2}, 12.5 \% \\
\mathrm{~N} \& \mathrm{~S}, 50 \% \mathrm{~W} \\
25 \% \mathrm{E}\end{array}$ \\
\hline Refrigerator & $669 \mathrm{kWh} / \mathrm{yr}$ & $671 \mathrm{kWh} / \mathrm{yr}$ & $671 \mathrm{kWh} / \mathrm{yr}$ & $671 \mathrm{kWh} / \mathrm{yr}$ & $671 \mathrm{kWh} / \mathrm{yr}$ & $671 \mathrm{kWh} / \mathrm{yr}$ & $671 \mathrm{kWh} / \mathrm{yr}$ & $671 \mathrm{kWh} / \mathrm{yr}$ & $671 \mathrm{kWh} / \mathrm{yr}$ \\
\hline $\begin{array}{l}\text { Cooking } \\
\text { Range }\end{array}$ & 45 Therms/yr & 45 Therms/yr & 45 Therms/yr & 45 Therms/yr & 45 Therms/yr & 45 Therms/yr & 45 Therms/yr & 45 Therms/yr & 45 Therms/yr \\
\hline
\end{tabular}


Table B.3 (continued). BEopt Option Results for Two-Story Case

\begin{tabular}{|c|c|c|c|c|c|c|c|c|c|}
\hline CATEGORY & BENCHMARK & $35 \%$ POINT & NEIGHBOR 1 & NEIGHBOR 2 & NEIGHBOR 3 & NEIGHBOR 4 & NEIGHBOR 5 & $\begin{array}{c}\text { NEXT POINT } \\
\text { ON OPT. } \\
\text { CURVE }\end{array}$ & $39 \%$ POINT \\
\hline Dishwasher & $\begin{array}{l}206 \mathrm{kWh} / \mathrm{yr} \text {, } \\
5 \mathrm{gal} \mathrm{DHW} / \text { day }\end{array}$ & $\begin{array}{l}\text { Standard, } 462 \\
\text { kWh, } 8 \text { place } \\
\text { setting capacity, } \\
131.6 \mathrm{kWh} / \mathrm{yr} \\
\text { machine energy, } \\
5.39 \text { gal/day } \\
\text { DHW }\end{array}$ & $\begin{array}{l}\text { Standard, } 462 \\
\text { kWh, eight } \\
\text { place setting } \\
\text { capacity, } 131.6 \\
\text { kWh/yr machine } \\
\text { energy, } 5.39 \\
\text { gal/day DHW }\end{array}$ & $\begin{array}{l}\text { Standard, } 462 \\
\text { kWh, eight } \\
\text { place setting } \\
\text { capacity, } 131.6 \\
\text { kWh/yr } \\
\text { machine } \\
\text { energy, } 5.39 \\
\text { gal/day DHW }\end{array}$ & $\begin{array}{l}\text { ENERGY } \\
\text { STAR, } 384 \\
\text { kWh, eight } \\
\text { place setting } \\
\text { capacity, } 82.2 \\
\text { kWh/yr machine } \\
\text { energy, } 3.76 \\
\text { gal/day DHW }\end{array}$ & $\begin{array}{l}\text { Standard, } 462 \\
\text { kWh, eight } \\
\text { place setting } \\
\text { capacity, } 131.6 \\
\text { kWh/yr } \\
\text { machine } \\
\text { energy, } 5.39 \\
\text { gal/day DHW }\end{array}$ & $\begin{array}{l}\text { Standard, } 462 \\
\text { kWh, eight } \\
\text { place setting } \\
\text { capacity, } 131.6 \\
\text { kWh/yr } \\
\text { machine } \\
\text { energy, } 5.39 \\
\text { gal/day DHW }\end{array}$ & $\begin{array}{l}\text { Standard, } 462 \\
\text { kWh, eight } \\
\text { place setting } \\
\text { capacity, } 131.6 \\
\text { kWh/yr } \\
\text { machine } \\
\text { energy, } 5.39 \\
\text { gal/day DHW }\end{array}$ & $\begin{array}{l}\text { Standard, } 462 \\
\text { kWh, eight } \\
\text { place setting } \\
\text { capacity, } 131.6 \\
\text { kWh/yr } \\
\text { machine } \\
\text { energy, } 5.39 \\
\text { gal/day DHW }\end{array}$ \\
\hline $\begin{array}{l}\text { Clothes } \\
\text { Dryer }\end{array}$ & $\begin{array}{l}\text { Gas - } 71.6 \\
\mathrm{kWh} / \mathrm{yr} \text {, } \\
\text { 31.3 Therms/yr }\end{array}$ & $\begin{array}{l}\text { Gas }-5.7 \mathrm{ft}^{3} \text {, } \\
2.75 \mathrm{EF}, 70.1 \\
\mathrm{kWh} / \mathrm{yr}, 31.8 \\
\text { therms/yr }\end{array}$ & $\begin{array}{l}\text { Gas }-5.7 \mathrm{ft}^{3} \text {, } \\
2.75 \mathrm{EF}, 70.1 \\
\mathrm{kWh} / \mathrm{yr}, 31.8 \\
\text { therms/yr }\end{array}$ & $\begin{array}{l}\text { Gas }-5.7 \mathrm{ft}^{3} \text {, } \\
2.75 \mathrm{EF}, 70.1 \\
\mathrm{kWh} / \mathrm{yr}, 31.8 \\
\text { therms/yr }\end{array}$ & $\begin{array}{l}\text { Gas }-5.7 \mathrm{ft}^{3} \text {, } \\
2.75 \mathrm{EF}, 70.1 \\
\mathrm{kWh} / \mathrm{yr}, 31.8 \\
\text { therms/yr }\end{array}$ & $\begin{array}{l}\text { Gas - } 5.7 \mathrm{ft}^{3}, \\
2.75 \mathrm{EF}, 70.1 \\
\mathrm{kWh} / \mathrm{yr}, 31.8 \\
\text { therms/yr }\end{array}$ & $\begin{array}{l}\text { Gas - } 5.7 \mathrm{ft}^{3}, \\
2.75 \mathrm{EF}, 70.1 \\
\mathrm{kWh} / \mathrm{yr}, 31.8 \\
\text { therms/yr }\end{array}$ & $\begin{array}{l}\text { Gas - } 5.7 \mathrm{ft}^{3} \text {, } \\
2.75 \mathrm{EF}, 70.1 \\
\mathrm{kWh} / \mathrm{yr}, 31.8 \\
\text { therms/yr }\end{array}$ & $\begin{array}{l}\text { Gas - } 5.7 \mathrm{ft}^{3}, \\
2.75 \mathrm{EF}, 70.1 \\
\mathrm{kWh} / \mathrm{yr}, 31.8 \\
\text { therms/yr }\end{array}$ \\
\hline $\begin{array}{l}\text { Clothes } \\
\text { Washer }\end{array}$ & $\begin{array}{l}105 \mathrm{kWh} / \mathrm{yr}, \\
15 \mathrm{gal} / \mathrm{day}\end{array}$ & $\begin{array}{l}\text { Standard, } 3.15 \\
\mathrm{ft}^{2}, 533 \mathrm{kWh} / \mathrm{yr}, \\
1.16 \mathrm{MEF}, 65.6 \\
\mathrm{kWh} / \mathrm{yr} \text { machine } \\
\text { energy, } 4.63 \\
\text { gal/day DHW }\end{array}$ & $\begin{array}{l}\text { Standard, } 3.15 \\
\mathrm{ft}^{3}, 533 \mathrm{kWh} / \mathrm{yr} \text {, } \\
1.16 \mathrm{MEF}, 65.6 \\
\mathrm{kWh} / \mathrm{yr} \text { machine } \\
\text { energy, } 4.63 \\
\text { gal/day DHW }\end{array}$ & $\begin{array}{l}\text { Standard, } 3.15 \\
\mathrm{ft}^{3}, 533 \mathrm{kWh} / \mathrm{yr} \text {, } \\
1.16 \mathrm{MEF} \text {, } \\
65.6 \mathrm{kWh} / \mathrm{yr} \\
\text { machine } \\
\text { energy, } 4.63 \\
\text { gal/day DHW }\end{array}$ & $\begin{array}{l}\text { Standard, } 3.15 \\
\mathrm{ft}^{3}, 533 \mathrm{kWh} / \mathrm{yr} \text {, } \\
1.16 \mathrm{MEF} \text {, } \\
65.6 \mathrm{kWh} / \mathrm{yr} \\
\text { machine } \\
\text { energy, } 4.63 \\
\text { gal/day DHW }\end{array}$ & $\begin{array}{l}\text { Standard, } 3.15 \\
\mathrm{ft}^{3}, 533 \mathrm{kWh} / \mathrm{yr}, \\
1.16 \mathrm{MEF} \text {, } \\
65.6 \mathrm{kWh} / \mathrm{yr} \\
\text { machine } \\
\text { energy, } 4.63 \\
\text { gal/day DHW }\end{array}$ & $\begin{array}{l}\text { Standard, } 3.15 \\
\mathrm{ft}^{3}, 533 \mathrm{kWh} / \mathrm{yr} \text {, } \\
1.16 \mathrm{MEF} \text {, } \\
65.6 \mathrm{kWh} / \mathrm{yr} \\
\text { machine } \\
\text { energy, } 4.63 \\
\text { gal/day DHW }\end{array}$ & $\begin{array}{l}\text { Standard, } 3.15 \\
\mathrm{ft}^{3}, 533 \mathrm{kWh} / \mathrm{yr} \text {, } \\
1.16 \mathrm{MEF} \text {, } \\
65.6 \mathrm{kWh} / \mathrm{yr} \\
\text { machine } \\
\text { energy, } 4.63 \\
\text { gal/day DHW }\end{array}$ & $\begin{array}{l}\text { Standard, } 3.15 \\
\mathrm{ft}^{3}, 533 \mathrm{kWh} / \mathrm{yr} \text {, } \\
1.16 \mathrm{MEF}, \\
65.6 \mathrm{kWh} / \mathrm{yr} \\
\text { machine } \\
\text { energy, } 4.63 \\
\text { gal/day DHW }\end{array}$ \\
\hline $\begin{array}{l}\text { Interior } \\
\text { Lighting }\end{array}$ & $\begin{array}{l}14 \% \text { CFL, } \\
2284 \mathrm{kWh} / \mathrm{yr} \\
\text { Hardwired, } \\
571 \mathrm{kWh} / \mathrm{yr} \\
\text { Plug in }\end{array}$ & $\begin{array}{l}14 \% \text { CFL, } 2534 \\
\text { kWh/yr } \\
\text { Hardwired, } 571 \\
\text { kWh/yr Plug in }\end{array}$ & $\begin{array}{l}14 \% \text { CFL, } 2534 \\
\text { kWh/yr } \\
\text { Hardwired, } 571 \\
\text { kWh/yr Plug in }\end{array}$ & $\begin{array}{l}14 \% \text { CFL, } \\
2534 \mathrm{kWh} / \mathrm{yr} \\
\text { Hardwired, } 571 \\
\text { kWh/yr Plug in }\end{array}$ & $\begin{array}{l}14 \% \text { CFL, } 2534 \\
\text { kWh/yr } \\
\text { Hardwired, } 571 \\
\text { kWh/yr Plug in }\end{array}$ & $\begin{array}{l}14 \% \text { CFL, } 2534 \\
\text { kWh/yr } \\
\text { Hardwired, } 571 \\
\text { kWh/yr Plug in }\end{array}$ & $\begin{array}{l}14 \% \text { CFL, } \\
2534 \mathrm{kWh} / \mathrm{yr} \\
\text { Hardwired, } 571 \\
\text { kWh/yr Plug in }\end{array}$ & $\begin{array}{l}14 \% \text { CFL, } 2534 \\
\text { kWh/yr } \\
\text { Hardwired, } 571 \\
\text { kWh/yr Plug in }\end{array}$ & $\begin{array}{l}14 \% \text { CFL, } \\
2534 \text { kWh/yr } \\
\text { Hardwired, } 571 \\
\text { kWh/yr Plug in }\end{array}$ \\
\hline $\begin{array}{l}\text { Air } \\
\text { Conditioner }\end{array}$ & $\begin{array}{l}\text { SEER 10, } \\
0.55 \text { W/CFM } \\
\text { AH Fan }\end{array}$ & $\begin{array}{l}\text { SEER } 12,4.00 \\
\text { Tons, } 0.365 \\
\text { W/CFM AH Fan }\end{array}$ & $\begin{array}{l}\text { SEER } 12,4.00 \\
\text { Tons, } 0.365 \\
\text { W/CFM AH Fan }\end{array}$ & $\begin{array}{l}\text { SEER } 12,4.00 \\
\text { Tons, } 0.365 \\
\text { W/CFM AH } \\
\text { Fan }\end{array}$ & $\begin{array}{l}\text { SEER } 13,4.00 \\
\text { Tons, } 0.365 \\
\text { W/CFM AH Fan }\end{array}$ & $\begin{array}{l}\text { SEER } 12,4.00 \\
\text { Tons, } 0.365 \\
\text { W/CFM AH } \\
\text { Fan }\end{array}$ & $\begin{array}{l}\text { SEER } 12,4.00 \\
\text { Tons, } 0.365 \\
\text { W/CFM AH } \\
\text { Fan }\end{array}$ & $\begin{array}{l}\text { SEER } 13,4.00 \\
\text { Tons, } 0.365 \\
\text { W/CFM AH } \\
\text { Fan }\end{array}$ & $\begin{array}{l}\text { SEER } 14,4.00 \\
\text { Tons, } 0.383 \\
\text { W/CFM AH } \\
\text { Fan }\end{array}$ \\
\hline Furnace & $78 \%$ AFUE & $\begin{array}{l}80 \% \text { AFUE, } 100 \\
\text { kBtu/hr }\end{array}$ & $\begin{array}{l}80 \% \text { AFUE, } 100 \\
\text { kBtu/hr }\end{array}$ & $\begin{array}{l}80 \% \text { AFUE, } \\
100 \mathrm{kBtu} / \mathrm{hr}\end{array}$ & $\begin{array}{l}80 \% \text { AFUE, } 100 \\
\text { kBtu/hr }\end{array}$ & $\begin{array}{l}80 \% \text { AFUE, } \\
125 \mathrm{kBtu} / \mathrm{hr}\end{array}$ & $\begin{array}{l}80 \% \text { AFUE, } \\
100 \mathrm{kBtu} / \mathrm{hr}\end{array}$ & $\begin{array}{l}80 \% \text { AFUE, } \\
100 \mathrm{kBtu} / \mathrm{hr}\end{array}$ & $\begin{array}{l}80 \% \text { AFUE, } \\
100 \mathrm{kBtu} / \mathrm{hr}\end{array}$ \\
\hline
\end{tabular}


Table B.3 (continued). BEopt Option Results for Two-Story Case

\begin{tabular}{|c|c|c|c|c|c|c|c|c|c|}
\hline CATEGORY & BENCHMARK & $35 \%$ POINT & NEIGHBOR 1 & NEIGHBOR 2 & NEIGHBOR 3 & NEIGHBOR 4 & NEIGHBOR 5 & $\begin{array}{l}\text { NEXT POINT } \\
\text { ON OPT. } \\
\text { CURVE }\end{array}$ & $39 \%$ POINT \\
\hline Ducts & $\begin{array}{l}65 \% \text { Attic, } \\
35 \% \\
\text { Conditioned } \\
\text { Space, } 1.5 \% \\
\text { AH fan flow } \\
\text { leakage to the } \\
\text { outside }\end{array}$ & $\begin{array}{l}\text { Inside } \\
\text { Conditioned } \\
\text { Space, SA } \\
\text { leakage = } 1 \% \text {, } \\
\text { OA leakage = } \\
0.23 \% \text { of fan } \\
\text { flow }\end{array}$ & $\begin{array}{l}\text { Inside } \\
\text { Conditioned } \\
\text { Space, SA } \\
\text { leakage = } 1 \% \text {, } \\
\text { OA leakage = } \\
0.23 \% \text { of fan } \\
\text { flow }\end{array}$ & $\begin{array}{l}\text { Inside } \\
\text { Conditioned } \\
\text { Space, SA } \\
\text { leakage = } 1 \% \text {, } \\
\text { OA leakage = } \\
0.23 \% \text { of fan } \\
\text { flow }\end{array}$ & $\begin{array}{l}\text { Inside } \\
\text { Conditioned } \\
\text { Space, SA } \\
\text { leakage = } 1 \% \text {, } \\
\text { OA leakage = } \\
0.23 \% \text { of fan } \\
\text { flow }\end{array}$ & $\begin{array}{l}\text { Inside } \\
\text { Conditioned } \\
\text { Space, SA } \\
\text { leakage = } 1 \% \text {, } \\
\text { OA leakage = } \\
0.23 \% \text { of fan } \\
\text { flow }\end{array}$ & $\begin{array}{l}\text { Inside } \\
\text { Conditioned } \\
\text { Space, SA } \\
\text { leakage }=1 \% \text {, } \\
\text { OA leakage = } \\
0.23 \% \text { of fan } \\
\text { flow }\end{array}$ & $\begin{array}{l}\text { Inside } \\
\text { Conditioned } \\
\text { Space, SA } \\
\text { leakage = } 1 \% \text {, } \\
\text { OA leakage = } \\
0.23 \% \text { of fan } \\
\text { flow }\end{array}$ & $\begin{array}{l}\text { Inside } \\
\text { Conditioned } \\
\text { Space, SA } \\
\text { leakage }=1 \% \text {, } \\
\text { OA leakage = } \\
0.23 \% \text { of fan } \\
\text { flow }\end{array}$ \\
\hline $\begin{array}{l}\text { Water } \\
\text { Heater }\end{array}$ & $\begin{array}{l}\text { Gas, } 40 \text { gal, } \\
0.54 \mathrm{EF} \\
0.76 \mathrm{RE}\end{array}$ & $\begin{array}{l}\text { Gas Standard, } \\
40 \text { gallons, } \\
0.55 \mathrm{EF}, 0.76 \mathrm{RE}\end{array}$ & $\begin{array}{l}\text { Gas Tankless, } \\
0.84 \mathrm{EF}\end{array}$ & $\begin{array}{l}\text { Gas Standard, } \\
40 \text { gallons, } \\
0.55 \mathrm{EF}, \\
0.76 \mathrm{RE}\end{array}$ & $\begin{array}{l}\text { Gas Standard, } \\
40 \text { gallons, } \\
0.55 \mathrm{EF}, 0.76 \\
\text { RE }\end{array}$ & $\begin{array}{l}\text { Gas Standard, } \\
40 \text { gallons, } \\
0.55 \mathrm{EF}, 0.76 \\
\text { RE }\end{array}$ & $\begin{array}{l}\text { Gas Standard, } \\
40 \text { gallons, } \\
0.55 \mathrm{EF}, 0.76 \\
\text { RE }\end{array}$ & $\begin{array}{l}\text { Gas Standard, } \\
40 \text { gallons, } \\
0.55 \mathrm{EF}, 0.76 \\
\text { RE }\end{array}$ & $\begin{array}{l}\text { Gas Standard, } \\
40 \text { gallons, } \\
0.55 \mathrm{EF}, \\
0.76 \mathrm{RE}\end{array}$ \\
\hline
\end{tabular}


Table B.4. BEopt Energy and Savings Results for Two-Story Case

\begin{tabular}{|c|c|c|c|c|c|c|c|c|c|}
\hline CATEGORY & BENCHMARK & $\begin{array}{l}35 \% \\
\text { POINT }\end{array}$ & $\underset{1}{\text { NEIGHBOR }}$ & $\begin{array}{c}\text { NEIGHBOR } \\
2\end{array}$ & $\begin{array}{c}\text { NEIGHBOR } \\
3\end{array}$ & $\begin{array}{c}\text { NEIGHBOR } \\
4\end{array}$ & $\begin{array}{c}\text { NEIGHBOR } \\
5\end{array}$ & $\begin{array}{l}\text { NEXT POINT ON OPT. } \\
\text { CURVE }\end{array}$ & $\begin{array}{l}39 \% \\
\text { POINT }\end{array}$ \\
\hline \multicolumn{10}{|c|}{ Energy End Use (MBtu/yr) } \\
\hline Misc. (E) & 67.94 & 66.84 & 66.84 & 66.84 & 66.33 & 66.84 & 66.83 & 66.83 & 66.84 \\
\hline Lights (E) & 25.98 & 25.98 & 25.98 & 25.98 & 25.98 & 25.98 & 25.98 & 25.98 & 25.98 \\
\hline Heating Fan (E) & 1.55 & 0.44 & 0.44 & 0.26 & 0.44 & 0.52 & 0.46 & 0.44 & 0.46 \\
\hline Cooling Fan (E) & 36.84 & 14.43 & 14.43 & 13.95 & 14.12 & 14.54 & 13.54 & 14.12 & 14.83 \\
\hline Cooling (E) & 185.20 & 97.13 & 97.13 & 93.23 & 90.68 & 98.17 & 90.82 & 90.68 & 83.76 \\
\hline Heating (G) & 24.00 & 10.30 & 10.30 & 6.40 & 10.30 & 12.00 & 10.60 & 10.30 & 10.20 \\
\hline Hot Water (G) & 16.32 & 14.54 & 8.25 & 14.54 & 14.24 & 14.54 & 14.54 & 14.54 & 14.54 \\
\hline Misc. (G) & 9.79 & 8.10 & 8.10 & 8.10 & 8.10 & 8.10 & 8.10 & 8.10 & 8.10 \\
\hline Total & 367.62 & 237.76 & 231.47 & 229.31 & 230.19 & 240.69 & 230.88 & 231.00 & 224.71 \\
\hline
\end{tabular}


Table B.4 (continued). BEopt Energy and Savings Results for Two-Story Case

\begin{tabular}{|c|c|c|c|c|c|c|c|c|}
\hline CATEGORY BENCHMARK & $\begin{array}{l}35 \% \\
\text { POINT }\end{array}$ & $\begin{array}{c}\text { NEIGHBOR } \\
1\end{array}$ & $\begin{array}{c}\text { NEIGHBOR } \\
2\end{array}$ & $\begin{array}{c}\text { NEIGHBOR } \\
\mathbf{3}\end{array}$ & $\begin{array}{c}\text { NEIGHBOR } \\
4\end{array}$ & $\begin{array}{c}\text { NEIGHBOR } \\
5\end{array}$ & $\begin{array}{l}\text { NEXT POINT ON OPT. } \\
\text { CURVE }\end{array}$ & $\begin{array}{l}39 \% \\
\text { POINT }\end{array}$ \\
\hline \multicolumn{9}{|l|}{ End Use Savings } \\
\hline Misc. (E) & $1.6 \%$ & $1.6 \%$ & $1.6 \%$ & $2.4 \%$ & $1.6 \%$ & $1.6 \%$ & $1.6 \%$ & $1.6 \%$ \\
\hline Lights (E) & $0.0 \%$ & $0.0 \%$ & $0.0 \%$ & $0.0 \%$ & $0.0 \%$ & $0.0 \%$ & $0.0 \%$ & $0.0 \%$ \\
\hline $\begin{array}{l}\text { Heating Fan } \\
(E)\end{array}$ & $71.5 \%$ & $71.5 \%$ & $83.1 \%$ & $71.6 \%$ & $66.7 \%$ & $70.2 \%$ & $71.6 \%$ & $70.1 \%$ \\
\hline $\begin{array}{l}\text { Cooling Fan } \\
\text { (E) }\end{array}$ & $60.8 \%$ & $60.8 \%$ & $62.1 \%$ & $61.7 \%$ & $60.5 \%$ & $63.3 \%$ & $61.7 \%$ & $59.7 \%$ \\
\hline Cooling (E) & $47.6 \%$ & $47.6 \%$ & $49.7 \%$ & $51.0 \%$ & $47.0 \%$ & $51.0 \%$ & $51.0 \%$ & $54.8 \%$ \\
\hline Heating (G) & $57.1 \%$ & $57.1 \%$ & $73.3 \%$ & $57.1 \%$ & $50.0 \%$ & $55.8 \%$ & $57.1 \%$ & $57.5 \%$ \\
\hline $\begin{array}{l}\text { Hot Water } \\
\text { (G) }\end{array}$ & $10.9 \%$ & $49.5 \%$ & $10.9 \%$ & $12.8 \%$ & $10.9 \%$ & $10.9 \%$ & $10.9 \%$ & $10.9 \%$ \\
\hline Misc. (G) & $17.2 \%$ & $17.2 \%$ & $17.2 \%$ & $17.2 \%$ & $17.2 \%$ & $17.2 \%$ & $17.2 \%$ & $17.2 \%$ \\
\hline $\begin{array}{l}\text { Total Energy } \\
\text { Savings }\end{array}$ & $35.3 \%$ & $37.0 \%$ & $37.6 \%$ & $37.4 \%$ & $34.5 \%$ & $37.2 \%$ & $37.2 \%$ & $38.9 \%$ \\
\hline
\end{tabular}




\section{BEopt Cost and Performance Input Assumptions}

As with any analysis study, the results of the analysis are subject to the assumptions used during the study. The cost and performance assumptions used in the present study are documented in this Appendix. These assumptions will be updated on a regular basis as new information becomes available from residential field studies. The use of specific manufacturer names in this Appendix does not represent an endorsement or recommendation for use of a specific product. This Appendix is limited to categories that include multiple options specific to the optimizations performed and may not representative of all the possible options currently available within BEopt.

Table B.5. Utility and Onsite Power Inputs

\begin{tabular}{|c|c|c|c|}
\hline Group & Input Variable & Value & Units \\
\hline \multirow[t]{9}{*}{ Economics } & $\begin{array}{l}\text { Electricity Source/Site } \\
\text { Ratio }\end{array}$ & 3 & \\
\hline & Electricity Cost & 0.0778 & $\$ / k W h$ \\
\hline & Natural Gas Cost & 0.7986 & \$/therm \\
\hline & Discount Rate & 0.05 & \\
\hline & Mortgage Interest Rate & 0.07 & \\
\hline & Marginal Income Tax Rate & 0.28 & \\
\hline & Analysis Period & 30 & years \\
\hline & $\begin{array}{l}\text { Net Metered Excess Sellback } \\
\text { Rate }\end{array}$ & Local electric rate & $\$ / k W h$ \\
\hline & Efficiency Cost Multiplier & 1 & \\
\hline \multirow[t]{5}{*}{ Photovoltaics } & Module & Sharp NEH120E1 & \\
\hline & Installed Cost & $\begin{array}{l}7.5 \text { (unless noted } \\
\text { otherwise) }\end{array}$ & $\$ /$ rated W \\
\hline & Derate Factor & Determined by location & $\%$ \\
\hline & Daily Incident Solar & Determined by location & $\mathrm{kWh} / \mathrm{m}^{2}$ \\
\hline & Average System Efficiency & Determined by location & $\%$ \\
\hline
\end{tabular}


Table B.6. BEopt Cost Assumptions

\begin{tabular}{|c|c|}
\hline CATEGORYIOPTION & UNIT COST \\
\hline Slab & $(\$ / f t)$ \\
\hline Uninsulated & $\$ 0.00$ \\
\hline 2-ft R5 Perimeter, R-5 Gap & $\$ 1.38$ \\
\hline 4-ft R5 Perimeter, R-5 Gap & $\$ 2.36$ \\
\hline 2-ft R10 Perimeter, R-5 Gap & $\$ 2.22$ \\
\hline 4-ft R10 Perimeter, R-5 Gap & $\$ 3.92$ \\
\hline 15-ft R10 Perimeter, R-5 Gap & $\$ 8.19$ \\
\hline Wall Construction & $\left(\$ / \mathrm{ft}^{2}\right)$ \\
\hline $\mathrm{R}-11$ batts, $2 \times 4,16$ in.oc & $\$ 3.15$ \\
\hline $\mathrm{R}-13$ batts, $2 \times 4,16$ in. oc & $\$ 3.17$ \\
\hline R-11 batts, $2 \times 4,16$ in. oc +1 -in. foam sheathing & $\$ 3.92$ \\
\hline R-19 batts, $2 \times 6,24$ in. oc & $\$ 3.28$ \\
\hline R-19 batts, $2 \times 6,24$ in. oc +1 -in. foam sheathing & $\$ 4.05$ \\
\hline R-19 batts, $2 \times 6,24$ in. oc +2 -in. foam sheathing & $\$ 4.24$ \\
\hline Ceiling Insulation & $\left(\$ / \mathrm{ft}^{2}\right)$ \\
\hline R-30 Fiberglass & $\$ 0.55$ \\
\hline R-40 Fiberglass & $\$ 0.73$ \\
\hline R-50 Fiberglass & $\$ 0.92$ \\
\hline R-60 Fiberglass & $\$ 1.10$ \\
\hline Thermal Mass & $\left(\$ / \mathrm{ft}^{2}\right)$ \\
\hline Standard $1 / 2$-in. Ceiling Drywall & $\$ 0.19$ \\
\hline
\end{tabular}


Table B.6 (continued). BEopt Cost Assumptions

\begin{tabular}{|c|c|}
\hline CATEGORYIOPTION & UNIT COST \\
\hline 5/8-in. Ceiling Drywall & $\$ 0.27$ \\
\hline $2 \times 1 / 2$-in. Ceiling Drywall & $\$ 0.38$ \\
\hline 2 × 5/8-in. Ceiling Drywall & $\$ 0.54$ \\
\hline Infiltration & $\left(\$ / \mathrm{ft}^{2}\right)$ \\
\hline Typical (SLA = 0.0005) & $\$ 0.00$ \\
\hline Tight $(\mathrm{SLA}=0.0003)$ & $\$ 0.54$ \\
\hline Windows & $\left(\$ / \mathrm{ft}^{2}\right)$ \\
\hline $\begin{array}{l}\text { Two-pane clear, } U=0.49, \mathrm{SHGC}=0.76 \text { Center of Glass, } \\
\text { insulated spacer, Vinyl frame }\end{array}$ & $\$ 21.99$ \\
\hline $\begin{array}{l}\text { Low-e }(e=0.01) \text {, double pane, } U=0.32, S H G C=0.64 \\
\text { Center of Glass, insulated spacer, Vinyl frame }\end{array}$ & $\$ 24.77$ \\
\hline $\begin{array}{l}\text { Low-e (e } 0.1 \mathrm{w} / \mathrm{tint}) \text {, double pane, } U=0.31, \mathrm{SHGC}=0.37 \\
\text { Center of Glass, insulated spacer, Vinyl frame }\end{array}$ & $\$ 24.77$ \\
\hline $\begin{array}{l}\text { Low-e }(e=0.04) \text {, double pane, } U=0.3, S H G C=0.44 \\
\text { Center of Glass, insulated spacer, Vinyl frame }\end{array}$ & $\$ 24.77$ \\
\hline $\begin{array}{l}\text { Low-e }(e=0.04 \mathrm{w} / \mathrm{tint}) \text {, double pane, } U=0.29, \mathrm{SHGC}= \\
0.29 \text { Center of Glass, insulated spacer, Vinyl frame }\end{array}$ & $\$ 24.77$ \\
\hline $\begin{array}{l}\text { Heat Mirror }(\mathrm{HM} 22), U=0.21, \mathrm{SHGC}=0.14 \text { Center of } \\
\text { Glass, insulated spacer, Vinyl frame }\end{array}$ & $\$ 30.32$ \\
\hline $\begin{array}{l}\text { Heat Mirror (HM TC88), } U=0.18, S H G C=0.48 \text { Center of } \\
\text { Glass, insulated spacer, Vinyl frame }\end{array}$ & $\$ 30.32$ \\
\hline Refrigerator & (\$/unit) \\
\hline Standard - $671 \mathrm{kWh} / \mathrm{yr}$ & $\$ 1,099.99$ \\
\hline ENERGY STAR - 572kWh/yr & $\$ 1,219.99$ \\
\hline
\end{tabular}


Table B.6 (continued). BEopt Cost Assumptions

\begin{tabular}{|c|c|}
\hline CATEGORYIOPTION & UNIT COST \\
\hline Dishwasher & (\$/unit) \\
\hline $\begin{array}{l}\text { Standard, } 462 \mathrm{kWh} \text {, eight place setting capacity, } \\
131.6 \mathrm{kWh} / \mathrm{yr} \text { machine energy, } 5.39 \mathrm{gal} / \text { day } \mathrm{DHW}\end{array}$ & $\$ 239.00$ \\
\hline $\begin{array}{l}\text { ENERGY STAR, } 384 \mathrm{kWh} \text {, eight place setting capacity, } \\
82.2 \mathrm{kWh} / \mathrm{yr} \text { machine energy, } 3.76 \text { gal/day DHW }\end{array}$ & $\$ 299.00$ \\
\hline Clothes Washer & (\$/unit) \\
\hline $\begin{array}{l}\text { Standard, } 3.15 \mathrm{ft}^{3}, 533 \mathrm{kWh} / \mathrm{yr}, 1.16 \mathrm{MEF} \\
65.6 \mathrm{kWh} / \mathrm{yr} \text { machine energy, } 4.63 \mathrm{gal} / \mathrm{day} \mathrm{DHW}\end{array}$ & $\$ 419.00$ \\
\hline $\begin{array}{l}\text { ENERGY STAR, top loader, } \mathrm{H} \text {-axis, } 2.9 \mathrm{ft}^{3}, 273 \mathrm{kWh} / \mathrm{yr} \text {, } \\
1.68 \mathrm{MEF}, 72.9 \mathrm{kWh} / \mathrm{yr} \text { machine energy, } 3.71 \mathrm{gal} / \mathrm{day} \\
\text { DHW }\end{array}$ & $\$ 799.00$ \\
\hline Lighting & (\$/bulb) \\
\hline Incandescent & $\$ 0.25$ \\
\hline CFL & $\$ 7.99$ \\
\hline Air Conditioner SEER value & $\begin{array}{c}\text { Efficiency Cost }(\$)= \\
0.817^{*}\left(\left(186^{*} \text { SEERvalue }\right)-1535\right)\end{array}$ \\
\hline 10 & $\$ 265.53$ \\
\hline 12 & $\$ 569.45$ \\
\hline 13 & $\$ 721.41$ \\
\hline 14 & $\$ 873.37$ \\
\hline 15 & $\$ 1,025.34$ \\
\hline 16 & $\$ 1,177.30$ \\
\hline 17 & $\$ 1,329.26$ \\
\hline 18 & $\$ 1,481.22$ \\
\hline
\end{tabular}


Table B.6 (continued). BEopt Cost Assumptions

\begin{tabular}{|c|c|}
\hline CATEGORYIOPTION & UNIT COST \\
\hline Air Conditioner Capacity (tons) & $\begin{array}{c}\text { Capacity Cost }(\$)= \\
0.817^{*}\left(563^{*} \text { tons }\right)\end{array}$ \\
\hline 0.5 & $\$ 229.99$ \\
\hline 1.0 & $\$ 459.97$ \\
\hline 1.5 & $\$ 689.96$ \\
\hline 2.0 & $\$ 919.94$ \\
\hline 2.5 & $\$ 1,149.93$ \\
\hline 3.0 & $\$ 1,379.91$ \\
\hline 3.5 & $\$ 1,609.90$ \\
\hline 4.0 & $\$ 1,839.88$ \\
\hline Furnace Efficiency (\% AFUE) & $\begin{array}{c}\text { Efficiency Cost }(\$)= \\
\left(23.57^{\star} \text { AFUE\%*100)-1621 }\right.\end{array}$ \\
\hline $80 \%$ & $\$ 264.60$ \\
\hline $92.5 \%$ & $\$ 559.23$ \\
\hline Furnace Capacity (kBtu/hr) & $\begin{array}{l}\text { Capacity Cost }(\$)= \\
2.92^{*} \mathrm{kBtu} / \mathrm{hr}\end{array}$ \\
\hline $25 \mathrm{kBtu} / \mathrm{hr}$ & $\$ 73.00$ \\
\hline $50 \mathrm{kBtu} / \mathrm{hr}$ & $\$ 146.00$ \\
\hline $75 \mathrm{kBtu} / \mathrm{hr}$ & $\$ 219.00$ \\
\hline $100 \mathrm{kBtu} / \mathrm{hr}$ & $\$ 292.00$ \\
\hline $125 \mathrm{kBtu} / \mathrm{hr}$ & $\$ 365.00$ \\
\hline $150 \mathrm{kBtu} / \mathrm{hr}$ & $\$ 438.00$ \\
\hline $175 \mathrm{kBtu} / \mathrm{hr}$ & $\$ 511.00$ \\
\hline $200 \mathrm{kBtu} / \mathrm{hr}$ & $\$ 584.00$ \\
\hline
\end{tabular}


Table B.6 (continued). BEopt Cost Assumptions

\begin{tabular}{|c|c|}
\hline CATEGORYIOPTION & UNIT COST \\
\hline Water Heater & (\$/unit, install + equip) \\
\hline Gas Standard, 40 gallons, $0.55 \mathrm{EF}$ & $\$ 428.00$ \\
\hline Gas Premium, 40 gallon , 0.62EF & $\$ 624.08$ \\
\hline Gas Tankless, 0.84 EF & $\$ 1,050.00$ \\
\hline Ducts & $\left(\$ / \mathrm{ft}^{2} \mathrm{FFA}\right)$ \\
\hline $\begin{array}{l}\text { Typical, SA leakage }=10 \% \text {, } \\
\text { OA leakage }=2.3 \% \text { of fan flow }\end{array}$ & $\$ 0.45$ \\
\hline $\begin{array}{l}\text { Improved, SA leakage }=2.3 \% \text {, } \\
\text { OA leakage }=0.5 \% \text { of fan flow }\end{array}$ & $\$ 0.69$ \\
\hline $\begin{array}{l}\text { Inside Conditioned Space, SA leakage }=1 \% \text {, } \\
\text { OA leakage }=0.23 \% \text { of fan flow }\end{array}$ & $\$ 0.77$ \\
\hline
\end{tabular}




\section{Appendix C: List of Key Trade-based Certifications}

\section{Preferred Contractors Program Draft}

Below is a preliminary list of the different trade classifications and the sub-specializations that could be associated with a new-home certified-contractors program. The concept is to have a broad range of specialist classifications, to acknowledge the fragmentation and specialization that is inherent in the construction industry. This encourages even those trades who do a very limited scope of work (i.e., just window installation or just duct rough in) to become certified specialists in their field, which requires them to also have a broader understanding of how that piece fits into the bigger house as a system. This concept will need to be discussed with manufacturers and trade contractors to determine its practicality.

1. HVAC

a. Space-Conditioning System Design Specialist

b. Duct Design Specialist

c. Air-Distribution System Installation Specialist

d. Equipment Installation and Start-up Specialist

i. Fossil and electric heating

ii. Refrigeration $-\mathrm{AC} /$ Heat Pump

e. Airflow Balancing Specialist

2. Carpentry

a. Framing Specialist

3. Thermal envelope

a. Insulation Specialist

b. Air-sealing Specialist

4. Above-grade moisture management

a. Window and Door Installation Specialist

b. Wall Drainage Plane Specialist

c. Roof Drainage and Flashing Specialist

5. Below-grade moisture management

a. Below-Grade Moisture Management Specialist

6. Designers

a. Architect / Residential Designer

b. Engineer 
Within each of the specializations is a more detailed description of the probable roles and competencies required.

1. HVAC

a. Space-Conditioning System Design Specialist

i. Load Calculation, Ventilation, and Equipment-Selection Specialist

1. Proficiency in ACCA Manual $\mathbf{J}$ method for load calculation and how to account for higher performance when calculating heating and cooling loads

2. Understands relationship between high-performance house (thermal envelope strategies to achieve high-performance homes) and heating and cooling loads to be satisfied by the space-conditioning equipment

3. Surface area competencies and understanding of thermal envelope assemblies (i.e., framing factors, window properties, etc.)

4. Understands the types of ventilation systems and their interaction with the heating and cooling equipment

5. Understands dedicated humidity control options and how to integrate with space-conditioning systems

6. Understands the internal gains and latent loads associated with people and ventilation

7. Understands the impact of climate, shading, and other environmental impacts on the building.

ii. Duct Design Specialist

1. Understands the impact of duct friction with respect to airflows (equivalent length methods - ACCA Manual D)

2. Familiarity with structural systems and limitations regarding using running duct systems within structural systems (floor-framing systems, walls, etc.)

3. Air distribution options in higher performance homes (high sidewall, central return, etc.)

4. Acoustics of air distribution systems

b. Air-Distribution System Installation Specialist

i. Follows layout by Duct-Design Specialist

ii. Understands duct-sealing techniques

iii. Understands ventilation system concepts as they relate to ducts and equipment installation issues

iv. Certified in duct-system leakage testing

v. Sets furnace and inside AC coils as part of air system 
c. Equipment Installation and Start-up Specialists

i. Installation of equipment and associated refrigeration

ii. Start-up and commissioning of heating, cooling and ventilation systems

d. Airflow Balancing Specialist

i. Airflow at the equipment

ii. Total system duct leakage testing

iii. Room-by-room airflow balancing and measurement

2. Carpentry

a. Framing Specialist

i. Optimum value engineering of wood frame structures

1. Stack framing

2. Wall layout and value engineering wall-framing techniques

3. Floor framing and interaction with HVAC system and plumbing system

4. Structural and code limitations

ii. Air-sealing techniques incorporated during framing (i.e., band joist gluing and sealing, mud sill sealing, cantilevers, floors over garages, chases, etc.)

3. Thermal envelope

a. Insulation Specialist

i. Insulation basics

1. How insulation works

2. Encapsulation requirements

3. Types of insulation products, limitations, and applications

4. Insulation and flame spread issues

ii. Blown-in wall techniques (new and retrofit)

1. Damp spray

2. Net and fill cavity

3. Two-hole method

4. Hole and tube (dense pack)

iii. Blown attic and horizontal cavity (floor, cantilever, etc.)

iv. Batt installation

v. Below-grade insulation systems (interior)

vi. Crawlspace vapor barrier installation

vii. Sub-Specialist designation 
b. Air-Sealing Specialist

viii. Envelope air-tightening techniques

ix. Window and door rough openings

x. Framing intersections

xi. Bypasses / chases / soffits

xii. Cantilevers, floors over unconditioned spaces

xiii. Fire codes and safety

xiv. Diagnostics

xv. Blower door

1. Pre- and post-testing

2. Blower door directed air-sealing techniques

xvi. Infrared imaging

xvii. Pressure diagnostics

4. Above-grade moisture management

a. Window and Door Installation Specialist

i. Flashings

ii. Integration to drainage plane

b. Wall Drainage Plane Specialist

i. Drainage plane installation

ii. Integration with windows and doors

iii. Integration with roof flashing systems

iv. Roof-flashing systems at wall intersections

c. Roof Drainage and Flashing Specialist

i. Roof-penetration flashings

ii. Roof wallflashing systems

iii. Integration to wall systems

iv. Gutter and downspouts

5. Below-grade moisture management

a. Below-Grade Moisture Management Specialist

i. Perimeter drainage systems

ii. Sub-slab capillary break and vapor diffusion control

iii. Capillary break at footing

iv. Vapor barrier at crawlspaces

v. Foundation damp-proofing systems

vi. Foundation waterproofing systems 
6. Designers

a. Architect / Residential Designer

b. Engineer 
Appendix D: National Housing Quality Rating Table

\section{Table D.1. Leadership}

Leaders align everyone in the organization with a common purpose, values, and priorities.

\begin{tabular}{|c|c|c|c|c|c|c|c|c|}
\hline & Level 1 & Level 2 & Level 3 & IBACOS Level 3 & Level 4 & IBACOS Level 4 & Level 5 & IBACOS Level 5 \\
\hline $\begin{array}{l}1.1 \\
\text { Company Mission, } \\
\text { Vision, and Values }\end{array}$ & $\begin{array}{l}\text { Company's main } \\
\text { quality goal is to } \\
\text { avoid customer } \\
\text { disappointment } \\
\text { and complaints. }\end{array}$ & $\begin{array}{l}\text { Quality and customer } \\
\text { satisfaction is } \\
\text { important to the } \\
\text { company but not } \\
\text { included in a written } \\
\text { mission statement. }\end{array}$ & $\begin{array}{l}\text { Written company } \\
\text { mission statement } \\
\text { includes a commitment } \\
\text { to quality and customer } \\
\text { satisfaction. }\end{array}$ & $\begin{array}{l}\text { Quality is defined in the } \\
\text { five key performance } \\
\text { metrics (Health, Safety, } \\
\text { Durability, Efficiency \& } \\
\text { Comfort) with } \\
\text { measurable attributes } \\
\text { associated with the } \\
\text { definition. }\end{array}$ & $\begin{array}{l}\text { In addition to level } 3 \text {, } \\
\text { values or principles } \\
\text { important to the } \\
\text { company are included } \\
\text { in a written statement. }\end{array}$ & $\begin{array}{l}\text { Performance metrics } \\
\text { of competition is } \\
\text { Benchmarked and } \\
\text { three of five area } \\
\text { exceed Benchmark } \\
\text { industry standards }\end{array}$ & $\begin{array}{l}\text { In addition to level } 4 \text {, } \\
\text { there is a compelling } \\
\text { future vision of what } \\
\text { the company can } \\
\text { become. }\end{array}$ & $\begin{array}{l}\text { Vision is created with } \\
\text { stretch goals for all five } \\
\text { performance metrics }\end{array}$ \\
\hline $\begin{array}{l}1.2 \\
\text { Senior } \\
\text { Management } \\
\text { Involvement }\end{array}$ & $\begin{array}{l}\text { Senior managers } \\
\text { get involved with } \\
\text { quality to handle } \\
\text { customer } \\
\text { complaints. }\end{array}$ & $\begin{array}{l}\text { Senior managers like } \\
\text { the idea of quality but } \\
\text { are not involved in } \\
\text { improvement activities. }\end{array}$ & $\begin{array}{l}\text { Senior managers } \\
\text { demonstrate personal } \\
\text { commitment to the } \\
\text { company's quality } \\
\text { mission and are often } \\
\text { involved in quality- } \\
\text { related activities }\end{array}$ & $\begin{array}{l}\text { Performance attributes } \\
\text { are given equal weight } \\
\text { to other quality criteria. } \\
\text { Quality Management is } \\
\text { a cross-cutting } \\
\text { management function }\end{array}$ & $\begin{array}{l}\text { Senior managers } \\
\text { constantly } \\
\text { communicate the } \\
\text { company's quality } \\
\text { mission to customers, } \\
\text { employees, and trade } \\
\text { contractors. }\end{array}$ & $\begin{array}{l}\text { One point of contact } \\
\text { for managing the } \\
\text { performance attributes } \\
\text { of the home from pre- } \\
\text { design through } \\
\text { warrantee. Goals of all } \\
\text { Senior managers tied } \\
\text { to achieving } \\
\text { performance metrics }\end{array}$ & $\begin{array}{l}\text { In addition to level } 4 \text {, } \\
\text { managers and } \\
\text { supervisors at all levels } \\
\text { are actively engaged in } \\
\text { reinforcing the } \\
\text { company mission, } \\
\text { vision, and values. }\end{array}$ & $\begin{array}{l}\text { All team members are } \\
\text { reinforcing } \\
\text { performance attributes } \\
\text { at all phases and } \\
\text { stages of product }\end{array}$ \\
\hline $\begin{array}{l}1.3 \\
\text { Leadership } \\
\text { Feedback and } \\
\text { Improvement }\end{array}$ & $\begin{array}{l}\text { Senior } \\
\text { management uses } \\
\text { their experience to } \\
\text { guide the company } \\
\text { toward their vision } \\
\text { for the future. }\end{array}$ & $\begin{array}{l}\text { Senior managers } \\
\text { actively seek } \\
\text { employee feedback to } \\
\text { gauge the } \\
\text { organization's } \\
\text { alignment toward the } \\
\text { company mission, } \\
\text { vision, and values. }\end{array}$ & $\begin{array}{l}\text { In addition to level } 2 \text {, } \\
\text { surveys measure the } \\
\text { alignment of employee } \\
\text { values and beliefs } \\
\text { toward those of the } \\
\text { organization. }\end{array}$ & $\begin{array}{l}\text { Performance metrics } \\
\text { are included in survey }\end{array}$ & $\begin{array}{l}\text { In addition to level } 3 \text {, } \\
\text { senior managers plan } \\
\text { initiatives to reinforce } \\
\text { the company mission, } \\
\text { vision, and values. }\end{array}$ & $\begin{array}{l}\text { Performance metrics } \\
\text { are included in } \\
\text { initiatives }\end{array}$ & $\begin{array}{l}\text { In addition to level } 4 \text {, } \\
\text { the leadership function } \\
\text { is managed as a } \\
\text { process that is } \\
\text { continuously improved } \\
\text { through evaluation, } \\
\text { adjustment, and } \\
\text { verification of results. }\end{array}$ & $\begin{array}{l}\text { Performance } \\
\text { achievements in } \\
\text { homes is used as one } \\
\text { measure of leadership } \\
\text { success }\end{array}$ \\
\hline
\end{tabular}


Table D.1. Leadership (continued)

\begin{tabular}{|c|c|c|c|c|c|c|c|c|}
\hline & Level 1 & Level 2 & Level 3 & IBACOS Level 3 & Level 4 & IBACOS Level 4 & Level 5 & IBACOS Level 5 \\
\hline $\begin{array}{l}1.4 \\
\text { Living the } \\
\text { Mission }\end{array}$ & $\begin{array}{l}\text { Employees may } \\
\text { have different } \\
\text { priorities but } \\
\text { there is a general } \\
\text { understanding of } \\
\text { what the } \\
\text { company is trying } \\
\text { to accomplish. }\end{array}$ & $\begin{array}{l}\text { Most employees } \\
\text { know key elements } \\
\text { of the company } \\
\text { mission, values, and } \\
\text { vision for the future } \\
\text { and could explain } \\
\text { how it relates to their } \\
\text { job. }\end{array}$ & $\begin{array}{l}\text { Most employees } \\
\text { recognize and } \\
\text { support } \\
\text { organizational } \\
\text { mission, values, and } \\
\text { vision, and use them } \\
\text { to guide their } \\
\text { decision making. }\end{array}$ & $\begin{array}{l}\text { Performance metrics } \\
\text { are instilled as one } \\
\text { component that is } \\
\text { used in decision } \\
\text { making }\end{array}$ & $\begin{array}{l}\text { In addition to level } 3 \text {, } \\
\text { survey data shows } \\
\text { that most employees } \\
\text { embrace the } \\
\text { company mission, } \\
\text { vision, and values. } \\
\text { There is a strong } \\
\text { feeling that everyone } \\
\text { is working toward } \\
\text { common goals. }\end{array}$ & $\begin{array}{l}\text { Survey includes } \\
\text { performance metrics } \\
\text { and evaluates } \\
\text { employee } \\
\text { understanding and } \\
\text { implementation of } \\
\text { performance } \\
\text { attributes }\end{array}$ & $\begin{array}{l}\text { In addition to level } 4 \text {, } \\
\text { employees actively } \\
\text { reinforce the } \\
\text { company mission, } \\
\text { vision, and values } \\
\text { among themselves } \\
\text { during the course of } \\
\text { everyday work. }\end{array}$ & $\begin{array}{l}\text { Employees are } \\
\text { empowered and } \\
\text { rewarded for } \\
\text { achieving } \\
\text { performance } \\
\text { metrics. }\end{array}$ \\
\hline $\begin{array}{l}1.5 \\
\text { Public } \\
\text { Responsibility }\end{array}$ & $\begin{array}{l}\text { Some people at } \\
\text { the company are } \\
\text { personally } \\
\text { involved in } \\
\text { activities that } \\
\text { benefit the } \\
\text { community, the } \\
\text { public, or the } \\
\text { housing industry. }\end{array}$ & $\begin{array}{l}\text { When asked, the } \\
\text { company supports } \\
\text { activities to benefit } \\
\text { the community, the } \\
\text { public, or the } \\
\text { housing industry. }\end{array}$ & $\begin{array}{l}\text { Being a responsible } \\
\text { corporate citizen is } \\
\text { regarded as good for } \\
\text { the company. } \\
\text { The company is } \\
\text { actively involved in } \\
\text { activities to benefit } \\
\text { the community, the } \\
\text { public, or the } \\
\text { housing industry. }\end{array}$ & $\begin{array}{l}\text { Company } \\
\text { involvement is } \\
\text { related to } \\
\text { performance metrics }\end{array}$ & $\begin{array}{l}\text { In addition to level } 3 \text {, } \\
\text { the company creates } \\
\text { opportunities to be } \\
\text { actively involved in } \\
\text { activities to benefit } \\
\text { the community, the } \\
\text { public, or the } \\
\text { housing industry. }\end{array}$ & $\begin{array}{l}\text { Company initiatives } \\
\text { action that related to } \\
\text { performance metrics }\end{array}$ & $\begin{array}{l}\text { For its size, the } \\
\text { company is one of } \\
\text { the area's leading } \\
\text { business supporters } \\
\text { of activities to benefit } \\
\text { the community, the } \\
\text { public, or the housing } \\
\text { industry. }\end{array}$ & $\begin{array}{l}\text { Company is a } \\
\text { regional or national } \\
\text { leader in supporting } \\
\text { initiatives related to } \\
\text { performance metrics }\end{array}$ \\
\hline
\end{tabular}

Note: Yellow denotes minimum level for considering adopting a 30\% whole-house energy-savings solution set. 
Table D.2. Strategic Planning

Achieving a future vision of what the company can become requires creating and executing a strategic plan for getting there.

\begin{tabular}{|c|c|c|c|c|c|c|c|c|}
\hline & Level 1 & Level 2 & Level 3 & IBACOS Level 3 & Level 4 & IBACOS Level 4 & Level 5 & IBACOS Level 5 \\
\hline $\begin{array}{l}2.1 \\
\text { Company-wide } \\
\text { Success Drivers } \\
\text { and Performance } \\
\text { Measures. }\end{array}$ & $\begin{array}{l}\text { Measures of } \\
\text { company } \\
\text { performance are } \\
\text { limited to sales } \\
\text { and profit. }\end{array}$ & $\begin{array}{l}\text { In addition to level } 1 \text {, } \\
\text { customer satisfaction } \\
\text { is important, but } \\
\text { performance data is } \\
\text { not tracked. }\end{array}$ & $\begin{array}{l}\text { The current customer } \\
\text { satisfaction rating is } \\
\text { one of the company's } \\
\text { monthly performance } \\
\text { measures } \\
\text { communicated to all } \\
\text { employees. }\end{array}$ & $\begin{array}{l}\text { Customer satisfaction } \\
\text { measurements include } \\
\text { consumer feedback on } \\
\text { performance metrics, } \\
\text { and limited testing to } \\
\text { verify performance } \\
\text { metrics are being } \\
\text { achieved }\end{array}$ & $\begin{array}{l}\text { In addition to level } 3 \text {, } \\
\text { company-wide } \\
\text { performance measures } \\
\text { link directly to key } \\
\text { success drivers for } \\
\text { achieving the company } \\
\text { mission and vision. }\end{array}$ & $\begin{array}{l}\text { Level } 3 \text { is } \\
\text { supplemented with } \\
\text { statistically valid } \\
\text { sampling plan is in } \\
\text { place to test } \\
\text { performance metrics }\end{array}$ & $\begin{array}{l}\text { In addition to level } 4 \text {, } \\
\text { operational } \\
\text { performance measures } \\
\text { through all levels of the } \\
\text { company fully support } \\
\text { company-wide } \\
\text { performance } \\
\text { measures. }\end{array}$ & $\begin{array}{l}100 \% \text { testing and } \\
\text { commissioning } \\
\text { strategy }\end{array}$ \\
\hline $\begin{array}{l}2.2 \\
\text { Strategic Plans }\end{array}$ & $\begin{array}{l}\text { Company } \\
\text { improvement } \\
\text { strategy is to } \\
\text { increase sales } \\
\text { and reduce costs, } \\
\text { but specific action } \\
\text { plans are not in } \\
\text { place. }\end{array}$ & $\begin{array}{l}\text { The company's } \\
\text { competitive business } \\
\text { strategy includes } \\
\text { improving customer } \\
\text { satisfaction and } \\
\text { products that enhance } \\
\text { homeowner value. }\end{array}$ & $\begin{array}{l}\text { In addition to level } 2 \text {, } \\
\text { written improvement } \\
\text { plans are in place with } \\
\text { measurable goals. } \\
\text { Plans explain how } \\
\text { performance } \\
\text { improvement goals will } \\
\text { be achieved. }\end{array}$ & $\begin{array}{l}\text { Written improvement } \\
\text { plans include } \\
\text { performance standards } \\
\text { and testing } \\
\text { requirements. } \\
\\
\text { Plan outlines cross } \\
\text { functional leader for } \\
\text { performance-based } \\
\text { quality initiative }\end{array}$ & $\begin{array}{l}\text { In addition to level } 3 \text {, } \\
\text { strategic plans link } \\
\text { directly to improvement } \\
\text { of company-wide } \\
\text { performance measures } \\
\text { and fully support the } \\
\text { company's mission and } \\
\text { values. }\end{array}$ & $\begin{array}{l}\text { Performance } \\
\text { measures are based in } \\
\text { integrated design and } \\
\text { construction approach. }\end{array}$ & $\begin{array}{l}\text { In addition to level } 4 \text {, a } \\
\text { systematic approach is } \\
\text { in place for using } \\
\text { factual information and } \\
\text { data to plan } \\
\text { improvements to } \\
\text { organizational } \\
\text { performance and } \\
\text { competitive position. }\end{array}$ & $\begin{array}{l}\text { Measured data form } \\
\text { preplanning through } \\
\text { warrantee costs are } \\
\text { tracked to evaluate } \\
\text { total system design } \\
\text { strategies and } \\
\text { implementation results }\end{array}$ \\
\hline $\begin{array}{l}2.3 \\
\text { Plan Deployment }\end{array}$ & $\begin{array}{l}\text { The senior } \\
\text { managers who } \\
\text { make the strategic } \\
\text { plans also carry } \\
\text { out the } \\
\text { improvement } \\
\text { initiatives. } \\
\text { Employees are } \\
\text { involved on an as- } \\
\text { needed basis. }\end{array}$ & $\begin{array}{l}\text { Senior managers } \\
\text { develop the strategic } \\
\text { plan with some } \\
\text { employee input. } \\
\text { The plan is used to set } \\
\text { departmental } \\
\text { objectives. }\end{array}$ & $\begin{array}{l}\text { In addition to level 2, } \\
\text { senior managers } \\
\text { organize employee } \\
\text { teams to carry out } \\
\text { improvement projects } \\
\text { that may involve } \\
\text { multiple departments. }\end{array}$ & & $\begin{array}{l}\text { A systematic process } \\
\text { is in place for involving } \\
\text { most employees in the } \\
\text { development of } \\
\text { strategic objectives, } \\
\text { carrying out action } \\
\text { plans to achieve them, } \\
\text { and monitoring } \\
\text { progress. }\end{array}$ & $\begin{array}{l}\text { Most employees are } \\
\text { involved in the } \\
\text { performance standards } \\
\text { setting process, and } \\
\text { understand the role } \\
\text { these standards play } \\
\text { within the context of a } \\
\text { larger quality initiative }\end{array}$ & $\begin{array}{l}\text { In addition to level } 4 \text {, } \\
\text { trade contractors, } \\
\text { product suppliers, and } \\
\text { business partners are } \\
\text { involved in the } \\
\text { company's strategic } \\
\text { improvement process. }\end{array}$ & $\begin{array}{l}\text { Outside partners are } \\
\text { an integrated part of } \\
\text { the performance } \\
\text { standard setting and } \\
\text { execution process, } \\
\text { particularly in the } \\
\text { design process and } \\
\text { construction phase. }\end{array}$ \\
\hline $\begin{array}{l}2.4 \\
\text { Monitoring } \\
\text { Progress to Plan }\end{array}$ & $\begin{array}{l}\text { Progress is } \\
\text { monitored on an } \\
\text { as-needed basis. }\end{array}$ & $\begin{array}{l}\text { Quarterly review } \\
\text { meetings monitor } \\
\text { improvement progress. }\end{array}$ & $\begin{array}{l}\text { Monthly review } \\
\text { meetings monitor } \\
\text { actual versus planned } \\
\text { improvement activities. } \\
\text { Adjustments to plans } \\
\text { are made to } \\
\text { accommodate current } \\
\text { status. }\end{array}$ & $\begin{array}{l}\text { Measurements of key } \\
\text { performance attributes } \\
\text { are made to judge } \\
\text { achievement of goals }\end{array}$ & $\begin{array}{l}\text { In addition to level } 3 \text {, } \\
\text { measurement data is } \\
\text { used to monitor } \\
\text { performance toward } \\
\text { strategic objectives. }\end{array}$ & $\begin{array}{l}\text { Track data as a } \\
\text { function of design } \\
\text { effectiveness and } \\
\text { construction } \\
\text { improvements }\end{array}$ & $\begin{array}{l}\text { In addition to level } 4 \text {, } \\
\text { root causes of plan } \\
\text { variances are } \\
\text { systematically } \\
\text { analyzed, understood, } \\
\text { and used to prevent } \\
\text { future problems and } \\
\text { project future } \\
\text { performance. }\end{array}$ & $\begin{array}{l}\text { Data is used to } \\
\text { feedback into design } \\
\text { process and records } \\
\text { are kept of } \\
\text { unsuccessful designs } \\
\text { and reasons for failure. }\end{array}$ \\
\hline
\end{tabular}

Note: Yellow denotes minimum level for considering adopting a 30\% whole-house energy-savings solution set 
Table D.3. Customer Satisfaction

Sustaining high levels of customer satisfaction requires performing well from the customer's point of view.

\begin{tabular}{|c|c|c|c|c|c|c|c|c|}
\hline & Level 1 & Level 2 & Level 3 & IBACOS Level 3 & Level 4 & IBACOS Level 4 & Level 5 & IBACOS Level 5 \\
\hline $\begin{array}{l}\text { 3.1a } \\
\text { Market Research }\end{array}$ & $\begin{array}{l}\text { Market } \\
\text { requirements are } \\
\text { learned mainly } \\
\text { from customer } \\
\text { requests. }\end{array}$ & $\begin{array}{l}\text { In addition to level } 1 \text {, } \\
\text { market trends are } \\
\text { learned from tours of } \\
\text { other builders' products } \\
\text { and builder magazines. }\end{array}$ & $\begin{array}{l}\text { In addition to level 2, } \\
\text { detailed price and } \\
\text { feature comparisons } \\
\text { with other builders are } \\
\text { used to analyze } \\
\text { competitive position } \\
\text { and uncover unfilled } \\
\text { market niches. } \\
\text { Feedback from lost } \\
\text { customers is used to } \\
\text { analyze unfilled needs. }\end{array}$ & $\begin{array}{l}\text { Product is } \\
\text { Benchmarked } \\
\text { compared to national } \\
\text { and local standards. } \\
\text { Feedback strategies } \\
\text { also capture data } \\
\text { regarding performance } \\
\text { attributes }\end{array}$ & $\begin{array}{l}\text { In addition to level } 3 \text {, } \\
\text { markets are analyzed } \\
\text { by demographic } \\
\text { groups. } \\
\text { Surveys or focus } \\
\text { groups identify } \\
\text { customer preferences } \\
\text { for features and } \\
\text { services. }\end{array}$ & $\begin{array}{l}\text { Focus groups also } \\
\text { include exploration of } \\
\text { key performance } \\
\text { features in housing } \\
\text { according to company } \\
5 \text {-year stretch } \\
\text { performance goals }\end{array}$ & $\begin{array}{l}\text { In addition to level } 4 \text {, } \\
\text { the design of products } \\
\text { and services anticipate } \\
\text { market trends. They } \\
\text { are planned through } \\
\text { analysis of changing } \\
\text { demographics, } \\
\text { economic forecasts, } \\
\text { emerging technologies, } \\
\text { style trends, and other } \\
\text { leading indicators. }\end{array}$ & $\begin{array}{l}\text { Predictive analysis of } \\
\text { trends in building } \\
\text { performance, world } \\
\text { energy, and builder } \\
\text { litigation inform market } \\
\text { trends }\end{array}$ \\
\hline $\begin{array}{l}3.1 \mathrm{~b} \\
\text { Product Design } \\
\text { Processes }\end{array}$ & $\begin{array}{l}\text { A company expert } \\
\text { or consultants } \\
\text { create new home } \\
\text { designs. }\end{array}$ & $\begin{array}{l}\text { In addition to level } 1 \text {, } \\
\text { select employees } \\
\text { provide some input into } \\
\text { the design process. }\end{array}$ & $\begin{array}{l}\text { A new home design } \\
\text { team includes } \\
\text { construction and sales } \\
\text { personnel. }\end{array}$ & & $\begin{array}{l}\text { In addition to level } 3 \text {, } \\
\text { homeowners, } \\
\text { employees, and trade } \\
\text { contractors are } \\
\text { systematically included } \\
\text { in the home design } \\
\text { process. }\end{array}$ & $\begin{array}{l}\text { Pre-design and } \\
\text { schematic design } \\
\text { phase activities are } \\
\text { used to incorporate a } \\
\text { integrated design } \\
\text { process that embraces } \\
\text { a systems approach to } \\
\text { performance }\end{array}$ & $\begin{array}{l}\text { In addition to level } 4 \text {, a } \\
\text { process is in place to } \\
\text { regularly review } \\
\text { existing designs and } \\
\text { feedback from } \\
\text { customers to make } \\
\text { design improvements. }\end{array}$ & $\begin{array}{l}\text { Existing product is } \\
\text { redesigned over time } \\
\text { to include more cost } \\
\text { effective } \\
\text { implementation of } \\
\text { performance metrics }\end{array}$ \\
\hline $\begin{array}{l}3.2 \\
\text { Customer } \\
\text { Satisfaction } \\
\text { Drivers }\end{array}$ & $\begin{array}{l}\text { Avoiding } \\
\text { homeowner } \\
\text { disappointment } \\
\text { with the } \\
\text { constructed } \\
\text { product is the main } \\
\text { customer } \\
\text { satisfaction priority. }\end{array}$ & $\begin{array}{l}\text { Completing the home } \\
\text { on time with a short } \\
\text { punch list at final } \\
\text { inspection is the } \\
\text { company's main focus } \\
\text { for satisfying } \\
\text { customers. }\end{array}$ & $\begin{array}{l}\text { In addition to level 2, } \\
\text { the customer } \\
\text { experience and } \\
\text { relationship with the } \\
\text { builder are important } \\
\text { customer satisfaction } \\
\text { drivers. } \\
\text { Meeting customer } \\
\text { expectations is } \\
\text { recognized as the key } \\
\text { to reliably satisfying } \\
\text { customers. }\end{array}$ & $\begin{array}{l}\text { Builder monitors } \\
\text { expectation set by } \\
\text { other builders, and } \\
\text { seeks to set similar } \\
\text { consumer expectations } \\
\text { through sales process }\end{array}$ & $\begin{array}{l}\text { Exceeding customer } \\
\text { expectations is an } \\
\text { important company } \\
\text { priority. } \\
\text { Employees understand } \\
\text { how their team and } \\
\text { department } \\
\text { performance } \\
\text { contributes to overall } \\
\text { customer satisfaction. }\end{array}$ & $\begin{array}{l}\text { Builder sets higher } \\
\text { customer expectations } \\
\text { than competition in } \\
\text { sales process, by } \\
\text { making performance } \\
\text { attributes explicit. }\end{array}$ & $\begin{array}{l}\text { In addition to level } 4 \text {, } \\
\text { anticipating individual } \\
\text { needs is recognized as } \\
\text { the means to achieve } \\
\text { the highest levels of } \\
\text { customer satisfaction. }\end{array}$ & $\begin{array}{l}\text { Builders guarantee } \\
\text { certain key success } \\
\text { drivers that are related } \\
\text { to the performance } \\
\text { standards and } \\
\text { attributes of the home } \\
\text { (i.e., energy costs and } \\
\text { supply, comfort, } \\
\text { durability, etc.) }\end{array}$ \\
\hline
\end{tabular}


Table D.3. Customer Satisfaction (continued)

\begin{tabular}{|c|c|c|c|c|c|c|c|c|}
\hline & Level 1 & Level 2 & Level 3 & IBACOS Level 3 & Level 4 & IBACOS Level 4 & Level 5 & IBACOS Level 5 \\
\hline $\begin{array}{l}3.3 \\
\text { Customer } \\
\text { Relationship } \\
\text { Management }\end{array}$ & $\begin{array}{l}\text { Maintaining good } \\
\text { customer } \\
\text { relationships } \\
\text { through final } \\
\text { inspection is the } \\
\text { main priority. } \\
\text { Everyone has his } \\
\text { or her own way of } \\
\text { working with } \\
\text { customers, with } \\
\text { varying degrees of } \\
\text { effectiveness. }\end{array}$ & $\begin{array}{l}\text { Maintaining good } \\
\text { customer relationships } \\
\text { through the end of the } \\
\text { warranty period is the } \\
\text { main priority. } \\
\text { Policies for dealing } \\
\text { with customers are in } \\
\text { place for the sales } \\
\text { process. }\end{array}$ & $\begin{array}{l}\text { Relationships with } \\
\text { customers are } \\
\text { recognized as a key } \\
\text { customer satisfaction } \\
\text { driver. } \\
\text { A process is in place } \\
\text { for creating positive } \\
\text { customer relationships } \\
\text { in sales, construction, } \\
\text { and service phases. }\end{array}$ & & $\begin{array}{l}\text { In addition to level } 3 \text {, } \\
\text { customer expectations } \\
\text { for key customer } \\
\text { satisfaction drivers are } \\
\text { systematically } \\
\text { managed throughout } \\
\text { the customer } \\
\text { relationship. } \\
\text { Customers are viewed } \\
\text { as customers for life. }\end{array}$ & $\begin{array}{l}\text { Key Satisfaction Divers } \\
\text { include Performance } \\
\text { standards }\end{array}$ & $\begin{array}{l}\text { In addition to level } 4 \text {, } \\
\text { the customer } \\
\text { relationship process is } \\
\text { designed to } \\
\text { systematically exceed } \\
\text { customer expectations. } \\
\text { Customer satisfaction } \\
\text { data on each customer } \\
\text { contact point is used to } \\
\text { set standards and } \\
\text { improve the } \\
\text { relationship process. }\end{array}$ & $\begin{array}{l}\text { Performance } \\
\text { Standards are } \\
\text { designed to set a } \\
\text { higher level of } \\
\text { customer expectation, } \\
\text { and process is in place } \\
\text { to exceed those } \\
\text { expectations }\end{array}$ \\
\hline $\begin{array}{l}3.4 a \\
\text { Customer } \\
\text { Satisfaction } \\
\text { Measurement }\end{array}$ & $\begin{array}{l}\text { Customer } \\
\text { satisfaction } \\
\text { feedback data } \\
\text { consists of final } \\
\text { inspection punch } \\
\text { lists and warranty } \\
\text { callbacks. }\end{array}$ & $\begin{array}{l}\text { Customer satisfaction } \\
\text { is measured } \\
\text { occasionally by } \\
\text { surveys or by asking } \\
\text { customers. } \\
\text { Some questions ask } \\
\text { customers to rate } \\
\text { employee } \\
\text { performance. }\end{array}$ & $\begin{array}{l}\text { All customers are } \\
\text { surveyed on their } \\
\text { satisfaction with the } \\
\text { home and the } \\
\text { customer experience } \\
\text { during the sales, } \\
\text { construction, and } \\
\text { warranty service } \\
\text { periods. } \\
\text { Questions focus on } \\
\text { process performance } \\
\text { rather than employee } \\
\text { ratings. }\end{array}$ & $\begin{array}{l}\text { Survey links } \\
\text { expectations of } \\
\text { housing performance } \\
\text { compared to actual } \\
\text { experience of living in } \\
\text { home (i.e., comfort, } \\
\text { energy performance, } \\
\text { durability, noise, etc.) }\end{array}$ & $\begin{array}{l}\text { In addition to level } 3 \text {, } \\
\text { customer satisfaction } \\
\text { survey questions are } \\
\text { directly linked to known } \\
\text { customer satisfaction } \\
\text { drivers. }\end{array}$ & $\begin{array}{l}\text { Measurements for } \\
\text { customer satisfaction } \\
\text { include questions on } \\
\text { key performance } \\
\text { drivers. }\end{array}$ & $\begin{array}{l}\text { In addition to level } 4 \text {, } \\
\text { feedback from } \\
\text { customers and } \\
\text { employees is used to } \\
\text { refine survey questions } \\
\text { and improve the } \\
\text { survey process. }\end{array}$ & $\begin{array}{l}\text { New metrics for } \\
\text { satisfaction are } \\
\text { developed for the } \\
\text { industry }\end{array}$ \\
\hline $\begin{array}{l}3.4 \mathrm{~b} \\
\text { Sharing of } \\
\text { Customer } \\
\text { Satisfaction } \\
\text { Feedback }\end{array}$ & $\begin{array}{l}\text { Customer } \\
\text { complaints are } \\
\text { shared with the } \\
\text { persons } \\
\text { responsible. }\end{array}$ & $\begin{array}{l}\text { Customer letters and } \\
\text { surveys are routinely } \\
\text { circulated among } \\
\text { employees. }\end{array}$ & $\begin{array}{l}\text { In addition to level 2, } \\
\text { Summary customer } \\
\text { satisfaction data is } \\
\text { available to all } \\
\text { employees. Trends } \\
\text { are tracked and posted } \\
\text { for all to see. } \\
\text { Senior managers } \\
\text { frequently discuss } \\
\text { customer feedback } \\
\text { with employees. }\end{array}$ & & $\begin{array}{l}\text { Customer satisfaction } \\
\text { ratings are routinely } \\
\text { communicated to the } \\
\text { organization as one of } \\
\text { the company-wide } \\
\text { performance } \\
\text { measures. } \\
\text { Relevant customer } \\
\text { satisfaction data is } \\
\text { shared with suppliers } \\
\text { and trade contractors. }\end{array}$ & $\begin{array}{l}\text { Performance data is } \\
\text { included in these } \\
\text { survey results }\end{array}$ & $\begin{array}{l}\text { Customer satisfaction } \\
\text { is one of the } \\
\text { company's vital few } \\
\text { key success measures } \\
\text { that are tracked } \\
\text { monthly by the } \\
\text { company's } \\
\text { performance } \\
\text { management system. }\end{array}$ & $\begin{array}{l}\text { Customer satisfaction } \\
\text { is linked to } \\
\text { performance of } \\
\text { housing, not just } \\
\text { buying and } \\
\text { construction process }\end{array}$ \\
\hline
\end{tabular}


Table D.3. Customer Satisfaction (continued)

\begin{tabular}{|c|c|c|c|c|c|c|c|c|}
\hline & Level 1 & Level 2 & Level 3 & IBACOS Level 3 & Level 4 & IBACOS Level 4 & Level 5 & IBACOS Level 5 \\
\hline $\begin{array}{l}3.5 \\
\text { Customer } \\
\text { Satisfaction } \\
\text { Results }\end{array}$ & $\begin{array}{l}\text { Percentage of } \\
\text { customers who } \\
\text { would recommend } \\
\text { the company to a } \\
\text { friend is not } \\
\text { measured. }\end{array}$ & $\begin{array}{l}\text { More than } 75 \% \text { of } \\
\text { customers surveyed } \\
\text { would recommend the } \\
\text { company to a friend. } \\
\text { Customer satisfaction } \\
\text { seems to be improving. }\end{array}$ & $\begin{array}{l}\text { More than } 85 \% \text { of } \\
\text { customers surveyed } \\
\text { would recommend the } \\
\text { company to a friend. } \\
\text { There are measured } \\
\text { improvements in } \\
\text { customer satisfaction. }\end{array}$ & $\begin{array}{l}\text { More than } 85 \% \text { of } \\
\text { customers surveyed } \\
\text { feel home meets the } \\
\text { company standard of } \\
\text { performance }\end{array}$ & $\begin{array}{l}\text { More than } 90 \% \text { of } \\
\text { customers surveyed } \\
\text { would recommend the } \\
\text { company to a friend. } \\
\text { Customer satisfaction } \\
\text { shows measured } \\
\text { improvements in most } \\
\text { products and services. }\end{array}$ & $\begin{array}{l}\text { More than } 90 \% \text { of } \\
\text { customers surveyed } \\
\text { feel home meets the } \\
\text { company standard of } \\
\text { performance }\end{array}$ & $\begin{array}{l}\text { More than } 95 \% \text { of } \\
\text { customers surveyed } \\
\text { would recommend the } \\
\text { company to a friend. } \\
\text { Customer satisfaction } \\
\text { shows strong } \\
\text { improvements in most } \\
\text { products and services. }\end{array}$ & $\begin{array}{l}\text { More than } 95 \% \text { of } \\
\text { customers surveyed } \\
\text { feel home meets the } \\
\text { company standard of } \\
\text { performance }\end{array}$ \\
\hline
\end{tabular}

Note: Yellow denotes minimum level for considering adopting a 30\% whole-house energy-savings solution set. 
Table D.4. Performance Management

\begin{tabular}{|c|c|c|c|c|c|c|c|c|}
\hline & Level 1 & Level 2 & Level 3 & IBACOS Level 3 & Level 4 & IBACOS Level 4 & Level 5 & IBACOS Level 5 \\
\hline $\begin{array}{l}4.1 \mathrm{a} \\
\text { Creating High- } \\
\text { Performance } \\
\text { Work Processes }\end{array}$ & $\begin{array}{l}\text { Meeting minimum } \\
\text { performance } \\
\text { expectations is an } \\
\text { important priority for } \\
\text { most employees. }\end{array}$ & $\begin{array}{l}\text { Most employees have } \\
\text { well-defined } \\
\text { responsibilities. } \\
\text { Finding ways to reduce } \\
\text { costs is the main focus } \\
\text { of work improvement } \\
\text { activities. }\end{array}$ & $\begin{array}{l}\text { Key work processes } \\
\text { are well defined. } \\
\text { Customer satisfaction } \\
\text { and cost are important } \\
\text { work improvement } \\
\text { priorities. }\end{array}$ & $\begin{array}{l}\text { "Building performance } \\
\text { quality management" } \\
\text { has been identified as } \\
\text { a key work process, } \\
\text { and has been assigned } \\
\text { within the organization }\end{array}$ & $\begin{array}{l}\text { Customer needs drive } \\
\text { work systems design } \\
\text { and improvements. } \\
\text { Some work systems } \\
\text { are modeled on } \\
\text { industry best practices. }\end{array}$ & $\begin{array}{l}\text { The integrated design } \\
\text { process has been } \\
\text { mapped and assigned }\end{array}$ & $\begin{array}{l}\text { Key processes have } \\
\text { high-performance } \\
\text { approaches and goals } \\
\text { based upon world- } \\
\text { class Benchmarks. } \\
\text { Key performance } \\
\text { metrics are tracked } \\
\text { and used for the } \\
\text { control and } \\
\text { improvement of } \\
\text { processes. }\end{array}$ & $\begin{array}{l}\text { All processes } \\
\text { associated with key } \\
\text { building-performance } \\
\text { standards have been } \\
\text { identified and } \\
\text { documented }\end{array}$ \\
\hline $\begin{array}{l}4.1 \mathrm{~b} \\
\text { Bench-Marking } \\
\text { Business } \\
\text { Processes }\end{array}$ & $\begin{array}{l}\text { Information on how } \\
\text { other builders do } \\
\text { things is obtained } \\
\text { mostly from } \\
\text { publications and } \\
\text { seminars. }\end{array}$ & $\begin{array}{l}\text { Occasional visits to } \\
\text { other builders are } \\
\text { made to get some } \\
\text { good ideas. }\end{array}$ & $\begin{array}{l}\text { Regular visits to other } \\
\text { builders are made to } \\
\text { compare performance } \\
\text { results and set } \\
\text { improvement } \\
\text { objectives. }\end{array}$ & $\begin{array}{l}\text { Those builders visited } \\
\text { include others who are } \\
\text { improving building } \\
\text { performance at Level } 3 \\
\text { and at least one at } \\
\text { Level } 4\end{array}$ & $\begin{array}{l}\text { In addition to level } 3 \text {, } \\
\text { detailed studies of } \\
\text { other builders' } \\
\text { operations are used to } \\
\text { design operational } \\
\text { improvements. }\end{array}$ & $\begin{array}{l}\text { Those builders visited } \\
\text { include others who are } \\
\text { improving building } \\
\text { performance at Level } 4 \\
\text { and at least one at } \\
\text { Level } 5\end{array}$ & $\begin{array}{l}\text { In addition to level } 4 \text {, a } \\
\text { systematic approach is } \\
\text { used to study } \\
\text { organizations outside } \\
\text { the construction } \\
\text { industry, make } \\
\text { improvements, and set } \\
\text { long-range goals. }\end{array}$ & $\begin{array}{l}\text { Outside organizations } \\
\text { studied reflect similar } \\
\text { core values of } \\
\text { performance in the } \\
\text { product developed }\end{array}$ \\
\hline $\begin{array}{l}4.2 \\
\text { Performance } \\
\text { Management }\end{array}$ & $\begin{array}{l}\text { Performance is } \\
\text { managed by } \\
\text { monitoring the } \\
\text { productivity of } \\
\text { individual employees. }\end{array}$ & $\begin{array}{l}\text { In addition to level } 1 \text {, } \\
\text { conformance to } \\
\text { department budgets is } \\
\text { used to manage } \\
\text { financial performance. }\end{array}$ & $\begin{array}{l}\text { Performance } \\
\text { management focuses } \\
\text { on the productivity of } \\
\text { key business } \\
\text { processes. } \\
\text { Results are tracked } \\
\text { and reviewed monthly. }\end{array}$ & $\begin{array}{l}\text { Building to a } \\
\text { predefined } \\
\text { performance standard } \\
\text { is identified as a key } \\
\text { business process }\end{array}$ & $\begin{array}{l}\text { In addition to level } 3 \text {, } \\
\text { key work processes } \\
\text { have performance } \\
\text { measures that link } \\
\text { directly to company- } \\
\text { wide key success } \\
\text { measures. } \\
\text { Results are shared } \\
\text { with all employees. }\end{array}$ & $\begin{array}{l}\text { Performance attributes } \\
\text { are measured and } \\
\text { used in this process }\end{array}$ & $\begin{array}{l}\text { In addition to level } 4 \text {, } \\
\text { employees, teams, and } \\
\text { trade contractors have } \\
\text { performance measures } \\
\text { for their own processes } \\
\text { that support company- } \\
\text { wide key success } \\
\text { measures. }\end{array}$ & $\begin{array}{l}\text { Trades perform } \\
\text { performance } \\
\text { measurements during } \\
\text { work }\end{array}$ \\
\hline $\begin{array}{l}4.3 \\
\text { Process } \\
\text { Improvement }\end{array}$ & $\begin{array}{l}\text { Problems are } \\
\text { handled as they } \\
\text { occur to avoid } \\
\text { customer complaints. }\end{array}$ & $\begin{array}{l}\text { Changes to company } \\
\text { processes are made } \\
\text { occasionally to prevent } \\
\text { recurring problems. } \\
\text { Some employees are } \\
\text { involved in } \\
\text { improvement projects. }\end{array}$ & $\begin{array}{l}\text { Improving company } \\
\text { processes is an } \\
\text { important part of } \\
\text { everyone's job. } \\
\text { There are many } \\
\text { improvements made } \\
\text { throughout the } \\
\text { company. } \\
\text { The company uses a } \\
\text { systematic method to } \\
\text { make improvements. }\end{array}$ & $\begin{array}{l}\text { Process of designing } \\
\text { and building for } \\
\text { performance is } \\
\text { identified as a key } \\
\text { process improvement } \\
\text { area }\end{array}$ & $\begin{array}{l}\text { An effective strategy } \\
\text { and goals are in place } \\
\text { for involving the entire } \\
\text { workforce in problem } \\
\text { solving and quality } \\
\text { improvement. } \\
\text { Most employees have } \\
\text { been trained in the } \\
\text { company's process } \\
\text { improvement methods. }\end{array}$ & $\begin{array}{l}\text { Quality Process } \\
\text { management involves } \\
\text { workforce to } \\
\text { continually improve } \\
\text { performance }\end{array}$ & $\begin{array}{l}\text { In addition to level } 4 \text {, } \\
\text { all major trade } \\
\text { contractors participate } \\
\text { in the company's } \\
\text { problem-solving and } \\
\text { quality improvement } \\
\text { system. }\end{array}$ & $\begin{array}{l}\text { Performance } \\
\text { measures are part of } \\
\text { trade feedback and } \\
\text { design process } \\
\text { involving trades }\end{array}$ \\
\hline
\end{tabular}


Table D.4. Performance Management (continued)

\begin{tabular}{|c|c|c|c|c|c|c|c|c|}
\hline & Level 1 & Level 2 & Level 3 & IBACOS Level 3 & Level 4 & IBACOS Level 4 & Level 5 & IBACOS Level 5 \\
\hline $\begin{array}{l}4.4 \\
\text { Improvement } \\
\text { Results }\end{array}$ & $\begin{array}{l}\text { Some company work } \\
\text { processes seem to } \\
\text { be improving, but } \\
\text { there are no } \\
\text { measures of } \\
\text { progress. }\end{array}$ & $\begin{array}{l}\text { Some company work } \\
\text { processes show } \\
\text { measured quality } \\
\text { improvements. }\end{array}$ & $\begin{array}{l}\text { Most company work } \\
\text { processes show } \\
\text { measured quality } \\
\text { improvements. }\end{array}$ & & $\begin{array}{l}\text { Most company work } \\
\text { processes show } \\
\text { measured quality } \\
\text { improvements and } \\
\text { excellent quality } \\
\text { results. }\end{array}$ & $\begin{array}{l}\text { Performance metrics } \\
\text { are included in this } \\
\text { measurement }\end{array}$ & $\begin{array}{l}\text { Most measures of } \\
\text { organizational } \\
\text { effectiveness are } \\
\text { considered } \\
\text { Benchmarks for the } \\
\text { industry. }\end{array}$ & $\begin{array}{l}\text { Performance } \\
\text { standards are } \\
\text { considered } \\
\text { Benchmarks as well }\end{array}$ \\
\hline \multirow{2}{*}{$\begin{array}{l}4.5 \\
\text { Financial } \\
\text { Improvement } \\
\text { Results }\end{array}$} & \multirow[t]{2}{*}{$\begin{array}{l}\text { Some improvements } \\
\text { have resulted in cost } \\
\text { reductions. }\end{array}$} & \multirow{2}{*}{$\begin{array}{l}\text { Substantial cost } \\
\text { reductions have been } \\
\text { made but have not yet } \\
\text { helped improve home } \\
\text { sales. }\end{array}$} & \multirow[t]{2}{*}{$\begin{array}{l}\text { Home sales and } \\
\text { company profitability } \\
\text { show improvement. }\end{array}$} & \multirow{2}{*}{$\begin{array}{l}\text { Profitability is in some } \\
\text { way attributable to } \\
\text { performance standards } \\
\text { (reduction in callbacks, } \\
\text { improved value, etc.) }\end{array}$} & $\begin{array}{l}\text { Company's share of } \\
\text { home sales is } \\
\text { increasing. }\end{array}$ & \multirow{2}{*}{$\begin{array}{l}\text { Metric is developed to } \\
\text { measure overall cross } \\
\text { cutting impact of } \\
\text { performance on Value, } \\
\text { cycle, and operations } \\
\text { to measure overall } \\
\text { profitability }\end{array}$} & \multirow{2}{*}{$\begin{array}{l}\text { In addition to level } 4 \text {, } \\
\text { company profitability is } \\
\text { consistently among the } \\
\text { best among builders in } \\
\text { the area. }\end{array}$} & \\
\hline & & & & & $\begin{array}{l}\text { Company profitability } \\
\text { shows excellent } \\
\text { results with positive } \\
\text { trends. }\end{array}$ & & & \\
\hline
\end{tabular}

Note: Yellow denotes minimum level for considering adopting a 30\% whole-house energy-savings solution set. 
Table D.5. Human Resources

The human resources system must develop the full potential of employees and drive the right behaviors in support of company performance and learning objectives.

\begin{tabular}{|c|c|c|c|c|c|c|c|c|}
\hline & Level 1 & Level 2 & Level 3 & IBACOS Level 3 & Level 4 & IBACOS Level 4 & Level 5 & IBACOS Level 5 \\
\hline $\begin{array}{l}5.1 a \\
\text { Employee } \\
\text { Satisfaction }\end{array}$ & $\begin{array}{l}\text { The company shows } \\
\text { a general concern for } \\
\text { employee well-being } \\
\text { and morale. }\end{array}$ & $\begin{array}{l}\text { Company shows that } \\
\text { employee well-being } \\
\text { and morale are } \\
\text { priorities in making } \\
\text { business decisions. } \\
\text { There are occasional } \\
\text { morale-building } \\
\text { activities. }\end{array}$ & $\begin{array}{l}\text { In addition to level 2, } \\
\text { employee satisfaction } \\
\text { is recognized as } \\
\text { important for the } \\
\text { company's success. } \\
\text { Senior managers take } \\
\text { initiatives to do what } \\
\text { they think will improve } \\
\text { the work environment. }\end{array}$ & & $\begin{array}{l}\text { The company } \\
\text { understands which } \\
\text { factors drive employee } \\
\text { satisfaction. } \\
\text { Employee surveys } \\
\text { measure employee } \\
\text { satisfaction and the } \\
\text { information is used to } \\
\text { improve the work } \\
\text { environment. }\end{array}$ & $\begin{array}{l}\text { Relationship to } \\
\text { performance standards } \\
\text { and end product is } \\
\text { measured as a } \\
\text { component of } \\
\text { employee satisfaction }\end{array}$ & $\begin{array}{l}\text { In addition to level } 4 \text {, } \\
\text { employee satisfaction } \\
\text { is integrated into the } \\
\text { company's strategic } \\
\text { planning process with } \\
\text { long-range goals and } \\
\text { action plans. }\end{array}$ & $\begin{array}{l}\text { Performance is one } \\
\text { metric used in the } \\
\text { strategic planning } \\
\text { process }\end{array}$ \\
\hline $\begin{array}{l}5.1 \mathrm{~b} \\
\text { Jobsite Safety }\end{array}$ & $\begin{array}{l}\text { There are occasional } \\
\text { safety-related training } \\
\text { activities. }\end{array}$ & $\begin{array}{l}\text { Health and safety } \\
\text { training is provided to } \\
\text { all field employees. }\end{array}$ & $\begin{array}{l}\text { Company shows that } \\
\text { employee health and } \\
\text { safety are priorities in } \\
\text { making business } \\
\text { decisions. }\end{array}$ & & $\begin{array}{l}\text { In addition to level } 3 \text {, } \\
\text { there is an organized } \\
\text { approach to analyzing } \\
\text { causes of injuries and } \\
\text { preventing accidents. }\end{array}$ & & $\begin{array}{l}\text { In addition to level } 4 \text {, } \\
\text { trade contractors are } \\
\text { involved in an } \\
\text { organized approach to } \\
\text { prevent injuries. }\end{array}$ & \\
\hline $\begin{array}{l}5.1 \mathrm{c} \\
\text { Job } \\
\text { Responsibilities }\end{array}$ & $\begin{array}{l}\text { Employees learn job } \\
\text { responsibilities from } \\
\text { on-the-job } \\
\text { experience. }\end{array}$ & $\begin{array}{l}\text { Job descriptions define } \\
\text { job responsibilities. }\end{array}$ & $\begin{array}{l}\text { In addition to level } 2 \text {, } \\
\text { most employees clearly } \\
\text { understand their job } \\
\text { responsibilities and } \\
\text { how their job } \\
\text { contributes to company } \\
\text { performance. }\end{array}$ & $\begin{array}{l}\text { Job Responsibilities are } \\
\text { also tied to Building } \\
\text { Performance }\end{array}$ & $\begin{array}{l}\text { In addition to level } 3 \text {, } \\
\text { employees feel } \\
\text { responsible for } \\
\text { performing their job to } \\
\text { meet the needs of other } \\
\text { employees who depend } \\
\text { on them. }\end{array}$ & $\begin{array}{l}\text { One measure is in } \\
\text { relation to building } \\
\text { performance by internal } \\
\text { survey of employees } \\
\text { and trades }\end{array}$ & $\begin{array}{l}\text { In addition to level } 4 \text {, } \\
\text { employees are } \\
\text { expected to take } \\
\text { initiatives that exceed } \\
\text { customer expectations } \\
\text { or solve their problems. }\end{array}$ & \\
\hline $\begin{array}{l}5.1 \mathrm{~d} \\
\text { Teamwork }\end{array}$ & $\begin{array}{l}\text { Individual effort is the } \\
\text { main way things get } \\
\text { done. }\end{array}$ & $\begin{array}{l}\text { Some natural work } \\
\text { groups are formed into } \\
\text { operating teams with } \\
\text { shared responsibilities. }\end{array}$ & $\begin{array}{l}\text { Most employees are } \\
\text { part of an operating } \\
\text { team with a well- } \\
\text { understood purpose. } \\
\text { Teams are the main } \\
\text { way that day-to-day } \\
\text { work gets done. }\end{array}$ & $\begin{array}{l}\text { Performance attributes } \\
\text { and standards are part } \\
\text { of the purpose within a } \\
\text { team }\end{array}$ & $\begin{array}{l}\text { In addition to level } 3 \text {, } \\
\text { teamwork is the } \\
\text { primary mechanism for } \\
\text { solving problems and } \\
\text { making performance } \\
\text { improvements. }\end{array}$ & $\begin{array}{l}\text { Problem solving and } \\
\text { improvements include } \\
\text { building performance } \\
\text { standards related } \\
\text { issues }\end{array}$ & $\begin{array}{l}\text { In addition to level } 4 \text {, } \\
\text { employees are actively } \\
\text { engaged in teams that } \\
\text { perform key } \\
\text { management functions } \\
\text { for the company. }\end{array}$ & $\begin{array}{l}\text { Integrated design } \\
\text { process brings team } \\
\text { members in from all } \\
\text { levels of the } \\
\text { organization and trade } \\
\text { partners }\end{array}$ \\
\hline
\end{tabular}


Table D.5. Human Resources (continued)

\begin{tabular}{|c|c|c|c|c|c|c|c|c|}
\hline & Level 1 & Level 2 & Level 3 & IBACOS Level 3 & Level 4 & IBACOS Level 4 & Level 5 & IBACOS Level 5 \\
\hline $\begin{array}{l}5.2 \\
\text { Workforce } \\
\text { Development }\end{array}$ & $\begin{array}{l}\text { Skills are learned } \\
\text { on the job. }\end{array}$ & $\begin{array}{l}\text { Work-related training } \\
\text { is delivered as } \\
\text { needed when time } \\
\text { and budget allows. }\end{array}$ & $\begin{array}{l}\text { There is a company } \\
\text { training budget. Most } \\
\text { employees receive } \\
\text { some training. } \\
\text { Most employees } \\
\text { have personal } \\
\text { training and } \\
\text { development plans. }\end{array}$ & $\begin{array}{l}\text { Key general training } \\
\text { on issues related to } \\
\text { building-performance } \\
\text { standards is provided } \\
\text { and specifically } \\
\text { related to company } \\
\text { performance } \\
\text { standards }\end{array}$ & $\begin{array}{l}\text { In addition to level } 3 \text {, } \\
\text { the company's } \\
\text { training and hiring } \\
\text { plan is aimed at } \\
\text { developing the skills } \\
\text { necessary for } \\
\text { achieving the long- } \\
\text { range company } \\
\text { vision. }\end{array}$ & $\begin{array}{l}\text { Training for building } \\
\text { performance is } \\
\text { specialized by } \\
\text { employee and } \\
\text { function, }\end{array}$ & $\begin{array}{l}\text { In addition to level } 4 \text {, } \\
\text { the company has a } \\
\text { systematic skills- } \\
\text { development } \\
\text { program for key job } \\
\text { positions. }\end{array}$ & $\begin{array}{l}\text { Key positions are } \\
\text { targeted for more in- } \\
\text { depth building- } \\
\text { science training }\end{array}$ \\
\hline $\begin{array}{l}5.3 \\
\text { Employee } \\
\text { Evaluation and } \\
\text { Compensation } \\
\text { Systems }\end{array}$ & $\begin{array}{l}\text { Most employees } \\
\text { receive an annual } \\
\text { performance } \\
\text { review. }\end{array}$ & $\begin{array}{l}\text { Annual employee } \\
\text { performance reviews } \\
\text { have well-defined } \\
\text { evaluation criteria. } \\
\text { Bonuses and } \\
\text { recognition reward } \\
\text { individual efforts. }\end{array}$ & $\begin{array}{l}\text { In addition to level } 2 \text {, } \\
\text { employee } \\
\text { performance } \\
\text { evaluation criteria are } \\
\text { linked to job } \\
\text { descriptions. } \\
\text { Bonuses focus on } \\
\text { team efforts. }\end{array}$ & $\begin{array}{l}\text { Evaluation criteria } \\
\text { include measurement } \\
\text { of achievement of } \\
\text { building-performance } \\
\text { standards }\end{array}$ & $\begin{array}{l}\text { Employee } \\
\text { performance } \\
\text { evaluation criteria are } \\
\text { based on fulfillment } \\
\text { of personal } \\
\text { development plans } \\
\text { and key elements of } \\
\text { the company mission, } \\
\text { vision, and values. }\end{array}$ & $\begin{array}{l}\text { Building Performance } \\
\text { standards are one of } \\
\text { the Key elements }\end{array}$ & $\begin{array}{l}\text { In addition to level } 4 \text {, } \\
\text { employee bonuses } \\
\text { are linked directly to } \\
\text { performance of the } \\
\text { company's key } \\
\text { success measures. }\end{array}$ & $\begin{array}{l}\text { Building performance } \\
\text { is one Key success } \\
\text { measure }\end{array}$ \\
\hline
\end{tabular}

Note: Yellow denotes minimum level for considering adopting a 30\% whole-house energy-savings solution set. 
Table D.6. Quality Construction Processes

Systematic quality management approaches are necessary to ensure high performing, trouble-free products and services.

\begin{tabular}{|c|c|c|c|c|c|c|c|c|}
\hline & Level 1 & Level 2 & Level 3 & IBACOS Level 3 & Level 4 & IBACOS Level 4 & Level 5 & IBACOS Level 5 \\
\hline $\begin{array}{l}6.1 \\
\text { Setting Quality } \\
\text { Expectations }\end{array}$ & $\begin{array}{l}\text { Informal standards } \\
\text { exist. "We know if it's } \\
\text { OK when we see it." }\end{array}$ & $\begin{array}{l}\text { Construction details } \\
\text { and workmanship } \\
\text { specifications control } \\
\text { known problem areas. }\end{array}$ & $\begin{array}{l}\text { In addition to level } 2 \text {, } \\
\text { the builder, contractor, } \\
\text { and other trades } \\
\text { collaborate to set } \\
\text { quality requirements. } \\
\text { Contract scopes of } \\
\text { work reference specific } \\
\text { construction standards } \\
\text { and workmanship } \\
\text { tolerances. }\end{array}$ & $\begin{array}{l}\text { Performance } \\
\text { standards are selected } \\
\text { and adopted by } \\
\text { builders to meet or } \\
\text { exceed Benchmark } \\
\text { levels in region }\end{array}$ & $\begin{array}{l}\text { In addition to level } 3 \text {, } \\
\text { requirements analysis } \\
\text { of building codes, } \\
\text { construction standards, } \\
\text { product installation } \\
\text { instructions, and } \\
\text { industry guidelines are } \\
\text { used to set quality } \\
\text { specifications. }\end{array}$ & $\begin{array}{l}\text { Building standards } \\
\text { exceed Benchmark } \\
\text { levels, and are based } \\
\text { on a whole-house } \\
\text { building-science } \\
\text { approach }\end{array}$ & $\begin{array}{l}\text { In addition to level } 4 \text {, } \\
\text { construction detail } \\
\text { drawings are provided } \\
\text { for nearly every aspect } \\
\text { of the home. }\end{array}$ & $\begin{array}{l}\text { Design documentation } \\
\text { includes performance } \\
\text { aspects and integrates } \\
\text { a significant amount of } \\
\text { means and methods } \\
\text { descriptions to assist } \\
\text { trades in } \\
\text { implementation, } \\
\text { including detailed } \\
\text { scopes of work }\end{array}$ \\
\hline $\begin{array}{l}6.2 \\
\text { Assuring } \\
\text { Quality Results }\end{array}$ & $\begin{array}{l}\text { The company fixes any } \\
\text { defects the } \\
\text { homeowner may find } \\
\text { at final walk-through or } \\
\text { during the warranty } \\
\text { process. }\end{array}$ & $\begin{array}{l}\text { Construction personnel } \\
\text { use their experience to } \\
\text { catch defects. }\end{array}$ & $\begin{array}{l}\text { There are inspection } \\
\text { checklists for most } \\
\text { trades. } \\
\text { Formal inspections are } \\
\text { performed for each } \\
\text { phase of construction } \\
\text { by the builder. }\end{array}$ & $\begin{array}{l}\text { Performance } \\
\text { standards are included } \\
\text { on checklists, some } \\
\text { performance testing is } \\
\text { included }\end{array}$ & $\begin{array}{l}\text { In addition to level } 3 \text {, } \\
\text { trade contractors use } \\
\text { checklists to perform } \\
\text { quality self-inspections. } \\
\text { The main function of } \\
\text { builder inspections is } \\
\text { to monitor quality } \\
\text { performance rather } \\
\text { than screen out } \\
\text { defects from trade } \\
\text { contractors. }\end{array}$ & $\begin{array}{l}\text { Performance } \\
\text { standards are included } \\
\text { on checklists, a higher } \\
\text { level of performance } \\
\text { testing is included }\end{array}$ & $\begin{array}{l}\text { Key trades have ISO } \\
9000 \text {-based quality } \\
\text { assurance systems. } \\
\text { Conformance to } \\
\text { specifications is a well- } \\
\text { documented process. } \\
\text { Company generally } \\
\text { needs only to spot } \\
\text { check trade contractor } \\
\text { or product quality. }\end{array}$ & $\begin{array}{l}\text { Performance } \\
\text { standards are included } \\
\text { on checklists, a higher } \\
\text { level (up to } 100 \% \text { ) of } \\
\text { performance testing is } \\
\text { included, but may be } \\
\text { done as part of the } \\
\text { trade contractors work. }\end{array}$ \\
\hline $\begin{array}{l}6.3 \\
\text { Quality } \\
\text { Problem } \\
\text { Prevention }\end{array}$ & $\begin{array}{l}\text { Quality problems are } \\
\text { corrected as needed. }\end{array}$ & $\begin{array}{l}\text { In addition to level 1, } \\
\text { actions are taken to } \\
\text { prevent chronic } \\
\text { problems. }\end{array}$ & $\begin{array}{l}\text { Defect data is } \\
\text { recorded, trends } \\
\text { monitored, and } \\
\text { improvement } \\
\text { objectives are set. } \\
\text { Actions to solve defect } \\
\text { problems occur } \\
\text { regularly. }\end{array}$ & $\begin{array}{l}\text { Troubleshooting } \\
\text { activities use building } \\
\text { science basis for } \\
\text { performance based } \\
\text { defect analysis }\end{array}$ & $\begin{array}{l}\text { In addition to level } 3 \text {, } \\
\text { systematic analysis of } \\
\text { root causes are } \\
\text { routinely used to } \\
\text { prevent defects. } \\
\text { Defect prevention } \\
\text { focuses on improving } \\
\text { processes. }\end{array}$ & $\begin{array}{l}\text { Mechanisms in place } \\
\text { to integrate root cause } \\
\text { prevention into design } \\
\text { process }\end{array}$ & $\begin{array}{l}\text { In addition to level } 4 \text {, } \\
\text { employees and trade } \\
\text { contractors are actively } \\
\text { engaged to continually } \\
\text { refine processes } \\
\text { toward zero defect } \\
\text { goals. }\end{array}$ & $\begin{array}{l}\text { Zero defect goals } \\
\text { include performance } \\
\text { attributes of buildings. } \\
\text { Zero Defect is well } \\
\text { defined relative to } \\
\text { performance standards }\end{array}$ \\
\hline
\end{tabular}


Table D.6. Quality Construction Processes (continued)

\begin{tabular}{|c|c|c|c|c|c|c|c|c|}
\hline & Level 1 & Level 2 & Level 3 & IBACOS Level 3 & Level 4 & IBACOS Level 4 & Level 5 & IBACOS Level 5 \\
\hline $\begin{array}{l}6.4 \\
\text { Warranty } \\
\text { Service }\end{array}$ & $\begin{array}{l}\text { Service callbacks are } \\
\text { handled but not } \\
\text { tracked. }\end{array}$ & $\begin{array}{l}\text { Systems are in place } \\
\text { to track warranty } \\
\text { complaints and their } \\
\text { completion. }\end{array}$ & $\begin{array}{l}\text { In addition to level 2, } \\
\text { warranty service data } \\
\text { is used to set priorities } \\
\text { for solving quality } \\
\text { problems. }\end{array}$ & $\begin{array}{l}\text { Warrantee service data } \\
\text { is broken down to } \\
\text { capture root causes }\end{array}$ & $\begin{array}{l}\text { In addition to level } 3 \text {, } \\
\text { response time and } \\
\text { customer satisfaction } \\
\text { with each service call } \\
\text { are important } \\
\text { performance } \\
\text { measures. }\end{array}$ & $\begin{array}{l}\text { Key performance } \\
\text { drivers are identified, } \\
\text { tracked and fed back } \\
\text { to reduce warrantee } \\
\text { calls and improve } \\
\text { customer satisfaction }\end{array}$ & $\begin{array}{l}\text { Warranty service } \\
\text { excellence is among } \\
\text { the best of builders in } \\
\text { the area and a } \\
\text { competitive advantage } \\
\text { of the company. }\end{array}$ & $\begin{array}{l}\text { Warranty specialist are } \\
\text { trained in building } \\
\text { science approach and } \\
\text { use diagnostic skills to } \\
\text { improve product }\end{array}$ \\
\hline $\begin{array}{l}6.5 \\
\text { Product and } \\
\text { Service Quality } \\
\text { Results }\end{array}$ & $\begin{array}{l}\text { Product and service } \\
\text { quality seems to be } \\
\text { improving, but there } \\
\text { are no measures of } \\
\text { progress. }\end{array}$ & $\begin{array}{l}\text { Problems found at final } \\
\text { inspection are } \\
\text { decreasing. } \\
\text { There are fewer } \\
\text { callbacks. }\end{array}$ & $\begin{array}{l}\text { Data shows that } \\
\text { constructed quality is } \\
\text { improving. }\end{array}$ & $\begin{array}{l}\text { Quality is defined } \\
\text { according to building } \\
\text { science based } \\
\text { performance metrics }\end{array}$ & $\begin{array}{l}\text { Most product and } \\
\text { service quality } \\
\text { performance indicators } \\
\text { show excellent results } \\
\text { with positive trends. } \\
\text { Zero defect final } \\
\text { inspections are } \\
\text { commonplace. }\end{array}$ & $\begin{array}{l}\text { Defects are also } \\
\text { measured by building } \\
\text { science performance } \\
\text { measurements, and } \\
\text { are measured by } \\
\text { testing }\end{array}$ & $\begin{array}{l}\text { All major product and } \\
\text { service quality } \\
\text { performance indicators } \\
\text { show positive } \\
\text { improvement trends } \\
\text { and excellent results. } \\
\text { Most homes have zero } \\
\text { defect final } \\
\text { inspections. }\end{array}$ & $\begin{array}{l}\text { Defects are also } \\
\text { measured by building- } \\
\text { science performance } \\
\text { measurements and are } \\
\text { measured by higher } \\
\text { levels (up to } 100 \% \text { ) } \\
\text { testing }\end{array}$ \\
\hline
\end{tabular}

Note: Yellow denotes minimum level for considering adopting a 30\% whole-house energy-savings solution set. 
Table D.7. Supplier Partnerships

Partnering approaches are essential for high performance relationships with trade contractors and product manufacturers.

\begin{tabular}{|c|c|c|c|c|c|c|c|c|}
\hline & Level 1 & Level 2 & Level 3 & IBACOS Level 3 & Level 4 & IBACOS Level 4 & Level 5 & IBACOS Level 5 \\
\hline $\begin{array}{l}7.1 \\
\text { Trade } \\
\text { Contractor and } \\
\text { Supplier } \\
\text { Relationships }\end{array}$ & $\begin{array}{l}\text { Difficult quality } \\
\text { problems are usually } \\
\text { solved by changing } \\
\text { contractors or } \\
\text { suppliers. }\end{array}$ & $\begin{array}{l}\text { A systematic process } \\
\text { is in place for the } \\
\text { selection of trade } \\
\text { contractors. } \\
\text { Trades and suppliers } \\
\text { participate in solving } \\
\text { problems. }\end{array}$ & $\begin{array}{l}\text { Key trade contractors } \\
\text { and suppliers are } \\
\text { considered partners. } \\
\text { Company helps them } \\
\text { improve quality and } \\
\text { reduce costs. }\end{array}$ & $\begin{array}{l}\text { Performance } \\
\text { standards are a metric } \\
\text { of quality, testing } \\
\text { measures } \\
\text { improvement }\end{array}$ & $\begin{array}{l}\text { In addition to level } 3 \text {, } \\
\text { most major trade } \\
\text { contractors and } \\
\text { suppliers participate in } \\
\text { a systematic approach } \\
\text { to problem-solving and } \\
\text { quality improvement. }\end{array}$ & $\begin{array}{l}\text { Company has } \\
\text { integrated design } \\
\text { process for contractors } \\
\text { to participate in new } \\
\text { construction and } \\
\text { building-science-based } \\
\text { solution / redesign } \\
\text { process for existing } \\
\text { product }\end{array}$ & $\begin{array}{l}\text { In addition to level } 4 \text {, } \\
\text { trade contractors and } \\
\text { suppliers participate in } \\
\text { planning and } \\
\text { implementing long- } \\
\text { term quality } \\
\text { improvements. }\end{array}$ & $\begin{array}{l}\text { Trades are actively } \\
\text { involved in identifying } \\
\text { proper scopes of work, } \\
\text { sequencing, and even- } \\
\text { flow scheduling with } \\
\text { builder }\end{array}$ \\
\hline $\begin{array}{l}7.2 \\
\text { Trade } \\
\text { Development }\end{array}$ & $\begin{array}{l}\text { There are no formal } \\
\text { initiatives to develop } \\
\text { the capabilities of trade } \\
\text { contractors. }\end{array}$ & $\begin{array}{l}\text { Improving trades is } \\
\text { focused on solving } \\
\text { problems. }\end{array}$ & $\begin{array}{l}\text { A general strategy is in } \\
\text { place to develop the } \\
\text { capabilities and } \\
\text { performance of trade } \\
\text { contractors. }\end{array}$ & $\begin{array}{l}\text { Builder provides } \\
\text { general training on } \\
\text { Performance } \\
\text { standards and trades } \\
\text { relation to standards }\end{array}$ & $\begin{array}{l}\text { The company's trade } \\
\text { development plans are } \\
\text { linked directly to } \\
\text { achieving the } \\
\text { company's long-range } \\
\text { vision. }\end{array}$ & $\begin{array}{l}\text { Trades are trained to } \\
\text { understand building } \\
\text { science approach and } \\
\text { integrated designs, } \\
\text { and interrelationship of } \\
\text { their work to the overall } \\
\text { performance standards } \\
\text { and company goals }\end{array}$ & $\begin{array}{l}\text { In addition to level } 4 \text {, } \\
\text { Key trades have their } \\
\text { own development } \\
\text { plans that support the } \\
\text { company vision. } \\
\text { The builder provides } \\
\text { incentives for trades } \\
\text { participating in training } \\
\text { improvement } \\
\text { programs. }\end{array}$ & $\begin{array}{l}\text { Builder required } \\
\text { certified trades in all } \\
\text { key performance } \\
\text { standards areas }\end{array}$ \\
\hline $\begin{array}{l}7.3 \\
\text { Trade } \\
\text { Contractor } \\
\text { Performance } \\
\text { Management }\end{array}$ & $\begin{array}{l}\text { Trade performance is } \\
\text { evaluated when } \\
\text { problems arise or } \\
\text { when contracts are } \\
\text { renewed. }\end{array}$ & $\begin{array}{l}\text { Trade performance } \\
\text { data consists of } \\
\text { inspection punch lists } \\
\text { and callbacks, but } \\
\text { trend data is not } \\
\text { tracked. }\end{array}$ & $\begin{array}{l}\text { Trade performance } \\
\text { trend data is tracked } \\
\text { and reviewed regularly } \\
\text { with the key trades and } \\
\text { used to improve quality } \\
\text { and prevent defects. }\end{array}$ & $\begin{array}{l}\text { Primary use is } \\
\text { checklists, some } \\
\text { performance test data } \\
\text { used to gauge trade } \\
\text { against performance } \\
\text { standards }\end{array}$ & $\begin{array}{l}\text { Customer satisfaction } \\
\text { survey data on } \\
\text { construction } \\
\text { workmanship is used } \\
\text { as a trade performance } \\
\text { indicator. }\end{array}$ & $\begin{array}{l}\text { Performance testing is } \\
\text { used as another metric } \\
\text { for trade performance }\end{array}$ & $\begin{array}{l}\text { Trades use builder } \\
\text { performance data to } \\
\text { monitor and improve } \\
\text { performance. } \\
\text { Trades are recognized } \\
\text { and rewarded for } \\
\text { outstanding } \\
\text { performance. }\end{array}$ & $\begin{array}{l}\text { Performance testing is } \\
\text { used as another metric } \\
\text { for trade performance }\end{array}$ \\
\hline $\begin{array}{l}7.4 \\
\text { Trade } \\
\text { Contractor and } \\
\text { Supplier } \\
\text { Results }\end{array}$ & $\begin{array}{l}\text { Trade contractor } \\
\text { quality seems to be } \\
\text { improving, but there } \\
\text { are no measures of } \\
\text { progress. }\end{array}$ & $\begin{array}{l}\text { Some trade } \\
\text { contractors show } \\
\text { measured quality } \\
\text { improvements. }\end{array}$ & $\begin{array}{l}\text { All major trade } \\
\text { contractors show } \\
\text { measured quality } \\
\text { improvements. }\end{array}$ & $\begin{array}{l}\text { Measurement system } \\
\text { includes key } \\
\text { performance attributes }\end{array}$ & $\begin{array}{l}\text { All major contractors } \\
\text { show excellent quality } \\
\text { results. } \\
\text { Most trade contractors } \\
\text { routinely meet quality } \\
\text { standards. }\end{array}$ & $\begin{array}{l}\text { Quality standards } \\
\text { include Performance } \\
\text { standards }\end{array}$ & $\begin{array}{l}\text { In addition to level } 4 \text {, } \\
\text { all major trade } \\
\text { contractors show } \\
\text { positive quality } \\
\text { improvement trends. }\end{array}$ & $\begin{array}{l}\text { Performance testing } \\
\text { shows improvement } \\
\text { trends. }\end{array}$ \\
\hline
\end{tabular}




\section{Appendix E. National Housing Quality Survey}

\begin{tabular}{|c|c|}
\hline NHQ Survey information & $\begin{array}{l}\text { Information } \\
\text { Champion }\end{array}$ \\
\hline \multicolumn{2}{|l|}{ Company Mission, Vision and Values } \\
\hline $\begin{array}{l}\text { What are the company mission statement, core values, and vision } \\
\text { for the future? How is this documented and communicated } \\
\text { amongst the staff? }\end{array}$ & \\
\hline $\begin{array}{l}\text { - How do senior managers demonstrate a commitment to the } \\
\text { company mission, values, and vision, and to what extent does } \\
\text { this translate to the actions of others throughout the organization? }\end{array}$ & \\
\hline $\begin{array}{l}\text { What feedback mechanisms exist from field to management } \\
\text { relating to company's ability to deliver to the company mission, } \\
\text { values, and progress towards vision? }\end{array}$ & \\
\hline $\begin{array}{l}\text { - How does the company understand if employees are in alignment } \\
\text { with the company mission, values, and vision, and are there } \\
\text { activities that specifically encourage and reinforce that alignment? }\end{array}$ & \\
\hline $\begin{array}{l}\text { Does the company facilitate and coordinate opportunities to } \\
\text { benefit the local community in alignment with the mission, values, } \\
\text { and vision? }\end{array}$ & \\
\hline \multicolumn{2}{|l|}{ Strategic Planning } \\
\hline $\begin{array}{l}\text { What measurement mechanisms exist to evaluate if the company } \\
\text { is achieving the mission, progressing towards the vision, and } \\
\text { achieving customer satisfaction and operational performance } \\
\text { metrics? }\end{array}$ & \\
\hline $\begin{array}{l}\text { Is there a written strategic plan that documents the improvement } \\
\text { process in different operational areas, the tools and systems used } \\
\text { to identify areas of weakness and measure company-wide } \\
\text { operational improvements, a detailed strategic plan for } \\
\text { improvements in key areas, and who is involved in developing } \\
\text { specific strategic improvement plans? }\end{array}$ & \\
\hline $\begin{array}{l}\text { What process is in place to implement the plan, and how far } \\
\text { throughout the organization does implementation reach? }\end{array}$ & \\
\hline $\begin{array}{l}\text { - What mechanisms are used and how often is review performed to } \\
\text { monitor how well the organization is improving relative to the } \\
\text { strategic plan? How often is the strategic plan updated? }\end{array}$ & \\
\hline
\end{tabular}




\begin{tabular}{|c|c|}
\hline NHQ Survey information & $\begin{array}{l}\text { Information } \\
\text { Champion }\end{array}$ \\
\hline \multicolumn{2}{|l|}{ Customer Satisfaction } \\
\hline $\begin{array}{l}\text { What market research mechanisms are in place to understand } \\
\text { customers, position relative to local competition, and forward } \\
\text { positioning of products based on leading indicators (e.g., } \\
\text { demographics, economic, style, etc.) }\end{array}$ & \\
\hline $\begin{array}{l}\text { What is the design process? Who is involved? What feedback } \\
\text { mechanisms exist? }\end{array}$ & \\
\hline $\begin{array}{l}\text { - What importance is placed on customer satisfaction, and how is } \\
\text { that expressed in the company mission, values, and vision? }\end{array}$ & \\
\hline $\begin{array}{l}\text { - What process is in place to guide the customer through the sales } \\
\text { and construction process? }\end{array}$ & \\
\hline $\begin{array}{l}\text { - How is customer satisfaction measured and used throughout the } \\
\text { company to improve the customer relationship process? }\end{array}$ & \\
\hline \multicolumn{2}{|l|}{ Performance Management } \\
\hline $\begin{array}{l}\text { - How does the organization set up work processes, identify work } \\
\text { process improvements, and Benchmark against other industry } \\
\text { and non-industry top performers? }\end{array}$ & \\
\hline $\begin{array}{l}\text { How are work processes measured, and do they support key } \\
\text { company wide success measures? }\end{array}$ & \\
\hline - How are work-processes evaluated and improved? & \\
\hline - How are work-processes tied to the quality of the house? & \\
\hline $\begin{array}{l}\text { - How are company financial results measured, and tied to work } \\
\text { processes? }\end{array}$ & \\
\hline \multicolumn{2}{|l|}{ Human Resources } \\
\hline $\begin{array}{l}\text { - Are employees are surveyed on job satisfaction and have input } \\
\text { on improving employee satisfaction? }\end{array}$ & \\
\hline $\begin{array}{l}\text { What is the company safety plan, and how far into the } \\
\text { organization does it reach? }\end{array}$ & \\
\hline $\begin{array}{l}\text { - How empowered are employees with respect to their job and } \\
\text { achieving key success metric? }\end{array}$ & \\
\hline $\begin{array}{l}\text { - How are teams utilized to perform management functions within } \\
\text { the organization? }\end{array}$ & \\
\hline $\begin{array}{l}\text { What kind of the training and employee development program } \\
\text { exists in the company? }\end{array}$ & \\
\hline
\end{tabular}




\begin{tabular}{|c|c|}
\hline NHQ Survey information & $\begin{array}{l}\text { Information } \\
\text { Champion }\end{array}$ \\
\hline $\begin{array}{l}\text { - How are employees and teams evaluated, compensated, and } \\
\text { given incentive toward key success measures for the company }\end{array}$ & \\
\hline Quality Construction Process & \\
\hline $\begin{array}{l}\text { What are the company's quality standards, and how are these } \\
\text { communicated throughout the organization and to trades? }\end{array}$ & \\
\hline $\begin{array}{l}\text { - How do management, field, and trades monitor consistency and } \\
\text { delivery of product that meets quality standards? }\end{array}$ & \\
\hline $\begin{array}{l}\text { How do the company and the trades monitor and evaluate quality } \\
\text { problems and develop process improvements to eliminate } \\
\text { problems? }\end{array}$ & \\
\hline $\begin{array}{l}\text { - How is warranty service used to identify and fix root causes of } \\
\text { quality problems? }\end{array}$ & \\
\hline $\begin{array}{l}\text { How have these improvements contributed to zero defect at final } \\
\text { inspection, and show positive trends in quality improvement and } \\
\text { excellent results }\end{array}$ & \\
\hline Supplier Partnerships & \\
\hline $\begin{array}{l}\text { - How are trade contractors and suppliers engaged in the } \\
\text { company's quality initiatives? }\end{array}$ & \\
\hline $\begin{array}{l}\text { What strategies are in place to align trade contractors with the } \\
\text { company mission, values, and vision; develop the trades to } \\
\text { achieve quality standards; and provide financial rewards for } \\
\text { achieving quality goals? }\end{array}$ & \\
\hline $\begin{array}{l}\text { How is trade contractor performance tracked, and how is that } \\
\text { data used to continually improve the trade contractor's } \\
\text { performance? }\end{array}$ & \\
\hline $\begin{array}{l}\text { What are the results associated with the trade contractor } \\
\text { initiatives? }\end{array}$ & \\
\hline
\end{tabular}




\section{Appendix F. SNAPSHOT Form}

\begin{tabular}{|l|l|l|l|}
\hline \multicolumn{3}{|c|}{ SNAPSHOT ${ }^{\circledR}$ "The Form" } \\
\cline { 1 - 1 } Lot \#: & Subdivision: & Address: & Date and time: \\
\hline Model: & & & \\
\hline
\end{tabular}

INITIALIZATION

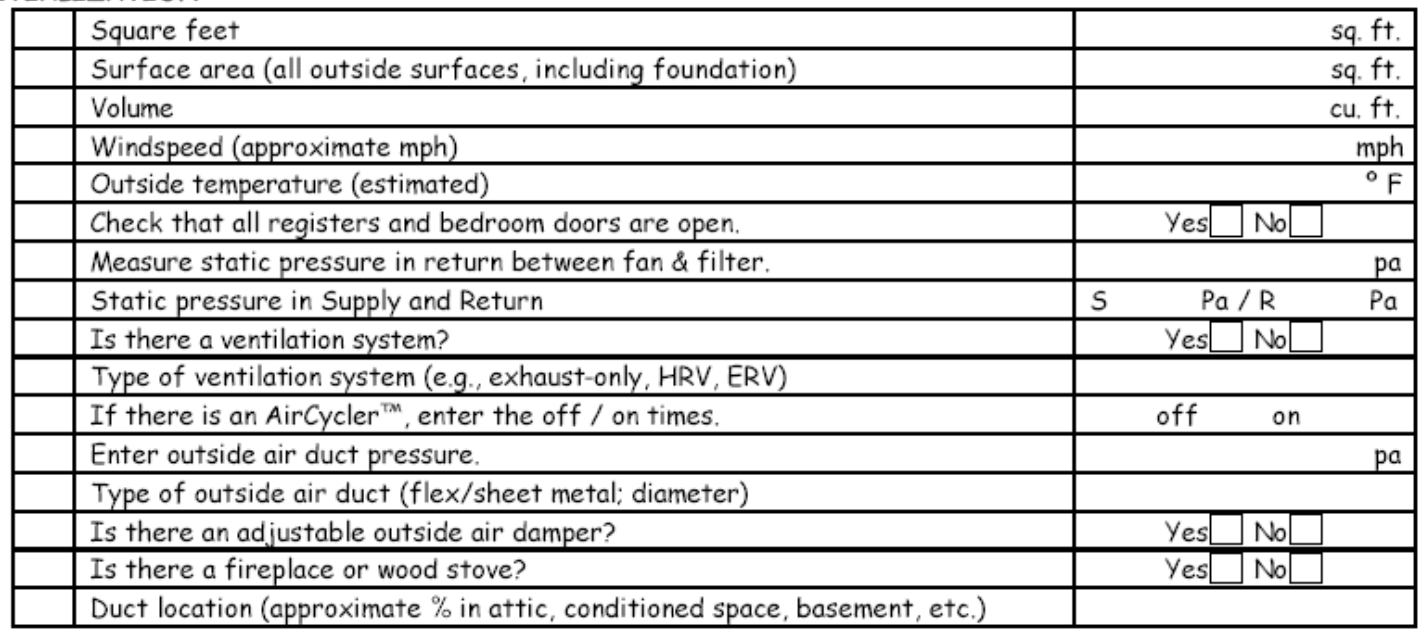

\section{PRESSURE TESTING}

\begin{tabular}{|c|c|c|}
\hline \multicolumn{2}{|c|}{ Stack Pressure (baseline with blower door installed; covers on) } & $\mathrm{pa}$ \\
\hline \multicolumn{2}{|c|}{ Dominant Duct Leak Effect (baseline with HVAC system running) } & $\mathrm{pa}$ \\
\hline \multicolumn{2}{|c|}{ Master Bedroom Door Closure Effect (ÄP from main space to outdoors) } & $\mathrm{pa}$ \\
\hline \multicolumn{2}{|c|}{ All Doors Closed Effect (ÄP from main space to outdoors) } & $\mathrm{pa}$ \\
\hline \multicolumn{2}{|c|}{ Fireplace/Wood Stove Zone HVAC Test } & $\mathrm{pa}$ \\
\hline \multirow{5}{*}{$\begin{array}{l}\text { Pressure In Each Closed Room (room label and } \\
\text { pressure) }\end{array}$} & pa & $\mathrm{pa}$ \\
\hline & $\mathrm{pa}$ & $\mathrm{pa}$ \\
\hline & $\mathrm{pa}$ & $\mathrm{pa}$ \\
\hline & pa & $\mathrm{pa}$ \\
\hline & pa & pa \\
\hline
\end{tabular}

BLOWER DOOR TESTING (BDT)

\begin{tabular}{|l|l|l|}
\hline & Blower Door Location & \\
\hline & Total CFM50 (add C \& $n$ values if available on multipoint test) & $C F M 50=\quad C=\quad n=$ \\
\hline
\end{tabular}

DUCT AIRTIGHTNESS TESTING (DAT)

\begin{tabular}{|l|l|l|}
\hline & DAT CFM25 TOTAL & \\
\hline DAT CFM25 OUTSIDE & \\
\hline
\end{tabular}

\section{MECHANICALS}

\begin{tabular}{|l|l|l|l|}
\hline & Furnace or air handler & Make: & Model: \\
\hline & Air Conditioning & Make: & Model: \\
\hline & Domestic hot water & Make: & Model: \\
\hline
\end{tabular}




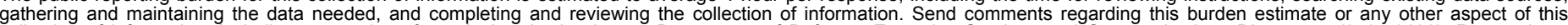

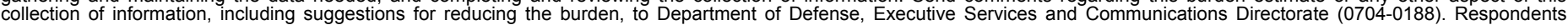

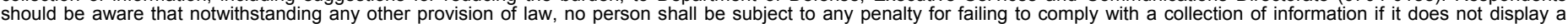
currently valid OMB control number.

PLEASE DO NOT RETURN YOUR FORM TO THE ABOVE ORGANIZATION.

\section{REPORT DATE (DD-MM-YYYY) January 2006 \\ 2. REPORT TYPE \\ Subcontract Report}

\section{TITLE AND SUBTITLE}

Building America Residential System Research Results: Achieving $30 \%$ Whole House Energy Savings Level in Hot-Dry and Mixed-Dry Climates

\section{AUTHOR(S)}

Building Industry Research Alliance (BIRA); Building Science Consortium (BSC); Consortium for Advanced Residential Buildings (CARB); Davis Energy Group (DEG); Florida Solar Energy Center (FSEC); IBACOS; National Association of Home Builders Research Center (NAHBRC); National Renewable Energy Laboratory (NREL)
3. DATES COVERED (From - To) January 2005 - November 2005

5a. CONTRACT NUMBER

DE-AC36-99-G010337

5b. GRANT NUMBER

5c. PROGRAM ELEMENT NUMBER

5d. PROJECT NUMBER

NREL/SR-550-38201

\section{5e. TASK NUMBER}

BET6.8004

\section{PERFORMING ORGANIZATION NAME(S) AND ADDRESS(ES)}

National Renewable Energy Laboratory

1617 Cole Blvd.

Golden, CO 80401-3393

9. SPONSORING/MONITORING AGENCY NAME(S) AND ADDRESS(ES)

5f. WORK UNIT NUMBER

\section{PERFORMING ORGANIZATION REPORT NUMBER}

NREL/SR-550-38201

10. SPONSOR/MONITOR'S ACRONYM(S) NREL

11. SPONSORING/MONITORING AGENCY REPORT NUMBER

12. DISTRIBUTION AVAILABILITY STATEMENT

National Technical Information Service

U.S. Department of Commerce

5285 Port Royal Road

Springfield, VA 22161

13. SUPPLEMENTARY NOTES

14. ABSTRACT (Maximum 200 Words)

The Building America program conducts the system research required to reduce risks associated with the design and construction of homes that use an average of $30 \%$ to $90 \%$ less total energy for all residential energy uses than the Building America Research Benchmark, including research on homes that will use zero net energy on annual basis. To measure the program's progress, annual research milestones have been established for five major climate regions in the United States. The system research activities required to reach each milestone take from 3 to 5 years to complete and include research in individual test houses, studies in pre-production prototypes, and research studies with lead builders that provide early examples that the specified energy savings level can be successfully achieved on a production basis. This report summarizes research results for the $30 \%$ energy savings level and demonstrates that lead builders can successfully provide 30\% homes in the Hot-Dry / Mixed-Dry Climate Region on a cost neutral basis.

15. SUBJECT TERMS

Building America; U.S. Department of Energy; systems research; Hot-Dry Mixed-Dry Climates; 30\% energy savings level; energy efficient housing

\begin{tabular}{|c|c|c|c|c|}
\hline \multicolumn{3}{|c|}{ 16. SECURITY CLASSIFICATION OF: } & \multirow{2}{*}{$\begin{array}{l}\text { 17. LIMITATION } \\
\text { OF ABSTRACT } \\
\text { UL }\end{array}$} & \multirow{2}{*}{$\begin{array}{l}\text { 18. NUMBER } \\
\text { OF PAGES }\end{array}$} \\
\hline $\begin{array}{l}\text { a. REPORT } \\
\text { Unclassified }\end{array}$ & $\begin{array}{l}\text { b. ABSTRACT } \\
\text { Unclassified }\end{array}$ & $\begin{array}{l}\text { c. THIS PAGE } \\
\text { Unclassified }\end{array}$ & & \\
\hline
\end{tabular}

19a. NAME OF RESPONSIBLE PERSON

19b. TELEPHONE NUMBER (Include area code) 


\section{A Strong Energy Portfolio for a Strong America}

Energy efficiency and clean, renewable energy will mean a stronger economy, a cleaner environment, and greater energy independence for America. Working with a wide array of state, community, industry, and university partners, the U.S. Department of Energy's Office of Energy Efficiency and Renewable Energy invests in a diverse portfolio of energy technologies.

\section{Research and Development of Buildings}

Our nation's buildings consume more energy than any other sector of the U.S. economy, including transportation and industry. Fortunately, the opportunities to reduce building energy useand the associated environmental impacts—are significant.

DOE's Building Technologies Program works to improve the energy efficiency of our nation's buildings through innovative new technologies and better building practices. The program focuses on two key areas:

\section{- Emerging Technologies} Research and development of the next generation of energy-efficient components, materials, and equipment

- Technology Integration Integration of new technologies with innovative building methods to optimize building performance and savings

For more information contact: EERE Information Center 1-877-EERE-INF (1-877-337-3463) www.eere.energy.gov

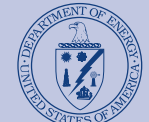

U.S. Department of Energy Energy Efficiency and Renewable Energy

An electronic copy of this publication is available on the Building America Web site at www.buildingamerica.gov

\section{Visit our Web sites at:}

\section{www.buildingamerica.gov}

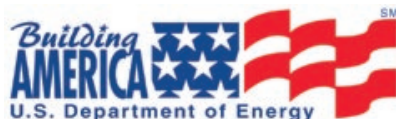

Building America Program

George S. James • New Construction • 202-586-9472 • fax: 202-586-8134• e-mail: George.James@ee.doe.gov

Terry Logee • Existing Homes • 202-586-1689 • fax: 202-586-4617• e-mail: terry.logee@ee.doe.gov

Lew Pratsch • Integrated Onsite Power • 202-586-1512 • fax: 202-586-8185 • e-mail: Lew.Pratsch@hq.doe.gov

Building America Program • Office of Building Technologies, EE-2J • U.S. Department of Energy $\bullet 1000$ Independence Avenue, S.W. • Washington, D.C. 20585-0121 • www.buildingamerica.gov

Building Industry Research Alliance (BIRA)

Robert Hammon • ConSol • 7407 Tam 0'Shanter Drive \#200 • Stockton, CA 95210-3370 • 209-473-5000 • fax: 209-474-0817 • e-mail: Rob@consol.ws•www.bira.ws

\section{Building Science Consortium (BSC)}

Betsy Pettit • Building Science Consortium (BSC) • 70 Main Street • Westford, MA $01886 \bullet 978-589-5100 \bullet$ fax: 978-589-5103• e-mail: Betsy@buildingscience.com • www.buildingscience.com

Consortium for Advanced Residential Buildings (CARB)

Steven Winter • Steven Winter Associates, Inc. • 50 Washington Street • Norwalk, CT $06854 \bullet 203-857-0200 \bullet$ fax: 203-852-0741 • e-mail: swinter@swinter.com • www.carb-swa.com

\section{Davis Energy Group}

David Springer • Davis Energy Group • 123 C Street • Davis, CA 95616 • 530-753-1100 • fax: 530-753-4125 •

e-mail: springer@davisenergy.com•deg@davisenergy.com • www.davisenergy.com/index.html

\section{IBACOS Consortium}

Brad Oberg •IBACOS Consortium • 2214 Liberty Avenue • Pittsburgh, PA $15222 \bullet 412-765-3664 \bullet$ fax: 412-765-3738 • e-mail: boberg@ibacos.com • www.ibacos.com

Industrialized Housing Partnership (IHP)

Subrato Chandra • Florida Solar Energy Center • 1679 Clearlake Road • Cocoa, FL 32922 • 321-638-1412 • fax: 321-638-1439 • e-mail: subrato@fsec.ucf.edu • www.baihp.org

\section{National Association of Home Builders (NAHB) Research Center}

Tom Kenney • National Association of Home Builders (NAHB) Research Center • 400 Prince George's Boulevard • Upper Marlboro, MD 20774 • 301-430-6246 • fax: 301-430-6180 • toll-free: 800-638-8556 • www.nahbrc.org/

National Renewable Energy Laboratory

Ren Anderson • 1617 Cole Boulevard, MS-2722 • Golden, C0 80401 • 303-384-7433 • fax: 303-384-7540 •

e-mail: ren_anderson@nrel.gov • www.nrel.gov

Tim Merrigan • 1617 Cole Boulevard, MS-2722 • Golden, C0 80401 • 303-384-7349 • fax: 303-384-7540 • e-mail: tim_merrigan@nrel.gov • www.nrel.gov

\section{Oak Ridge National Laboratory}

Pat M. Love • P.0. Box 2008・ One Bethel Valley Road • Oak Ridge, TN 37831 • 865-574-4346• fax: 865-574-9331 • e-mail: lovepm@ornl.gov • www.ornl.gov

Produced for the U.S. Department of Energy (DOE) by the National Renewable Energy Laboratory, a DOE national laboratory. January 2006 - NREL/SR-550-38201

Printed with a renewable-source ink on paper containing at least $50 \%$ wastepaper, including $10 \%$ postconsumer waste. 